\title{
Markets and human behavior
}

Citation for published version (APA):

Nigus, H. Y. (2021). Markets and human behavior: evidence from artefactual field experiments. [Doctoral Thesis, Maastricht University]. ProefschriftMaken. https://doi.org/10.26481/dis.20210914hn

Document status and date:

Published: 01/01/2021

DOI:

10.26481/dis.20210914hn

Document Version:

Publisher's PDF, also known as Version of record

\section{Please check the document version of this publication:}

- A submitted manuscript is the version of the article upon submission and before peer-review. There can be important differences between the submitted version and the official published version of record.

People interested in the research are advised to contact the author for the final version of the publication, or visit the DOI to the publisher's website.

- The final author version and the galley proof are versions of the publication after peer review.

- The final published version features the final layout of the paper including the volume, issue and page numbers.

Link to publication

\footnotetext{
General rights rights.

- You may freely distribute the URL identifying the publication in the public portal. please follow below link for the End User Agreement:

www.umlib.nl/taverne-license

Take down policy

If you believe that this document breaches copyright please contact us at:

repository@maastrichtuniversity.nl

providing details and we will investigate your claim.
}

Copyright and moral rights for the publications made accessible in the public portal are retained by the authors and/or other copyright owners and it is a condition of accessing publications that users recognise and abide by the legal requirements associated with these

- Users may download and print one copy of any publication from the public portal for the purpose of private study or research.

- You may not further distribute the material or use it for any profit-making activity or commercial gain

If the publication is distributed under the terms of Article $25 \mathrm{fa}$ of the Dutch Copyright Act, indicated by the "Taverne" license above, 


\section{Markets and Human Behavior}

\section{Evidence from Artefactual Field Experiments}

Halefom Yigzaw Nigus 
Copyright $@$ Halefom Yigzaw Nigus, 2021

ISBN 978-94-6423-341-4

Cover Design: Stefanie van den Herik

Printing: ProefschriftMaken || www.proefschriftmaken.nl

All rights reserved. No part of this publication may be reproduced, stored in a retrieval system, or transmitted in any form, or by any means, electronic, mechanical, photocopying, recording or otherwise, without the prior permission in writing, from the author. 


\title{
Markets and Human Behavior
}

\section{Evidence from Artefactual Field Experiments}

\begin{abstract}
DISSERTATION
to obtain the degree of Doctor at Maastricht University, on the authority of the Rector Magnificus Prof. dr. Rianne M. Letschert, in accordance with the decision of the Board of Deans, to be defended in public on Tuesday 14 September 2021, at 13:00 hours.
\end{abstract}

by

HALEFOM YIGZAW NIGUS 
SUPERVISORS:

Prof. Dr. Ir. Eleonora Nillesen

Prof. Dr. Pierre Mohnen

CO-SUPERVISOR:

Prof. Dr. Salvatore Di Falco

ASSESSMENT COMMITTEE:

Prof. Dr. Franziska Gassmann (Chair)

Prof. Dr. Abigail Barr (University of Nottingham, United Kingdom)

Prof. Dr. Jaap Bos

Dr. Ir. Francesco Cecchi (Wageningen University)

Dr. Micheline Goedhuys

Prof. Dr. Catherine Guirkinger (University de Namur, Belgium)

Funding:

Nuffic - Netherlands Fellowship Programme (NFP) 


\section{SUMMARY}

The overarching objective of this dissertation is to investigate whether and how markets shape human behavior. The dissertation is based on the premise that markets are not only economic but also social and political institutions and do more than a mere allocation of resources. Since markets are social spaces where people meet, interact and converse with each other and humans are not automata, these market interactions may, directly or indirectly, influence human behavior. Put together, the dissertation sought to shed some light on the effect of markets on socially responsible behavior, social capital, and investment decisions. The dissertation comprises five chapters. The introductory chapter provides the motivation, research questions, research setting, methodology, and the structure of the dissertation. The subsequent three chapters investigate whether markets nurture or erode socially responsible behavior, whether weather index insurance crowds in or crowds out social capital and the impact of exposure to markets on investment decisions, respectively.

Chapter 2 examines the effect of markets on socially responsible behavior, the role punishment and religion play in promoting social responsibility in markets, and the sequels of eroding socially responsible behavior. This chapter contributes to the longstanding debate on whether markets nurture or corrupt moral and socially responsible behavior. To this end, a two-stage experiment was used. In the first stage, a laboratory competitive product market, where sellers and buyers, respectively, have the option to produce and buy a low-cost product with or a high-cost product without a negative externality, was used. Participants were randomly assigned to a version of a game framed as a market, market with punishment, market with religious priming, or neutral (non-market) contexts. The results show that in contrast to the predictions of the self-interest theory, irrespective of the framed context, participants reveal substantial socially responsible behavior. However, socially responsible behavior is less prevalent in market contexts relative to non-market contexts. Notably, the results reveal that punishment and religion promote social responsibility in markets. To elucidate the consequences of eroding socially responsible behavior, in the second stage, subjects participated in the joy-of-destruction game. While anti-social behavior is ubiquitous in environments where socially responsible behavior is eroded, this does not differ across the market and non-market contexts. This implies that market participants engage in advantageous inequality, but not in a disadvantageous inequality.

Chapter 3 evaluates the effect of weather index insurance (WII) on social capital. This chapter contributes to the literature on whether the introduction of formal institutions complements or alienates pre-existing informal institutions. Household survey 
and lab-in-the-field experimental data were collected from farm-household with (insured and uninsured) and without access to WII. Using instrumental variable (IV) approach and propensity score matching (PSM), to account for the non-random uptake of WII, the chapter shows that WII appeared to crowd out social capital. The free-riding problem created by WII and perceptions of self-sufficiency are the plausible channels underlying these results. WII creates positive externalities on uninsured households, which induces them to free-ride. Anticipating this, insured households respond by lowering their investment in social capital. Besides, WII increases perceptions of self-sufficiency, that is, insured households perceive that they need to rely less on others in times of need and thereby invest less in social capital.

Chapter 4 examines the effect of exposure to markets on farm households' agricultural investment decisions using both survey and incentivized experimental data. The chapter employed Endogenous Switching Probit (ESP) and IV-Probit models to attenuate the potential self-selection and simultaneity biases. The ESP results show that market exposure induces farmers to adopt profitable agricultural technologies, such as chemical fertilizer, improved seeds, manure, and row planting. The estimation results also show that market exposure promotes investment behavior by attenuating farmers' risk-aversion and enhancing their internal locus of control. The results in this chapter highlight the importance of the penetration of rural markets in Sub-Saharan Africa and elsewhere in developing countries to enhance the adoption of high-risk high-return farm technologies, improve agricultural productivity of rural households, and ultimately enabling farmers to exit risk-induced poverty trap.

Chapter 5 concludes the dissertation by providing key findings, policy implications, limitations and suggestions for further research. 


\section{ACKNOWLEDGEMENTS}

I am fortunate enough to be surrounded by many wonderful people during this Ph.D. journey. Now, it is time to owe an enormous thanks to everyone who have contributed to the completion of this dissertation.

First and foremost, I am deeply grateful to my promoter and supervisor, Professor Pierre Mohnen. Pierre, I will forever be thankful for your outstanding research guidance, steadfast support, and swift responses to my requests. I also truly appreciate your compassion and open-door policy. You are a role model for me in academia and life, and I trust for everyone at MERIT. I have learned a great deal from you, and I am extremely lucky to have you in my supervision team. I could not have imagined having a better supervisor and promoter for my Ph.D. study. A very big thank you for everything, Pierre! I also owe a special thank you to my supervisor Professor Eleonora (Lonneke) Nillesen, for the intellectual freedom, ambition, and confidence in me. Professor Eleonora, you have provided me perfect academic freedom to navigate every piece of literature liberally but also making sure that I am on the right track. My sincere gratitude also goes to my supervisor, Professor Salvatore Di Falco, for his support, encouragement, and spotting and sharing very important events.

I would like to extend my heartfelt gratitude to the members of the dissertation assessment committee: Prof. Dr. Franziska Gassmann (Chair), Prof. Dr. Abigail Barr, Prof. Dr. Jaap Bos, Dr. Ir. Francesco Cecchi, Dr. Micheline Goedhuys, and Prof. Dr. Catherine Guirkinger for spending their invaluable time in providing thought-provoking comments and insightful suggestions. Their comments and suggestions significantly enriched this dissertation.

I duly acknowledge the Netherlands government for the generous financial support via the NWO-NUFFIC Netherlands Fellowship Programme, without which this dissertation would not have been realized. I am also grateful to UNU-MERIT for extending my scholarship after my NUFFIC scholarship came to an end.

I am highly indebted to everyone at UNU-MERIT for creating a wonderful academic and social environment. Indeed, my utmost gratitude goes to Eveline in de Braek, who has always been a source of optimism and inspiration in the institute, for her well-rounded support, encouragement, and dedication. I have been feeling like I am at home because of you, Eveline. Special recognition also goes to Wilma Coenegract, the former administrator of my NUFFIC scholarship, for her candid cooperation and timely release of my fieldwork budget. Dear Wilma, my fieldwork would have been demanding without your tremendous cooperation and support. I owe a debt of thanks to Liesbeth Noben, who took over the administration of my scholarship from Wilma 
for amazingly handling my scholarship. I also thank other administrative staff at UNU-MERIT: Ad Notten, Herman Pijpers, Marc Vleugels, Monique Raedts, Mourik Jan Heupink, and Sueli Brodin for the continued support throughout my Ph.D. study.

I am immensely grateful to my classmates: Bart, Beatriz, Danilo, Emmanuel, Joseph, Giulia, Kaleab, Patima, Rose, Tamara, and Victor for making my Ph.D. journey enjoyable and memorable. I am thankful for the discussions, funs, and preparing dinners that reflected the countries and cultures we come from. My officemates: Anny (Yip Ching Yu), Bruhan Konda, Musa Ahmed, Clotilde Mah'e, and Hampton (Pui Hang Wong) also deserve a special thank you. My heartfelt gratitude goes to my Ethiopian friends: Aderajew Shumet, Eleni Yitbarek, Hayelom Kebede, Hiwot Mesfin, Hibret Maemir, Hassen Wako, Jemal Adem, Kaleab Haile, Musa Ahmed, Tigist Melesse, Wondimagen Tesfaye, and Yesuf Awel for making my time in Maastricht unforgettable. Dear friends, my stay in Maastricht would not have been enjoyable without your company and help. Hiwot and Musa, it was truly a blessing to have you both by my side during the difficult COVID-19 time. I am also grateful to my colleagues Chen, Chuks, Gideon, Godsway, Late Ibrahima, Iman, Mario, Michelle, Robert, Racky, Sabrina, Solomon, Tatenda, and many more.

My Ph.D. journey has also been enjoyable because of the many wonderful people I have met in Maastricht. I am highly thankful for my landlady, Ingrid Bos (Inge). Inge, my early years in Maastricht would have been extremely tough without your support. Maastricht has become a home away from home because of you, Inge. The EthioEritrean community: Beletu, Genet (thank you for the Injera), Eskinder, Hellen, Tomas, and Tsegaye, thank you all for your hospitality, emotional and material support. I have had the privilege of being surrounded by many smart and kind-hearted friends during this journey. My friends Kahsay Haile, Aregawi Gebremariam, Micheallay Haftu (Micheal), and (Keshi) Negasi Gidey deserve heartfelt thanks. Kahsish and Agu, thank you for providing your comments and suggestions on my research ideas. Micheal, I am thankful, as ever, for your great friendship and your support during my fieldwork. Thank you, buddies, for always being there for me through highs and lows. A special thank you goes to the compassionate and supportive friends Endale Gebre, Eyoual Demeke, Gezahegn Medo, and Tewodros Assefa. I can't thank you enough for all that you have done for me, comrades.

My eternal gratitude goes to my family. I am deeply thankful to my awesome wife, Atsede Redae, without whom this journey would have been hardly possible to complete. Atse, you are not only a life partner but also a best friend and an inspiration. Thank you for your endless patience, unconditional love, and affection. Thank you for all the sacrifices you have made for the sake of this study. I am also highly thankful for unbelievably taking care of our beloved daughter and matters at home, alone. Maedot, my beloved daughter, although this journey has deprived you of the time and care you deserve, you were exceptionally able to understand that I was away for something 
really important. Your voice has been the source of my energy, strength, and persistence. Thank you for being more than a daughter to me and your mom. I have never seen a kid as considerate, caring, and calm as you in my life, Maedotey. I am also grateful to my son, Zetseat (Exodus), who joined us recently. Son, your arrival has brought many great things to our life, including the completion of this dissertation. Each day I go to the office, your morning smiles are the source of my energy. Thank you for making us feel special, Son. Dr. Hailu Nigus Weldeana, thank you very much for being an awesome uncle, and at the same time, a best friend. I am thankful for always being there for me to share my ups and downs. My late grandparents (Nigus Weldeanenya and Hadas Equar), thank you very much for everything you have done for me. You made my childhood times truly joyful, and I am who I am because of you. My parents (Yigzaw Nigus and Abeba Gebrekidan), my beloved sisters (Birhan and Tirhas), my brother (Mulugeta) and my parents' in-law (Keshi Redae and Endhafti Dargo), my brothers and sisters-in-law, particularly Mitu, deserves a special mention for the unlimited all-rounded support and backing-up my family during my study in the Netherlands.

I also express my sincere gratitude to the farm households in several villages of Tigray who have participated in the lengthy survey questionnaires and strange experimental games for their endless patience and unconditional cooperation. Dear farmers, this dissertation would not have existed without your gallant participation and incredible cooperation. I would also like to take this opportunity to thank the research assistants and enumerators for their extraordinary efforts in the data collection.

Finally, thanks also due to families, friends, and colleagues who have contributed to the completion of this dissertation, whom I have not mentioned here. 
To my wife, Atsede Redae; my children Maedot and Zetseat; and my family. 


\section{CONTENTS}

$1 \quad$ INTRODUCTION 1

1.1 Motivation .......................... I

1.2 Objectives and Research Questions . . . . . . . . . . . . . . . . . . 4

1.3 Research Setting and Data . . . . . . . . . . . . . . . . . . 4

1.4 Methodology.......................... . . 5

1.4.1 Field Experiments ...................... 6

1.4.2 Quasi-experimental and Non-experimental Designs . . . . . . 7

1.5 Structure of the Dissertation . . . . . . . . . . . . . . . . . . 9

$\begin{array}{lr}\text { References } & 13\end{array}$

2 MARKETS AND SOCIALLY RESPONSIBLE BEHAVIOR: DO PUNISHMENT AND RELIGION PROMOTE SOCIAL RESPONSIBILITY IN MARKETS 17

2.1 Introduction ....................... 18

2.2 Experimental Design and Procedure . . . . . . . . . . . . . 20

2.2.1 Experimental Design ................... 20

2.2.2 Experimental Procedure ................... . 25

2.2.3 Descriptive Statistics and Balance Test . . . . . . . . . . . . 26

2.2.4 Inequity Aversion Model Predictions . . . . . . . . . . . . . . . 27

2.3 Empirical Strategy . . . . . . . . . . . . . . . . . . . . . . . 29

2.4 Results ............................ . 31

2.4.1 Socially Responsible Behavior in Markets . . . . . . . . . . . 31

2.4.2 Punishment, Religious Beliefs and Social Responsibility . . . . 36

2.4.3 Is Eroding Socially Responsible Behavior (SRB) Harmful? . . . . 41

2.4.4 Is the Effect of the Erosion of SRB More Pronounced in Markets? 43

2.4.5 Does the Effects of Punishment and Religious Priming Persist? . 46

2.4.6 Welfare Impacts . . . . . . . . . . . . . . . . . . . . 49

2.5 Conclusion ......................... . 50

$\begin{array}{lr}\text { References } & 52\end{array}$

$\begin{array}{ll}\text { A APPENDIX } & 55\end{array}$

3 THE EFFECT OF WEATHER INDEX INSURANCE ON SOCIAL CAPITAL: EVIDENCE FROM RURAL ETHIOPIA $\quad 79$

3.1 Introduction .................... 80 
3.2 Conceptual Framework . . . . . . . . . . . . . . . . . 83

3.3 Context, Data and Experimental Design . . . . . . . . . . . . . . 84

3.3.1 The Weather Index Insurance Scheme . . . . . . . . . . . . . 84

3.3 .2 Data . . . . . . . . . . . . . . . . . 86

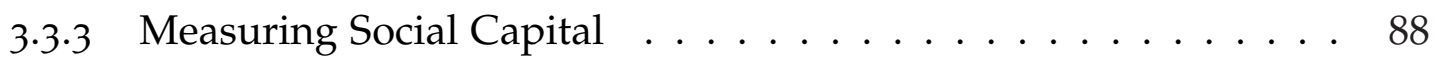

3.3.4 Descriptive Statistics . . . . . . . . . . . . . . . . 90

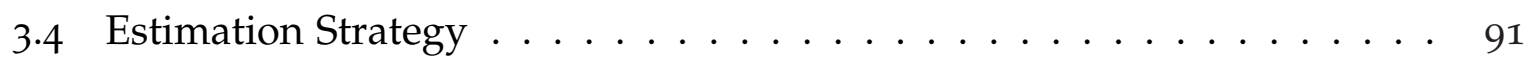

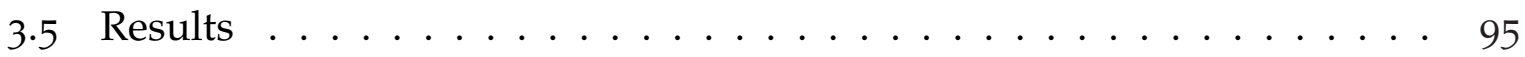

3.5.1 Does WII Crowds Out Social Capital? . . . . . . . . . . . . 95

3.5.2 Does WII Premium Payment Modality Matter? . . . . . . . . . . 100

3.5.3 Robustness Checks . . . . . . . . . . . . . . . . . 103

3.5 .4 Impact Pathways . . . . . . . . . . . . . . . 111

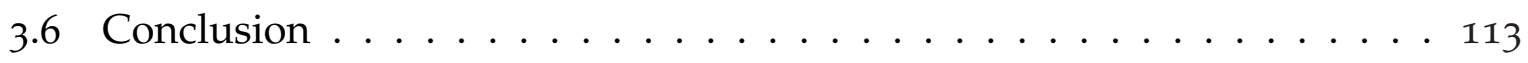

$\begin{array}{ll}\text { References } & 116\end{array}$

$\begin{array}{lr}\text { B APPENDIX } & 122\end{array}$

4 Does exposure to MARKets promote farmers' inVestMent beHAVIOR? EMPIRICAL EVIDENCE FROM RURAL ETHIOPIA 133

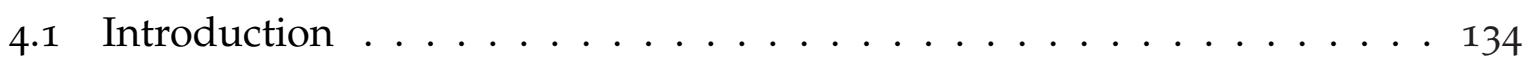

4.2 Context and Data . . . . . . . . . . . . . . . . . . 137

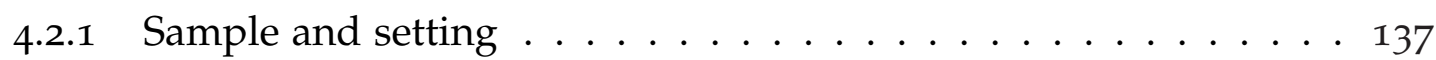

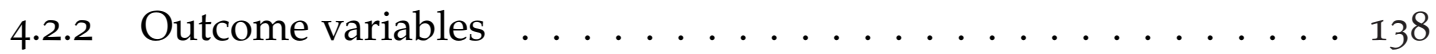

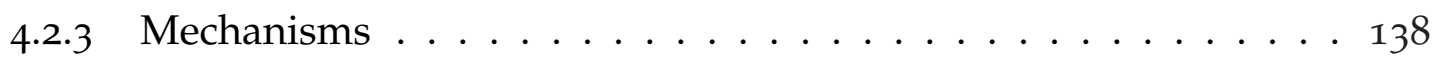

4.3 Estimation Strategy . . . . . . . . . . . . . . . . . . . 141

4.3.1 Endogenous switching probit model . . . . . . . . . . . 142

4.3.2 Instrumental Variable (IV) Approach . . . . . . . . . . . . . 144

4.4 Results and Discussions . . . . . . . . . . . . . . . . 145

4.4.1 Results of Endogenous Switching Probit Model . . . . . . . . 145

4.4.2 Results of the IV Probit Model . . . . . . . . . . . . . 147

4.4 .3 Mechanisms . . . . . . . . . . . . . . . . . . 149

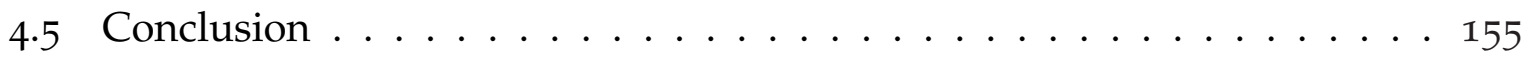

$\begin{array}{ll}\text { References } & 157\end{array}$

$\begin{array}{lll}C & \text { APPENDix } & 163\end{array}$

5 CONCLUSION 175

5.1 Contributions and Main Findings . . . . . . . . . . . . 175

5.2 Policy Implications . . . . . . . . . . . . . . . . . . . . . 178

5.3 Limitations and Avenue for Future Research $\ldots \ldots \ldots \ldots$. . . . 180 
References 


\section{LIST OF TABLES}

Table 1.1

Table 2.1

Table 2.2

Table 2.3

Table 2.4

Table 2.5

Table 2.6

Table 2.7

Table 2.8

Table 2.9

Table 2.10

Table 2.11

Table A.I

Table A.2

Table A.3

Table A.4

Table A.5

Table A.6

Table A.7

Table A. 8

Table 3.1

Table 3.2

Table $3 \cdot 3$

Table 3.4

Table 3.5

Table 3.6
Research Topics, Empirical Data and Empirical Strategies . . . . 8

Number of Subjects Across Sessions and Treatment Arms . . . . 26

Regressions of Prices by Product Type . . . . . . . . . . . . 32

Socially Responsible Behavior in Market and Non Market Con-

ditions ......................... 35

Punishment and Socially Responsible Behavior of Buyers and

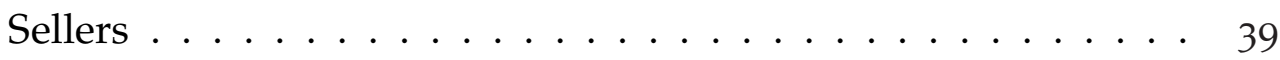

Probit Regressions of Socially Responsible Behavior in Market

Baseline and Alternative Market Conditions . . . . . . . . . 40

The Effect of Eroding SRB on Anti-social Behavior . . . . . . . . 43

Is the Effect of Eroding SRB More Pronounced in Markets? . . . 44

Does the Effect of Punishment Persists? . . . . . . . . . . . 48

Does the Effect of Religious Priming Persists? . . . . . . . . . . . . . . . . 48

Gains Across Varying Market Conditions . . . . . . . . . . . . . . 49

Loss Across Varying Market Conditions . . . . . . . . . . . . . . . . . . . . . . 49

Variables Definitions . . . . . . . . . . . . . . . 56

Descriptive Statistics and Balance Test . . . . . . . . . . 57

Random-Effects Probit Regressions of Socially Responsible Behavior in Market and No Market Conditions . . . . . . . . . . 59

Random-Effects Probit Regressions of Socially Responsible Behavior in Market Baseline and Alternative Market Conditions . 60

Firth Logit Model - The Effect of Eroding SRB on Anti-social Behavior ................... 61

Firth Logit Model - Is the Effect of Eroding SRB Pronounced in Market Context? . . . . . . . . . . . . . . . . . . 61

Purchasing Unfair product or selecting unfair distribution burn-

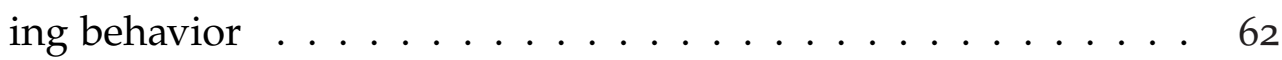

Do the third parties retaliate? . . . . . . . . . . . . . 62

Weather Index Insurance Adoption Rate in Treated Villages . . 88

OLS, Probit and Tobit Estimates on the Effect of WII on Social

Capital . . . . . . . . . . . . . . . . . 96

Tests on the Validity of the Selected Instrument . . . . . . . . . 97

IV Estimates on the Effect of WII on Social Capital . . . . . . . 100

Does WII Premium Payment Modality Matter? . . . . . . . . . . 102

Balance Test by Access to WII Using the 2007 Census Data . . . 104 
Table 3.7

Table 3.8

Table 3.9

Table 3.10

Table 3.11

Table B.1

Table B.2

Table B.3

Table B.4

Table B. 5

Table 4.1

Table 4.2

Table 4.3

Table 4.4

Table 4.5

Table C.I

Table C.2

Table C.3

Table C.4

Table C.5

Table C.6

Table C.7

Table C. 8

Table C.9
The Effect Access to WII on Social Capital . . . . . . . . . . 106 Impact of WII on Real-life Measures of Social Capital . . . . . 109 Matching Quality Test . . . . . . . . . . . . . . 110 Impact of WII on Social Capital - Matching Results . . . . . . . 111 Free-riding and Self-sufficiency Behaviours as the Causal Mechanisms? . . . . . . . . . . . . . . . 112 Summary Statistics - Full Sample . . . . . . . . . . . . . . . 122 Descriptive Statistics by Access to WII . . . . . . . . . . . . . . 123 Descriptive Statistics by WII Uptake . . . . . . . . . . . . . . . . . . . . . . . . . . . . . . Determinants of WII Uptake . . . . . . . . . . . . . . . 125 Covariate Balance Test - Matching Quality Test . . . . . . . . . . 126 Components of Internal Locus of Control . . . . . . . . . . 140 Impact of Market Exposure on Agricultural Investment Decisions145 Effects of Market Experience on Agricultural Investment Decisions . . . . . . . . . . . . . . . . . . . . . 149 Impact of Market Exposure on Risk-Aversion and Locus of Control . . . . . . . . . . . . . . . . . 152 Impact of Market Exposure on Risk-Aversion and Locus of Control . . . . . . . . . . . . . . . . . . . . . . 154 Variable Definitions and Summary Statistics . . . . . . . . . . . 164 Mean Difference Test of Variables . . . . . . . . . . . . . . . 165 Endogenous Switching Probit Estimation . . . . . . . . . . . 166 Endogenous Switching Probit Estimation . . . . . . . . . . 167 Test on the Validity of the Selection Instruments - Outcome Variables . . . . . . . . . . . . . . . . . . . . 168 First Stage Estimation Results . . . . . . . . . . . . . . . . . 169 Correlation Between Risk Aversion, Locus of Control and Investment Behavior . . . . . . . . . . . . . . 170 Endogenous Switching Regression . . . . . . . . . . . . 171 First Stage Estimation Results - Mechanisms . . . . . . . . . 172 


\section{LIST OF FIGURES}

Figure 2.1 Fair Product Purchase Across Market and No Market Conditions, $95 \%$ CI. . . . . . . . . . . . . . . . 32

Figure 2.2 Market Participants Fair Product Choice Across Market and Non-Market Conditions . . . . . . . . . . . . . . 33

Figure 2.3 Fair Product Purchase Across Varying Market Conditions, 95\% CI. . . . . . . . . . . . . . . . . 37

Figure 2.4 Production and Purchase of Fair Product Across Varying Market Conditions . . . . . . . . . . . . . . . 38

Figure $2.5 \quad$ Purchase of Fair Product and Punishment . . . . . . . . . . . 38

Figure A.1 $\quad$ Price of the Fair and Unfair Products . . . . . . . . . . . . . 58

Figure B.1 Propensity score distribution and common support for propensity score estimation . . . . . . . . . . . . . . 127

Figure B.2 Kernel density distribution of propensity scores for treated and control groups . . . . . . . . . . . . . . . . . . . . . . . . . . . 127

Figure $4.1 \quad$ Distribution of Farmers' Risk-aversion . . . . . . . . . . . 139 Figure 4.2 Distribution of Farmers' Internal Locus of Control (Standardized)140 Figure 4.3 Market Exposure, Risk-aversion and Locus of Control, 95\% CI . 151 Figure C.1 Distribution of Farmers' Risk Aversion . . . . . . . . . . 170 Figure C.2 Distribution of Farmers' Internal Locus of Control (Standardized)170 


\section{INTRODUCTION}

\subsection{MOTIVATION}

"MARKETS and OTHER economic institutions do more than allocate goods and services: they also influence the evolution of tastes, values and personalities. Economists have long assumed otherwise; the axiom of exogenous preferences is as old as liberal political philosophy itself."

Samuel Bowels, 1998

There hardly exists a central concept as markets in the economics discipline. Markets have been at the centerpiece of mainstream economics since its conception. As a consequence, "the study of economics is virtually synonymous with the study of markets" (Al-Ubaydli \& List, 2017). Markets are fundamental drivers of material well-being, and it is widely discernible that market societies are to a great extent materially better off relative to non-market societies. As theoretically documented in the First and Second Welfare Theorems (Mas-Colell et al., 1995) and later substantiated via lab and field experimental studies from developed countries (Chamberlin, 1948; Smith, 1962; List, 2004; List \& Millimet, 2008), markets are also unambiguously associated with the efficient allocation of scarce resources and often yield Pareto-optimal outcomes. Most notably, the experimental studies found efficiency rates as high as $100 \%$ though these findings do not fully extend to different contexts and cultures, particularly to environments where participants originated from rural areas of developing countries with limited exposure to markets (Fiala, 2015; Bulte et al., 2017). However, there has been a long-standing argument that markets do more than a mere allocation of resources. As the statements from Bowles (1998) indicate, markets also influence values and preferences and thereby shape human behavior. Therefore, given that markets are ubiquitous in our daily life and our societies are increasingly growing into market societies, how markets affect human behavior is an immensely important question.

Markets are economic, social, and political institutions (Bowles, 1991) and may directly or indirectly shape human behavior in a various respects. However, our understanding of how the market shapes human behavior is still low. This dissertation contributes to this scant but emerging literature and attempts to examine the effect of 
markets on socially responsible behavior, social capital, preferences, personality traits, and investment behavior.

The interplay between markets and morals has been one of the most debated topics in economics and other social sciences. This debate dates back at least to the time of Adam Smith - thought to be the founding father of Economics. Markets are hypothesized to affect moral virtues in two opposing ways. First, the market is hypothesized to have a civilizing and moralizing effect. Second, is the destructive (asocial) effects of markets. The doux commerce hypothesis argues that markets hinge on and nurture moral virtues and civility (Montesquieu, 1989/1748; Smith, 1979/1776; Storr \& Choi, 2019). For instance, Montesquieu (1989/1748) argued that "commerce cures destructive prejudices, and it is an almost general rule that everywhere there are gentle mores, there is commerce and that everywhere there is commerce, there are gentle mores." He further argued that "commerce polishes and softens barbarous mores". Likewise, Smith (1979/1776) argued that markets are moral spaces and make people more virtuous and he asserted that "whenever commerce is introduced into any country, probity and punctuality always accompany it ... Of all the nations of Europe, the Dutch, the most commercial, are the most faithful to their word." However, others are against the doux commerce hypothesis and argue that markets have destructive effects and alienate instead of foster moral values (Marx, 1957/1867; Veblen, 1899; Hirsch, 1976). This is because markets promotes envy and lead to exclusion and coercion. Interestingly, Smith (1979/1776) also lend support to this argument and stated that engaging in market activities erode moral values though he concludes that material benefits of markets outweigh the corresponding moral costs. More recently, (Shleifer, 2004) suggested that market competition induces firms to engage in unethical behaviors such as paying a bribe and hiring children to reduce costs.

Despite a long-standing concern, there has been a paucity of empirical evidence on whether markets foster or corrupt moral and socially responsible behavior. Recently, small but emerging experimental studies echo both the civilizing and destructive effects of markets. For instance, while Falk \& Szech (2013) and Bartling et al. (2015) find that moral and socially responsible behavior is less prevalent in markets, Storr \& Choi (2019) show that markets hinge on and nurture moral virtues. This dissertation contributes to this debate using artefactual field experiments from a developing country context. It examines whether or not engaging in market activities erodes socially responsible behavior. It also investigates the possible ways through which markets can be combined with other economic and social institutions to pursue improved moral virtues. More specifically, it aims to uncover the role of regulation mechanisms (punishment) and culture (religion) on social responsibility in markets. Furthermore, it provides new evidence on the social sequels of the erosion of socially responsible behavior. 
Despite growing cross-country studies demonstrate that informal institutions such as social capital are essential for economic growth and development (Knack \& Keefer, 1997; Zak \& Knack, 2001), insofar greater attention has been given only to the importance of formal institutions. For a long time, informal institutions have been considered as appendages and substitutes to the formal institutions. As a consequence, the standard approach in developing countries has been to transplant formal institutions. It is, therefore, imperative to enhance our understanding on whether the introduction of formal institutions such as formal insurance markets crowds in or crowds out existing informal institutions such as individuals' risk sharing and cooperative behavior. This dissertation contributes to the literature on the impact of formal insurance markets on informal insurance mechanisms (Attanasio \& Rios-Rull, 2000; Dercon \& Krishnan, 2003; Landmann et al., 2012; Cecchi et al., 2016; Takahashi et al., 2018). This dissertation provides novel empirical evidence on the effect of the introduction of a formal insurance market - weather index insurance (WII) - on social capital. It further explores the potential mechanisms through which WII may crowd in or crowd out social capital.

Poverty and food insecurity are pervasive in rural areas of developing countries, particularly in Sub-Saharan African countries. This has been mainly attributed to low agricultural productivity, which in turn is driven by the low uptake of profitable farm technologies in the region. Despite concerted policy and academic efforts, the adoption rates remain low. Market imperfections, including imperfect input, output, credit, and insurance markets, are identified as significant constraints on farmers' investment in profitable agricultural technologies (Zeller et al., 1998; Duflo et al., 2011; Minten et al., 2013; Karlan et al., 2014; Aggarwal et al., 2018; Aggarwal, 2018). Poor access to input and out markets due to poor transportation infrastructure limits adoption of improved agricultural inputs through increasing transaction and transportation costs and makes it hard to benefit from high prices for agricultural output (Zeller et al., 1998; Minten et al., 2013; World Bank, 2017; Aggarwal et al., 2018; Aggarwal, 2018). In developing countries where liquidity constraints and climate risks are ubiquitous, the use of high-risk high-return technologies is also constrained by imperfect credit and insurance markets (Duflo et al., 2011; Giné et al., 2008; Karlan et al., 2014). Most notably, Karlan et al. (2014) show that investments in agricultural inputs with high expected profits are lower in environments where credit and insurance markets are imperfect. They further show that relaxing credit and insurance market constraints improved investments in risky but profitable agricultural inputs. Recent evolving literature relates investment in profitable agricultural inputs to behavioral factors such as risk preference (Liu, 2013; Brick \& Visser, 2015; Holden \& Quiggin, 2017), locus of control (Bernard et al., 2014; Abay et al., 2017; Taffesse \& Tadesse, 2017). This dissertation adds to this literature, and it provides new evidence by relating markets and behavioral factors which affect investment in agricultural technologies. Specifically, it 
examines the effect of exposure to markets on risk-aversion and locus of control, and eventually on investment behavior.

\subsection{OBJECTIVES AND RESEARCH QUESTIONS}

The overarching objective of this dissertation is to improve our understanding of whether and how markets affect human behavior. More specifically, this dissertation provides empirical evidence on (1) the effect of markets on socially responsible behavior and the role of regulation mechanisms and culture on social responsibility in markets (2) the impact of weather index insurance on farmers' risk-sharing and cooperative behavior and (3) the impact of farmers' exposure to market on their risk-aversion, locus of control and then technology adoption. More specifically, the chapters in this dissertation address the following research questions.

1. Do markets erode socially responsible behavior? Do punishment and religion promote social responsibility in markets? What are the adverse consequences of the erosion of socially responsible behavior? (Chapter 2)

2. Does weather index insurance crowds in or crowds out social capital? What are the potential mechanisms through which weather index insurance crowds in or crowds out social capital? (Chapter 3)

3. Does exposure to markets promote farmers' investment behavior? If so, how does exposure to markets affect farmers' investment behavior? (Chapter 4 )

\subsection{RESEARCH SETTING AND DATA}

This dissertation was carried out in the Tigray regional state of northern Ethiopia, bordered by Eritrea, Sudan, Amhara, and Afar regional states of Ethiopia. Tigray is the hub of cultural heritages and ancient civilizations, including the Axumite civilizations, because of which the region is one of the main tourist attraction sites in the country. The region is known by the fact that the two dominant religions, Christianity and Islam, were introduced (entered) in the $4^{\text {th }}$ and $7^{\text {th }}$ centuries, respectively, into Ethiopia via this region. It is also widely believed that Tigray is the home to the ark of the covenant. Currently, however, the majority (about 8 o percent) of the population in the region is dependent on rain-fed agriculture, and the region is characterized by poor agro-ecological conditions: low soil quality, sparse and erratic rainfall, and frequent droughts (Hagos et al., 1999), mainly caused by the frequent inter and intra-country wars and change in global climatic conditions. Most of the regional highlands are highly degraded, and the average yield of cereal crops in the region is less than the 
national average (Pender \& Gebremedhin, 2007). Tigray is one of the most droughtprone regions in the country, with more than 25 severe drought periods in the last millennium (Di Falco et al., 2007). Although the region has achieved profound economic growth and development post-1991 and, as a result, poverty has reduced from $55 \%$ in the early 1990 s to about $27 \%$ currently, it appears that the region is economically going backward to where it was about three decades ago due to the recent ongoing war.

Tigray was chosen as a research site because the recent financial innovation - weather index insurance - was first introduced in the region (Chapter 2) before spreading out to the rest part of the country, particularly to the Amhara region. In addition, the region was selected due to the prevalence of significant heterogeneity in market exposure among farm-households (Chapters 1 and 3). On top of this, the region was almost the only one that had no security-related threats in the country during the fieldwork period. The chapters in this dissertation are based on primary data collected in two waves from a total of 928 farm-households in 38 villages (Tabias) in six districts of Tigray. The first wave was conducted in March-May, 2017, and data were collected from 384 farm-households in 8 villages. The second wave was conducted in the fall of 2018, and data were collected from 544 farm-households in 32 villages. Both survey and incentivized field experimental data were collected using tablets with the help of computer-assisted personal interviews (CAPI). The sampling strategy and the data collection process will be detailed in each of the subsequent chapters.

\subsection{METHODOLOGY}

The core aim in the empirical economics literature is to make a causal inference about the effect of dependent variables on independent variables. However, the obvious challenge, which this dissertation has also faced, is to plausibly gauge the cause and effect relationships among economic variables. This is attributed to the endogeneity problem stemmed from the ubiquitous selection bias, which arises when subjects are selected for treatment based on characteristics that may also affect their outcomes and makes it difficult to disentangle the impact of the treatment from the factors that drove selection (Duflo et al., 2008), omitted variable bias, reverse causality (simultaneity bias) - a bidirectional causality between economic variables, and measurement errors (Angrist \& Pischke, 2008).

Numerous methods can be used to overcome the issue of endogeneity and making a causal inference tenable. One way is using randomization (randomized controlled trials (RCT) and randomized field experiments), that is, randomly assigning subjects to the treatment and comparison groups. When randomization is not feasible, other ways the causal inference problem can be addressed are using quasiexperimental and non-experimental methods, including regression discontinuity \& 
propensity score matching and instrumental variables \& endogenous switching regressions, respectively (Duflo et al., 2008). This dissertation has attempted to attenuate the endogeneity problem and thereby to make a causal inference by combining experimental, quasi-experimental, and non-experimental designs. More specifically, this dissertation has utilized randomized field experiments, propensity score matching, endogenous switching regression, and instrumental variables methods, as briefly described below.

\subsubsection{Field Experiments}

The use of experiments in economics research dates back at least to the time of Chamberlin (1948) - a prominent Harvard Economist who is known for his seminal contributions on market theories. Chamberlin conducted economic experiments to test the tenability of fundamental economic theories, such as the neoclassical market theory and found a mismatch between theory and evidence. ${ }^{1}$ Chamberlin is thought to be the pioneer not only in the market experiment but also in any kind of economic experiment. However, the consolidation of economic experiments did not come immediately after Chamberlin (1948)'s work. The intensification of experimental approaches started after the seminal works of the 2002 Noble Prize winner Vernon Smith on market experiments. Smith (1962, 1964) extended Chamberlin (1948)'s study by publicly announcing the information about traders' agreed price and allowing agents to interact repeatedly and finds otherwise - sales and prices are very close to the competitive market equilibrium. Experiments are being increasingly used ever since to objectively measure and thoroughly understand the complex human behavior (Plott, 1983; List, 2002, 2004; Harrison \& List, 2004; Levitt \& List, 2007, 2009; Gerber \& Green, 2012; Al-Ubaydli \& List, 2017).

In the absence of field data, experiments allow generating data either in the lab or in the field to test theories and predictions. Experimental approaches are useful to generate experimental data in an incentive-compatible way with real monetary payoffs and represent the most convincing method of creating a counterfactual, as they directly construct a control group through randomization (Harrison \& List, 2004). Experimental methods are broadly classified into two categories: 1) Lab experiments, 2) Field experiments. According to Harrison \& List (2004), field experiments are further classified into three broad categories. First, artefactual field experiments (also known as lab-in-the-field experiments) are the same as lab experiments except for experimenting with a 'non-standard' (non-student) population. Second, framed field experiments are the same as artefactual field experiments, but they contextualize the field setting with commodity, task, or information sets used by subjects. Third, natural field experi-

1 Chamberlin (1948) finds sales substantially higher and prices lower than predicted by the competitive market theory. 
ments are also the same as framed field experiments, except participants are observed in their natural environment, and at the same time, subjects are unaware of that they are participating in an experiment.

All the Chapters (Chapters 2, 3, and 4) in this dissertation used lab-in-the-field experiments by drawing participants from smallholder farmers who reside in several villages of Tigray. More specifically, Chapter 2 employed lab-in-the-field experiments to measure otherwise difficult economic concepts, such as markets, socially responsible behavior, and anti-social behavior. To this end, a laboratory product market and joy-of-destruction games were used. Likewise, Chapter 3 used the public goods game to measure farm households' cooperative behavior, which we used it as a proxy for social capital. Chapter 4 of this dissertation also used decontextualized risk game to measure farm-households risk preferences (risk aversion). This dissertation attempted to link the information from the field experiments to farmers' socio-economic and demographic characteristics.

The use of experiments is not, however, without practical challenges. The common challenge is related to ethical issues. Participants are required to provide full consent to participate in an experiment. Participation in experiments should also be entirely voluntary, and if at any time the participants find that it is something they do not wish to participate in for any reason, they should be allowed to withdraw at any time without asking permission regardless of whether the experiments have started or not. Accordingly, in our experiments, prior to their participation, subjects were first conveyed with detailed explanations about the purpose of the study, compensation for their participation, potential risks, benefits, and confidentiality. We then obtained written informed consent from all participants. All participants were provided with an oral explanation of the experiment, and participants were asked participants to actively participate in some trial rounds with no real earnings. In addition, they received some exercises to test for comprehension. Once all the test exercises had been completed correctly and all questions raised were answered, we conducted the experimental games.

\subsubsection{Quasi-experimental and Non-experimental Designs}

In reality, it is not often possible to use randomization in economic researches. When randomization is not feasible for practical or ethical reasons, causal inferences can still be made using other (though not perfect) alternatives to controlled experiments such as quasi-experimental and non-experimental methods (Cook et al., 2006; Duflo et al., 2008). As is the case with the experimental designs, in these types of methods subjects are not assigned randomly to treatment and control groups, rather they self-select either to receive the treatment or not. Cook et al. (2006) suggested that well-designed quasi-experiments may provide results as convincing as randomized designs. While 
these designs are internally less valid compared to "true" experiments, they are externally more valid than most "true" experiments as they usually employ naturally occurring data and involve real-world settings instead of artificial lab settings.

Hence, along with field experiments, this dissertation has attempted to address the causal inference problem by using quasi-experimental and non-experimental methods including propensity score matching, endogenous switching regression and probit, and instrumental variables approaches. In Chapter 3, we used instrumental variables approach and propensity score matching to examine the effect of weather index insurance on social capital. Instrumental variables (IV) approach account for endogeneity problems stemmed from both observables and unobservables (Angrist \& Pischke, 2008). However, the IV approach requires that the unpalatable assumptions should be satisfied. To do so, there should be a credible instrument that is strongly correlated with the endogenous variable, but has no direct association with the outcome variable. In this chapter, we used distance to insurance foreman's residence as an instrument for weather index insurance purchase. To probe the robustness of the IV approach, we used propensity score matching (PSM) that has been extensively used in the economics literature for the last four decades (Rosenbaum \& Rubin, 1983). PSM mimics the pattern of the randomized experiments to create comparison groups but the validity of matching estimates hinge on two important identifying assumptions: the conditional independence assumption (CIA) and the common support condition. In addition, PSM does not account for selection bias due to unobservables. In Chapter 3 , to check whether the identifying assumptions are met, we conduct a series of tests.

Table 1.1: Research Topics, Empirical Data and Empirical Strategies

\begin{tabular}{lllll}
\hline Chapter & Focus & Topics & Empirical Data & Empirical strategy \\
\hline Chapter 2 & Markets \& & Rationality, & Lab-in-the-field & Probit, Random \\
& Socially & inequality aversion & experiments & Effects Probit, \\
& responsible & and negative & and house- & OLS and \\
behavior & externalities & hold survey & Firth Logit \\
Chapter 3 & Weather index & Formal and & Lab-in-the-field & Instrumental Variables \\
& insurance \& & informal & experiments and & (IV) \& Propensity Score \\
& Social capital & institutions & household survey & Matching (PSM) \\
Chapter 4 & Markets and & Markets, risk & Lab-in-the-field & Endogenous Switching \\
& Investment & aversion, locus & experiments & regression \& Probit \\
behavior & of control \& tech & \& household & \& Instrumental \\
& -nology adoption & survey & Variables (IV) \\
\hline
\end{tabular}


In Chapter 4, we used endogenous switching regression (ESR) model, endogenous switching probit (ESP), and instrumental variables (IV) techniques to investigate the effect of farmers' exposure to markets on their investment behavior, particularly, investment in agricultural technologies. ESR attenuates both endogeneity and sample selection problems by using full information maximum likelihood method. To account for a binary outcome measures of technology adoption, we employ the endogenous switching probit (Lokshin \& Sajaia, 2011) which is analogous to the ESR model used for the continuous outcomes. To probe the robustness of the ESR and ESP models, we utilize the IV (2SLS and IV probit) methods. Over all, Table 1.I summarizes the empirical data and empirical strategies used in the subsequent chapters.

\subsection{STRUCTURE OF THE DISSERTATION}

This dissertation is structured into five chapters. Chapter 1 provides the road-map of the dissertation. It highlights the motivation, research questions, research setting \& data and methodology of the dissertation.

There has been a long-standing concern on the cultural consequences of markets, in the sense that markets may corrupt moral and socially responsible behavior. Adam Smith, thought to be the father of modern economic science, was among the first to point out this concern. He argued that while markets bring material wealth, they could alienate morals (Smith, 1896/1763). This concern has been at the center of discourses on the entwined relationships between markets and morals, and as a consequence, the debate has increasingly garnered the attention of researchers ever since. There have been continued arguments on whether markets erode morals and otherregarding motives for about two and half centuries. While some scholars support the idea that an increase in market exchanges lead to egoistic and asocial behaviors (Marx, 1957/ 1867; Veblen, 1899; Schumpeter, 1994/1942; Hirsch, 1976; Bowles, 1998; Shleifer, 2004; Sandel, 2012), others are against this argument in that markets are moral spaces that hinge on and nurture moral virtues (Montesquieu, 1989/1748; Smith, 1896/1763; Storr \& Choi, 2019). Despite the debate on the interplay between markets and morals is contested, it is only recently scholars attempted to provide empirical evidence on this matter (Plott, 1983; Falk \& Szech, 2013; Bartling et al., 2015; Storr \& Choi, 2019).

Chapter 2 contributes to this literature. Specifically, this chapter is closest to the seminal paper by Bartling et al. (2015) and examines the effect of markets on socially responsible behavior and the role of regulation mechanisms and culture on social responsibility in markets. Further, it examines the consequences of eroding socially responsible behavior. To this end, we used field-experimental data from households in the Tigray regional state. We use a laboratory competitive product market where we randomly assigned subjects a role as sellers, buyers, third parties, and observers. Sellers and buyers, respectively, have the option to produce and buy a low-cost prod- 
uct with or a high-cost product without a negative externality on third parties. While third parties hold a passive role: they neither sell nor buy, observers observe sellers' and buyers' decisions and decide whether to punish or not. We randomly assign participants to a version of a game framed as a "market" context, "market" with punishment, "market" with religious priming, or as a "neutral" (non-market) context. The primary finding of this chapter is that subjects, irrespective of the framed context, revealed a substantial concern for the welfare of others: they prefer to produce and purchase goods with less adverse social impacts at a personal cost. However, in line with previous studies, we find that social concern is less prevalent in markets relative to the non-market context.

The chapter also provides evidence that punishment and religion are effective in promoting socially responsible behavior in markets. To uncover the sequel of the erosion of social responsibility in markets, we also conducted a second experimental game - the joy-of-destruction game. The results show that subjects exhibit relatively higher anti-social behavior in environments where socially responsible behavior is more eroded. Furthermore, the results present suggestive evidence that unregulated markets may yield lower welfare compared to regulated markets. Overall, the findings in this chapter imply that voluntary internalization of negative externalities could serve as a remedy by itself. In addition, monitoring and sanctioning strategies may play a crucial role in fostering socially responsible behavior, and thereby welfare in market contexts. Preventing the erosion of socially responsible behavior in markets may also contribute to the nurturing of other-regarding motives in markets.

A growing theoretical and empirical evidence documented that institutions are vital for the overall economic growth and development of countries. In the absence of well-functioning institutions, countries could be dragged into an institution-induced poverty trap (North, 1990). However, for a long time, too much attention has been given only to the importance of formal institutions, and informal institutions have been considered as appendages to the formal institutions. As a consequence, the standard practice has been to transplant formal institutions, particularly in developing countries. However, this practice has been widely criticized for undermining the role informal institutions play in developing countries as growing cross-country studies demonstrate that informal institutions are essential for economic growth too (Knack \& Keefer, 1997; Zak \& Knack, 2001). Formal institutions do not occur in a vacuum, and social fabric has been crucial for countries' overall economic progress. It is, therefore, imperative to uncover whether the introduction of formal institutions alters or reinforces existing informal institutions. Recently, there is an evolving body literature which investigates the interplay between formal and informal institutions, including formal and informal insurance mechanisms(e.g., see Attanasio \& R1os-Rull (2000); Cecchi et al. (2016); Landmann et al. (2012); Dercon \& Krishnan (2003)). Chapter 3 builds on this literature and explores the effect of the introduction of a formal insurance 
mechanism - weather index insurance - on informal insurance mechanisms and social capital.

Chapter 3 empirically investigates whether weather index insurance (WII) crowds in or crowds out social capital. Further, it uncovers the mechanisms through which WII crowds in or crowds out social capital. In so doing, the chapter utilized both household survey and field-experimental data from smallholder farmers with access (those who purchased WII and those who did not but have access to WII) and without access to WII in the Tigray regional state. So as to attenuate the self-selection and simultaneity biases, and thereby make a casual inference, the instrumental variables approach is used. The findings in this chapter reveal that WII does not crowd in, if anything, crowds out social capital. We find that insured households contribute significantly less to the public good than uninsured households. The findings from the experimental games are corroborated with real-life measures of social capital, such as informal transfers to fellow villagers and financial contributions to community projects. We find support for two channels through which WII crowds out social capital. The first mechanism lays in the premise that WII creates positive externalities on uninsured households, which in turn induces them to free-ride on insured households. Anticipating this, households with WII respond by lowering their investment in social capital. The second channel is that WII make insured households feel selfsufficient, and thereby need to rely less on others, particularly on uninsured households, in times of need. The findings in this chapter imply that formal institutions such as formal insurance mechanisms may have unintended effects - crowd out informal insurance mechanisms and thus, calls for a novel insurance product design and marketing strategies to ameliorate such unintended effects.

Despite concerted policy and academic efforts to promote the adoption of remunerative modern agricultural technologies, the low adoption rate remains a practical challenge and an empirical puzzle. There has been extensive research in search of what explains the low adoption of agricultural technologies in developing countries. A large body of literature demonstrate that external constraints, including access to input and output markets (Zeller et al., 1998; Minten et al., 2013; Aggarwal et al., 2018; Aggarwal, 2018), imperfect credit and insurance markets (Duflo et al., 2011; Karlan et al., 2014), weather risks (Alem et al., 2010; Dercon \& Christiaensen, 2011; Holden \& Quiggin, 2017), heterogeneous return to agricultural technologies (Suri, 2011), social network and learning (Oster \& Thornton, 2012; Maertens \& Barrett, 2012; Conley \& Udry, 2010; Krishnan \& Patnam, 2013), quality of inputs (Bold et al., 2017) as limiting factors to technology adoption in Sub-Saharan Africa. Recently, the behavioral economics literature argues that farmers in developing countries are less likely to adopt risky but profitable agricultural technologies because they suffer from internal constraints that may impede investments in "high-risk" "high-return" agricultural 
technologies (Duflo et al., 2011; Liu, 2013; Brick \& Visser, 2015; Bernard et al., 2014; Abay et al., 2017; Taffesse \& Tadesse, 2017).

This chapter contributes to this literature by acknowledging the interdependence of both factors and attempted to reconcile both groups of literature. As external constraints such as markets may affect internal constraints, including (risk) preferences and personality traits (locus of control), this chapter argues markets may affect investment in profitable agricultural technologies by shaping risk aversion and locus of control. Further, previous studies on the role of markets focused on the supply side effect of markets on technology adoption. This chapter instead takes a different route (demand side) through which markets affect investment in remunerative agricultural investments. This chapter also contributes to the literature about whether preferences and personality traits are exogenous and stable. To this end, survey and experimental data were collected from rural areas in the Tigray regional state. The findings indicated that market experience promotes farmers' investment behavior by attenuating risk-aversion and enhancing internal locus of control. The findings of Chapter 4 imply that market expansion in rural Africa could have a multiplier effect and contribute to poverty alleviation by improving access to modern agricultural technologies, reducing transaction and transportation costs, and most importantly, by bringing about desirable farmers' economic behavior.

Finally, Chapter 5 concludes the dissertation, by answering the research questions, identifying its policy implications, and limitations of the dissertation before suggesting avenues for future research. 


\section{REFERENCES}

Abay, K. A., Blalock, G. \& Berhane, G. (2017), 'Locus of control and technology adoption in developing country agriculture: Evidence from ethiopia', Journal of Economic Behavior E Organization 143, 98-115.

Aggarwal, S. (2018), 'Do rural roads create pathways out of poverty? Evidence from India', Journal of Development Economics 133, 375-395.

Aggarwal, S., Giera, B., Jeong, D., Robinson, J. \& Spearot, A. (2018), Market access, trade costs, and technology adoption: Evidence from northern tanzania, Technical report, National Bureau of Economic Research. NBER working paper No. w25253.

Al-Ubaydli, O. \& List, J. A. (2017), Field experiments in markets, in 'Handbook of Economic Field Experiments', Vol. 1, Elsevier, pp. 271-307.

Alem, Y., Bezabih, M., Kassie, M. \& Zikhali, P. (2010), 'Does fertilizer use respond to rainfall variability? panel data evidence from ethiopia', Agricultural Economics 41(2), 165-175.

Angrist, J. D. \& Pischke, J. S. (2008), Mostly harmless econometrics: An empiricist's companion, Princeton University Press.

Attanasio, O. \& Rios-Rull, J.-V. (2000), 'Consumption smoothing in island economies: Can public insurance reduce welfare?', European Economic Review 44(7), 1225-1258.

Bartling, B., Weber, R. A. \& Yao, L. (2015), 'Do markets erode social responsibility?', Quarterly Journal of Economics 130(1), 219-266.

Bernard, T., Dercon, S., Orkin, K., Taffesse, A. et al. (2014), The future in mind: Aspirations and forward-looking behaviour in rural Ethiopia, Centre for Economic Policy Research London.

Bold, T., Kaizzi, K. C., Svensson, J. \& Yanagizawa-Drott, D. (2017), 'Lemon technologies and adoption: measurement, theory and evidence from agricultural markets in uganda', The Quarterly Journal of Economics 132(3), 1055-1100.

Bowles, S. (1991), 'What markets can-and cannot-do', Challenge 34(4), 11-16.

Bowles, S. (1998), 'Endogenous preferences: The cultural consequences of markets and other economic institutions', Journal of Economic Literature 36(1), 75-111.

Brick, K. \& Visser, M. (2015), 'Risk preferences, technology adoption and insurance uptake: A framed experiment', Journal of Economic Behavior $\mathcal{E}$ Organization 118, 383396.

Bulte, E., Kontoleon, A., List, J., Turley, T. \& Voors, M. (2017), 'From personalized exchange towards anonymous trade: A field experiment on the workings of the invisible hand', Journal of Economic Behavior E Organization 133, 313-330. 
Cecchi, F., Duchoslav, J. \& Bulte, E. (2016), 'Formal insurance and the dynamics of social capital: Experimental evidence from Uganda', Journal of African Economies 25(3), 418-438.

Chamberlin, E. H. (1948), 'An experimental imperfect market', Journal of Political Economy 56(2), 95-108.

Conley, T. G. \& Udry, C. R. (2010), 'Learning about a new technology: Pineapple in ghana', American economic review 100(1), 35-69.

Cook, T. D., Shadish, W. \& Wong, V. C. (2006), 'Within-study comparisons of experiments and non-experiments: Can they help decide on evaluation policy', Mimeo. Northwestern University. .

Dercon, S. \& Christiaensen, L. (2011), 'Consumption risk, technology adoption and poverty traps: Evidence from ethiopia', Journal of development economics 96(2), 159173.

Dercon, S. \& Krishnan, P. (2003), 'Risk sharing and public transfers', The Economic Journal 113(486), C86-C94.

Di Falco, S., Chavas, J.-P. \& Smale, M. (2007), 'Farmer management of production risk on degraded lands: the role of wheat variety diversity in the Tigray region, Ethiopia', Agricultural Economics 36(2), 147-156.

Duflo, E., Kremer, M. \& Robinson, J. (2011), 'Nudging farmers to use fertilizer: Theory and experimental evidence from kenya', American economic review 101(6), 2350-90.

Duflo, E., Rachel, G. \& Kremer, M. (2008), 'Using randomization in development economics research: A toolkit', Handbook of Development Economics 4, 3896-3962.

Falk, A. \& Szech, N. (2013), 'Morals and markets', Science 340(6133), 707-711.

Fiala, N. (2015), 'Skills in the marketplace: Market efficiency, social orientation, and ability in a field-based experiment', Journal of Economic Behavior E Organization 120, 174-188.

Gerber, A. \& Green, D. (2012), Field Experiments. Design, Analysis and Interpretation, New York: W.W. Norton \& Company, Inc.

Giné, X., Townsend, R. \& Vickery, J. (2008), 'Patterns of rainfall insurance participation in rural India', The World Bank Economic Review 22(3), 539-566.

Hagos, F., Pender, J. \& Gebreselassie, N. (1999), Land degradation in the highlands of Tigray and strategies for sustainable land management. Socioeconomic and Policy Research Working Paper 25.

Harrison, G. W. \& List, J. A. (2004), 'Field experiments', Journal of Economic Literature 42(4), 1009-1055.

Hirsch, F. (1976), 'Social limits to growth'.

Holden, S. T. \& Quiggin, J. (2017), 'Climate risk and state-contingent technology adoption: shocks, drought tolerance and preferences', European Review of Agricultural Economics 44(2), 285-308. 
Karlan, D., Osei, R., Osei-Akoto, I. \& Udry, C. (2014), 'Agricultural decisions after relaxing credit and risk constraints', The Quarterly Journal of Economics 129(2), 597652.

Knack, S. \& Keefer, P. (1997), 'Does social capital have an economic payoff? A crosscountry investigation', The Quarterly Journal of Economics 112(4), 1251-1288.

Krishnan, P. \& Patnam, M. (2013), 'Neighbors and extension agents in ethiopia: Who matters more for technology adoption?', American Journal of Agricultural Economics 96(1), 308-327.

Landmann, A., Vollan, B. \& Frölich, M. (2012), Insurance versus savings for the poor: Why one should offer either both or none. IZA Discussion Paper No. 6298.

Levitt, S. D. \& List, J. A. (2007), 'What do laboratory experiments measuring social preferences reveal about the real world?', Journal of Economic Perspectives 21(2), 153174 .

Levitt, S. D. \& List, J. A. (2009), 'Field experiments in economics: The past, the present, and the future', European Economic Review 53(1), 1-18.

List, J. A. (2002), 'Testing neoclassical competitive market theory in the field', Proceedings of the National Academy of Sciences 99(24), 15827-15830.

List, J. A. (2004), 'Testing neoclassical competitive theory in multilateral decentralized markets', Journal of Political Economy 112(5), 1131-1156.

List, J. A. \& Millimet, D. L. (2008), 'The market: Catalyst for rationality and filter of irrationality', The BE Journal of Economic Analysis \& Policy 8(1).

Liu, E. M. (2013), 'Time to change what to sow: Risk preferences and technology adoption decisions of cotton farmers in china', Review of Economics and Statistics 95(4), 1386-1403.

Lokshin, M. \& Sajaia, Z. (2011), 'Impact of interventions on discrete outcomes: Maximum likelihood estimation of the binary choice models with binary endogenous regressors', The Stata Journal 11(3), 368-385.

Maertens, A. \& Barrett, C. B. (2012), 'Measuring social networks' effects on agricultural technology adoption', American Journal of Agricultural Economics 95(2), 353-359.

Marx, K. (1957/1867), Capital: Vol. I. A critique of political economy, London: Penguin Books.

Mas-Colell, A., Whinston, M. D., Green, J. R. et al. (1995), Microeconomic theory, Vol. 1, Oxford university press New York.

Minten, B., Koru, B. \& Stifel, D. (2013), 'The last mile (s) in modern input distribution: Pricing, profitability, and adoption', Agricultural Economics 44(6), 629-646.

Montesquieu, C. (1989/1748), 'The spirit of the laws'.

North, D. C. (1990), Institutions, institutional change and economic performance, Cambridge university press. 
Oster, E. \& Thornton, R. (2012), 'Determinants of technology adoption: Peer effects in menstrual cup take-up', Journal of the European Economic Association 1o(6), 1263-1293.

Pender, J. \& Gebremedhin, B. (2007), 'Determinants of agricultural and land management practices and impacts on crop production and household income in the highlands of Tigray, Ethiopia', Journal of African Economies 17(3), 395-450.

Plott, C. R. (1983), 'Externalities and corrective policies in experimental markets', The Economic Journal 93(369), 106-127.

Rosenbaum, P. R. \& Rubin, D. B. (1983), 'The central role of the propensity score in observational studies for causal effects', Biometrika 70(1), 41-55.

Sandel, M. J. (2012), What Money Can't Buy: The Moral Limits of Markets, (Farrar, Straus and Grioux, New York).

Schumpeter, J. A. (1994/1942), Socialism, capitalism and democracy, London: Routledge. Shleifer, A. (2004), 'Does competition destroy ethical behavior?', American Economic Review Papers and Proceedings 94(2), 414-418.

Smith, A. (1896/1763), Lectures on jurisprudence, in R. Meek, D. Raphael \& P. Stein, eds, 'The Glasgow Edition of the Works and Correspondence of Adam Smith: VI: Correspondence', Cambridge: Cambridge University Press.

Smith, A. (1979/1776), '1976. an inquiry into the nature and causes of the wealth of nations', The Glasgow edition of the works and correspondence of Adam Smith 2.

Smith, V. L. (1962), 'An experimental study of competitive market behavior', Journal of Political Economy 70(2), 111-137.

Smith, V. L. (1964), 'Effect of market organization on competitive equilibrium', The Quarterly Journal of Economics 78(2), 181-201.

Storr, V. H. \& Choi, G. S. (2019), Do markets corrupt our morals?, Springer Nature.

Suri, T. (2011), 'Selection and comparative advantage in technology adoption', Econometrica 79(1), 159-209.

Taffesse, A. S. \& Tadesse, F. (2017), 'Pathways less explored-locus of control and technology adoption', Journal of African Economies 26(suppl_1), i36-i72.

Takahashi, K., Barrett, C. B. \& Ikegami, M. (2018), 'Does index insurance crowd in or crowd out informal risk sharing? evidence from rural ethiopia', American Journal of Agricultural Economics 101(3), 672-691.

Veblen, T. (1899), 'The theory of the leisure class'.

World Bank (2017), 'Enabling the business of agriculture 2017. washington, dc: World bank'.

Zak, P. J. \& Knack, S. (2001), 'Trust and growth', The Economic Journal 111(470), 295321.

Zeller, M., Diagne, A. \& Mataya, C. (1998), 'Market access by smallholder farmers in malawi: Implications for technology adoption, agricultural productivity and crop income', Agricultural Economics 19(1-2), 219-229. 


\section{2}

MARKETS AND SOCIALLY RESPONSIBLE BEHAVIOR: DO PUNISHMENT AND RELIGION PROMOTE SOCIAL RESPONSIBILITY IN MARKETS

\section{ABSTRACT}

This study investigates the effect of markets on socially responsible behavior in a typical Sub-Saharan African country, Ethiopia. In our first experiment, we use a laboratory competitive product market where sellers and buyers, respectively, have the option to produce and buy a low-cost product with or a high-cost product without a negative externality. We randomly assign participants to a version of a game framed as a "market" context or as a "neutral" (non-market) context. We find that, contrary to the prediction of pure self-interest theory, participants exhibit considerable levels of socially responsible behavior irrespective of the framed context. We also find evidence that socially responsible behavior is less prevalent in markets compared to non-market contexts. Further, our experimental results show that regulating mechanisms and culture, such as punishment and religion, play a significant role in promoting socially responsible behavior in markets. In our second experiment, we use the joy-of-destruction game to test whether the erosion of social responsibility leads to subsequent anti-social behavior. We find that anti-social behavior is ubiquitous in environments where socially responsible behavior is eroded, but this does not differ across the market and non-market contexts. Finally, we look at the welfare effects and find suggestive evidence that unregulated markets yield lower welfare compared to regulated markets. These findings emphasize the role of monitoring and sanctioning in fostering socially responsible behavior, and thus welfare in market contexts.

JEL Classification: C93, Do3, D62, D63, K42, L51, M14, Z12

Keywords: Markets; punishment; religious priming; socially responsible behavior

The chapter is based on:

Nigus, H. Y., Nillesen, E., Mohnen, P. \& Di Falco, S. (2021). Markets and socially responsible behavior: Do punishment and religion promote social responsibility in markets? Journal of Economic Behaviour and Organization revise and resubmit. 


\subsection{INTRODUCTION}

section2.1 The debate on the interplay between markets and morals dates back to the time wherein Adam Smith wrote his books, The Theory of Moral Sentiments, and The Wealth of Nations, in the $18^{\text {th }}$ century. While Smith's first book extols the moral forces such as sympathy that restrain selfish behavior, his second book expounded the idea of the invisible hand metaphor, that channels the pursuit of rational self-interest into social good. There has been a long-standing debate on whether or not markets corrupt moral behavior ever since. While some argue that markets promote moral virtues (Montesquieu, 1989/1748; Smith, 1896/1763), others emphasize the adverse effects of markets on moral values (Marx, 1957/ 1867; Veblen, 1899; Schumpeter, 1994/1942; Hirsch, 1976). Despite markets and morals ${ }^{1}$ being historically intertwined, there exists little systematic research on the idea that markets are causally related to changes in moral values.

Recently a growing body of literature stressed that markets may erode socially responsible behavior and moral values. For instance, Bowles (1998) suggests that economic institutions such as markets have far-reaching influence besides the allocation of scarce resources; markets can influence people's moral preferences, and failing to account for these potential effects may inhibit a proper evaluation of the consequences of institutional changes. Shleifer (2004) also argues that market competition may encourage market participants to engage in unethical behaviors such as corruption and hiring children to reduce the costs of production. Likewise, Sandel (2012) argues that market transactions may crowd out moral norms and suggests being cautious about the scope and limits of markets. Recent experimental studies also show that market framing (Cappelen et al., 2013; Ellingsen et al., 2012; Cohn et al., 2014) and mere thoughts of "money"2 through experimental priming (Vohs et al., 2006; Vohs, 2015) induce people to behave less pro-socially.

Despite the long-standing concern on the effect of markets on socially responsible behavior and moral values, only quite recently scholars have provided direct empirical evidence on this matter. Falk \& Szech (2013) test this in a controlled laboratory setting where participants decide between either saving the life of a mouse or receiving money. The authors show that compared to subjects in the control group, that were given an individual choice between killing a mouse and receiving EUR 1o or saving the life of the mouse and not receiving any money, a higher proportion of subjects in the treatment group that participated in bilateral and multilateral markets chose receiving money instead of saving the life of the mouse. In another laboratory

I Following recent studies (e.g., Kaplow \& Shavell (2007); Falk \& Szech (2013); Rössler \& Friehe (2020)), we define 'moral' as adhering to the moral rules of not harming others for the sake of oneself or not inflicting an uncompensated harm on others.

2 Money is commonly considered as a key representation of free-market system (Vohs et al., 2006; Vohs, 2015). 
experiment Bartling et al. (2015) find that participants in a non-market context exhibit significantly higher socially responsible behavior (mitigating a negative externality on uninvolved third parties at a personal cost in a laboratory product market) than participants in a market context.

New studies are investigating plausible underlying mechanisms that may explain how markets may erode socially responsible behavior and moral values, and assess the impact of degree of market competition (Bartling et al., 2015; Sutter et al., 2020; Pigors \& Rockenbach, 2016), the anonymity of actions of market actors (Irlenbusch \& Saxler, 2019; Kirchler et al., 2015), market framing (Irlenbusch \& Saxler, 2019), diffusion of responsibility (Irlenbusch \& Saxler, 2019), lack of pivotality (Falk et al., 2020), the scope of externality (Bartling et al., 2019) and growth in consumers income (Bartling et al., 2018) on moral and socially responsible behavior. Competition, social information (observability of the actions of market participants), and growth in consumers' income are all positively and significantly associated with socially responsible behavior, while diffusion of responsibility, lack of pivotality, and market framing induce subjects to make more self-interested decisions.

We build on this literature in a number of ways. First, using a competitive laboratory product market similar to Bartling et al. $(2015,2019)$, we test whether markets erode socially responsible behavior in a developing country context. Second, hypothesizing that markets are more likely to erode socially responsible behavior compared to non-market contexts, we seek to understand whether such negative impacts can be mitigated through two well-known regulating mechanisms, punishment and religious priming, in a setting where market policies are either weak or nonexistent, and market regulations are not well defined nor enforced. Ethiopia represents such a setting. Third, eroding socially responsible behavior and thus imposing negative externalities on uninvolved third parties may lead to an unequivocal increase in inequality between market (non-market) participants and third parties, which, in turn, may have negative social impacts by inflicting conflict between them (e.g., see Fehr (2018)). We directly examine the effect of the erosion of socially responsible behavior on a subsequent conflicting behavior using a second behavioral experiment, the joyof-destruction game, as in Abbink \& Sadrieh (2009) and Abbink \& Herrmann (2011) that we execute immediately after the market (non-market) experiments. Further, we study whether this effect is more pronounced in the market context compared to the non-market context. Fourth, we test whether the punishment and religious priming treatments deter subsequent conflicting behavior. Finally, this paper sheds light on the welfare effects of regulated and unregulated markets.

Our experimental findings are summarized as follows. First, we find that market participants reveal considerable socially responsible behavior. While this finding is in contrast to the theory of purely self-interest, it is consistent with the findings of previous experimental studies (Bartling et al., 2015, 2019). Yet, in contrast to Bartling 
et al. $(2015,2019)$, we observe that the social concerns of market participants decay as they are exposed to frequent market interactions. Second, in line with our hypothesis and findings of previous studies (Falk \& Szech, 2013; Bartling et al., 2015), socially responsible behavior is less prevalent in markets compared to non-market contexts. Third, we find that regulating mechanisms are effective - punishment and religious priming have a positive and significant effect on socially responsible behavior relative to the market baseline condition. However, the effect of religious priming fades over time, that is, the proportion of sellers and buyers of the fair product has dropped from 0.6 ( 0.78 for buyers) in round one to about 0.12 (0.18 for buyers) in round 10 in our market experiment. Fourth, the estimation results show that the erosion of socially responsible behavior leads to income inequality, which, in turn, triggers anti-social behavior as exhibited in the joy-of-destruction experiment. This result is in line with our hypothesis and findings of earlier studies (Fehr, 2018) that income inequality caused by morally questionable means inflicts anti-social behavior. Further, we find that this effect is not more pronounced in the market than in the non-market context. While we find evidence for retaliation among the third parties (recipients of the negative externality), buyers seem to engage in advantageous than in a dis-advantageous inequality. Fifth, the results show that the effects of punishment and religious priming persist $e x$ post in the sense that both mechanisms deter subsequent anti-social behavior. Finally, we find that unregulated markets yield low social welfare compared to regulated markets, suggesting the potential role of monitoring and sanctioning in mitigating market failure and fostering socially responsible behavior in competitive market contexts.

The remainder of the paper is organized as follows. Section 2.2 discusses the experimental design and procedure, the predictions of the inequality aversion model, the research hypotheses, descriptive statistics, and balance test. Section 2.3 presents the empirical strategy. Section 2.4 presents the results for our two experiments and different treatment arms. The last section concludes.

\subsection{EXPERIMENTAL DESIGN AND PROCEDURE}

\subsubsection{Experimental Design}

We conduct two lab-in-the-field experiments with farm-households in several villages in the Tigray regional state of Ethiopia. In the first experiment, subjects participated in a laboratory product market experiment using a design similar to Bartling et al. (2015, 2019). In the second one, a subset of subjects (buyers (players B) and uninvolved third parties (players $C$ ) in the first experiment) participated in the joy-of-destruction game of Abbink \& Sadrieh (2009) and Abbink \& Herrmann (2011).

Our market experiment comprises four treatment arms: market baseline, market baseline with punishment, market baseline with religious priming, and a non-market 
condition. We randomized both at village and session levels. We conducted the randomization at a village level to avoid intra-village contamination and reduce the cognitive burden for our enumerators conducting the experiments with the villagers. First, villages were randomly assigned to one of the four treatment arms. Subsequently, participants within each treatment arm were randomly assigned to their respective roles in the experiment. We describe the different market treatment arms in detail below.

\subsubsection{A Market Baseline Game}

We use a slightly modified version of the market design by Bartling et al. (2019). Our main modification pertains to the production capacity of sellers. In the Bartling et al. (2019) design, a single seller can serve the entire market, while in our experimental design, a single seller can only serve half of the entire market to reflect the real-world production capacity of sellers in our context. Also, we ran the experiments for 10 rounds instead of 24 to make sure we could finish all activities in the village well within a day and travel to the next one still on that same day. The game comprises three types of players: players A, B, and C. In the market baseline experiment players A are labelled as "sellers", players B as "buyers", and players C as "third parties". We have 16 people per village participating in this experiment: four sellers, six buyers, and six third parties. Participants were randomly assigned a role either as a seller, a buyer, or a third party at the beginning of the experiment and their role remained unchanged throughout all activities. After ten rounds, we randomly selected one round for payment.

At the beginning of each round, each participant received an endowment of 60 Ethiopian Birr ${ }^{3}$ (henceforth Birr). Market participants (buyers and sellers) are instructed to trade two types of products - products with (unfair) and without (fair) a negative externality on the third party. Both products have the same value of 40 Birr to the buyers but differ in their negative external impacts on uninvolved third parties and the cost of production. The unfair product poses a negative external cost of 50 Birr on the uninvolved third parties, while the fair product has no external costs. Production costs for the fair and unfair products are 20 and o Birr, respectively. Exchanging the unfair product has a net social cost of 1o Birr, i.e., the social benefit of 40 Birr minus the social loss due to the negative externality of 50 Birr $(S B=40-50=-10)$. Trading the fair product has a net social benefit of 20 Birr - the social benefit of 40 Birr minus the production cost of 20 Birr $(S B=40-20=20)$. Market participants could also decide not to trade at all.

The experiment consists of two stages. In the first stage, sellers simultaneously decide on which type of product to produce (fair or unfair product) and its price. The price of both products should be between o and 40 Birr. Each seller can sell his/her

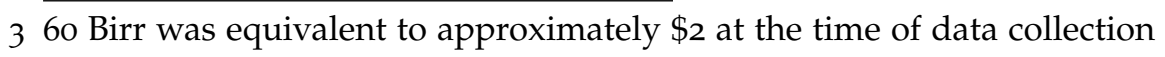


product to a maximum of three buyers, indicating that all six buyers can buy from only two sellers. Each seller earns the number of products he sold, multiplied by the difference between the price of the product and the production cost. Sellers are given three minutes to decide on which type of product to produce and determine the price. In the second stage, buyers simultaneously decide on which offered product to purchase or not to purchase at all. In addition to the 6o Birr initial endowment, each buyer receives 40 Birr that he/she can spend on either product. Buyers are also given three minutes to decide which offered product to purchase. Buyers can buy either product at any price between o and 40 Birr. In case more than three buyers accept an offer from a single seller, the three buyers who accept the offer first purchase the product. The third parties have a passive role, i.e., they can neither sell nor buy a product. At the beginning of the experiment, each of the six buyers is randomly matched with each of the six third parties. As a result, a third party's earning depends entirely on the decisions of its matched buyer. If a buyer either purchases a fair product or decides not to trade, the matched third party earns 6o Birr. However, if a buyer buys an unfair product, the matched third party incurs a loss of 50 Birr. Matched participants never learn each other's identity during and after the experiment. The payoff of each player is determined as follows.

$$
\begin{aligned}
& \text { Payoff } f^{\text {seller }}= \begin{cases}60+q(p-c), & \text { if a seller sells its product at price } p \\
60, & \text { otherwise }\end{cases} \\
& \text { Payoff } f^{\text {buyer }}= \begin{cases}60+40-p, & \text { if a buyer buys a product at price } p \\
60, & \text { otherwise }\end{cases} \\
& \text { Payof } f^{\text {thirdparty }}= \begin{cases}10, & \text { if a matched buyer buys unfair product } \\
60, & \text { otherwise }\end{cases}
\end{aligned}
$$

A seller earns an initial endowment of 60 Birr plus the number of products sold $(q)$ multiplied by the price of the product for an unfair product. A buyer earns an initial endowment of 60 Birr plus 40 Birr minus the price of the offered product $(p)$, and a matched third party earns only 1o Birr, i.e., an initial endowment of 60 Birr minus the negative externality of 50 Birr. On the other hand, if a fair product is purchased; a seller earns 60 Birr plus the number of products sold $(q)$ multiplied by the difference between price $(p)$ and production cost $(c)$ of 20 Birr, the buyer earns 6o Birr plus 40 Birr minus price of the purchased product $(p)$ and a matched third party earns 60 Birr. If a trade does not take place, all players gain an equal amount of 60 Birr. 


\subsubsection{B Market Baseline Game with Punishment}

This treatment arm extends the market baseline game by introducing a fourth player (an observer). We now have 18 people per session participating in this treatment; four sellers, six buyers, six third parties, and two observers. We randomly assign five participants (two sellers and three buyers) to each of the two observers, and this assignment remains fixed throughout the experiment. At the end of each round, each observer is informed about the decisions of their group and thereby asked to decide whether he/she wants to punish. ${ }^{4}$ Punishment is costly, and the observer incurs a loss of 1 Birr if he/she wants to punish others by 5 Birr. At the beginning of each round, the observer receives an initial endowment of 60 Birr. The maximum amount of punishment that an observer can assign per participant is 20 Birr, which is equivalent to a loss of $100\left(20^{*} 5\right)$ Birr, equal to the maximum level of earnings. The pay-off structure now looks as follows:

$$
\begin{aligned}
\text { Payoff } f^{\text {seller }} & = \begin{cases}60+q(p-c)-5 . f, & \text { if a seller sells its product at price } p \\
60, & \text { otherwise }\end{cases} \\
\text { Payoff } f^{\text {buyer }} & = \begin{cases}60+40-p-5 . f, & \text { if a buyer buys a product at price } p \\
60, & \text { otherwise }\end{cases} \\
\text { Payoff thirdparty } & = \begin{cases}10, & \text { if a matched buyer buys an unfair product } \\
60, & \text { otherwise }\end{cases} \\
\text { Payoff } f^{\text {observer }} & = \begin{cases}60-f, & \text { if an observer punishes market participants } \\
60, & \text { otherwise }\end{cases}
\end{aligned}
$$

where $f$ is the number of punishments imposed by the observer.

\subsubsection{Baseline Market Game with Religious Priming}

Religion plays an important role in the daily lives of many people in developing countries, and several studies report positive impacts of religion and religious primes on pro-social behavior (Henrich et al., 2010; Shariff et al., 2016). If we believe that pro-social behavior is (somewhat) reflective of socially responsible behavior, religious primes may thus serve as alternative non-monetary regulating mechanisms to induce desirable behavioral outcomes in markets. We therefore randomly assign a subsample to a religious prime where subjects (both sellers and buyers) were asked to

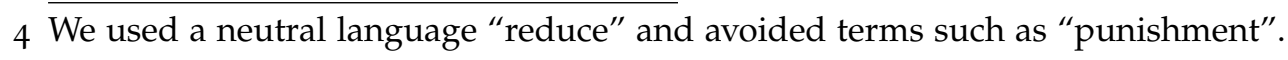


explain the meaning of the following commandments; "Do to others as you would have them do to you", "Love your neighbor as yourself" and "A Man reaps what he sows". Afterward, subjects were invited to play the market game, identical to the market baseline experiment.

\subsubsection{No Market Condition}

Our design in the no-market condition also follows Bartling et al. (2015). The nomarket experiment allows us to exogenously vary market context exposure and compare socially responsible behavior in the market and no-market contexts by using neutral frames. Analogous to the market baseline experiment, the no-market experiment is a three-player experiment with neutral frames to denote sellers, buyers, trade, etc. In the no-market case, players are labelled as "player A", "player B" and "player $C^{\prime \prime}$. In total, 18 people per session participate in this experiment: six players $A$, six players $B$, and six players $C$. The experiment follows the same format and rules as the market baseline experiment. However, unlike the seller in the market experiment who can decide on which type of product to produce and at what price he/she wants to sell the product, player $\mathrm{A}$ in the non-market context remains passive.

After having received the initial endowment of 60 Birr per round, player B is asked to choose between two distribution types; one is with a 50 Birr loss for player $\mathrm{C}$ (unfair), and the other one with no loss for player $C$ (fair). The unfair distribution enables players A and B to earn 40 Birr jointly on top of the 6o Birr initial endowment. However, the distribution with no loss for player $C$ enables players $A$ and $B$ to earn only 20 Birr together on top of the initial endowment of 60 Birr. Furthermore, in the no market context, there is a third option called "do not select a new distribution" that is analogous to the "no trade" condition in the market experiment. If player B opts for "do not select a new distribution", all players earn the same amount of 60 Birr.

\subsubsection{E The Joy-of-Destruction Experiment}

Our second experiment is the joy-of-destruction (JOD) experiment, in which we play with all matched buyers/players B and third parties/players $C$ to examine the effect of eroding socially responsible behavior on subsequent anti-social behavior. ${ }^{6}$ JOD is a two-player game where each player is endowed with an equal endowment, and both players simultaneously decide on whether or not to burn other players' endowment at

5 The priming experiment was enacted between a short survey and the market game. The household survey extracted information on individual characteristics, including participants' religious denomination, Church attendance, and their religiosity irrespective of Church attendance. Shortly after the survey questions on religion, we asked subjects in this treatment to explain the meaning of some religious commandments which condemn intentionally hurting others for the sake of oneself.

6 In this game, each buyer/player B was matched with the same third party/player C as in the market experiment (vice-versa) and all subjects were fully aware of this. 
a cost to oneself. In our experiment, matched subjects are asked to decide whether or not to destroy another player's income. To avoid other sources of income inequalities other than the previous income inequality in the market and non-market experiments, both players received an equal endowment of 40 Birr. Reducing a partner's income by 3 Birr has a personal cost of 1 Birr.

We executed the one-shot JOD experiment shortly after the market experiment. Before the experiment begins, we informed all subjects about their partner's role, decisions, and earnings in the market and non-market experiments but protecting all players' identity. For any subject, "not burning" is a dominant strategy as burning entails no material benefit for the destroyer. Once subjects decided on whether or not to burn their partner's earning, we asked them to guess the burning decision of their counterpart players to control for the effect of belief about others burning behavior on own decision to burn. We did not reward players for guessing correctly to disentangle beliefs from behavior (Gächter \& Renner, 2010).

\subsubsection{Experimental Procedure}

The data for this study were collected from 544 farm household heads in the fall of 2018. Households belong to 32 villages located in five woredas (districts) 7 in Tigray regional state of Ethiopia. Villages were randomly assigned to one of the four treatments - the non-market condition, market baseline, market baseline with punishment, and market baseline with religious priming. We then recruited either 16 or 18 household heads per village using the list of all households obtained from the village chief as a sampling frame.

The experiments were conducted in public schools and local government office halls. Upon arrival, participants received an ID number and asked to sit at a separate desk. Once situated, but prior to their participation in the economic experiments, we provided them with a detailed explanation about the purpose of the study, compensation for their participation, potential risks, benefits, and confidentiality. We then obtained written informed consent from all participants. ${ }^{8}$ We proceeded with an oral explanation of the experiment to all participants. After the experimenter read the instructions, we asked participants to actively participate in some trial rounds with no real earnings. In addition, they received some exercises to test for comprehension.

At the beginning of each session, subjects were asked to pick one out of either three or four envelopes, which determined their role in the experiments. Consequently, subjects were assigned a role as either a seller, a buyer, a third party or an observer in the market context, and a role as either player A, player B, or player $C$ in the

7 Kilte Awulaelo, Endamehoni, Hintalo Wajirat, Enderta, and Raya Azebo districts.

8 Our research study protocol was approved by the Ethical Review Committee Inner City (ERCIC) of Maastricht University (reference no. ERCIC_085_10_05_2018). 
non-market context. After the market experiment was completed, we asked buyers (players B) and third parties (players C) to participate in a one-shot joy-of-destruction experiment. ${ }^{9}$ Finally, participants took part in an exit survey, and the payment was made immediately afterward. Sessions lasted about 2.5 hours. On average, including a show-up fee, subjects earned approximately $\$ 4$.

We conducted a between-subject design so that each subject participated in only one treatment. Table 2.1 presents an overview of the treatments and the number of subjects assigned across the treatments. We had eight villages (sessions) per treatment with 144, 128, 144, and 128 subjects.

Table 2.1: Number of Subjects Across Sessions and Treatment Arms

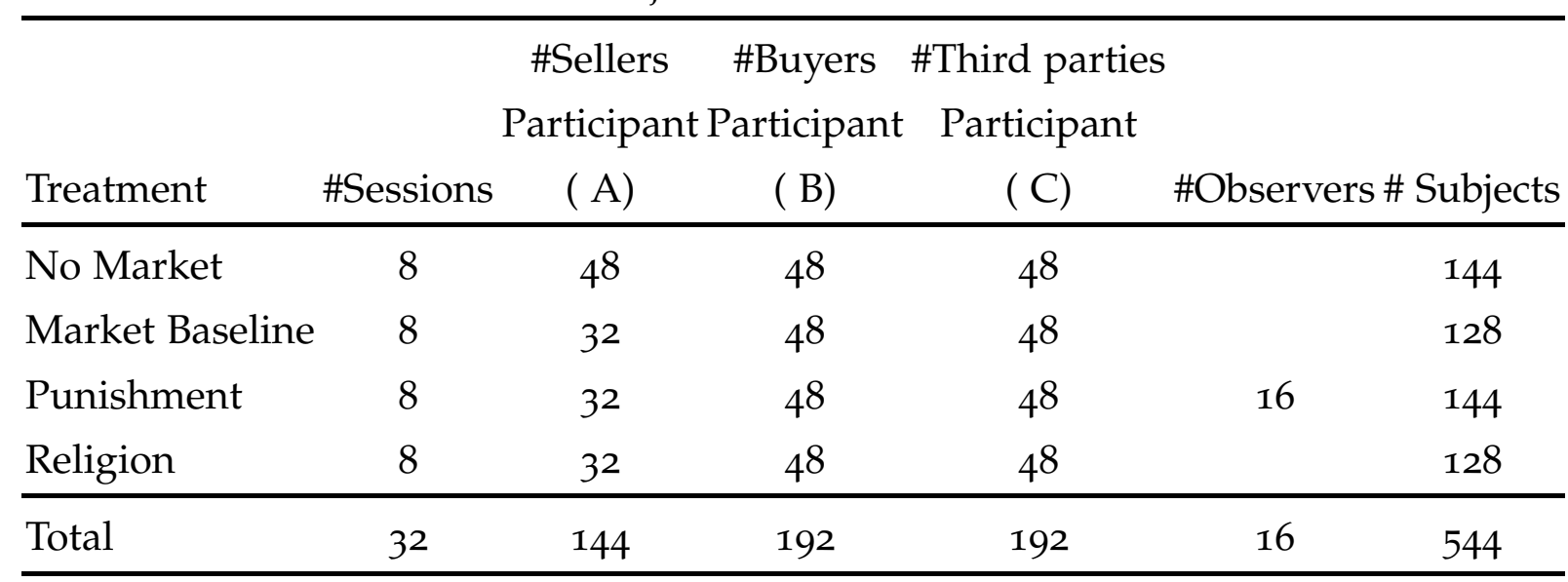

\subsubsection{Descriptive Statistics and Balance Test}

Table A.2 in the appendix reports descriptive statistics and balance test results across the four groups. Columns (1), (2), (3), and (4) present the mean and standard deviation for the No Market condition, Market Baseline condition, Market Baseline with Punishment, and Market Baseline with Religious Priming groups, respectively. Column (5) reports the mean and standard deviation for the entire sample. The last column reports the p-value of the joint orthogonality test for the equality of mean values across the four groups. Table A.2 shows that most variables are balanced across the groups. Only the age of the household head and village exposure to drought are marginally different between the groups. We control for these differences in our analysis.

Column (5) of Table A.2 reports that household heads are, on average, 44 years old. $25 \%$ of households are female-headed households. The average household size is about 5.8 persons per household. Approximately 59\% of household heads can read and write. $95 \%$ of the household heads own agricultural land, and households own,

9 At this stage, participants (sellers, players A, and observers) who would not participate in the joy-ofdestruction experiment completed a follow-up survey and received their show-up fee and earnings from the activities. 
on average, 4.3 Tropical Livestock Units (TLU). About $78 \%, 46 \%$, and $41 \%$ of household heads are members in a local funeral insurance group (iddir), local rotating saving and credit association (eqqub), and a large social protection program (Ethiopian productive safety net program (PSNP)), respectively. Households go to the nearest weekly markets three days a month. Villages are, on average, 2.25 hours walking distance from the nearest district town, and they are exposed to drought at least once every five years.

\subsubsection{Inequity Aversion Model Predictions}

In the past few decades, economists have increasingly demonstrated that people care not only about their own material payoff but also about their relative position. In their inequity-aversion model, Fehr \& Schmidt (1999) show that inequity-averse people dislike inequitable outcomes whether it is advantageous or disadvantageous. However, subjects are strongly inequity-averse if it is to their disadvantage. In this section, following Fehr \& Schmidt (1999) and Bartling et al. (2015) we illustrate the socially responsible behavior of sellers and buyers under competitive markets. First, we present the price premium that a buyer is willing to pay for the fair product. Second, we illustrate the price premium under which a seller is willing to offer the fair product. Third, we discuss the conditions under which trade of the fair product is feasible. Finally, we illustrate market equilibrium under inequity-averse preferences.

Suppose the buyer's utility function from purchasing the fair and unfair products has the form in equations 2.1 and 2.2, respectively:

$$
\begin{gathered}
U_{i}\left(x^{\text {fair }}\right)=x_{i}+v-p^{\text {fair }}-\beta_{i} \frac{1}{n-1} \sum_{j \neq i} \max \left\{x_{i}+v-p^{f a i r}-x_{j} ; 0\right\} \\
U_{i}\left(x^{\text {unfair }}\right)=x_{i}+v-p^{u n f a i r}-\beta_{i} \frac{1}{n-1} \sum_{j \neq i} \max \left\{x_{i}+v-p^{u n f a i r}-\left(x_{j}-e\right) ; 0\right\}
\end{gathered}
$$

where $0 \leq \beta<1,\left(x_{i}+v-p^{\text {fair }}\right)$ is the payoff of the buyer with $x_{i}$ denotes buyer's initial endowment, $v$ refers to the value of the product and $p^{\text {fair }}$ is the price of the fair product. The second term in equation 2.1, $\beta_{i} \frac{1}{n-1} \sum_{j \neq i} \max \left\{x_{i}+v-p^{\text {fair }}-x_{j} ; 0\right\}$, measures dis-utility from advantageous inequality with $x_{j}$ denotes third party's initial endowment. While $n$ represents the number of players, $p^{\text {unfair }}$ and $e$ in equation 2.2 represents price of the unfair product and the size of the negative externality, respectively.

In the two-player case $(n=2)$ equations 2.1 and 2.2 simplify to 2.3 and a buyer decides to purchase the fair product instead of the unfair product if; 


$$
\begin{array}{r}
U_{i}\left(x^{\text {fair }}\right)=x_{i}+v-p^{\text {fair }}-\beta\left\{x_{i}+v-p^{\text {fair }}-x_{j} ; 0\right\} \geq \\
x_{i}+v-p^{\text {unfair }}-\beta\left\{x_{i}+v-p^{\text {unfair }}-\left(x_{j}-e\right) ; 0\right\}=U_{i}\left(x^{\text {unfair }}\right)
\end{array}
$$

With $p^{\text {fair }} \leq v$ and $p^{\text {unfair }} \leq v$, a buyer prefers the fair product instead of the unfair product if;

$$
p^{\text {fair }}-p^{\text {unfair }} \leq \frac{\beta e}{1-\beta}
$$

On other hand, a seller decides to offer the fair product instead of the unfair product if;

$$
\begin{array}{r}
\pi_{i}\left(x^{\text {fair }}\right)=x_{i}+p^{\text {fair }}-c-\beta \max \left\{x_{i}+p^{\text {fair }}-c-x_{j} ; 0\right\} \geq \\
x_{i}+p^{\text {unfair }}-\beta \max \left\{x_{i}+p^{\text {unfair }}-\left(x_{j}-e\right) ; 0\right\}=\pi_{i}\left(x^{\text {unfair }}\right)
\end{array}
$$

where $c$ is the production cost of the fair product. In our case, the production cost of the fair product is 20 Birr $(c=20)$ while the unfair product costs o to produce.

With $p^{\text {fair }} \geq c$ and $p^{\text {unfair }} \geq 0$, a seller prefers to sell the fair product instead of the unfair product if;

$$
p^{\text {fair }}-p^{\text {unfair }} \geq c-\frac{\beta e}{1-\beta}
$$

The trade of the fair product is feasible if buyers willingness to pay for the fair product is greater than or equal to the price premium that the seller is willing to accept to offer the fair product;

$$
\frac{\beta^{b} e}{1-\beta^{b}} \geq c-\frac{\beta^{s} e}{1-\beta^{s}}
$$

where $\beta^{b}$ and $\beta^{s}$ represents buyer's and seller's concern about the third party.

In case buyers and sellers exhibit the same concern for the third party $\left(\beta=\beta^{b}=\beta s\right)$, trade of the fair product is feasible if;

$$
\beta \geq \frac{c}{c+2 e}
$$

We introduce a competition among sellers thereby relaxing the assumption in Bartling et al. (2015) that limits the capacity of sellers to produce only one unit of a certain product. In our case, a single seller can produce up to three units of a certain product and only half of the sellers can serve the entire market. Hence, according to the predictions of purely self-interested theory, the competition among sellers drives the price to be equal to the cost of production in equilibrium. As a consequence, the price of the 
fair product will be $p^{\text {fair }}=c$ (in our case, $\mathrm{c}=20$ ) and the price of unfair product will be $p^{\text {unfair }}=0$. In a similar vein, purely self-interested buyers prefer to purchase the unfair product at price of $p^{\text {unfair }}=0$ instead of the fair product at price of $p^{\text {fair }}=20$. In sum, according to the predictions of purely self-interested theory only the unfair product is sold in equilibrium.

However, several studies have documented heterogeneity of preferences among subjects (Fehr \& Schmidt, 1999). For example, the Fehr - Schmidt model suggested that $30 \%$ of subjects do not care about inequality and are purely self-interested with $\beta=0$, $30 \%$ subjects have $\beta=0.25$ and the remainder $40 \%$ have $\beta=0.6$. Hence, the market equilibrium predicted under these heterogeneous preferences, production cost of $c=20$ and negative externality of $e=50$ is given as follows.

- The market share of the fair product is $40 \%$.

- The fair product trades at a price of $p^{\text {fair }}=20$ and the unfair product trades at a price of $p^{u n f a i r}=0$.

That is, $60 \%$ of sellers with $\beta=0$ or $\beta=0.25$ prefer to sell the unfair product at $p^{\text {unfair }}=0$ and the $60 \%$ buyers with $\beta=0$ or $\beta=0.25$ also prefer to purchase the unfair product. The $40 \%$ of sellers with $\beta=0.6$ prefer to sell a fair product at $p^{\text {fair }}=20$ and the $40 \%$ buyers with $\beta=0.6$ also prefer to buy the fair product. We test the tenability of this model using the four hypotheses below.

We hypothesize that:

Hypothesis 1. Participants in a non-market context exhibit significantly higher socially responsible behavior than participants in a market context.

Hypothesis 2. Regulation mechanisms and cultures such as punishment and religious beliefs, enhance socially responsible behavior in markets.

Hypothesis 3. The erosion of socially responsible behavior creates income inequality, which, in turn, inflicts anti-social behavior. This effect is more pronounced in the market than in the non-market context.

Hypothesis 4. The effects of punishment and religious priming persist outside the market.

\subsection{EMPIRICAL STRATEGY}

We first test if markets erode socially responsible behavior compared to non-market contexts using the following probit model:

$$
S R B_{i}=\alpha+\beta \text { Market }_{i}+\gamma \text { Period }_{t}+\phi X_{i}+\varepsilon_{i}
$$

where $S R B_{i}$ denotes the socially responsible behavior for subject $i$, taking on value 1 
if subject $i$ purchased or selected a fair product or distribution, o otherwise. Market $_{i}$ is a measure of our treatment variable, taking on value 1 if a subject comes from market baseline, o otherwise. Period denotes the number of experimental rounds with $t \in\{1, \ldots, 10\} . X_{i}$ is a vector of household covariates, and $\varepsilon_{i}$ is the random error term of the equation. Standard errors are clustered at a subject level. From earlier findings, (Falk \& Szech, 2013; Bartling et al., 2015), we expect less socially responsible behavior in market than in non-market environments.

Next, we explore the potential ways to mitigate market-driven negative externalities. We emphasize on the role of monitoring and sanctioning subjects who impose a negative externality on the uninvolved third parties. We also examine the role of religious priming that condemns people who intentionally hurt others for their benefit. We estimate:

$$
\begin{gathered}
S R B_{i}=\alpha+\beta \text { Punishment }_{i}+\gamma \text { Period }_{t}+\phi X_{i}+\varepsilon_{i} \\
S R B_{i}=\alpha+\beta \text { Religiosity }_{i}+\gamma \text { Period }_{t}+\phi X_{i}+\varepsilon_{i}
\end{gathered}
$$

where Punishment P $_{i}$ takes on value 1 if the subject comes from the punishment treatment, o otherwise. Religiosity $i$ takes on value 1 if the subject comes from the religious priming treatment, o otherwise. In both cases, the omitted category is the market baseline treatment. Other notations have the same meaning as in equation 2.9.

We further examine whether eroding socially responsible behavior inflicts antisocial or conflict behavior between buyers/players B and uninvolved third parties/players $C$ through creating income inequality between the two groups. Additionally, we examine whether this effect is more pronounced in the market than in the nonmarket context.

$$
D_{i}=\alpha+\beta E S R B_{i}+\gamma \text { Belief }_{i}+\phi X_{i}+\varepsilon_{i}
$$

$$
D_{i}=\alpha+\beta E S R B_{i}+\delta \text { Market }_{i}+\lambda\left(\text { ESRB }_{i} \text { XMarket }_{i}\right)+\gamma \text { Belief }_{i}+\phi X_{i}+\varepsilon_{i}
$$

where $D_{i}$ refers to burning a partner's income, at a cost to oneself. $D_{i}$ is a binary variable, taking on value 1 if subject $i$ decides to burn his/her partner's income, o otherwise. Belief $f_{i}$ represents subject $i$ 's belief about the burning decision of his or her partner. $E S R B_{i}$ denotes the erosion of socially responsible behavior for subject $i$, taking on value 1 if subject $i$ (a buyer/player B) purchased/selected an unfair produc$\mathrm{t}$ /distribution, or if subject $i$ (third party/player $\mathrm{C}$ ) incurred a negative externality, o otherwise. The interaction term between ESRB and Market shows whether the effect of eroding socially responsible behavior is more pronounced in markets. Other notations are the same as in equation 2.9. The analysis in equations 2.12 and 2.13 is 
based on the decisions of buyers \& third parties in the market experiment and players B \& C in the non-market experiment. Following the findings of Fehr (2018), we expect higher money burning in environments wherein socially responsible behavior is eroded (when unfair product is produced and traded). Further, we expect high money burning in market environments than in non-market environments. We also expect that the probability of burning a partner's income increases if subjects expect others to destroy their income.

Finally, in equations 2.14 and 2.15, we examine whether our punishment and religion treatments have a differential effect at the decision to burn compared to the market baseline treatment.

$$
\begin{aligned}
& D_{i}=\alpha+\beta E S R B_{i}+\delta \text { Punishment }_{i}+\lambda(\text { ESRB } \left._{i} \text { XPunishment }_{i}\right) \\
&+\gamma \text { Belief }_{i}+\phi X_{i}+\epsilon_{i} \\
& \\
& D_{i}=\alpha+\beta \text { ESRB }_{i}+\text { SReligiosity }_{i}+\lambda\left(\text { ESRB }_{i} \text { XReligiosity }_{i}\right) \\
&+\gamma \text { Belief }_{i}+\phi X_{i}+\epsilon_{i}
\end{aligned}
$$

Where $E S R B_{i}$ takes value 1 if a buyer purchased an unfair product or the uninvolved third party incurred a negative externality, o otherwise. The analysis in equations 2.14 and 2.15 is based on the decisions of buyers \& third parties in the market baseline, market with punishment and religion treatments. $\delta$ measures the effect of the treatments (punishment or religious priming) and $\lambda$ the treatment effect conditional on eroding socially responsible behavior which gauges whether the effect of punishment and religious priming sustains ex-post. The omitted category in equations 2.14 and 2.15 is the market baseline treatment. We expect significantly less money burning in the punishment and religious priming treatments than in the market baseline treatment.

\subsection{RESULTS}

\subsubsection{Socially Responsible Behavior in Markets}

We start discussing our results from the market baseline experiment and present the market share of the product with no negative externality and its corresponding price.

Figure 2.I below displays the proportion of fair products (products with no negative externality) purchased by consumers in the market baseline experiment. It shows that, in contrast to the predictions of the standard purely self-interested theory, consumers exhibit a substantial socially responsible behavior. The market share of the fair product in the market baseline is approximately $21 \%$. Likewise, producers also reveal a substantial concern for the external impacts of their actions in the market. Of the total 
production, the share of the fair products is about $24 \%$. The socially responsible behavior of market actors is also revealed in their persistent willingness to pay a higher price for the fair product than the unfair product. Figure A.I in the appendix shows that the price of the fair product is considerably higher than the price of the unfair product. ${ }^{10}$ More formally, Table 2.2 reports regression results that complement these findings. Column (I) of Table 2.2 shows that the price of the fair product is higher by approximately 8.5 Birr than the price of the unfair product. Although the price difference between the two product types declines once we control for the period and an interaction effect between period and product type, the fair product still trades at a significantly higher price than the unfair product, i.e., on average, the fair product costs 5 Birr more than the unfair product.

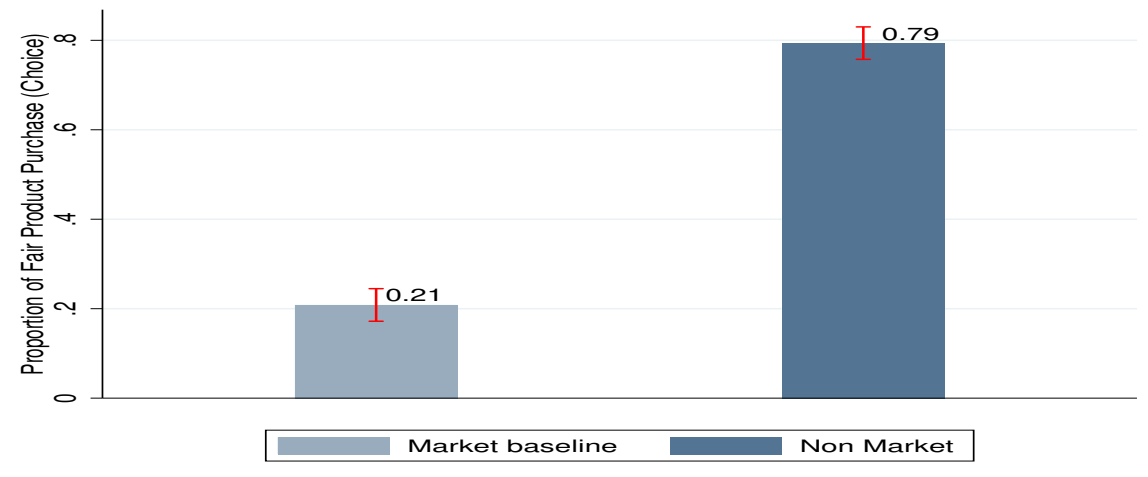

Figure 2.1: Fair Product Purchase Across Market and No Market Conditions, 95\% CI.

Table 2.2: Regressions of Prices by Product Type

\begin{tabular}{lccc}
\hline & $(1)$ & $(2)$ & $(3)$ \\
& Prices & Prices & Prices \\
\hline Fair product & $8.492^{* * *}$ & $5.957^{* * *}$ & $4.790^{* * *}$ \\
Period & $(0.447)$ & $(0.460)$ & $(0.901)$ \\
Fair product X Period & & $-1.008^{* * *}$ & $-1.044^{* * *}$ \\
& & $(0.084)$ & $(0.092)$ \\
Constant & & & 0.307 \\
& $15.618^{* * *}$ & $21.693^{* * *}$ & $(0.206)$ \\
Number of subjects & $(0.277)$ & $(0.558)$ & $\left(0.598^{* * *}\right.$ \\
Observations & 48 & 48 & 48 \\
R-squared & 480 & 480 & 480 \\
\hline
\end{tabular}

Notes. The dependent variable in all columns is the price of the purchased product. Period takes an integer value between 1 and 10. Fair product is a binary variable taking a value of $I$ if a fair product is purchased, o otherwise. Robust standard errors in parentheses, ${ }^{* * *} \mathrm{p}<0.01,{ }^{* *} \mathrm{p}<0.05,{ }^{*} \mathrm{p}<0.1$.

10 While the price of the fair product cannot drop below 20 Birr, the price of the unfair product can drop below 20 Birr. This is because while the fair product costs 20 Birr to produce, it costs nothing to produce the unfair product. Hence, if consumers persistently agreed to pay a higher price for the fair product instead of a cheaper price for an unfair product, this can be considered as a sign of SRB. 
Our result is consistent with earlier findings that market participants are willing to internalize negative externalities (Bartling et al., 2015, 2019). However, while the market share of fair products in our experimental market $(21 \%)$ is slightly higher than the market share of fair products in China (16\%) (Bartling et al., 2015), it is significantly less than the market share of fair products in Switzerland (44 - 48\%) (Bartling et al., 2015, 2019). ${ }^{11}$ This suggests that institutional and cultural differences may have a significant effect on the efficiency of market outcomes besides other fundamental economic factors (Bulte et al., 2017; Fiala, 2015; Smith, 1962; List, 2004). Intuitively, economic factors and culture seem to play an important role in subjects' socially responsible behavior. In general, subjects in well-advanced countries (Switzerland) exhibit significantly higher socially responsible behavior than subjects in less-advanced (China and Ethiopia).
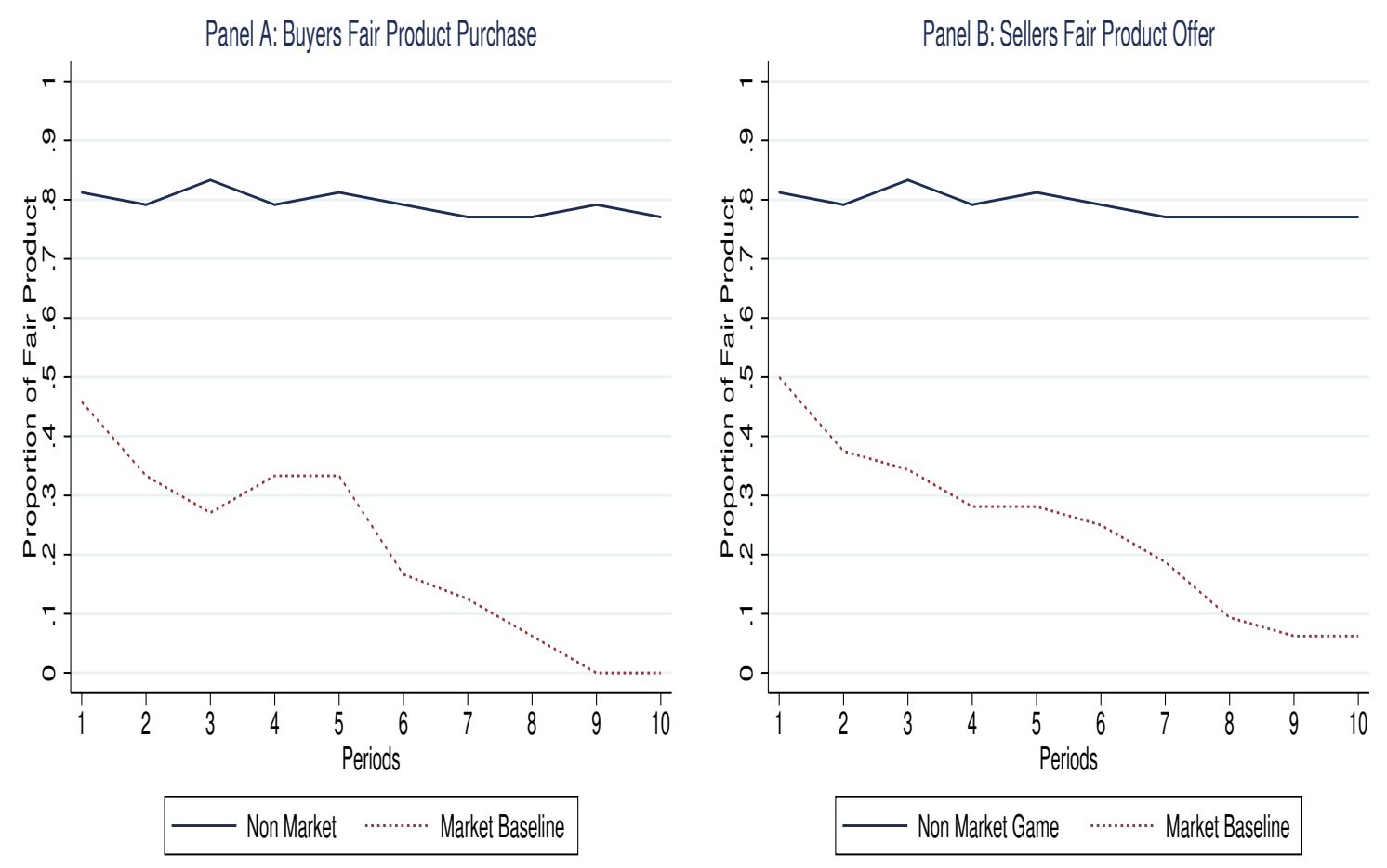

Figure 2.2: Market Participants Fair Product Choice Across Market and Non-Market Conditions

We next ask whether the socially responsible behavior manifested in the market baseline is stable across periods. Panel A of Figure 2.2 displays the share of the fair product purchased by consumers across the 10 periods. It shows that although consumers reveal substantial socially responsible behavior $(46 \%)$ at the beginning of the experiment, their concern for the welfare of uninvolved third parties declines over

11 While the subjects in Switzerland and China played exactly the same market game, the subjects in Ethiopia played a slightly different game. 
time and finally reaches the point where none of the consumers purchase the fair product. All consumers shift towards purchasing the unfair products in the final two periods. Panel B of Figure 2.2 also displays producers' concern about the welfare effects of their market actions on the uninvolved third-party decays over time. In the first period, the share of the fair product was about $50 \%$, but subsequently declines to less than $10 \%$ at the end of the experiment. In sum, we find that although market participants reveal considerable socially responsible behavior, it is not stable over time and this contrasts findings by Bartling et al. $(2015,2019)$ who report a stable concern of market participants about the social impacts of their actions in markets.

In our experiment, we include a "No-Market" condition to compare the socially responsible behavior in the market and non-market contexts. Figures 2.1 and 2.2 report the proportion of fair product purchases in the market context and fair distribution in a non-market context. Figure 2.1 illustrates that the proportion of socially responsible behavior in the non-market context is considerably higher than in the market context. More precisely, while the share of fair distribution in the non-market context is about $79 \%$, the share of fair products in the market context is approximately $21 \%$. This is in line with the earlier findings that social responsibility is less prevalent in markets compared to non-market contexts (Falk \& Szech, 2013; Bartling et al., 2015). Falk \& Szech (2013) for example show that the subject's willingness to exchange the life of a mouse for a small amount of money is substantially higher in markets than in individual decisions. In their experimental study in Switzerland and China, Bartling et al. (2015) also demonstrate that socially responsible behavior is significantly higher in non-market contexts than in market contexts. ${ }^{12}$

Markets may erode socially responsible behavior via market framing that diverts the attention of market participants from the negative external effects of their market actions, social information, diffusion of responsibility (Irlenbusch \& Saxler, 2019), lack of pivotality (Falk et al., 2020), or competition (Bartling et al., 2015; Sutter et al., 2020; Pigors \& Rockenbach, 2016). Irlenbusch \& Saxler (2019) argue that the erosion in socially responsible behavior in markets is mainly driven by the market framing effects compared to diffusion of responsibility and social information. Although in this study we are unable to pinpoint the underlying channels through which markets erode socially responsible behavior, we speculate that market framing and frequency of market interaction are the potential mechanisms. In support of the latter, Figure 2.2 displays that the socially responsible behavior decays across periods in the market context. In contrast, socially responsible behavior is reasonably stable across periods in the non-market context.

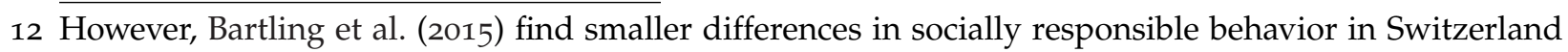
$(48.3 \%$ versus $62.4 \%)$ than in China ( $16.3 \%$ versus $60.4 \%)$ and suggest that social responsibility may be more robust to markets in some populations than others. 
Table 2.3: Socially Responsible Behavior in Market and Non Market Conditions

\begin{tabular}{|c|c|c|c|}
\hline & $\begin{array}{c}\quad(1) \\
\text { Market vs. } \\
\text { No Market }\end{array}$ & $\begin{array}{c}\quad(2) \\
\text { Market vs. } \\
\text { No Market }\end{array}$ & $\begin{array}{l}\quad(3) \\
\text { Market vs. } \\
\text { No Market }\end{array}$ \\
\hline Treatment (Market Baseline) & $\begin{array}{c}-0.651^{* * *} \\
(0.084)\end{array}$ & $\begin{array}{c}-0.678^{* * *} \\
(0.088)\end{array}$ & $\begin{array}{c}-0.804^{* * *} \\
(0.100)\end{array}$ \\
\hline Period & & $\begin{array}{c}-0.040^{* * *} \\
(0.007)\end{array}$ & $\begin{array}{c}-0.047^{* * *} \\
(0.008)\end{array}$ \\
\hline Age & & & $\begin{array}{l}-0.031 \\
(0.026)\end{array}$ \\
\hline Age square & & & $\begin{array}{c}0.000 \\
(0.000)\end{array}$ \\
\hline Male & & & $\begin{array}{l}-0.139 \\
(0.126)\end{array}$ \\
\hline Household size & & & $\begin{array}{l}-0.011 \\
(0.021)\end{array}$ \\
\hline Education & & & $\begin{array}{c}0.063 \\
(0.123)\end{array}$ \\
\hline Own land & & & $\begin{array}{l}-0.202 \\
(0.139)\end{array}$ \\
\hline Livestock & & & $\begin{array}{l}-0.026 \\
(0.020)\end{array}$ \\
\hline Iddir member & & & $\begin{array}{l}0.183^{*} \\
(0.104)\end{array}$ \\
\hline Eqqub member & & & $\begin{array}{l}-0.024 \\
(0.092)\end{array}$ \\
\hline PSNP participation & & & $\begin{array}{l}-0.161 \\
(0.120)\end{array}$ \\
\hline Religiosity & & & $\begin{array}{l}-0.067 \\
(0.173)\end{array}$ \\
\hline Market exposure & & & $\begin{array}{c}0.000 \\
(0.007)\end{array}$ \\
\hline Village distance to market & & & $\begin{array}{l}-0.017^{*} \\
(0.010)\end{array}$ \\
\hline Village exposure to drought & & & $\begin{array}{c}-0.043^{* * *} \\
(0.012)\end{array}$ \\
\hline Pseudo $R^{2}$ & 0.264 & 0.292 & 0.407 \\
\hline Observations & 960 & 960 & 960 \\
\hline Number of subjects & 96 & 96 & 96 \\
\hline
\end{tabular}

Notes. The dependent variable in all columns takes a value of 1 if a buyer or participant $B$ purchased or chose a fair product or distribution, o otherwise. The table reports marginal effects. The omitted category is Non-Market condition, and Treatment is a binary variable takes a value of $I$ if a subject comes from Market Baseline, o otherwise. Period takes an integer value between $I$ and 10 . Robust standard errors (clustered by subject) in parentheses, *** $\mathrm{p}<0.01,{ }^{* *} \mathrm{p}<0.05,{ }^{*} \mathrm{p}<0.1$. 
Table 2.3 presents the results of probit regressions to explain the effect of markets on socially responsible behavior. The results are consistent with the results from Figures 2.1 and 2.2 in the sense that subjects in the non-market context exhibit higher socially responsible behavior than subjects in the market context. More specifically, column (3) of Table 2.3 shows that subjects in the non-market context reveal 80 percentage points higher socially responsible behavior than those in the market context. Column (3) of Table 2.3 also shows that the socially responsible behavior of subjects is correlated to a range of household and village covariates. Being a member of an informal insurance group (iddir), in which its main objective is to help each other during bereavement, is positively and significantly correlated with socially responsible behavior. More precisely, being an iddir member increases the probability of purchasing a fair product or selecting a fair distribution by about 18 percentage points. Moreover, subjects' socially responsible behavior is significantly correlated with village characteristics such as village distance to the nearest weekly market and village exposure to frequent covariate shocks (drought). Subjects who reside in villages nearby to weekly markets are less likely to exhibit socially responsible behavior compared to subjects who reside in villages farther away from weekly markets. Likewise, subjects who live in villages exposed to frequent droughts are less likely to behave socially responsibly than those who live in less drought exposed villages. To account for the correlation across periods and to probe the robustness of our results in Table 2.3, we run a random-effects probit regression model. As shown in Table A.3 in the appendix, the results are qualitatively the same as in Table 2.3 in the sense that social responsibility is less prevalent in the market context than in the non-market context.

\subsubsection{Punishment, Religious Beliefs and Social Responsibility}

In section 2.4.1, we have established that market participants behave less socially responsibly compared to non-market participants. This section focuses on the potential ways to foster socially responsible behavior in competitive markets. Particularly, we investigate whether regulation mechanisms and cultures, such as punishment and religious beliefs, improve social responsibility in markets.

Figure 2.3 below displays the proportion of fair product purchases across varying market conditions. The Figure reveals that the purchase of a product with no negative social impact is prevalent in the punishment treatment followed by the religious priming treatment. The proportion of fair product purchases in the punishment treatment is close to $95 \%$, which is even higher than the share of fair distributions in the nonmarket context $(79 \%)$. On the other hand, the proportion of fair product purchases in the religious priming treatment is approximately $32 \%$, indicating a substantial improvement in socially responsible behavior from the market baseline treatment. The results suggest that punishing market participants who engage in exchanges with 
negative external impacts, and priming market participants with religious commandments that condemn hurting someone for the sake of oneself promote socially responsible behavior in the market.

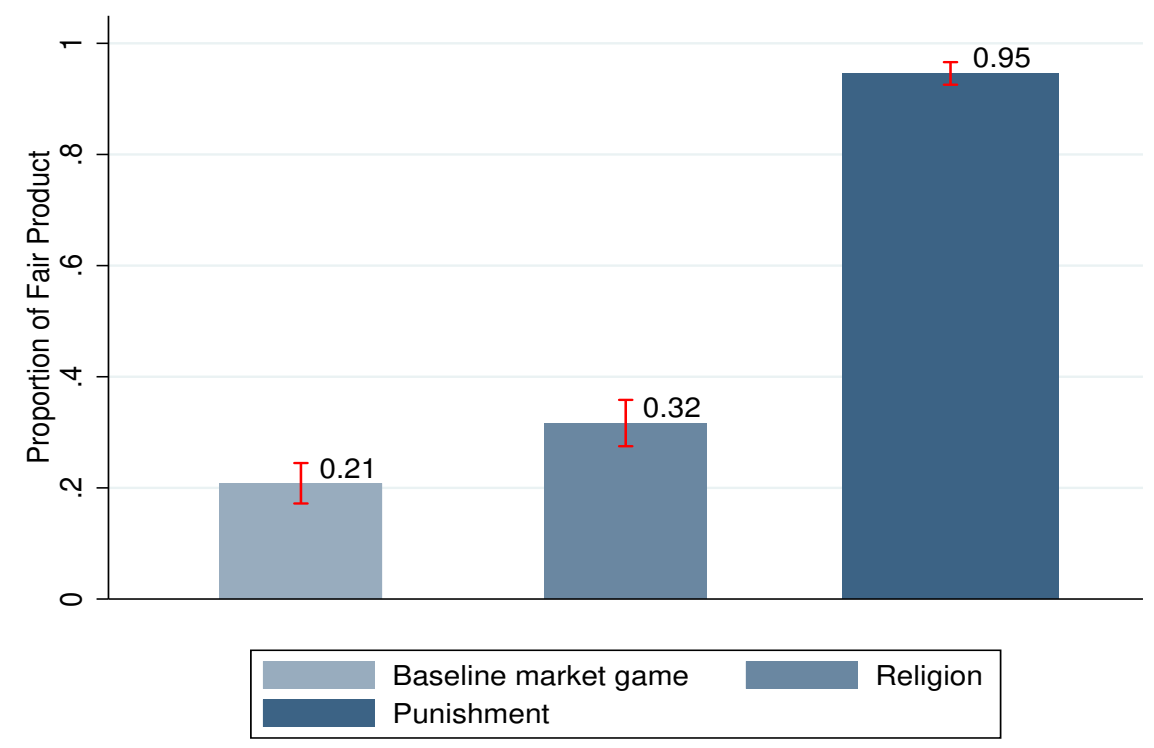

Figure 2.3: Fair Product Purchase Across Varying Market Conditions, 95\% CI.

Since the market experiment ran for ten periods, we next investigate whether the socially responsible behavior revealed across varying market conditions is stable across periods. Figure 2.4 displays the trend in the production and purchase of a product without negative externality across varying market conditions and periods. While the proportion of the fair product diminishes across periods in the market baseline and religious priming treatments, it continuously increases in the punishment treatment. Despite some overlaps, the share of the fair product is considerably higher in the religious priming treatment than in the market baseline treatment. Most importantly, at the beginning of the experiment, participants in the religion treatment exhibited higher socially responsible behavior than those in the other two (market baseline and punishment) treatments. This indicates that although religion can be a strong prime, it is something that people need to be reminded of right before an action is taken to bring about any behavioral change.

Thus far, we observed that although socially responsible behavior is prevalent in markets, it decays over time as market participants are exposed to frequent market interactions. Market participants behave as if completely self-interested in the final two periods of the experiments. On the one hand, this may be because frequent market interactions promote a rational behavior of market participants (Cecchi \& Bulte, 2013; List \& Millimet, 2008) and thus, induce them to act self-interestedly. On the other hand, previous studies documented that subjects pursue their material self-interest in the final rounds of repeated experiments such as public good game (Fehr et al., 2006). 
The latter explanation is, however, unlikely to drive our results as we would otherwise also observe a decay in the socially responsible behavior in the non-market context, which we did not. Frequent market interactions may, therefore, be a more plausible explanation explaining the observed difference in the market and non-market contexts. ${ }^{13}$
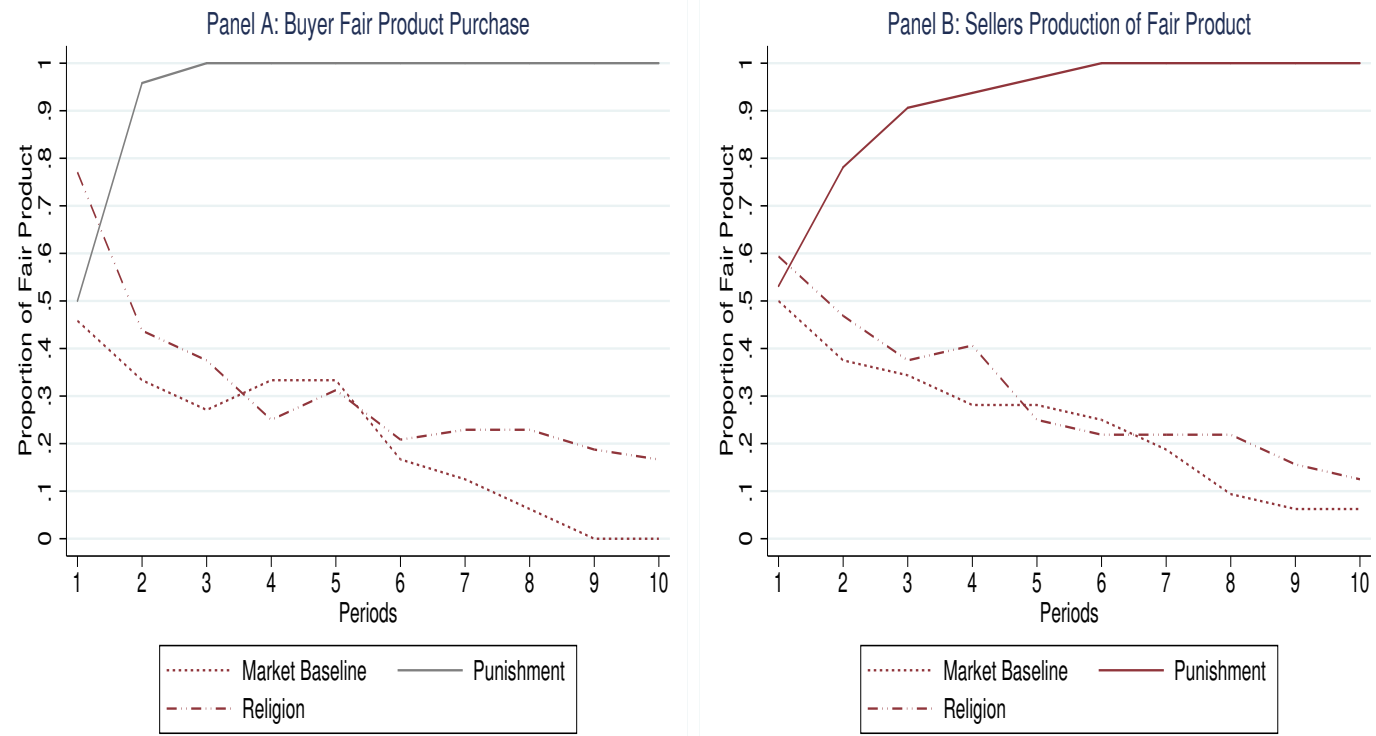

Figure 2.4: Production and Purchase of Fair Product Across Varying Market Conditions
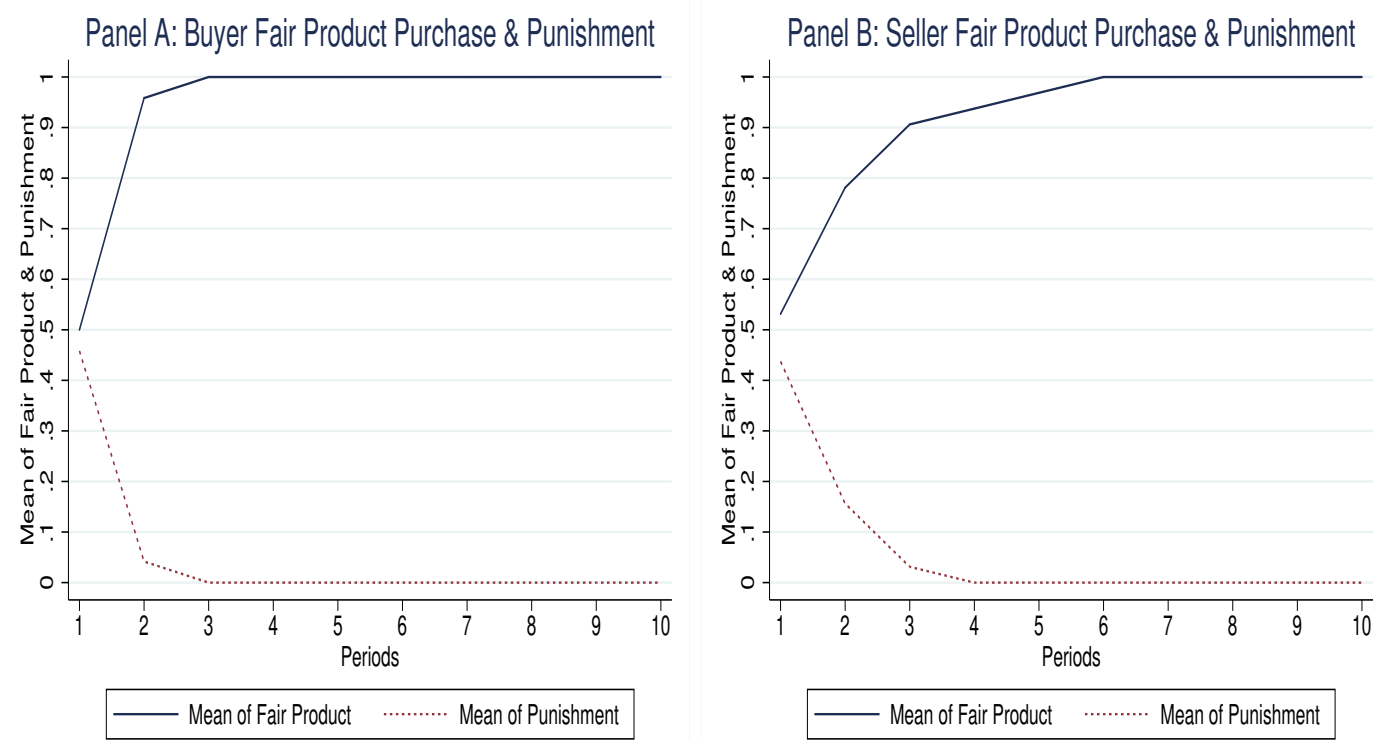

Figure 2.5: Purchase of Fair Product and Punishment

13 The discussion in this chapter is also thematically related to the literature on market microstructure. Particularly, this is evident in the discussion of heterogeneity of preferences caused by different preferences and different levels of knowledge \& information. 
Table 2.4: Punishment and Socially Responsible Behavior of Buyers and Sellers

\begin{tabular}{|c|c|c|c|c|c|c|}
\hline & $\begin{array}{c}(1) \\
\text { Buyers }\end{array}$ & $\begin{array}{c}(2) \\
\text { Sellers }\end{array}$ & $\begin{array}{c}\text { (3) } \\
\text { Buyers }\end{array}$ & $\begin{array}{c}(4) \\
\text { Sellers }\end{array}$ & $\begin{array}{c}(5) \\
\text { Buyers }\end{array}$ & $\begin{array}{c}(6) \\
\text { Sellers }\end{array}$ \\
\hline Punishment & $\begin{array}{c}-0.996^{* * *} \\
(0.003)\end{array}$ & $\begin{array}{c}-0.973^{* * *} \\
(0.019)\end{array}$ & $\begin{array}{c}-0.983^{* * *} \\
(0.012)\end{array}$ & $\begin{array}{c}-0.930^{* * *} \\
(0.050)\end{array}$ & $\begin{array}{c}-0.980^{* * *} \\
(0.014)\end{array}$ & $\begin{array}{c}-0.917^{* * *} \\
(0.060)\end{array}$ \\
\hline Period & & & $\begin{array}{c}0.003 \\
(0.002)\end{array}$ & $\begin{array}{c}0.010 \\
(0.007)\end{array}$ & $\begin{array}{c}0.003 \\
(0.002)\end{array}$ & $\begin{array}{c}0.010 \\
(0.007)\end{array}$ \\
\hline PunishmentXPeriod & & & & & $\begin{array}{l}-0.003 \\
(0.002)\end{array}$ & $\begin{array}{l}-0.010 \\
(0.007)\end{array}$ \\
\hline Constant & $\begin{array}{c}0.996^{* * *} \\
(0.003)\end{array}$ & $\begin{array}{c}0.973^{* * *} \\
(0.019)\end{array}$ & $\begin{array}{c}0.980^{* * *} \\
(0.014)\end{array}$ & $\begin{array}{c}0.917^{* * *} \\
(0.060)\end{array}$ & $\begin{array}{c}0.980^{* * *} \\
(0.014)\end{array}$ & $\begin{array}{c}0.917^{* * *} \\
(0.060)\end{array}$ \\
\hline R-squared & 0.919 & 0.695 & 0.920 & 0.704 & 0.920 & 0.704 \\
\hline Observations & 480 & 320 & 480 & 320 & 480 & 320 \\
\hline
\end{tabular}

Notes. The dependent variable in columns (1) and (3) takes a value of 1 if a buyer purchased a fair product, o otherwise. Whereas the dependent variable in columns (2) and (4) takes a value of 1 if a seller offered a fair product, o otherwise. Punishment is a binary variable takes a value of 1 if a subject is punished by the observer, o otherwise. Period takes an integer value between 1 and 1o. Robust standard errors (clustered by subject) in parentheses, ${ }^{* * *} \mathrm{p}<0.01,{ }^{* *} \mathrm{p}<0.05,{ }^{*} \mathrm{p}<0.1$.

The punishment treatment dramatically increases socially responsible behavior. As shown in Figures 2.4 and 2.5, at the beginning of the experiment, the share of the fair product was close to 50\%. Market participants increased the purchase of the fair product starting from the second period but shifted towards the purchase of the fair product only starting from the third period. This may be because participants were punished only after they made their decision in the first round. This implies that mere exposure to regulations, such as punishment, does not bring about the desired behavioral change until these instruments are used. Table 2.4 also presents a negative and statistically significant correlation between punishment and purchase of a fair product, indicating observers indeed punish their assignees if they purchase an unfair product and vice versa. The results of Figures 2.4 and 2.5, and Table 2.4 have an important real-world implication in that, for market regulations to be effective, they need to be enforced.

Table 2.5 presents probit regressions of socially responsible behavior in varying market conditions. The dependent variable in all columns is a binary taking a value of $I$ if a buyer purchased a fair product, o otherwise. The treatment variable is also binary, taking a value of $I$ if a subject comes from either of the alternative market conditions (punishment or religious priming), o otherwise. Column (1) shows that punishment has a positive and statistically significant effect on socially responsible behavior, and it retains its significant effect after controlling for the period variable (column 3 ) and other household and village characteristics (column 5). Similarly, column (2) shows - 
Table 2.5: Probit Regressions of Socially Responsible Behavior in Market Baseline and Alternative Market Conditions

Eqqub member

PSNP participation

Religiosity

Market exposure

Village distance to market

Market Baseline Market Baseline Market Baseline Market Baseline Market Baseline Market Baseline

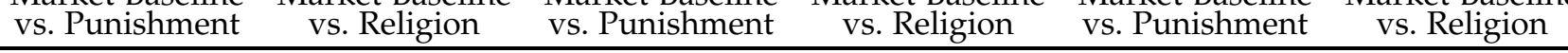

\begin{tabular}{|c|c|c|c|c|c|c|}
\hline & & & & & & \\
\hline Treatment & $\begin{array}{c}0.737^{* * *} \\
(0.029)\end{array}$ & $\begin{array}{l}0.108^{* *} \\
(0.054)\end{array}$ & $\begin{array}{c}0.739^{* * *} \\
(0.029)\end{array}$ & $\begin{array}{l}0.121^{* *} \\
(0.057)\end{array}$ & $\begin{array}{c}0.826^{* * *} \\
(0.028)\end{array}$ & $\begin{array}{l}0.185^{* * *} \\
(0.064)\end{array}$ \\
\hline Period & & & $\begin{array}{l}-0.012 \\
(0.009)\end{array}$ & $\begin{array}{c}-0.052^{* * *} \\
(0.005)\end{array}$ & $\begin{array}{l}-0.011 \\
(0.010)\end{array}$ & $\begin{array}{l}-0.054^{* * * *} \\
(0.005)\end{array}$ \\
\hline Age & & & & & $\begin{array}{c}0.002 \\
(0.012)\end{array}$ & $\begin{array}{l}-0.022 \\
(0.018)\end{array}$ \\
\hline Age square & & & & & $\begin{array}{l}-0.000 \\
(0.000)\end{array}$ & $\begin{array}{l}0.000 \\
(0.000)\end{array}$ \\
\hline Male & & & & & $\begin{array}{c}0.089 \\
(0.105)\end{array}$ & $\begin{array}{c}-0.188^{* *} \\
(0.094)\end{array}$ \\
\hline Household size & & & & & $\begin{array}{c}0.002 \\
(0.015)\end{array}$ & $\begin{array}{l}0.030^{* * *} \\
(0.015)\end{array}$ \\
\hline Education & & & & & $\begin{array}{l}-0.038 \\
(0.050)\end{array}$ & $\begin{array}{c}0.068 \\
(0.061)\end{array}$ \\
\hline Own land & & & & & $\begin{array}{l}-0.026 \\
(0.091)\end{array}$ & $\begin{array}{c}0.003 \\
(0.095)\end{array}$ \\
\hline Livestock & & & & & $\begin{array}{l}-0.007 \\
(0.006)\end{array}$ & $\begin{array}{l}-0.007 \\
\text { (0.010) }\end{array}$ \\
\hline Iddir member & & & & & $\begin{array}{c}0.012 \\
(0.054)\end{array}$ & $\begin{array}{c}0.003 \\
(0.054)\end{array}$ \\
\hline Eqqub member & & & & & $\begin{array}{l}-0.007 \\
(0.050)\end{array}$ & $\begin{array}{c}0.086 \\
(0.056)\end{array}$ \\
\hline PSNP participation & & & & & $\begin{array}{l}-0.032 \\
(0.055)\end{array}$ & $\begin{array}{c}-0.188^{* * * *} \\
(0.046)\end{array}$ \\
\hline Religiosity & & & & & $\begin{array}{l}0.186^{* *} \\
(0.092)\end{array}$ & $\begin{array}{c}0.090 \\
(0.060)\end{array}$ \\
\hline Market exposure & & & & & $\begin{array}{l}-0.003 \\
(0.007)\end{array}$ & $\begin{array}{c}0.001 \\
(0.006)\end{array}$ \\
\hline Village distance to market & & & & & $\begin{array}{c}-0.010^{* *} \\
(0.005)\end{array}$ & $\begin{array}{c}0.003 \\
(0.007)\end{array}$ \\
\hline Village exposure to drought & & & & & $\begin{array}{c}-0.032^{* * * *} \\
(0.007)\end{array}$ & $\begin{array}{l}-0.018^{* *} \\
(0.007)\end{array}$ \\
\hline $\begin{array}{l}\text { Pseudo R2 } \\
\text { Observations }\end{array}$ & $\begin{array}{c}0.470 \\
960\end{array}$ & $\begin{array}{c}0.0132 \\
960\end{array}$ & $\begin{array}{c}0.472 \\
060\end{array}$ & $\begin{array}{c}0.112 \\
960\end{array}$ & $\begin{array}{c}0.506 \\
060\end{array}$ & 0.200 \\
\hline Number of subjects & 96 & 96 & 96 & 96 & 96 & 96 \\
\hline
\end{tabular}

Notes. The dependent variable in all columns takes a value of 1 if a buyer purchased a fair product, o otherwise. The table reports marginal effects after probit. The omitted category is Market Baseline and Treatment is a binary variable takes a value of 1 if a subject comes from either punishment or religion treatment, o otherwise. Period takes an integer value between 1 and 10. Robust standard errors (clustered by subject) in parentheses, ${ }^{* * *} \mathrm{p}<0.01,{ }^{* *} \mathrm{p}<0.05,{ }^{*} \mathrm{p}<0.1$. 
subjects in the religious priming treatment have a higher propensity of purchasing a fair product than those in the baseline treatment. Priming market participants with religious commandments significantly increases socially responsible behavior in markets even when we control for period and a battery of household and village characteristics (columns 4 and 6). The results from random effects probit regressions in Table A.4 in the appendix also report qualitatively similar results. Further, Table 2.5 shows that only a few household and village covariates are correlated with subjects socially responsible behavior. Columns (5) and (6) report that subjects residing in villages with frequent exposure to covariate shocks such as drought are less likely to exhibit socially responsible behavior.

\subsubsection{Is Eroding Socially Responsible Behavior (SRB) Harmful?}

This section examines the effect of eroding socially responsible behavior on subsequent conflicting behavior. We hypothesized that the decay of social responsibility is harmful regardless of the context, i.e., whether it is in the market or non-market environments. It may lead to an unequivocal increase in inequality, which may, in turn, lead to subsequent anti-social behavior.

Recall that in our market and non-market experiments, subjects were allowed to choose between two options. While the first option has no negative external impact on the uninvolved third parties (or players C), and market participants (or players A and B) earn only 20 Birr together on top of their initial endowment of 60 Birr, the second option has a 50 Birr negative externality on the third parties (or players C), and market participants (or players A and B) earn 40 Birr together on top of their initial endowment. In the first (fair) option, the average potential difference in earning between the uninvolved third parties (or players $C$ ) and market participants (or players A and B) is only 1o Birr. However, the second (unfair) option yields up to 70 Birr gap in earning between the two groups. We, therefore, expect more conflicting behavior when socially responsible behavior is eroded, i.e., when the unfair option (product) is chosen.

As shown in section 2.4.1, a large number of subjects, particularly in the market context, chose the option with a negative external impact on the uninvolved third parties (or players $\mathrm{C}$ ). As a consequence, we find that buyers and players B on average earn a significantly higher income than their matched third parties and players $\mathrm{C}$ 79 Birr and 37 Birr, respectively. This inequality in earning is mainly driven by those who caused and bore ( 85 and 1o Birr, respectively) the negative externality than those who did not (73 and 6o Birr, respectively). This indicates that income inequality is pervasive, particularly among the causers ${ }^{14}$, and recipients of the negative externality,

14 In this study we only consider buyers as the causers of the negative externality. This is due to the fact that each of the 6 buyers were randomly matched with each of the 6 third parties before the 
and this may, in turn, trigger conflict between the two parties. To this end, we use the behavior in the experimental joy-of-destruction game.

We find that approximately 23 percent of subjects decided to destroy their partners' income in the experiments. This is in line with the findings from previous studies (Abbink \& Sadrieh, 2009; Abbink \& Herrmann, 2011; Prediger et al., 2014; Fehr, 2018). In a one-shot joy-of-destruction game, Abbink \& Herrmann (2011), Prediger et al. (2014) and Fehr (2018) report destruction rates of $26 \%, 32 \%$, and $20-42 \%$, respectively. Likewise, in a repeated joy-of-destruction game, Abbink \& Sadrieh (2009) find a destruction rate of approximately $40 \%$. Further, we find that the erosion of socially responsible behavior leads to higher propensity of burning partners' income (one-sided Fisher's exact test, $\mathrm{p}=0.000, \mathrm{n}=192$ ). More formally, Table 2.6 reports the results of linear probability model of subjects' burning decision. The observations in this regression include all buyers and third parties in the market context and players $\mathrm{B}$ and $C$ in the non-market context. Column (1) shows that burning partners' income is more prevalent among those matched subjects who either caused or incurred the negative externality. This result remains robust even after controlling for subjects' beliefs about their partners' burning decisions (which is potentially endogenous) and other household and village covariates in columns (2) and (3), respectively. To be precise, the erosion of socially responsible behavior (ESRB), on average, increases the probability of burning others' income by 49 percentage points (column 3). We also find qualitatively similar results using a Firth logit model. ${ }^{1516}$ Being in the group who either caused or incurred the negative externality increases the probability of reducing partners' income by 50 percentage points (Table A.5). In sum, we find that conflicting behavior is ubiquitous in environments where socially responsible behavior is less prevalent. ${ }^{17}$

experiment begins, and we informed buyers that their decision directly affects their partners' (third parties') earning. Buyers decision is a sufficient condition for the third parties to incur the negative externality, while sellers decision is not. In addition, in the non-market context, only players B make a decision, while players $A$ and $C$ remained passive. Thus, to compare the consequences of eroding socially responsible behavior on the subsequent ant-social behavior in the market and non-market contexts, we need to focus on the decisions of buyers and players B.

15 We used the linear probability model because of the (quasi) complete separation problem in logistic regression. The (quasi) complete separation problem is a situation in which the maximum likelihood estimates tend to infinity (become inestimable). To overcome this problem, we used the Firth logit model besides the linear probability model. Heinze \& Schemper (2002) recommended using this method that is originally developed by Firth (1993) to reduce bias in maximum likelihood estimates. Firth's method provides finite estimates using the penalized maximum likelihood estimation. Further, it also provides consistent estimates wherein the conventional maximum likelihood estimates do not exist because of the separation problem. We used the Stata command written by Coveney (2015) for the Firth logit regressions.

16 We also used linear probability model in Tables 2.7 through 2.9. Using linear probability model for a binary dependent variable is common in previous studies, e.g., see Prediger et al. (2014).

17 Since ESRB could be endogenous for former player Bs, the findings in 2.6 through 2.9 are correlational. 
Table 2.6: The Effect of Eroding SRB on Anti-social Behavior

\begin{tabular}{lccc}
\hline & $(1)$ & $(2)$ & $(3)$ \\
& Reduce Money & Reduce Money & Reduce Money \\
\hline ESRB & $0.494^{* * *}$ & $0.449^{* * *}$ & $0.485^{* * *}$ \\
& $(0.053)$ & $(0.057)$ & $(0.065)$ \\
Belief & & $0.369^{* * *}$ & $0.369^{* * *}$ \\
& & $(0.130)$ & $(0.133)$ \\
Constant & 0.001 & 0.001 & 0.212 \\
& $(0.001)$ & $(0.001)$ & $(0.365)$ \\
Observations & 192 & 192 & 192 \\
R-squared & 0.344 & 0.383 & 0.429 \\
Controls & NO & NO & YES \\
\hline
\end{tabular}

Notes. The dependent variable in all specifications is subjects' burning decision ( $1=b u r n, 0=$ not burn). The Table reports estimation results of linear probability model. Column (3) includes controls for age, age square, gender, education, number of active people, land and livestock ownership, iddir and eqqub membership, PSNP participation, market exposure, village distance to market and exposure to drought, and religiosity. Robust standard errors in parentheses, ${ }^{* * *}$ $\mathrm{p}<0.01,{ }^{* *} \mathrm{p}<0.05,{ }^{*} \mathrm{p}<0.1$.

\subsubsection{Is the Effect of the Erosion of SRB More Pronounced in Markets?}

In section 2.4 .3 , we find that the erosion of socially responsible behavior, be it in a market or non-market context is socially harmful. Next, we examine whether this effect is more pronounced in the market than in the non-market context.

In section 2.4.1, we have established that socially responsible behavior is less prevalent in the market than in the non-market context, and this leads to pervasive income inequality in the former. Buyers and third parties in the market baseline, on average, earn 82 Birr and 24 Birr, respectively. On the contrary, players B and C in the nonmarket context, on average, earn about 75 Birr and 50 Birr, respectively. Hence, we anticipate that the effect of the erosion of socially responsible behavior on anti-social behavior to be more pronounced in the market than in the non-market context.

In our experiment, we find that while about $36.5 \%$ of market participants destroyed their partners' income, approximately only $10 \%$ of the non-market participants burned their partners' income (one-sided Fisher's exact test, $\mathrm{p}=0.000, \mathrm{n}=192$ ). Table 2.7 also presents the regression results of the linear probability model, where we regress participants' burning decisions on the treatment variable (treatment $=1$ if market baseline), erosion of socially responsible behavior (purchase of an unfair product), interaction terms, beliefs, and other covariates. Column (1) shows that market participants are more likely to burn their partners' earning compared to the non-market participants. On average, being in the market baseline treatment increases the probability 
of burning partners' income by approximately 27 percentage points. ${ }^{18}$ However, the significant effect of the market treatment vanishes when we control for the erosion of socially responsible behavior (unfair product purchase), indicating market context may not have a direct effect on anti-social behavior but through its impact on socially responsible behavior (column 2).

Table 2.7: Is the Effect of Eroding SRB More Pronounced in Markets?

\begin{tabular}{|c|c|c|c|c|c|}
\hline & $\begin{array}{c}\text { (1) } \\
\text { Reduce } \\
\text { Money }\end{array}$ & $\begin{array}{c}\quad(2) \\
\text { Reduce } \\
\text { Money }\end{array}$ & $\begin{array}{c}\text { (3) } \\
\text { Reduce } \\
\text { Money }\end{array}$ & $\begin{array}{c}(4) \\
\text { Reduce } \\
\text { Money }\end{array}$ & $\begin{array}{c}\quad(5) \\
\text { Reduce } \\
\text { Money }\end{array}$ \\
\hline Treatment & $\begin{array}{c}0.271^{* * *} \\
(0.058)\end{array}$ & $\begin{array}{c}0.011 \\
(0.057)\end{array}$ & $\begin{array}{l}-0.001 \\
(0.001)\end{array}$ & $\begin{array}{l}-0.001 \\
(0.001)\end{array}$ & $\begin{array}{l}-0.001 \\
(0.043)\end{array}$ \\
\hline ESRB & & $\begin{array}{c}0.488^{* * *} \\
(0.061)\end{array}$ & $\begin{array}{c}0.474^{* * *} \\
(0.116)\end{array}$ & $\begin{array}{l}0.415^{* * *} \\
(0.111)\end{array}$ & $\begin{array}{l}0.426^{* * *} \\
(0.114)\end{array}$ \\
\hline ESRBXTreatment & & & $\begin{array}{c}0.026 \\
(0.131)\end{array}$ & $\begin{array}{c}0.043 \\
(0.122)\end{array}$ & $\begin{array}{c}0.078 \\
(0.137)\end{array}$ \\
\hline Belief & & & & $\begin{array}{c}0.372^{* * *} \\
(0.134)\end{array}$ & $\begin{array}{c}0.378^{* * *} \\
(0.137)\end{array}$ \\
\hline Constant & $\begin{array}{l}0.094^{* * *} \\
(0.030)\end{array}$ & $\begin{array}{l}-0.003 \\
(0.014)\end{array}$ & $\begin{array}{c}0.001 \\
(0.001)\end{array}$ & $\begin{array}{l}0.001^{* *} \\
(0.000)\end{array}$ & $\begin{array}{c}0.206 \\
(0.362)\end{array}$ \\
\hline Observations & 192 & 192 & 192 & 192 & 192 \\
\hline R-squared & 0.104 & 0.344 & 0.344 & 0.384 & 0.431 \\
\hline Controls & $\mathrm{NO}$ & $\mathrm{NO}$ & $\mathrm{NO}$ & $\mathrm{NO}$ & YES \\
\hline
\end{tabular}

Notes. The dependent variable in all specifications is subjects' burning decision ( $1=$ burn, $0=$ not burn). Treatment is a binary variable takes a value of 1 if a subject comes from Market Baseline and o if a subject comes from Non-Market condition. Column (3) includes controls for age, age square, gender, education, number of active people, land and livestock ownership, iddir and eqqub membership, PSNP participation, market exposure, village distance to market and exposure to drought, and religiosity. Robust standard errors in parentheses, ${ }^{* * *} \mathrm{p}<0.01,{ }^{* *} \mathrm{p}<0.05,{ }^{*} \mathrm{p}<0.1$.

To further scrutinize whether market context inflicts conflicting behavior through inducing participants to engage in exchanges with a negative external effect on the third parties, we introduce an interaction term between unfair product purchase and being in the market baseline (columns 4 - 6). We find no significant effect of the interaction term on subjects' burning behavior. On the other hand, the erosion of socially responsible behavior keeps having a stable effect on subjects' burning behavior. This suggests that while the participants who either produced or incurred the negative externality are mainly responsible for the observed anti-social behavior, this is not

18 Results from the Firth logit model also shows that, on average, the probability of burning partners' income increases by 27 percentage points if the subject was from the market baseline (Table ??). 
mainly driven by the subjects coming from the market baseline treatment. Further, we find that subjects' belief about others' behavior positively and significantly affects own burning decision. Our findings from a Firth logit model also corroborate the results in Table 2.7. Overall, while the results from the Fisher's exact test and columns (1) of Table 2.7 suggest that the effect of eroding socially responsible behavior appears to be more pronounced in the market context, this result is not replicated in columns 2 through 5 of Table 2.7 .

Next, we turn to a more detailed analysis of burning behavior. Particularly, we look at who burns partners' money (buyers and players B - the causers of the negative externality or the third parties and players $C$ - the recipients of the negative externality), whether there is a significant difference in burning between buyers and players $\mathrm{B}$ on the one hand, and third parties and players $C$ on the other hand, and who is the target of income reductions.

We first examine whether there is a significant difference in burning partners' income between buyers in the market context and players B in the non-market context. Further, we also examine the burning behavior of those who purchased (chose) unfair product (distribution) and those who did not. The results of the linear probability model show no robust statistically significant difference in burning others' income between buyers in the market context and players B in the non-market context (Table A.7). This suggests that market induces market participants (buyers) to engage in an advantageous inequality (trading a product with a negative externality to increase own earning at the expense of others (Table 2.3), but not in a disadvantageous inequality (burning others' income at a cost to oneself, (Table A.7)). We next investigate whether engaging in less socially responsible behavior induces subjects to behave more anti-socially in the joy-of-destruction experiment, regardless of the context. Table A.7 shows that participants who were involved in exchanges with negative externality in the market and non-market experiments are more likely to burn their partners' income than those who did not (column 2 - 4). However, the significant effect vanishes when controlling for beliefs, household and village covariates (column 5), suggesting the existence of no statistically significant difference in reducing others' income among the two groups.

Next, we ask whether the third parties who were the recipients of the negative externality in the market or non-market experiments would retaliate if given the opportunity. Specifically, the interest here is to examine whether the third parties reciprocate differently in response to the fair and unfair decisions by the buyers and players B. Earlier studies argue that people reciprocate positively in response to fair actions; conversely, people reciprocate negatively in response to unfair actions (Rabin, 1993; Fehr \& Gachter, 2000). The data from the second (JOD) experiment with the third parties allow us to test whether this hypothesis holds. Further, we are interested to dig deep 
to see if the burning behavior is more pronounced in the market context compared to non-market context and is driven by the third parties.

Table A.8 in the appendix reports the regression results of the linear probability model, where we regress the third parties' and players $C^{\prime}$ s burning decision on whether or not they incurred a negative externality, beliefs, interaction term, and other controls. In line with our hypothesis and previous findings, we find a statistically significant and economically sizeable difference in reciprocity between the third parties and players $C$, who suffered from the negative externality and those who did not. Columns 2 through 5 present a positive and statistically significant effect of morally questionable decisions on retaliation, indicating that those who were adversely affected by the negative externality are more likely to retaliate. The estimation results are robust to several specifications, controlling for the subjects' belief about their partners' burning decision, household, and village covariates, and confirm that it is the opportunity to retaliate, causing the money burning. Interestingly, belief has no significant effect on subjects' burning decision. On average, being a recipient of the negative externality increases the probability of burning partner's income by 6o percentage points (column 5). In a nutshell, "people like to help those who are helping them, and to hurt those who are hurting them" (Rabin, 1993).

To deepen our understanding of the drivers of burning behavior, we next scrutinize whether the effect is more pronounced in the market compared to the non-market experiment. A first inspection reveals a statistically significant difference in destroying partners' income between the third parties in the market context compared to participants in the non-market context. Column (1) of Table A.8 shows that the probability of burning partners' income, on average, increases by 42 percentage points if the subject comes from the market baseline. However, the significant effect vanishes once we control for the unfair product purchase (product with negative externality). Further, we find that the interaction term of incurring a negative externality and being in the market baseline treatment has no significant effect on subjects' burning decision.

\subsubsection{Does the Effects of Punishment and Religious Priming Persist?}

In section 2.4.2, we have documented that punishing subjects for creating negative externality on uninvolved third parties and priming subjects with some religious commandments enhance socially responsible behavior in markets. The interest here is to investigate whether the effects of punishment and religious priming persist ex-post (after the market experiment). To this end, we examine the burning behavior of matched buyers and third parties in the market baseline compared to those in the market baseline with punishment and market baseline with religious priming treatments in the joy-of-destruction game. 
Recall from section 2.4 .4 that $36.5 \%$ (35 out of 96) of subjects in the market baseline decided to burn their partners' income. In contrast, about $17 \%$ ( 16 out of 96) of participants reduce their partners' income in the market baseline with punishment treatment (one-sided Fisher's exact test, $\mathrm{p}=0.002, \mathrm{n}=192$ ), suggesting money burning is significantly higher in the market baseline than in the market baseline with punishment treatment. On the other hand, about $29 \%$ ( 28 out of 96 ) of subjects in the market baseline with religious priming treatment reduce their partners' income, however, this is not statistically different from the destruction rate observed in the market baseline (one-sided Fisher's exact test, $\mathrm{p}=0.178, \mathrm{n}=192$ ).

To study the effect of punishment and religious priming in greater detail, we present the regression results of the linear probability model. Tables 2.8 and 2.9 provide the estimation results for punishment and religious priming treatments, respectively. The treatment variable is a binary variable taking the value of 1 if the subject comes from the market baseline treatment, o otherwise. Column (1) of Table 2.8 shows that the effect of punishing unfair behavior sustains ex-post. On average, being in the market baseline increases the probability of reducing partners' income by nearly 20 percentage points compared to being in the punishment treatment. However, the treatment variable enters insignificantly when controlling for the purchase of the unfair product (column 2). To test whether market baseline inflicts burning behavior through inducing subjects to trade products with a negative external effect on the third parties, we introduce an interaction term between unfair product purchase and being in the market baseline (columns $3-5$ ). We find a positive and statistically significant effect of the interaction term on burning the partners' income. This suggests that the participants who either produced or incurred a negative externality and, at the same time, coming from the market baseline, are mainly responsible for the observed anti-social behavior.

The positive sign of the treatment variable in column (1) of Table 2.9 suggests that subjects in the market baseline are more likely to reduce partners' income than those in the religious priming, although the effect is not significant at the conventional level. In columns (3) through (5), we introduced the interaction term between the unfair product and the treatment variable. The coefficient of the interaction term is positive and statistically significant, suggesting market participants who either caused or bore the negative externality and at the same time come from the market baseline are more likely to burn partner's income. Overall, we find that the effect religious priming sustains ex-post, indicating religious priming significantly reduces conflicting behavior among market participants. 
Table 2.8: Does the Effect of Punishment Persists?

\begin{tabular}{lccccc}
\hline & $(1)$ & $(2)$ & $(3)$ & $(4)$ & $(5)$ \\
& Reduce & Reduce & Reduce & Reduce & Reduce \\
& Money & Money & Money & Money & Money \\
\hline Treatment & $0.198^{* * *}$ & -0.059 & $-0.167^{* * *}$ & $-0.163^{* * *}$ & $-0.170^{* *}$ \\
& $(0.062)$ & $(0.058)$ & $(0.040)$ & $(0.039)$ & $(0.086)$ \\
ESRB & & $0.386^{* * *}$ & -0.000 & 0.004 & -0.018 \\
& & $(0.069)$ & $(0.159)$ & $(0.159)$ & $(0.163)$ \\
ESRBXTreatment & & & $0.500^{* * *}$ & $0.456^{* * *}$ & $0.486^{* * *}$ \\
& & & $(0.170)$ & $(0.171)$ & $(0.182)$ \\
Belief & & & & $0.351^{* *}$ & $0.35^{* *}$ \\
& & & & $(0.160)$ & $(0.169)$ \\
Constant & $0.167^{* * *}$ & $0.143^{* * *}$ & $0.167^{* * *}$ & $0.163^{* * *}$ & 0.450 \\
& $(0.038)$ & $(0.039)$ & $(0.040)$ & $(0.039)$ & $(0.392)$ \\
Observations & & & & & \\
R-squared & 192 & 192 & 192 & 192 & 192 \\
Controls & 0.050 & 0.148 & 0.177 & 0.203 & 0.248 \\
\hline
\end{tabular}

Notes. The dependent variable in all specifications is subjects' burning decision ( $1=$ burn, $0=$ not burn). Treatment is a binary variable takes a value of 1 if a subject comes from Market Baseline and o if a subject comes from Market Baseline with punishment. ESRB refers to erosion of socially responsible behavior. Column (5) includes controls for age, age square, gender, education, number of active people, land and livestock ownership, iddir and eqqub membership, PSNP participation, market exposure, village distance to market and exposure to drought, and religiosity. Robust standard errors in parentheses, ${ }^{* * *} \mathrm{p}<0.01{ }^{* *}$ $\mathrm{p}<0.05,{ }^{*} \mathrm{p}<0.1$.

Table 2.9: Does the Effect of Religious Priming Persists?

\begin{tabular}{lccccc}
\hline & $(1)$ & $(2)$ & $(3)$ & $(4)$ & $(5)$ \\
& Reduce & Reduce & Reduce & Reduce & Reduce \\
& Money & Money & Money & Money & Money \\
\hline Treatment & 0.073 & 0.057 & $-0.100^{*}$ & $-0.048^{*}$ & -0.138 \\
& $(0.068)$ & $(0.063)$ & $(0.055)$ & $(0.025)$ & $(0.095)$ \\
ESRB & & $0.385^{* * *}$ & $0.279^{* * *}$ & $0.236^{* * *}$ & $0.231^{* * *}$ \\
& & $(0.053)$ & $(0.082)$ & $(0.063)$ & $(0.069)$ \\
ESRBXTreatment & & & $0.221^{* *}$ & $0.204^{* *}$ & $0.255^{* *}$ \\
& & & $(0.102)$ & $(0.085)$ & $(0.124)$ \\
Belief & & & & $0.518^{* * *}$ & $0.502^{* * *}$ \\
& & & & $(0.098)$ & $(0.109)$ \\
Constant & & & $0.100^{*}$ & $0.048^{*}$ & -0.065 \\
& $0.292^{* * *}$ & 0.027 & $(0.055)$ & $(0.025)$ & $(0.392)$ \\
Observations & $(0.047)$ & $(0.048)$ & 192 & 192 & 192 \\
R-squared & 192 & 192 & 0.156 & 0.280 & 0.370 \\
Controls & 0.006 & 0.144 & NO & NO & YES \\
\hline
\end{tabular}

Notes. The dependent variable in all specifications is subjects' burning decision ( $1=b u r n, 0=$ not burn). Treatment is a binary variable takes a value of $\mathrm{I}$ if a subject comes from Market Baseline and o if a subject comes from Market Baseline with religious priming. Column (5) includes controls for age, age square, gender, education, number of active people, land and livestock ownership, iddir and eqqub membership, PSNP participation, market exposure, village distance to market and exposure to drought, and religiosity. Robust standard errors in parentheses, ${ }^{* * *} \mathrm{p}<0.01,{ }^{* *} \mathrm{p}<0.05,{ }^{*} \mathrm{p}<0.1$. 


\subsubsection{Welfare Impacts}

In this section, to further posit the need to mitigate the social ills of unregulated markets, we extend our analysis to the welfare effects of varying market conditions. For this purpose, we compare the gains and losses between the market baseline and alternative market conditions. We define gains and losses as the average earning of subjects from the market experiment and the amount of money lost in the joy-ofdestruction experiment, respectively.

Table 2.10: Gains Across Varying Market Conditions

\begin{tabular}{lccccc}
\hline Treatments & \multicolumn{1}{c}{ Market } & Alternative Markets & Diff. & P-value & Observations \\
\hline Market vs. Punishment & 55.584 & 65.516 & -9.932 & 0.000 & 2560 \\
Market vs. Religion & 55.584 & 56.740 & -1.156 & 0.330 & 2560 \\
Total observations & & & & & 3840 \\
\hline
\end{tabular}

Table 2.10 shows that the average income of participants in the market baseline experiment is about 56 Birr. On the other hand, the average income of participants in the punishment and religious priming treatments is approximately 66 Birr and 57 Birr respectively. This indicates that while punishment results in a significantly high welfare, religious priming does not lead to differential impacts on welfare compared to the market baseline treatment.

To further scrutinize the welfare effects of varying market conditions, we examine the amount of losses in the three treatments. On average, participants (buyers and third parties) in the market baseline experiment have destroyed about 23 Birr of their endowment, while those participants in the punishment and religious priming treatments burned nearly 7 Birr and 17 Birr respectively. Table 2.11 shows that while punishment considerably reduces the loss due to money burning, we find no significant effect for religious priming. This reinforces our findings in Table 2.10 in that regulated markets lead to higher welfare compared to unregulated markets.

Table 2.11: Loss Across Varying Market Conditions

\begin{tabular}{|c|c|c|c|c|c|}
\hline Treatment & Market & Alternative Markets & Diff. & P-value & Observations \\
\hline Market vs. Punishment & 22.97 & 7.03 & 15.94 & 0.000 & 192 \\
\hline Market vs. Religion & 22.97 & $17 \cdot 38$ & $5 \cdot 59$ & 0.234 & 192 \\
\hline Total observations & & & & & 288 \\
\hline
\end{tabular}




\subsection{CONCLUSION}

Markets are ubiquitous in the daily life of humankind, and thus, shape human behavior in numerous ways. This study contributes to a rapidly emerging body of literature on whether markets erode socially responsible and moral behavior. Specifically, this study provides an empirical evidence on whether market participants are concerned about the social impacts of their actions in markets and willing to internalize negative externalities. Further, this study explores whether social responsibility is less prevalent in markets compared to non-market environments and the role of regulating mechanisms such as punishment and religious priming in promoting socially responsible behavior. This study also examines whether eroding social responsibility is socially harmful and whether the effect of the aforementioned mechanisms persists ex-post.

We use data from lab-in-the-field experiments involving 544 subjects from 32 villages in Ethiopia. We conducted two lab-in-the-field experiments - market and joyof-destruction experiments. Our experimental findings can be summarized as follows. First, market participants reveal a nontrivial concern for the negative social impacts of their actions in markets. More than $20 \%$ of market participants are willing to exchange fair products to avoid a negative externality on uninvolved third parties. However, in contrast to the results in Bartling et al. $(2015,2019)$, subjects' concern diminishes when they are engaged in frequent market interactions. Second, compared to non-market environments, socially responsible behavior is less prevalent in market contexts. This result is in line with our hypothesis and the results of earlier findings (Bartling et al., 2015; Falk \& Szech, 2013). While the share of fair products in the market context is nearly $21 \%$, the share of fair distributions in the non-market context is about $79 \%$. We speculate that markets erode socially responsible behavior by channels reported in the recent studies such as, market framing, which diverts the focus of market participants from the negative social impacts of their market actions (Irlenbusch \& Saxler, 2019), diffusion of responsibility (Irlenbusch \& Saxler, 2019), and frequency of market interactions. We find support for the latter as market participant's concern about the social impact of their actions steadily declines across market periods.

Third, we find that punishing subjects for their unfair behavior and priming subjects with religious commandments that prohibit deliberately hurting others for the sake of oneself promote socially responsible behavior. However, while punishment becomes an effective instrument after it is enforced, religious priming becomes less effective over time, suggesting that proper enforcement of regulation mechanisms and continuous priming of subjects is key in fostering social responsibility in markets. Fourth, we find that the erosion of socially responsible behavior has adverse social consequences, in the sense that it inflicts conflicting behavior among participants as exhibited in the money burning experiment. Unequivocal income inequality caused 
by the exchange of products with negative externality on the third parties is the causal mechanism through which the erosion of socially responsible behavior triggers antisocial or conflict behavior. This result is in line with our hypothesis and findings of previous studies (Fehr, 2018) that income inequality caused by morally questionable means plays a significant role in inflicting anti-social behavior. Further, though not robust across different specification, the results show that this effect is more pronounced in the market than in the non-market context. Fifth, we find that the effects of both punishment and religious priming sustain ex-post in that it reduces anti-social behavior. Finally, we examine the social welfare impacts of market baseline, market baseline with punishment and religious priming. The market baseline (unregulated) results in lower social welfare compared to regulated (punishment) markets, suggesting a need for market regulations to reap the efficiency and other benefits of markets.

While the findings in this study provide important insights, it has opened several questions to be addressed in future studies. First, market actors in Bartling et al. $(2015,2019)$ revealed stable social concern, while market actors in our experiment do not. The present study does not provide an answer for this divergence. Further, since we made minor changes in our experimental design, we are unable to make a direct comparison between our findings and the findings in Bartling et al. (2015, 2019), which could have provided useful information on the effect of markets on socially responsible behavior in different contexts, institutions, and cultures. Second, in our religious priming treatment, subjects were primed only at the beginning of the experiment. As a consequence, we find that the effect of religious beliefs fades overtime. Hence, further research is needed to explore the effect of continuous priming on market participants' socially responsible behavior. Third, to understand the adverse social effects of eroding social responsibility in markets, we allowed subjects to play in the joy-of-destruction. While this setup provides important information on the effect of the erosion of socially responsible behavior on anti-social behavior, as destruction entails no material benefit for the destroyer, it is somehow difficult to gauge its effect on social preferences in general. Thus, further research is needed to investigate the effect of eroding socially responsible behavior on pro-social behaviors such as fairness, altruism, trust, and cooperation. Finally, the ESRB may be endogenous for buyers in the market context and player Bs in the non-market context. That is, their decision in the JOD experiment may be still driven by some unobservable factors. This may raise concerns that the findings from estimations based on a sample that includes JOD decisions by these subjects is only correlational. Hence, future research is recommended for investigating the causal impact of the erosion of socially responsible behavior on subsequent anti-social behavior. 


\section{REFERENCES}

Abbink, K. \& Herrmann, B. (2011), 'The moral costs of nastiness', Economic Inquiry 49(2), 631-633.

Abbink, K. \& Sadrieh, A. (2009), 'The pleasure of being nasty', Economics Letters 105(3), 306-308.

Bartling, B., Valero, V. \& Weber, R. A. (2018), 'Is social responsibility a normal good?'. CESifo Working Paper, No. 7263.

Bartling, B., Valero, V., Weber, R. et al. (2019), 'On the scope of externalities in experimental markets', Experimental Economics 22(3), 610-624.

Bartling, B., Weber, R. A. \& Yao, L. (2015), 'Do markets erode social responsibility?', Quarterly Journal of Economics 130(1), 219-266.

Bowles, S. (1998), 'Endogenous preferences: The cultural consequences of markets and other economic institutions', Journal of Economic Literature 36(1), 75-111.

Bulte, E., Kontoleon, A., List, J., Turley, T. \& Voors, M. (2017), 'From personalized exchange towards anonymous trade: A field experiment on the workings of the invisible hand', Journal of Economic Behavior E Organization 133, 313-330.

Cappelen, A. W., Sørensen, E. Ø. \& Tungodden, B. (2013), 'When do we lie?', Journal of Economic Behavior \& Organization 93, 258-265.

Cecchi, F. \& Bulte, E. (2013), 'Does market experience promote rational choice? Experimental evidence from rural Ethiopia', Economic Development and Cultural Change 61(2), 407-429.

Cohn, A., Fehr, E. \& Maréchal, M. A. (2014), 'Business culture and dishonesty in the banking industry', Nature 516(7529), 86.

Coveney, J. (2015), 'Firthlogit: Stata module to calculate bias reduction in logistic regression'. Statistical Software Components S456948, Department of Economics, Boston College.

Ellingsen, T., Johannesson, M., Mollerstrom, J. \& Munkhammar, S. (2012), 'Social framing effects: Preferences or beliefs?', Games and Economic Behavior 76(1), 117-130.

Falk, A., Neuber, T. \& Szech, N. (2020), 'Diffusion of being pivotal and immoral outcomes', The Review of Economic Studies .

Falk, A. \& Szech, N. (2013), 'Morals and markets', Science 340(6133), 707-711.

Fehr, D. (2018), 'Is increasing inequality harmful? Experimental evidence', Games and Economic Behavior 107, 123-134.

Fehr, E. \& Gachter, S. (2000), 'Cooperation and punishment in public goods experiments', American Economic Review 9o(4), 980-994. 
Fehr, E., Naef, M. \& Schmidt, K. M. (2006), 'Inequality aversion, efficiency, and maximin preferences in simple distribution experiments: Comment', American Economic Review 96(5), 1912-1917.

Fehr, E. \& Schmidt, K. M. (1999), 'A theory of fairness, competition, and cooperation', The Quarterly Journal of Economics 114(3), 817-868.

Fiala, N. (2015), 'Skills in the marketplace: Market efficiency, social orientation, and ability in a field-based experiment', Journal of Economic Behavior $\mathcal{E}$ Organization 120, 174-188.

Firth, D. (1993), 'Bias reduction of maximum likelihood estimates', Biometrika pp. 2738.

Gächter, S. \& Renner, E. (2010), 'The effects of (incentivized) belief elicitation in public goods experiments', Experimental Economics 13(3), 364-377.

Heinze, G. \& Schemper, M. (2002), 'A solution to the problem of separation in logistic regression', Statistics in medicine 21(16), 2409-2419.

Henrich, J., Ensminger, J., McElreath, R., Barr, A., Barrett, C., Bolyanatz, A., Cardenas, J. C., Gurven, M., Gwako, E., Henrich, N. et al. (2010), 'Markets, religion, community size, and the evolution of fairness and punishment', Science 327(5972), 1480-1484.

Hirsch, F. (1976), 'Social limits to growth'.

Irlenbusch, B. \& Saxler, D. J. (2019), 'The role of social information, market framing, and diffusion of responsibility as determinants of socially responsible behavior', Journal of Behavioral and Experimental Economics 80, 141-161.

Kaplow, L. \& Shavell, S. (2007), 'Moral rules, the moral sentiments, and behavior: toward a theory of an optimal moral system', Journal of Political Economy 115(3), 494514 .

Kirchler, M., Huber, J., Stefan, M. \& Sutter, M. (2015), 'Market design and moral behavior', Management Science 62(9), 2615-2625.

List, J. A. (2004), 'Testing neoclassical competitive theory in multilateral decentralized markets', Journal of Political Economy 112(5), 1131-1156.

List, J. A. \& Millimet, D. L. (2008), 'The market: Catalyst for rationality and filter of irrationality', The BE Journal of Economic Analysis $\mathcal{E}$ Policy 8(1).

Marx, K. (1957/1867), Capital: Vol. I. A critique of political economy, London: Penguin Books.

Montesquieu, C. (1989/1748), 'The spirit of the laws'.

Pigors, M. \& Rockenbach, B. (2016), 'Consumer social responsibility', Management Science 62(11), 3123-3137.

Prediger, S., Vollan, B. \& Herrmann, B. (2014), 'Resource scarcity and antisocial behavior', Journal of Public Economics 119, 1-9.

Rabin, M. (1993), 'Incorporating fairness into game theory and economics', The American Economic Rreview 85(3), 1281-1302. 
Rössler, C. \& Friehe, T. (2020), 'Liability, morality, and image concerns in product accidents with third parties', European Journal of Law and Economics pp. 1-18.

Sandel, M. J. (2012), What Money Can't Buy: The Moral Limits of Markets, (Farrar, Straus and Grioux, New York).

Schumpeter, J. A. (1994/1942), Socialism, capitalism and democracy, London: Routledge. Shariff, A. F., Willard, A. K., Andersen, T. \& Norenzayan, A. (2016), 'Religious priming: A meta-analysis with a focus on prosociality', Personality and Social Psychology Review 20(1), 27-48.

Shleifer, A. (2004), 'Does competition destroy ethical behavior?', American Economic Review Papers and Proceedings 94(2), 414-418.

Smith, A. (1896/1763), Lectures on jurisprudence, in R. Meek, D. Raphael \& P. Stein, eds, 'The Glasgow Edition of the Works and Correspondence of Adam Smith: VI: Correspondence', Cambridge: Cambridge University Press.

Smith, V. L. (1962), 'An experimental study of competitive market behavior', Journal of Political Economy 70(2), 111-137.

Sutter, M., Huber, J., Kirchler, M., Stefan, M. \& Walzl, M. (2020), 'Where to look for the morals in markets?', Experimental Economics 23(1), 30-52.

Veblen, T. (1899), 'The theory of the leisure class'.

Vohs, K. D. (2015), 'Money priming can change people's thoughts, feelings, motivations, and behaviors: An update on 10 years of experiments.', Journal of Experimental Psychology: General 144(4), e86.

Vohs, K. D., Mead, N. L. \& Goode, M. R. (2006), 'The psychological consequences of money', Science 314(5802), 1154-1156. 


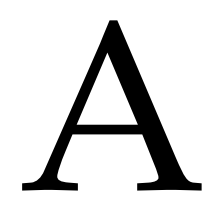

APPENDIX 
TABLES AND FIGURES

Table A.1: Variables Definitions

\begin{tabular}{|c|c|}
\hline Variables & Descriptions of variables \\
\hline \multicolumn{2}{|l|}{ Outcome Variables } \\
\hline Socially responsible behavior & Dummy: $=1$ if the respondent purchased /chose product/distribution with no negative externality, $=0$ otherwise \\
\hline Anti-social behavior & Dummy: $=1$ if the respondent decided to burn partner's income, $=0$ otherwise \\
\hline Social welfare & Continuous: the average income of respondents from the experiments \\
\hline \multicolumn{2}{|l|}{ Treatments } \\
\hline Market Baseline & Dummy: $=1$ if the respondent comes from the market baseline treatment, $=0$ otherwise \\
\hline Market Baseline with punishment & Dummy: $=1$ if the respondent comes from the market baseline with punishment treatment, $=0$ otherwise \\
\hline Market Baseline with religious priming & Dummy: $=1$ if the respondent comes from the market baseline with religious priming treatment, $=0$ otherwise \\
\hline No Market condition & Dummy: $=1$ if the respondent comes from the no market treatment, $=0$ otherwise \\
\hline \multicolumn{2}{|l|}{ Socio-demographic Characteristics } \\
\hline Age & Continuous: Age of the household head (years) \\
\hline Male & Dummy: $=1$ if the household head is Male,$=0$ Female \\
\hline Household size & Continuous: number of persons in the household \\
\hline Education & Dummy: $=1$ if the household head attend formal education, $=0$ otherwise \\
\hline Own land & Dummy: $=1$ if the household head own agricultural land, $=0$ otherwise \\
\hline Livestock & Continuous: total livestock holding in tropical livestock units \\
\hline Iddir member & Dummy: $=1$ if the household head is member of funeral association, $=0$ otherwise \\
\hline Eqqub member & Dummy: $=1$ if the household head is member of rotating credit and saving association, $=0$ otherwise \\
\hline PSNP member & Dummy: $=1$ if the household head is member of Productive Safety Net Program, $=0$ otherwise \\
\hline Religiosity & Dummy: $=1$ if the household head perceive himself $/$ herself as religious person,$=0$ otherwise \\
\hline Market exposure & Continuous: Average trips to markets in a typical month \\
\hline Village distance to market & Continuous: village distance to nearest weekly market in $\mathrm{km}$ \\
\hline Village exposure to drought & Continuous: number of years the village exposed to drought in the past 30 years \\
\hline
\end{tabular}


Table A.2: Descriptive Statistics and Balance Test

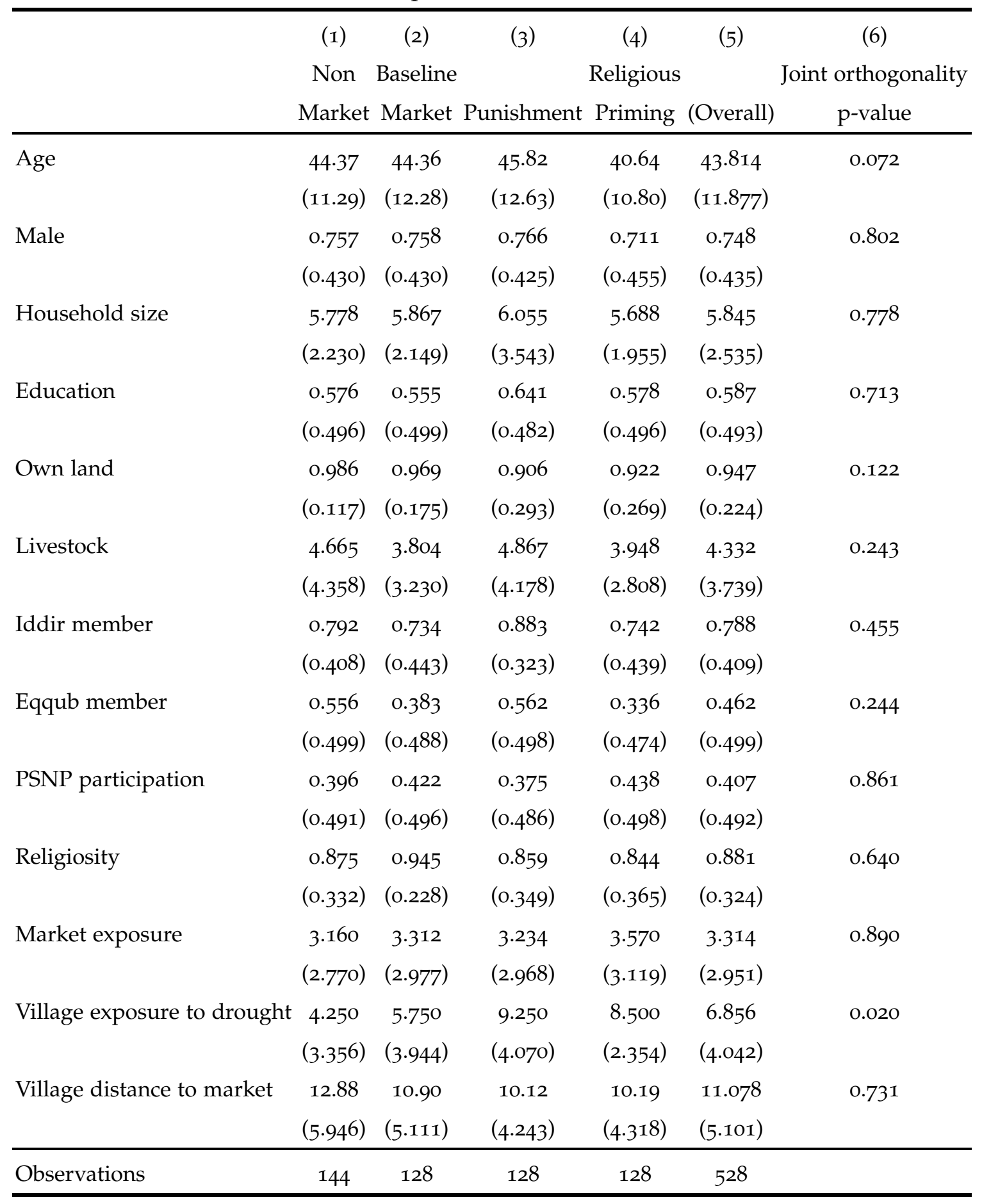

Notes. Standard deviations in parentheses. P-value computed with robust standard errors (clustered at the village level), ${ }^{* * *} \mathrm{p}<0.01,{ }^{* *} \mathrm{p}<0.05,{ }^{*} \mathrm{p}<0.1$. 


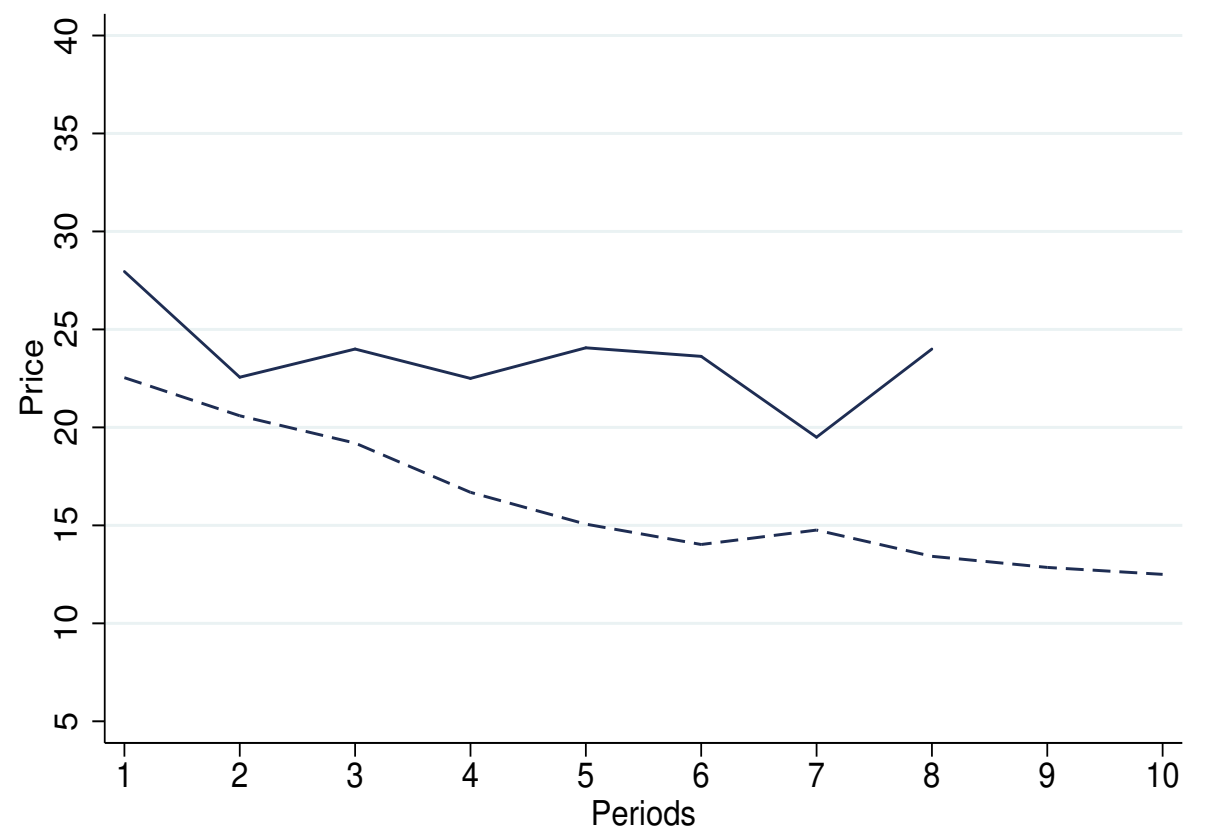

Fair Product - - - - Unfair Product

Figure A.1: Price of the Fair and Unfair Products 
Table A.3: Random-Effects Probit Regressions of Socially Responsible Behavior in Market and No Market Conditions

\begin{tabular}{|c|c|c|c|}
\hline & (1) & (2) & (3) \\
\hline Treatment & $\begin{array}{c}-0.399^{* * *} \\
(0.056)\end{array}$ & $\begin{array}{c}-0.398^{* * *} \\
(0.060)\end{array}$ & $\begin{array}{c}-0.496^{* * *} \\
(0.040)\end{array}$ \\
\hline Period & & $\begin{array}{c}-0.023^{* * *} \\
(0.007)\end{array}$ & $\begin{array}{c}-0.028^{* * *} \\
(0.005)\end{array}$ \\
\hline Age & & & $\begin{array}{l}-0.014 \\
(0.015)\end{array}$ \\
\hline Age square & & & $\begin{array}{c}0.0002 \\
(0.0002)\end{array}$ \\
\hline Male & & & $\begin{array}{l}-0.058 \\
(0.082)\end{array}$ \\
\hline Household size & & & $\begin{array}{c}0.001 \\
(0.013)\end{array}$ \\
\hline Education & & & $\begin{array}{c}0.033 \\
(0.077)\end{array}$ \\
\hline Own land & & & $\begin{array}{l}-0.108 \\
(0.074)\end{array}$ \\
\hline Livestock & & & $\begin{array}{l}-0.018 \\
(0.012)\end{array}$ \\
\hline Iddir member & & & $\begin{array}{c}0.094 \\
(0.064)\end{array}$ \\
\hline Eqqub member & & & $\begin{array}{l}-0.036 \\
(0.052)\end{array}$ \\
\hline PSNP participation & & & $\begin{array}{l}-0.064 \\
(0.067)\end{array}$ \\
\hline Religiosity & & & $\begin{array}{l}-0.083 \\
(0.104)\end{array}$ \\
\hline Market exposure & & & $\begin{array}{c}0.001 \\
(0.004)\end{array}$ \\
\hline Village distance to market & & & $\begin{array}{c}-0.014^{* *} \\
(0.007)\end{array}$ \\
\hline Village exposure to drought & & & $\begin{array}{c}-0.028^{* * *} \\
(0.007)\end{array}$ \\
\hline$\sigma$ & $\begin{array}{c}1.628^{* * *} \\
(0.269)\end{array}$ & $\begin{array}{c}1.944^{* * *} \\
(0.347)\end{array}$ & $\begin{array}{c}1.510^{* * *} \\
(0.277)\end{array}$ \\
\hline$\rho$ & $\begin{array}{c}0.726^{* * *} \\
(0.066)\end{array}$ & $\begin{array}{c}0.791^{* * *} \\
(0.059)\end{array}$ & $\begin{array}{l}0.695^{* * *} \\
(0.0777)\end{array}$ \\
\hline Observations & 960 & 960 & 960 \\
\hline Number of subjects & 96 & 96 & 96 \\
\hline
\end{tabular}

Notes. The dependent variable in all columns takes a value of 1 if a buyer or participant B purchased or chose a fair product or distribution and o otherwise. The table reports marginal effects. The omitted category is No Market condition and Treatment is a binary variable takes a value of $I$ if a subject comes from Market Baseline and o otherwise. Period takes an integer values between 1 and 10. Robust standard errors (clustered by subject) in parentheses, ${ }^{* * *} \mathrm{p}<0.01,{ }^{* *}$ $\mathrm{p}<0.05{ }^{*} \mathrm{p}<0.1$. 
Table A.4: Random-Effects Probit Regressions of Socially Responsible Behavior in Market Baseline and Alternative Market Conditions

\begin{tabular}{|c|c|c|c|c|c|c|}
\hline & $\begin{array}{c}\text { (I) } \\
\text { Market Baseline } \\
\text { vs. Punishment }\end{array}$ & $\begin{array}{c}(2) \\
\text { Market Baseline } \\
\text { vs. Religion }\end{array}$ & $\begin{array}{c}\text { (3) } \\
\text { Market Baseline } \\
\text { vs. Punishment }\end{array}$ & $\begin{array}{c}\text { (4) } \\
\text { Market Baseline } \\
\text { vs. Religion }\end{array}$ & $\begin{array}{c}(5) \\
\text { Market Baseline } \\
\text { vs. Punishment }\end{array}$ & $\begin{array}{c}(6) \\
\text { Market Baseline } \\
\text { vs. Religion }\end{array}$ \\
\hline Treatment & $\begin{array}{l}0.467^{* * *} \\
(0.016)\end{array}$ & $\begin{array}{l}0.123^{*} \\
(0.067)\end{array}$ & $\begin{array}{c}0.467^{* * *} \\
(0.015)\end{array}$ & $\begin{array}{l}0.127^{*} \\
(0.068)\end{array}$ & $\begin{array}{l}0.543^{* * *} \\
(0.019)\end{array}$ & $\begin{array}{c}0.194^{* * *} \\
(0.073)\end{array}$ \\
\hline Period & & & $\begin{array}{l}-0.006 \\
(0.005)\end{array}$ & $\begin{array}{c}-0.060^{* * * *} \\
(0.006)\end{array}$ & $\begin{array}{l}-0.006 \\
(0.005)\end{array}$ & $\begin{array}{c}-0.057^{* * * *} \\
(0.005)\end{array}$ \\
\hline Age & & & & & $\begin{array}{c}0.002 \\
(0.006)\end{array}$ & $\begin{array}{l}-0.020 \\
(0.020)\end{array}$ \\
\hline Age square & & & & & $\begin{array}{l}-0.000 \\
\text { (0.001) }\end{array}$ & $\begin{array}{c}0.000 \\
(0.000)\end{array}$ \\
\hline Male & & & & & $\begin{array}{c}0.047 \\
(0.050)\end{array}$ & $\begin{array}{l}-0.145^{*} \\
(0.088)\end{array}$ \\
\hline Household size & & & & & $\begin{array}{c}0.002 \\
(0.008)\end{array}$ & $\begin{array}{l}0.031^{*} \\
(0.016)\end{array}$ \\
\hline Education & & & & & $\begin{array}{l}-0.021 \\
(0.026)\end{array}$ & $\begin{array}{c}0.070 \\
(0.069)\end{array}$ \\
\hline Own land & & & & & $\begin{array}{l}-0.011 \\
(0.045)\end{array}$ & $\begin{array}{l}-0.009 \\
(0.109)\end{array}$ \\
\hline Livestock & & & & & $\begin{array}{l}-0.003 \\
(0.003)\end{array}$ & $\begin{array}{l}-0.010 \\
(0.012)\end{array}$ \\
\hline Iddir member & & & & & $\begin{array}{c}0.004 \\
(0.027)\end{array}$ & $\begin{array}{l}-0.014 \\
(0.058)\end{array}$ \\
\hline Eqqub member & & & & & $\begin{array}{c}0.000 \\
(0.026)\end{array}$ & $\begin{array}{l}0.076 \\
0.056\end{array}$ \\
\hline PSNP participation & & & & & $\begin{array}{l}-0.011 \\
(0.028)\end{array}$ & $\begin{array}{c}-0.188^{* * *} \\
(0.053)\end{array}$ \\
\hline Religiosity & & & & & $\begin{array}{l}0.088^{* *} \\
(0.042)\end{array}$ & $\begin{array}{c}0.069 \\
(0.082)\end{array}$ \\
\hline Market exposure & & & & & $\begin{array}{l}-0.001 \\
(0.004)\end{array}$ & $\begin{array}{c}0.000 \\
(0.007)\end{array}$ \\
\hline Village distance to market & & & & & $\begin{array}{l}-0.005^{* *} \\
(0.003)\end{array}$ & $\begin{array}{l}-0.001 \\
(0.008)\end{array}$ \\
\hline Village exposure to drought & & & & & $\begin{array}{c}-0.016^{* * * *} \\
(0.003)\end{array}$ & $\begin{array}{c}-0.021^{* * * *} \\
(0.008)\end{array}$ \\
\hline$\sigma$ & $\begin{array}{c}0.430^{* * *} \\
(0.091)\end{array}$ & $\begin{array}{c}0.920^{* * *} \\
(0.133)\end{array}$ & $\begin{array}{c}0.445^{* * *} \\
(0.096)\end{array}$ & $\begin{array}{c}1.244^{* * *} \\
(0.183)\end{array}$ & $\begin{array}{l}0.23^{* * * *} \\
(0.152)\end{array}$ & $\begin{array}{c}1.044^{* * *} \\
()\end{array}$ \\
\hline$\rho$ & $\begin{array}{c}0.160^{* * *} \\
(0.056)\end{array}$ & $\begin{array}{c}0.459^{* * * *} \\
(0.072)\end{array}$ & $\begin{array}{l}0.165^{* * *} \\
(0.059)\end{array}$ & $\begin{array}{c}0.608^{* * *} \\
(0.070)\end{array}$ & $\begin{array}{l}0.521^{* * * *} \\
(0.044)\end{array}$ & $\begin{array}{c}* * * \\
(0.073)\end{array}$ \\
\hline Observations & 960 & 960 & 960 & 960 & $\begin{array}{l}9.044) \\
960\end{array}$ & 960 \\
\hline Number of subjects & 96 & 96 & 96 & 96 & 96 & 96 \\
\hline
\end{tabular}

Notes. The dependent variable in all columns takes a value of 1 if a buyer purchased a fair product, o otherwise. The table reports raw probit coefficients. The omitted category is Market Baseline and Treatment is a binary variable takes a value of $\mathrm{I}$ if a subject comes from either punishment or religion treatment and o otherwise. Period takes an integer values between 1 and 10 . Robust standard errors (clustered by subject) in parentheses, ${ }_{* * *} p<0.01,{ }^{* *} p<0.05{ }^{*} p<0.1$. 
Table A.5: Firth Logit Model - The Effect of Eroding SRB on Anti-social Behavior

\begin{tabular}{lccc}
\hline & $(1)$ & $(2)$ & $(3)$ \\
& Reduce Money & Reduce Money & Reduce Money \\
\hline \multirow{2}{*}{ ESRB } & $0.490^{* * *}$ & $0.463^{* * *}$ & $0.502^{* * *}$ \\
& $(0.053)$ & $(0.054)$ & $(0.053)$ \\
Belief & & $0.169^{* *}$ & $0.173^{* *}$ \\
& & $(0.070)$ & $(0.081)$ \\
Observations & 192 & 192 & 192 \\
Controls & NO & NO & YES \\
\hline
\end{tabular}

Notes. Firth logit average marginal effects are reported. The dependent variable in all specifications is subjects' burning decision ( $1=$ burn, $0=$ not burn). ESRB refers to erosion of socially responsible behavior. Column (3) includes controls for age, age square, gender, education, number of active people, land and livestock ownership, iddir and eqqub membership, PSNP participation, market exposure, village distance to market and exposure to drought, and religiosity. Standard errors in parentheses, ${ }^{* * *} \mathrm{p}<0.01,{ }^{* *} \mathrm{p}<0.05,{ }^{*} \mathrm{p}<0.1$.

Table A.6: Firth Logit Model - Is the Effect of Eroding SRB Pronounced in Market Context?

\begin{tabular}{lccccc}
\hline & $(1)$ & $(2)$ & $(3)$ & $(4)$ & $(5)$ \\
& Reduce & Reduce & Reduce & Reduce & Reduce \\
& Money & Money & Money & Money & Money \\
\hline Treatment & $0.268^{* * *}$ & 0.012 & 0.121 & 0.115 & 0.146 \\
& $(0.057)$ & $(0.060)$ & $(0.192)$ & $(0.187)$ & $(0.165)$ \\
ESRB & & $0.482^{* * *}$ & $0.510^{* * *}$ & $0.477^{* * *}$ & $0.484^{* * *}$ \\
& & 0.064 & $(0.093)$ & $(0.100)$ & $(0.093)$ \\
ESRBXTreatment & & & -0.107 & -0.097 & -0.082 \\
& & & $(0.195)$ & $(0.198)$ & $(0.192)$ \\
Belief & & & $0.176^{* *}$ & $0.186^{* *}$ \\
& & & & $(0.078)$ & $(0.091)$ \\
Observations & 192 & 192 & 192 & 192 & 192 \\
Controls & NO & NO & NO & NO & YES \\
\hline
\end{tabular}

Notes. Firth logit average marginal effects are reported. The dependent variable in all specifications is subjects' burning decision ( $1=$ burn, $o=$ not burn). Treatment is a binary variable takes a value of 1 if a subject comes from Market Baseline and o if a subject comes from Non-Market condition. Column (5) includes controls for age, age square, gender, education, number of active people, land and livestock ownership, iddir and eqqub membership, PSNP participation, market exposure, village distance to market and exposure to drought, and religiosity. Robust standard errors in parentheses, ${ }^{* * *} \mathrm{p}<0.01,{ }^{* *} \mathrm{p}<0.05,{ }^{*}$ $\mathrm{p}<$ 0.1. 
Table A.7: Purchasing Unfair product or selecting unfair distribution burning behavior

\begin{tabular}{lccccc}
\hline & $\begin{array}{c}(1) \\
\text { Reduce } \\
\text { Money }\end{array}$ & $\begin{array}{c}(2) \\
\text { Reduce } \\
\text { Money }\end{array}$ & $\begin{array}{c}(3) \\
\text { Reduce } \\
\text { Money }\end{array}$ & $\begin{array}{c}(4) \\
\text { Reduce } \\
\text { Money }\end{array}$ & $\begin{array}{c}(5) \\
\text { Reduce } \\
\text { Money }\end{array}$ \\
\hline Treatment & $0.125^{*}$ & & -0.032 & 0.001 & -0.070 \\
& $(0.067)$ & & $(0.075)$ & $(0.001)$ & $(0.062)$ \\
ESRB & & $0.273^{* * *}$ & $0.290^{* * *}$ & $0.333^{* *}$ & 0.013 \\
& & $(0.068)$ & $(0.082)$ & $(0.161)$ & $(0.102)$ \\
ESRBXTreatment & & & & -0.076 & 0.234 \\
& & & & $(0.177)$ & $(0.134)$ \\
Belief & & & & & $0.739^{* * *}$ \\
& & & & -0.001 & $-0.146)$ \\
Constant & $0.062^{*}$ & -0.001 & 0.008 & $(0.001)$ & $(0.485)$ \\
& $(0.035)$ & $(0.001)$ & $(0.019)$ & 96 & 96 \\
Observations & 96 & 96 & 96 & 0.173 & 0.623 \\
R-squared & 0.036 & 0.169 & 0.171 & NO & YES \\
Controls & NO & NO & NO & \\
\hline
\end{tabular}

Notes. The dependent variable in all specifications is buyers' and play B's burning decision ( $1=$ burn, $\mathrm{o}=$ not burn). Treatment is a binary variable takes a value of $\mathrm{I}$ if a subject comes from Market Baseline and o if a subject comes from Non-Market condition. Column (3) includes controls for age, age square, gender, education, number of active people, land and livestock ownership, iddir and eqqub membership, PSNP participation, market exposure, village distance to market and exposure to drought, and religiosity. Robust standard errors in parentheses, ${ }^{* * *} p<0.01,{ }^{* *} p<0.05,{ }^{*} p<0.1$.

Table A.8: Do the third parties retaliate?

\begin{tabular}{lccccc}
\hline & $(1)$ & $(2)$ & $(3)$ & $(4)$ & $(5)$ \\
& $\begin{array}{l}\text { Reduce } \\
\text { Money }\end{array}$ & $\begin{array}{c}\text { Reduce } \\
\text { Money }\end{array}$ & $\begin{array}{c}\text { Reduce } \\
\text { Money }\end{array}$ & $\begin{array}{c}\text { Reduce } \\
\text { Money }\end{array}$ & $\begin{array}{c}\text { Reduce } \\
\text { Money }\end{array}$ \\
\hline Treatment & $0.417^{* * *}$ & & 0.064 & $-0.001^{* * *}$ & 0.070 \\
& $(0.087)$ & & $(0.079)$ & $(0.000)$ & $(0.069)$ \\
ESRB & & $0.711^{* * *}$ & $0.678^{* * *}$ & $0.600^{* * *}$ & $0.601^{* * *}$ \\
& & $(0.068)$ & $(0.083)$ & $(0.158)$ & $(0.162)$ \\
ESRBXTreatment & & & & 0.143 & 0.063 \\
& & & & $(0.175)$ & $(0.211)$ \\
Belief & & & & & 0.036 \\
& & & & & $(0.242)$ \\
Constant & $0.125^{* *}$ & -0.001 & -0.016 & 0.001 & 0.262 \\
& $(0.048)$ & $(0.001)$ & $(0.020)$ & $(0.001)$ & $(0.412)$ \\
Observations & 96 & 96 & 96 & 96 & 96 \\
R-squared & 0.195 & 0.567 & 0.570 & 0.574 & 0.621 \\
Controls & NO & NO & NO & NO & YES \\
\hline
\end{tabular}

Notes. The dependent variable in all specifications is third parties' and player C's burning decision ( $1=$ burn, $\mathrm{O}=$ not burn). Treatment is a binary variable takes a value of 1 if a subject comes from Market Baseline and o if a subject comes from Non-Market condition. Column (3) includes controls for age, age square, gender, education, number of active people, land and livestock ownership, iddir and eqqub membership, PSNP participation, market exposure, village distance to market and exposure to drought, and religiosity. Robust standard errors in parentheses, ${ }^{* * *} \mathrm{p}<0.01,{ }^{* *} \mathrm{p}<0.05,{ }^{*} \mathrm{p}<0.1$. 


\section{Good morning!}

Thank you all for taking the time to come today.

Today, you will participate in some activities which may take 4 to 5 hours. If you think that you will not be able to stay that long, please let us know now. In today's session, you will be participating in some activities with real money. That is, the amount of money you earn in these activities will be yours to keep and take home. You will receive 20 Birr for your participation. Besides, you will earn additional money based on your decisions and/or those of the other participants. After all activities are finished, you will receive your earnings in cash including the show-up fee of 20 Birr in private. But you should know that this is not my own personal money. This money comes from the Netherlands Fellowship Program (NFP) to use for research.

All your responses will be kept secret. That is, other participants will neither learn your identity nor your decisions anytime. In addition, no one learns about the amount of money you earn in today's activities. Thus, your identity, decisions and payments will be kept anonymous.

Please note that it is not allowed to communicate with other participants. It is very important that you obey this rule. If you do not obey the rule, you will be excluded from these activities. If you have any question, please raise your hand and we will come to you and answer your question in private. Do not worry if you do not completely understand these activities as we go through some examples here in the group. Moreover, it is important that you listen to the instructions as carefully as possible, because only people who understand the activity will actually be able to participate.

Your participation in these activities is entirely voluntary. If at any time you find that this is something that you do not wish to participate in for any reason, you can withdraw at any time without asking permission regardless of whether we have started the activity or not.

From now onward, you will participate in three activities. You will earn money from participating in these activities. For real payment, one of the three activities will be randomly selected and paid out to you in cash after all activities are finished. Because you do not know which activity will be selected randomly, you must consider your decisions in all activities very carefully. 


\section{Activity 4 [Market Game - Baseline]}

In this activity, there are three types of participants: participants $A, B$, and C. In total, 16 people will participate in this activity: 4 participants $A, 6$ participants $B$, and 6 participants C. Participants A are sellers, participants B are buyers, and participants $C$ are neither sellers nor buyers, but they can incur losses due to the transactions between the participants $A$ and $B$.

Participants will be randomly assigned a role either as participant $\mathrm{A}$, participant $\mathrm{B}$ or participant $C$ at the beginning of the activity. The activity consists of 10 rounds and participants' role will remain unchanged throughout the activity. For real payment, one round will be randomly selected and paid in cash at the end of the session. Because you do not know which round will be selected randomly, you must consider your decisions in all rounds very carefully.

Participants A will decide to produce either a product with no effect on participant C or a product with a loss for participant $C$. The product with no effect on participant $C$ costs 20 Birr to produce for participant A but the product with a loss for participant $\mathrm{C}$ costs o Birr to produce.

Irrespective of the type of the product, the value of the product is always 40 Birr for participant B.

In this activity, first, participants A will decide which product to produce and determine its corresponding price. The price of either product should be always between (including) $\mathrm{o}$ and 40 Birr. Participants A will be given 3 minutes to decide which type of product to produce and determine its corresponding price. Each participant A can sell his/her product to a maximum of 3 participants $B$. This means there is a possibility that 6 participants B can purchase from only 2 participants A.

Next, each participant B will decide whether he/she would accept the offer made by participants A. Maximum of 3 participants B can purchase from a single participant A. In case more than 3 buyers accept the offer from a single participant A, the 3 participants $B$ who accepted the offer quickly will purchase the product and the remaining participants $B$ will be given a chance to buy from the other participants $A$.

The participants $C$ will neither sell nor buy a product throughout the activity. At the beginning of the activity, each of the 6 participants $B$ will be randomly matched to each of the 6 participants $C$. If participant $B$ purchases the product with a loss for a participant $C$, the randomly matched participant $C$ will incur a loss of 50 Birr. On the other hand, if participant $B$ either purchases a product with no effect on participant $C$ 
or does not purchase a product at all, the randomly matched participant $C$ will incur no loss.

\section{Payment}

At the beginning of each round, each participant will be given an initial endowment of 60 Birr. The payment of each participant A (seller), participant B (buyer), and participant $\mathrm{C}$ in each round will be determined as follows:

\section{Participant A's payment}

- If participant B accepts participant A's offer Payment $=60$ Birr + quantity(price of the product - costs of production)

- while the production costs for a "product without effect on participant C" amount to 20 Birr, the production costs for a "product with a loss for participant $\mathrm{C}$ amount to o Birr.

- If no participant B accepts participant A's offer Payment $=\mathbf{6 0}$ Birr.

\section{Participant B's payment}

- If participant B accepts participant A's offer Payment $=60$ Birr +40 Birr - price of the product

- If participant B does not accept participant A's offer Payment $=60$ Birr.

\section{Participant C's payment}

- If the randomly matched participant B purchases a product with a loss for participant $C$,

Payment $=60$ Birr -50 Birr $=10$ Birr

- If the randomly matched participant B either purchases a product with no effect on participant $C$ or does not purchase a product,

Payment $=60$ Birr

\section{The procedure Step 1: Participant A's activities}

- Participants A will simultaneously decide which of the two products to produce

- A product with a loss for participant C

- A product with no effect on participant C 
- Participants A will then determine the price of the product they decided to produce.

The price of the product

- ((The price of both products, a product with a loss for participant $C$ and a product without effect on participant $C$, should be between (including) o to 40 Birr.))

Step 2: Participant B's activities Once all participants A have made their decisions,

- All participants B will see the type of products produced by participants A and the corresponding prices.

- Participants B will then simultaneously decide whether to select one of the offers made by the participants $A$ or decide not to purchase.

Once all participants B made their decisions, each participant B will learn his/her own payment, the payment of the randomly matched participant $\mathrm{C}$ and the payment of participant A from whom he/she purchased the product.

Each participant A will also learn his/her own payment, once all participants B made their decisions.

Participants $\mathrm{C}$, who have no any active role in the activity, will learn their payment after the participants $\mathrm{A}$ and participants $\mathrm{B}$ made their decisions.

After all participants learn their payments in a given round, the next round will begin.

Do you have any question? If yes, please raise your hand. We will come to you and answer your question in private. Otherwise, we ask you to answer the following control questions.

\section{Control Questions}

- Suppose that participant A offers a product with a loss on participant $C$ at the price of 20 Birr and participant B accepts the offer.

How much are the payments for: Participant A: Participant B: Participant C:

- Suppose that participant A offers a product with no effect on participant $C$ at the price of 20 Birr and participant B accepts the offer.

How much are the payments for: Participant A: Participant B: Participant C: 
- Suppose that participant A offers a product with no effect on participant $C$ at the price of 40 Birr and no participant B accepts the offer.

How much are the payments for: Participant A: __ Participant B: _ Participant C:

- Suppose that participant A offers a product with a loss on participant $C$ at the price of 40 Birr and no participant $B$ accepts the offer.

How much are the payments for: Participant A:

Participant B: Participant C:

- Suppose that participant $A$ offers a product with a loss on participant $C$ at the price of 30 Birr and participant B accepts the offer.

How much are the payments for: Participant A: Participant B: Participant C:

- Suppose that participant A offers a product with no effect on participant $\mathrm{C}$ at the price of 30 Birr and participant B accepts the offer.

How much are the payments for: Participant A: __ Participant B: __ Participant C: 


\section{Activity 4 [Market Game - Punishment]}

In this activity, there are four types of participants: participants $A, B, C$ and $D$. In total, 18 people will participate in this activity; 4 participants $A, 6$ participants $B, 6$ participants $C$ and 2 participants D. Participants A are sellers, participants B are buyers, participants $C$ are neither sellers nor buyers, but they can incur losses due to the transactions between the participants A and B and participants D are observers.

Participants will be randomly assigned a role either as participant A, participant B, participant $\mathrm{C}$ or participant $\mathrm{D}$ at the beginning of the activity. The activity consists of 20 rounds and participants' role will remain unchanged throughout the activity. For real payment, one round will be randomly selected and paid in cash at the end of the session. Because you do not know which round will be selected randomly, you must consider your decisions in all rounds very carefully.

Participants A will decide to produce either a product with no effect on participant C or a product with a loss for participant $C$. The product with no effect on participant $C$ costs 20 Birr to produce for participant A but the product with a loss for participant $\mathrm{C}$ costs o Birr to produce.

Irrespective of the type of the product, the value of the product is always 40 Birr for participant B.

In this activity, first, participants A will decide which product to produce and determine its corresponding price. The price of either product should be always between (including) o and 40 Birr. Participants A will be given 3 minutes to decide which type of product to produce and determine its corresponding price. Each participant A can sell his/her product to a maximum of 3 participants $B$. This means there is a possibility that 6 participants $B$ can purchase from only 2 participants $A$.

Next, each participant B will decide whether he/she would accept the offer made by participants A. Maximum of 3 participants B can purchase from a single participant A. In case more than 3 buyers accept the offer from a single participant A, the 3 participants $B$ who accepted the offer quickly will purchase the product and the remaining participants B will be given a chance to buy from the other participants A.

Participants $C$ will neither sell nor buy a product throughout the activity. At the beginning of the activity, each of the 6 participants $B$ will be randomly matched to each of the 6 participants C. If participant B purchases the product with a loss for a participant $C$, the randomly matched participant $C$ will incur a loss of 50 Birr. On the other hand, if participant $B$ either purchases a product with no effect on participant $C$ or 
does not purchase a product at all, the randomly matched participant $C$ will incur no loss.

At the beginning of the activity, 5 participants (2 participants $A$ and 3 participants $B$ ) will be assigned to each of the 2 participants D. This assignment will be made randomly and will remain unchanged throughout the activity.

Once all participants A and participants B made their decisions, each participant D will learn the decisions made by the randomly assigned 3 participants B and 2 participants A. Each participant D will be given an initial endowment of 6o Birr at the beginning of each round. From this endowment, participant D can assign any amount of Birr for the participants who are assigned to him/her but the maximum amount he/she can assign per participant is 20 Birr. Each Birr assigned by participant D has the following consequences for himself/herself and the participants who are assigned to him/her.

Each Birr assigned by participant D reduces his/her endowment by 1 Birr. But, each Birr assigned by participant $D$ reduces the endowment of the participants assigned to him/her by 5 Birr. For example, if participant D assigns 3 Birr to the first participant A, 5 Birr to the second participant A, o Birr to the first participant B, 4 Birr to the second participant $B$ and 10 Birr to the third participant $B$, participant D's endowment will be reduced by $22 \operatorname{Birr}(3+5+0+4+10)$ and his/her payment will be 38 Birr (60-22).

Endowment of the participants who are assigned to the participant D will be determined as follows.

- Earnings of the first participant A will be deducted by $15 \operatorname{Birr}\left(3^{*} 5\right)$

- Earnings of the second participant A will be deducted by 25 Birr $\left(5^{*} 5\right)$

- Earnings of the first participant B will be deducted by o Birr $\left(\mathrm{O}^{*} 5\right)$

- Earnings of the second participant B will be deducted by 20 Birr $\left(4^{*} 5\right)$

- Earnings of the third participant B will be deducted by 50 Birr $\left(10^{*} 5\right)$

If the earnings of participants $A$ and $B$ are negative, the respective loss will not be deducted from their initial endowment of 20 Birr.

At the end of each round, each participant will be informed about the decisions made by participant $D$ assigned to him/her and thereby each participant $A$, participant $B$, participant $\mathrm{C}$, and participant $\mathrm{D}$ will be informed about their respective earnings. 


\section{Payment}

At the beginning of each round, each participant will be given an initial endowment of 60 Birr. The payments for each participant will be determined as follows:

\section{Participant A'S payment}

- If participant B accepts participant A's offer

Payment $=60$ Birr - costs of production $-5^{*}$ number of Birrs assigned by participant $D+$ price of the product

- while the production costs for a "product without effect on participant C" amount to 20 Birr, the production costs for a "product with a loss for participant $\mathrm{C}$ amount to o Birr.

- If no participant B accepts participant A's offer

Payment $=60$ Birr $-5^{*}$ number of Birrs assigned by participant D

\section{Participant B's payment}

- If participant B accepts participant A's offer Payment $=60$ Birr +40 Birr - price of the product $-5^{*}$ number of Birrs assigned by participant $D$

- If participant B does not accept participant A's offer Payment $=60$ Birr $-5^{*}$ number of Birrs assigned by participant $D$

\section{Participant C's payment}

- If the randomly matched participant B purchases a product with a loss for participant C, Payment $=60$ Birr -50 Birr $=10$ Birr

- If the randomly matched participant B either purchases a product with no effect on participant $\mathrm{C}$ or does not purchase a product, Payment $=60$ Birr

\section{Participant D's payment}

Payment $=60$ Birr - number of Birrs assigned to participants A and B

The procedure

Step 1: Participant A's activities

- Participants A will simultaneously decide which of the two products to produce - A product with a loss for participant C 
- A product with no effect on participant C

- Participants A will then determine the price of the product they decided to produce

The price of the product

- ((The price of both products, a product with a loss for participant $C$ and a product without effect on participant $C$, should be between (including) o to 40 Birr.))

\section{Step 2: Participant B's activities}

Once all participants A have made their decisions,

- All participants B will see the type of products produced by participants A and the corresponding prices.

- Participants B will then simultaneously decide whether to select one of the offers made by the participants $A$ or decide not to purchase.

\section{Step 3: Participant D's activities}

Once all participants B have made their decisions,

- Participants D will see the decision made by both participants A and B assigned to him/her

- Participants D will then decide whether to assign and reduce the earnings of participants $\mathrm{A}$ and $\mathrm{B}$

- Participants D can assign Birr to either none, some or all the participants assigned to him/her

- Each Birr assigned reduces participant D's earning by 1 Birr

- Each Birr assigned to participants A and B by participant D reduce participant A's and B's payment by 5 Birr

Once all participants $\mathrm{D}$ made their decisions, each participants A, participants B, participants $C$ and participants $D$ will be informed about their respective earnings.

After all participants learn their payments in a given round, the next round will begin.

Do you have any question? If yes, please raise your hand. We will come to you and answer your question in private. Otherwise, we ask you to answer the following control questions. 


\section{Control Questions}

1. Suppose that participant $A$ offers a product with a loss on participant $C$ at the price of 20 Birr and participant B accepts the offer but participant D assigns 5 Birr to both participant A and B.

How much are the payments for: Participant A: __ Participant B: _ Participant $\mathrm{C}$ :__ participant D:

2. Suppose that participant $A$ offers a product with no effect on participant $C$ at the price of 20 Birr and participant $B$ accepts the offer and participant $D$ assigns o Birr to both participant A and B. How much are the payments for: Participant A: __ Participant B: Participant C: participant D:

3. Suppose that participant $A$ offers a product with no effect on participant $C$ at the price of 40 Birr and no participant $B$ accepts the offer and participant D assigns 5 Birr to participant B and 1o Birr to participant A.

How much are the payments for: Participant A: __ Participant B: __ Participant C: _ p participant D:

4. Suppose that participant $A$ offers a product with a loss on participant $C$ at the price of 40 Birr and no participant $B$ accepts the offer and participant D assigns 5 Birr to participant B and 20 Birr to participant A.

How much are the payments for: Participant A: __ Participant B: _ Participant C:__ participant D:

5. Suppose that participant $A$ offers a product with a loss on participant $C$ at the price of 30 Birr and participant B accepts the offer and participant D assigns 10 Birr to participant B and 15 Birr to participant A.

How much are the payments for: Participant A: __ Participant B: _ Participant $\mathrm{C}$ :__ participant D:

6. Suppose that participant A offers a product with no effect on participant $C$ at the price of 30 Birr and participant $B$ accepts the offer and participant D assigns o Birr to both participant A and B. How much are the payments for: Participant A: __ Participant B Participant C: participant D: 


\section{Activity 4 [No Market Condition]}

In this activity, there are three types of participants: participants $A, B$, and $C$. The participants are divided into groups of 3 people. There is one participant $A$, one participant $B$, and one participant $C$ in each group.

Participants will be randomly assigned as participant A, participant B or participant $C$ at the beginning of the activity. The activity consists of 10 rounds and participants' role will remain unchanged throughout the activity. For real payment, one round will be randomly selected and paid out in cash at the end of the session. Because you do not know which round will be selected randomly, you must consider your decisions in all rounds very carefully.

In each round, participants $A, B$, and $C$ first receive an endowment of 60 Birr.

The Participant $B$ in a group can select a different distribution of Birrs. In case of a new distribution, the sum of the payments that participants $A$ and $B$ receive is 20 or 40 Birr on the top of the initial endowment of 6o Birr each.

There are two types of distributions: a distribution with no effect on participant $C$ and a distribution with a loss for participant $C$.

If a participant $B$ selects a distribution with a loss for participant $C$, the assigned participant $C$ incurs a loss of 50 Birr. If a participant $B$ selects a distribution with no effect on participant $C$ or does not opt for a new distribution, the assigned participant $\mathrm{C}$ will not incur any loss.

In case of a distribution with a loss for participant $C$, the sum of the payments for participant A and participant B is 40 Birr higher than if no new distribution is chosen, for example 8o Birr for participant A and 8o Birr for participant B (and $60-50=10$ Birr for participant C).

In case of a distribution without effect on participant $C$, the sum of the payments for participant $A$ and participant $B$ is 20 Birr higher than if no new distribution is chosen, for example 75 Birr for participant A and 65 Birr for participant B (and 6o Birr for participant C).

If a participant $B$ does not opt for a new distribution, the payments for participants $A$, $\mathrm{B}$, and $\mathrm{C}$ is 60 Birr. 


\section{Payment}

At the beginning of each round, each participant will be given an initial endowment of 60 Birr. The payment of each participant $A$, participant $B$, and participant $C$ in each round will be determined as follows:

\section{Participant A's payment}

- If the randomly assigned participant B selects a new distribution Payment $=$ Payment in the new distribution

- If participant B does not select a new distribution Payment $=60$ Birr

\section{Participant B's payment}

- If participant B selects a new distribution Payment $=$ Payment in the new distribution

- If participant B does not select a new distribution Payment $=60$ Birr

\section{Participant C's payment}

- If the randomly matched participant B chooses a distribution with loss for participant $\mathrm{C}$, Payment $=60$ Birr -50 Birr $=10$ Birr

- If the randomly matched participant B chooses a distribution with no effect on participant $\mathrm{C}$ or does not select a new distribution, Payment $=60$ Birr

\section{The procedure}

In each round, participants B can select from four possible new distributions. Maximum of 3 participants $B$ can select a new distribution. In case of more than 3 participants (B) selecting the same new distribution, the 3 participants B who selected the new distribution quickly will be assigned to those distributions and the remaining participant (s) B will be given a chance to select from the remaining new distributions.

Once all participants $B$ made their decisions, the assigned participants $A$ and $C$ will be informed of the decision and each participant $A, B$, and $C$ will learn their payments.

Participants $\mathbf{A}$ and $\mathrm{C}$ cannot make any decisions during this activity. We ask the participants $\mathrm{A}$ and $\mathrm{C}$, however, to indicate their expectations about the participant B's behavior in each period. 
After all participants learn their payments in a given round, the next round will begin.

Do you have any question? If yes, please raise your hand. We will come to you and answer your question in private. Otherwise, we ask you to answer the following control questions.

\section{Control Questions}

1. Suppose that participant B chooses a new distribution without effect on participant $C$

How much are the payments for: Participant A: __ Participant B: _ Participant C:

2. Suppose that participant $B$ chooses a new distribution with a loss on participant $\mathrm{C}$ How much are the payments for: Participant A: Participant B: Participant C:

3. Suppose that participant B chooses no new distribution How much are the payments for: Participant A: Participant B: Participant C: 


\section{Activity 5 [Joy of Destruction Game]}

In this activity, you are matched with the participant who was randomly matched with you in the fourth activity. Yet, none of you will learn each other's identity. But, you will learn your partner's role, decision and earning in the fourth activity and vice versa your partner will learn about your role, decision and earning in the fourth activity.

In this activity, you will earn money and the amount of money you will earn depends on your decision and the decision of your partner who you are matched with. This activity consists of only one round. This means, both of you will play this activity only once.

At the beginning of the activity, you and your partner both receive an endowment of 40 Birr. You then have to decide whether to reduce your partner's income or to leave it as it is. Reducing your partner's income by 3 Birr will cost you 1 Birr. This means, by paying 1 Birr, you can reduce your partner's income by 3 Birr. Your partner simultaneously takes the same decision. He/she can also choose between leaving your income as it is or reducing it by any amount he/she wants to reduce. Your partner will incur the same cost of 1 Birr if he/she decides to reduce your income by 3 Birr.

To better understand the activity, let us do the following examples.

1. If both of you choose to reduce the other person's income by 30 Birr, both of you will earn o Birr (40-30-10).

2. If you choose not to reduce your partner's income, but your partner chooses to reduce your income by 15 Birr, you will earn 25 Birr (40-15-0) and your partner will earn 35 Birr (40-0-5).

3. If both of you choose to leave the other person's income as it is, both of you will earn 40 Birr (40-0).

4. If you decide to reduce your partner's income by 30 Birr, but your partner decides not to reduce your income, you will earn 30 Birr (40-0-10) and your partner will earn 1o Birr (40-30-0).

Do you have any questions? Now you may start

Please keep in mind that the decisions are private and that your decision will not be disclosed to anybody else. 


\section{W. Maastricht University in Leaming!}

Faculty of Science and Engineering

Faculty Board

Postbus 616

6200 MD Maastricht

Ethical Review Committee Inner City Faculties

Ourreference
ERCIC_085_10_05_2018

Maastricht

10 July 2018

Dear Board,

After examination of the research study protocol entitled 'Markets and preferences', submitted by Pierre Mohnen, the Ethical Review Committee Inner City faculties (ERCIC) came to the conclusion that there are no objections to the execution of the research project.

Any changes in the research design require a renewed review by ERCIC.

Yours sincerely,

Prof. Wiebe Bijker

Chair

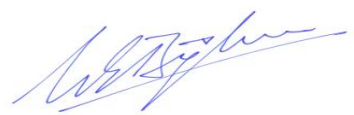

Dr. Natasja Reslow

Secretary

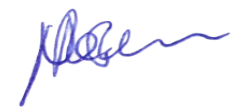

CC Pierre Mohnen; Halefom Nigus; Eleonora Nillesen

\section{ERCIC}

Chair: W. Bijker

Secretary: N. Reslow

Tel: 0433884834

Email: ercic@maastrichtuniversity.n!

URL: https://www.maastrichtuniversity.nl/ercic 



\section{3}

THE EFFECT OF WEATHER INDEX INSURANCE ON SOCIAL CAPITAL: EVIDENCE FROM RURAL ETHIOPIA

\section{ABSTRACT}

This study examines the impact of Weather Index Insurance (WII) on social capital. We measure social capital using a lab-in-the-field experiment and relate it to the actual purchase of WII. To account for the non-random uptake of WII, we use an instrumental variable approach. We find that WII crowds out social capital - insured households contribute significantly less to the public good than uninsured households. Our findings from the experiment are corroborated using real-life measures of social capital, including informal transfers to fellow villagers and financial contributions to community projects. We find support for two channels underlying these results: (i) WII creates positive externalities on uninsured households, which induces them to freeride. Anticipating this, insured households respond by lowering their investment in social capital. And (ii), WII increases perceptions of self-sufficiency that is, insured households need to rely less on others in times of need.

JEL Classification: $\mathrm{C}_{93}, \mathrm{G}_{22}, \mathrm{H}_{41}, \mathrm{O}_{17}$

Keywords: Weather index insurance; free-riding; self-sufficiency; social capital; Ethiopia

The chapter is based on:

Nigus, H. Y., Nillesen, E. and Mohnen, P. (2018). The effect of weather index insurance on social capital: Evidence from rural Ethiopia. Journal of Risk and Insurance revise and resubmit. An earlier version of the chapter has been published as UNU-MERIT working paper \# 2018-007. 


\subsection{INTRODUCTION}

Weather risks are ubiquitous in developing countries and a constant welfare threat to especially poor farmers. Weather risks have long remained uninsured because most households lacked access to traditional crop insurance due to concerns of adverse selection, moral hazard as well as high transaction costs. In the absence of formal insurance markets, households rely on alternative informal insurance mechanisms to overcome a wide variety of risks. However, informal insurance mechanisms are best suited to overcome idiosyncratic rather than covariate risks, such as drought occurring at the village level or beyond (Townsend, 1994; Morduch, 1999). The relatively recent introduction of index insurance in developing countries aims to fill this gap. Index insurance is a promising innovation and relies on the premise that it deals with classical asymmetric information problems as payouts are made based on a meteorological index, which is on the one hand exogenously determined for the insured, and on the other hand directly observed by the insurer (Leblois \& Quirion, 2013). Index insurance indemnifies covariate risks such as drought which are hardly covered by any pre-existing informal risk management strategies.

A growing literature focuses on uncovering the drivers of demand for index insurance and, once adopted, its impact on agricultural investment and welfare. Previous studies show that despite heavy promotion, demand for index insurance is still very low. For example, the take-up rate is about 5 to $10 \%$ in India (Cole et al., 2013), $2 \%$ to 8\% was reported in Ethiopia (Belissa et al., 2019; Dercon et al., 2014) ${ }^{1}$ and $17-33 \%$ in Malawi (Giné \& Yang, 2009). Previous studies point out that both price and non-price factors are responsible for the low take-up of index insurance. Index insurance takeup decreases with price (Mobarak \& Rosenzweig, 2012; Karlan et al., 2014; Collier, 2018), risk aversion (Hill et al., 2013), liquidity constraints (Belissa et al., 2019; Giné et al., 2008), basis risk ${ }^{2}$ (Giné et al., 2008; Karlan et al., 2014; Clarke, 2016; Collier, 2018), lack of trust on the insurer (Belissa et al., 2019; Cole et al., 2013; Karlan et al., 2014), households poor financial literacy (Awel \& Azomahou, 2015) and enrollment in government social protection programs (Duru, 2016). On the other hand, demand for index insurance increases with subsidy, high fertilizer use (McIntosh et al., 2013) and wealth (Giné et al., 2008; Hill et al., 2013). Moreover, whilst some studies find that selling index insurance to informal insurance groups increases its uptake (Belissa et al., 2019; Mobarak \& Rosenzweig, 2012; Dercon et al., 2014), some other studies show

1 A relatively high take-up rate of about $27 \%$ is reported when WII is sold to iddirs (funeral insurance groups), whose leaders received training to emphasize on the benefit of sharing idiosyncratic basis risk among iddir members (Dercon et al., 2014). Likewise, when WII is promoted via iddirs and farmers are given the option to pay the WII premium after harvest time results in a greater uptake of $43 \%$ (Belissa et al., 2019).

2 Basis risk is the mismatch between the actual losses incurred by the insurance purchasers and insurance payouts paid by the insurers. The main drawback of weather index insurance is that it does not cover idiosyncratic risks including basis risk. 
that pre-existing informal insurance mechanisms dampen the demand for index insurance (De Janvry et al., 2014; Munro, 2015). In spite of low average take-up, there is some evidence of its impact on agricultural investment and welfare. For example, Karlan et al. (2014), de Nicola (2015), and Cole et al. (2017) show that index insurance induces farmers to adopt riskier but more profitable technologies, and thus, enhance agricultural investments. Moreover, index insurance also has profound impacts on ex-post risk coping strategies such as consumption smoothing and livestock protection (Janzen \& Carter, 2018; de Nicola, 2015; Bertram-Huemmer \& Kraehnert, 2017). More recently, a growing literature also documented that index insurance enhance subjective well-being (Tafere et al., 2018).

A widely underexplored research question is whether index insurance crowds in or crowds out pre-existing informal insurance mechanisms and related social capital. The present study aims to fill this void and investigates the effect of weather index insurance (WII) on social capital uncovering the underlying mechanisms at work. Since an important feature of social capital lies in the ability of social groups to overcome free-riding problems in the provision of public goods (Coleman, 1988), the present study utilizes the behaviour in the public good game as a measure of social capital. The use of a public good game to measure social capital is not new. A growing body of empirical literature uses public good experiment to measure social capital in an incentive-compatible way (e.g., (Carpenter et al., 2004; Karlan, 2005; Gilligan et al., 2015; Attanasio et al., 2015; Cecchi et al., 2016)). We also used survey measures of social capital such as households' participation in community projects, making transfers to fellow villagers, and membership in informal institutions such as iddir and eqqub.

The focus of this study is to uncover the impact of a large and unsubsidized WII scheme several years after its introduction (see section 3.3.1 for more information about the WII scheme). The peculiar feature of this study is that it focuses on the largest WII scheme in Africa with a relatively high adoption rate of up to $32 \%$. We use an instrumental variable approach to address the non-random allocation of WII uptake. We utilize the low mobility of farmers in rural Ethiopia to instrument WII purchase with the distance of the household's residence to the residence of an insurance foreman, the person who is in charge of advertising and selling the insurance product. Our empirical results show that the introduction of WII crowds out social capital. This effect is due to a lower contribution of insured households in the public good experiment, lower informal transfers to fellow villagers and financial contribution to community projects. We also find that concerns about free-riding and the development of self-sufficiency behaviour are two channels through which the observed crowding out occurs.

Our findings echo previous studies which documented the crowding out effect of indemnity insurances such as welfare programs (Attanasio \& Rios-Rull, 200o), public transfers (Dercon \& Krishnan, 2003), health insurance (Strupat \& Klohn, 2018; Cec- 
chi et al., 2016) and context-free (experimental) insurance (Lin et al., 2014; Landmann et al., 2012) on various aspects of social capital. Attanasio \& Rios-Rull (2000) find that the welfare program in Mexico crowds out private transfers. Likewise, in rural areas of Ethiopia, Dercon \& Krishnan (2003) show that public transfers in the form of food aid crowd out informal risk sharing mechanisms. Experimental evidence from the laboratory (Lin et al., 2014) and the field (Landmann et al., 2012) confirm these findings in the sense that the introduction of formal insurance crowds out informal risk sharing strategies. Interestingly, Landmann et al. (2012) further assert that the effect of insurance persists even after the insurance mechanism is removed. More recently, a growing literature shows that the introduction of health insurance crowds out social capital. For example, Strupat \& Klohn (2018) demonstrated that the introduction of health insurance in Ghana crowds out informal transfers among informal insurance groups - insured households decrease the probability and the amount of made and received informal transfers. In rural Uganda, Cecchi et al. (2016) also documented that formal health insurance crowds out social capital. Cecchi et al. (2016) used the contribution to a common pot in a public good game as a measure of social capital.

We contribute to this empirical literature in at least three ways. First, the extant studies focus on the effect of indemnity insurances, which only cover idiosyncratic risks, on social capital. We complement these studies by documenting the effect of weather index insurance (WII), which indemnifies covariate risks, such as drought, on social capital. Theoretically, the relationship between indemnity insurance and social capital is somehow straightforward. As both insurance mechanisms cover idiosyncratic risks, they might substitute for each other. However, the theoretical relationship between WII and social capital is ambiguous (see section 3.2 for more information). Thus, this study investigates whether WII and social capital complement or substitute for each other. Second, most existing studies focus on the effect of indemnity insurance on only one component of social capital. Unlike most existing studies, this study focuses on both cognitive and structural dimensions of social capital (see Van Rijn et al. (2012) for detail information on the different dimensions of social capital). Moreover, while previous studies measure social capital either using experimental games or self-reported surveys, we use both experimental and survey measures of social capital. Third, this study evaluates a large and unsubsidized formal insurance scheme with a relatively higher adoption rate of up to $32 \%$ some six to eight years after its introduction.

The rest of this paper is organized as follows. The next section provides the conceptual framework that demonstrates the theoretical link between weather index insurance and social capital. Section 3.3 briefly discusses the evolution of weather index insurance in Ethiopia, the data type, measurement of social capital, and descriptive statistics. Section 3.4 presents the estimation strategy. In section 3.5, we present our key findings and a number of robustness checks. The last section concludes. 


\subsection{CONCEPTUAL FRAMEWORK}

How may WII affect social capital? The theoretical relationship between WII and social capital is ambiguous. Theoretically, WII could affect social capital in either direction. On the one hand, first, as WII and social capital insure two different types of risks, the introduction of WII may crowd in social capital. WII covers covariate risks, whereas social capital covers idiosyncratic risks including basis risk (basis risk is the mismatch between the actual losses incurred by the insurance purchasers and insurance payouts paid by the insurer). Thus, as people buying WII may be those that can also safeguard themselves against the idiosyncratic basis risk, the introduction of WII may crowd in social capital. Dercon et al. (2014) and Berg et al. (2017) show that the presence of an idiosyncratic basis risk in index insurance makes the two insurance mechanisms complement for each other. However, they look at the opposite perspective, that is, whether informal insurance arrangements increase index insurance uptake. The interest in this study, however, is to directly explore the effect of index insurance uptake on social capital. Second, from the perspective of our study, WII may crowd in social capital as focus group discussions and trainings provided by the insurance companies and other partners may enhance social capital in villages with access to WII. The trainings provided by the insurance companies focused on the concept of WII, how the insurance payouts are determined, the amount of premium and its corresponding liability. Moreover, the trainings also emphasized on disaster risk reduction activities such as soil fertility management strategies (Oxfam America, 2013). Hence, participating in meetings organized by the insurance companies may result in frequent interactions among fellow villagers, which in turn may lead to higher social capital. This hypothesis is consistent with the economic theory and empirical evidence that repeated interactions lead to higher trust and social capital (e.g., Engle-Warnick \& Slonim (2004, 2006); Fudenberg \& Maskin (2009); Cochard et al. (2004); Mehrotra et al. (2019)). Third, WII may crowd in social capital as insured households may share very important information in risk reduction activities and other information disseminated by the insurance companies to uninsured households. This can be explained by the theory of reciprocity in the sense that people reward positive actions and punish negative ones (e.g., Falk \& Fischbacher (2006); Fehr \& Gächter (2000); Rabin (1993)). If insured households share relevant information to uninsured ones, the latter may respond by rewarding such action, for example, by strengthening their network with the former and provide help in times of need.

On the other hand, WII may crowd out social capital in at least three ways. First, WII purchase may encourage insured households to adopt or experiment very risky technologies and thereby impose external costs (a moral hazard problem) on informal insurance groups, specifically, on the uninsured households. Consequently, to get rid of these external costs, uninsured households may reduce their investment 
in social capital (Boucher \& Delpierre, 2014). Second, in societies where there exist strong norms of redistribution, insurance payouts in the aftermath of common shocks may be expected to be shared, which implies WII purchase by an individual creates a positive externality on others (uninsured ones) and in turn induces free-riding behavior (De Janvry et al., 2014). Insured households would be aware of this free-riding problem before they decide to purchase WII. Therefore, to protect themselves from free-riders (uninsured households), insured households may decide to invest less in social capital. This argument may be corroborated by the growing literature on the adverse effects of social norms of redistribution. In developing countries, particularly in Sub-Saharan Africa, norms of redistribution of income are common (Collier \& Garg, 1999). Accordingly, more recently, the adverse effects of coercive norms of redistribution have garnered the attention of several researchers. It is documented that people adopt costly strategies to hide their income to escape the pressure of the redistributive norms (Jakiela \& Ozier, 2015; Boltz et al., 2019; Beekman et al., 2015; Di Falco et al., 2018; Baland et al., 2011; Grimm et al., 2017; Di Falco \& Bulte, 2011). In a similar vein, insured households may decide to invest less in social capital to escape the pressure of redistributing insurance payouts in the aftermaths of weather shocks.

Third, as WII covers covariate risks such as drought in which the adverse effects span over several years, insured households may perceive less of a need to depend on others and develop some form of individualistic or self-sufficient behavior. As a consequence, insured households may decide to invest less in social capital. In support of this hypothesis, growing studies in the economics and psychology literature have documented that market-based mechanisms induce people to be less helpful, individualistic, and materialistic. People exposed to such mechanisms also exhibit less fear of social exclusion, prefer solitary activities, and reduce interaction with others (Vohs et al., 2006; Di Tella et al., 2007; Bowles, 2008; Zhou et al., 2009; Vohs et al., 2008). As a result, we expect that WII - a market-based product - may lead to higher individualistic or self-sufficient behaviour and crowd out social capital.

\subsection{CONTEXT, DATA AND EXPERIMENTAL DESIGN}

In this section, we discuss the evolution of weather index insurance, the data type and source, and the sampling strategy. We also present the experimental design and procedure, descriptive statistics and balance test results across the treatment and control groups.

\subsubsection{The Weather Index Insurance Scheme}

As in many agrarian economies, Ethiopian farmers are constantly threatened by weatherrelated shocks. The absence of formal insurance markets exacerbates the adverse ef- 
fects implied by these shocks. Until recently, there was no formal insurance product specifically designed to address such shocks. Only since 2006 there has been a wide experimentation of formal insurance with the World Bank implementing a pilot project with 28 farmers on WII in Alaba district, southern Ethiopia. The results from the pilot project revealed key issues that required considerable attention to scale up and sustain the project in the country. For more detail information on the evolution of microinsurance in Ethiopia, see Amha et al. (2013).

In this study, we focus on the WII scheme initially known as Horn of Africa Risk Transfer for Adaptation (HARITA), which was initiated by Relief Society of Tigray (REST) in collaboration with Oxfam America, International Research Institute (IRI), Nyala Insurance Share Company (NISCO), Dedebit Credit and Saving Institution (DECSI) and Swiss Re in Adiha tabia ${ }^{3}$, Kolla Temben district, Tigray region in 2009. The WII offers a payout when the rainfall amount is below a pre-determined threshold level, for example, if the total amount of rainfall at key growth stages of the crops falls below 80 - $100 \mathrm{~mm}$ depending on the crop type. Unlike the traditional indemnity crop insurance, insurance payout in WII does not require plot level inspection and is based on the amount of rainfall measured by rain gauges in the villages or satellites. As a consequence, the insurance payout in WII is entirely exogenous to the policyholder. Given the encouraging results from the pilot tabia, the HARITA project was expanded to four additional tabias (Geneti, Hade Alga, Awet Bikalsi and Hadush Adi) in 2010.

In 2011, the World Food Programme (WFP) and Oxfam America (OA) sustained and scaled up the WII scheme building on the initial success of the HARITA project. The scaling up process has taken place between 2011 and 2013. By 2013, the WII scheme scaled up to 11 districts and more than 80 tabias insuring about 20,000 households (Oxfam America, 2013). Since 2014, the focus was mainly on increasing the number of beneficiaries within treated villages rather than treating new villages, specifically in Tigray region. Consequently, in 2017, the total number of insured households increased to about 27,136 farmers, of which about 23,567 farmers in the region of Tigray and 2,322 farmers in the region of Amhara (Oxfam America, 2017). The insurance product insures different types of crops (Wheat, Maize, Teff, and Sorghum) grown in the regions. Interestingly, the WII market in the Tigray region has a unique feature in that farmers have an option to pay the insurance premium either in cash or in labor by working an additional number of days in the Ethiopian Productive Safety Net Program (PSNP). The insurance companies introduced the insurance-for-work model (IFW) to enable poor and cash-constrained farm households participating in the PSNP to pay the WII premium in labour. However, non-PSNP farmers, relatively

3 Tabia is the lowest administrative unit in the Ethiopian government's administrative structure comprising about four kushets (sub-village). In this article, village is synonymous with tabia in Tigray region, Ethiopia. The administrative structure of the country in ascending order goes as follows: Tabia, Woreda, Zone, Region and Federal 
richer and less liquidity constrained, pay the insurance premium fully in cash. Farmhouseholds can choose between two insurance premiums, (i) the basic (minimum) premium where farmers pay an insurance premium of about 160 Ethiopian Birr with a corresponding liability of about 800 Birr (\$36), (ii) the maximum of about 500 Birr premium with a corresponding liability of 3000 Birr (\$136). Farmers, on average, pay a premium of about $20 \%$ of the insurance liability. Although farmers were provided with an insurance premium of up to 500 Birr, they often preferred to pay the basic (minimum) premium. Nevertheless, even the basic policy has significant economic implications for poor farmers whose livelihood predominantly depends on rain-fed agriculture. Farmers can cover the cost of their primary farm inputs with the minimum liability. In the rural areas of Tigray region, the maximum liability of 3000 Birr is nearly equivalent to $69 \%$ and $25 \%$ of per capita food and total (food and non-food) consumption expenditure (National Planning Commission, 2017).

\subsubsection{Data}

Our study is set in Tigray region, northern Ethiopia, where about 80 percent of the population lives in rural areas with their livelihoods mainly dependent on rain-fed agriculture. The region is characterized by low soil quality, sparse and erratic rainfall and frequent droughts (Hagos et al., 1999). More than half of the regional highlands are highly degraded and the average yield of cereal crops in the region is less than one ton per hectare, which is less than the national average of about 1.5 tons per hectare. The average landholding per household in the region is about one hectare, which is also less than the national average of 1.37 hectares per household. Regional mean annual rainfall has been estimated at about $650 \mathrm{~mm}$ ranging from $300 \mathrm{~mm}$ to over 1200mm (Pender \& Gebremedhin, 2007). Tigray is one of the most drought prone regions in the country with more than 25 severe drought periods in the last millennium (Di Falco et al., 2007). Tigray together with Wollo, northern part of Amhara region, were the most severely affected regions by the deadliest 1984 drought (Dercon \& Porter, 2014).

The WII scheme was introduced in 2009 to strengthen farmers' food and income security in the region. Adiha tabia in Kolla Temben district was the first to receive the WII scheme. In 2010, the WII scheme scaled up to three districts - Kolla Temben, Raya Azebo and Saesie Tsaedaemba. The WII scheme further scaled up to 11 districts and more than 80 tabias between 2010 and 2013. Districts have been selected to receive the WII scheme based on their vulnerability to frequent droughts. Subsequently, tabias within selected districts were selected to receive the access to WII based on the following two criteria. First, tabias had to be vulnerable to frequent droughts. Second, there had to be a close match between climate data collected from satellite images and farmers' self-reported climate data. While all tabias in our sample are vulnerable to 
drought and in principle would have been eligible, various tabias did not meet the second criterion: there was not a close enough match between satellite climate data and farmers' self-reports. The second criterion is important for the insurance companies because the mismatch may indicate the presence of basis risk (the mismatch between the actual losses incurred by the insurance purchasers and insurance payouts paid by the insurer) and they are less likely (and willing) to sell WII in areas with high basis risk. There are many possible reasons for such a mismatch to occur, some of them plausibly related to the difficulty of accurately measuring rainfall through satellite images in some areas. We however believe that none of these are systematically correlated with our outcome variable (social capital). We show that for most variables that are arguably time-invariant, there is no systematic difference between households with and those without access to WII. We return to these issues in more detail later.

The data for this study were collected from two randomly selected districts (Raya Azebo and Alamata). Both districts are vulnerable to frequent drought related shocks. In the past 30 years, drought occurs on average once every three years. To address the adverse effects of frequent droughts, WII has been introduced in 2010 in Raya Azebo and in 2011 in Alamata districts. In total, 16 tabias have access to the WII scheme, of which 10 tabias are in Raya Azebo district and the remaing 6 tabias are in Alamata district. Of the 16 tabias with access to WII, we randomly selected five tabias: three from Raya Azebo district and two from Alamata district. Following Cecchi et al. (2016), to estimate the effect of access to WII on social capital, we also randomly selected three tabias (two from Raya Azebo and one from Alamata district) without access to the WII scheme. So as to have comparable access and no access tabias at least in their vulnerability to droughts, we selected the no access tabias from those tabias exposed to frequent droughts but left untreated because of the mismatch between satellite and farmers' self-reported climate data. In our sampling procedure, we did not include tabias that were not eligible to receive the WII scheme. That is, tabias with less vulnerability to frequent droughts were excluded from the sampling frame.

We selected a total of $384^{4}$ households using a two-stage stratified random sampling procedure. First, we stratified households based on their access to WII, and we randomly sampled 240 with and 144 households without access to WII respectively. Second, households were stratified by their insurance status, that is, households that purchased WII and those that did not purchase WII. Of the 240 households with access to WII (where the main analysis is based on this sample), 120 of them were insured households (i.e., those with a valid (not lapsed) contract during the data collection period) and the remaining 120 were uninsured households (i.e., those that did have access to but have never purchased WII, in other words, the non-compliers in our treatment group). We used two sampling frames. Within each tabia we obtained a list of all insured households from the person responsible for selling the insurance

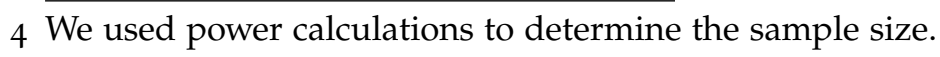


(the insurance foremen) and randomly selected 120 insurance purchasers from this list. Our second sampling frame comprised a list of all households living in the tabia obtained from the village leaders. After earmarking all households that took up insurance, we randomly selected 120 households among those that were not insured. Name lists were cross-checked with the insurance foremen.

As shown in Table 3.1, the total number of households in the treated tabias is more or less similar. The number of households in these tabias adds up to 9,964 households. Each tabia constitutes 18 to $22 \%$ of the total number of households. For this reason, we randomly selected the same number of observations from each tabia. In doing so, we relatively oversampled the insured households to obtain a sufficiently large number of observations from this group for the estimation. To address this concern, we used an appropriate sampling weight in our analysis.

Data were collected on tablets during the slack period of March to May, 2017.5 Households first participated in a public goods experiment that we use as our key measure of social capital. After the experiment, households participated in a short socio-economic survey. The survey included questions on household assets and wealth, details on insurance access, insurance purchase, household demographics, informal transfers, financial contributions to community projects, and membership in local associations etc.

Table 3.1: Weather Index Insurance Adoption Rate in Treated Villages

\begin{tabular}{lcccc}
\hline District & Village & $\begin{array}{c}\text { Total } \\
\text { Households }\end{array}$ & $\begin{array}{c}\text { Insured } \\
\text { Households }\end{array}$ & $\begin{array}{c}\text { WII Adoption } \\
\text { Rate }\end{array}$ \\
\hline Raya Azebo & Hadealga & 1952 & 625 & $32 \%$ \\
& Hawelti & 2275 & 398 & $18 \%$ \\
& Mechare & 1874 & 368 & $20 \%$ \\
Alamata & Gerjale & 2045 & 425 & $21 \%$ \\
& Laelay dayu & 1818 & 357 & $20 \%$ \\
\hline
\end{tabular}

Source: REST office in Raya Azebo and Alamata districts.

\subsubsection{Measuring Social Capital}

Quantitatively measuring social capital has been the centerpiece of previous empirical studies. The key challenge in the literature is that social capital has been defined and

5 This period is part of the Belg crop season (March-August), which comes after the main crop season (Meher). While more than 95\% of the nation's total cereal output is produced during the Meher season, only less than $5 \%$ of cereal output is produced during the Belg season (Taffesse et al., 2012). As Belg rains are very erratic and uncertain, farmers are relatively idle during this season. 
measured in several ways. However, although measuring social capital is fraught with difficulties, an important feature of it lies in the ability of social groups to overcome free-riding problems in the provision of public goods (Coleman, 1988). For this reason, in this study, we use the behaviour in a public good game in a lab-in-the-field experiment as a measure of social capital. The use of a public good game to measure social capital is not new. It is commonly used in empirical economic studies to measure social preferences and cooperative behaviour among community members in an incentive-compatible way. For example, Carpenter et al. (2004) used a public good game to measure social capital among urban slum dwellers, Karlan (2005) to examine whether social capital in the experimental game could predict social capital measured via non-experimental methods. The use of public good game as a measure of social capital has even garnered greater attention quite recently. Gilligan et al. (2015) used it to study the effect of wartime violence on social capital. More recently, Attanasio et al. (2015) and Cecchi et al. (2016) employed it to gauge the effect of conditional cash transfer and health insurance on social capital respectively. However, these types of games are often criticized for having low predictive power for real-life behavior (REF) (Levitt \& List, 2007). To probe the robustness of our results we also used survey measures of social capital such as households' participation in community projects, making informal private transfers to fellow villagers, and membership in local informal institutions such as iddir (a local funeral insurance group in which members help each other during bereavement) and eqqub (a local rotating saving and credit association (ROSCA)).

Our experimental setting is a one-shot linear public good game. We chose it so as to circumvent learning and reputation effects in multi-round public good games (Cecchi et al., 2016). Moreover, a one-shot public good game has an advantage over multi-round public good games to avoid subject's fatigue. The main caveat of oneshot public game is that it might not measure the outcome of real interest if subjects do not understand the game. In this study, much care has been taken to ensure that subjects understood the game. They participated in several trial rounds and were given questions of comprehension, which should be correctly answered, before they played the real game. We return to this issue later in the section.

This is how the public good game was played. At the beginning of the experiment participants were given an initial endowment and asked how much of their endowment they want to contribute to the community project and how much to keep for themselves. The sum of the contributions in the community project is doubled by the experimenter and shared equally by all members of the group regardless of their contribution to the community project. The share of the endowment that is kept privately is only beneficial to the individual who is keeping it. The payoff function for individual $i$ from the public good experiment is given as follows; 


$$
\pi_{(i)}=\left(E_{i}-C_{i}\right)+\alpha\left(\sum_{n=1}^{4} C_{h}\right)
$$

where $\left.\pi_{(} i\right)$ denotes the payoff of individual $i, E_{i}$ is the initial endowment, $\left.C_{(} i\right)$ is the contribution of individual $i$ to the public good and $\alpha$ is marginal per capita return (MPCR) from the public good. In this experiment, MPCR is equals to 0.5 , meaning that each participant would receive 0.5 Birr for each token contributed to the public good. At the beginning of the experiment, each participant receives an endowment, $E_{i}$, of 20 tokens (which is equivalent to 20 Ethiopian Birr) with one 10, one 5 and five one Birr notes.

The public good experiment was conducted at local public schools. Upon arrival, participants were randomly given an identification number and asked to be seated alone on a desk in a class room. Before the experiment began, we obtained informed consent from all participants. The experimenters provided oral instructions on the experiment as the majority of the participants were unable to read or write. After the instructions, we provided them with several examples to ensure they all understood the game and the calculation of payoffs. We checked for comprehension through several exercises and only once all the exercises had been completed and we were sure all respondents understood the procedures we started the actual experiment. Participants had the opportunity to ask questions privately but were not allowed to talk with other participants during the entire experiment. In total, 384 households participated in the experiment. Sessions took up to one hour. Including a show-up fee, on average, participants earned 8o Ethiopian Birr. ${ }^{6}$

After completing the public good experiment, respondents participated in a short socio-economic survey. This is the common trend in the literature. Of the 384 households, only one person did not participate in the survey for reasons unrelated to the research. ${ }^{7}$ Payments were made privately and in cash, immediately after the survey had been completed.

\subsubsection{Descriptive Statistics}

Table B.I in the appendix shows the summary statistics of sample households. The total sample size is 383 household heads. Of the total sample, $76 \%$ are male headed households. The average age of a household head is about 41 years and the mean household size in the sample is 5.24 , which is slightly higher than the regional average. Nearly, $5 \%$ of the household heads have secondary levels of education, $22 \%$ have

68 o Birr was equivalent to $\$ 3.5$ at the time of data collection.

7 Before signing the informed consent, participants were informed that their participation was entirely voluntary, and that they could withdraw at any time without giving reasons. This one candidate who left told us on his own that he was leaving because of family reasons. 
primary levels of education, $13 \%$ of the respondents have no formal education but can read and write, while the remainder $60 \%$ are illiterate. About $95 \%$ and $42 \%$ of the sample households participate in a local funeral insurance (iddir) and local rotating saving and credit association (eqqub) respectively. The mean landholding of households in the sample is 4.75 tsimad (approximately 1.19 hectare) ${ }^{8}$, which is slightly higher than the regional average of only 1 hectare per household (Pender \& Gebremedhin, 2007). Mean livestock holdings are 4.3 Tropical Livestock Units (TLU). ${ }^{9}$ Nearly, $45 \%$ of the households in the sample own corrugated iron sheet roof houses and the remaining $55 \%$ own houses with a thatched roof. About $75 \%$ of the respondents own a mobile phone and only $20 \%$ of the sample households own a radio. On average, participants contributed about $45 \%$ of their endowment to the public good, which is consistent with earlier evidence on the contribution in the public good game. ${ }^{10}$

Table B.2 in the appendix presents the balance test of sample households disaggregated by their access to WII. Table B.2 shows that for most of variables that are arguably time invariant, there is no systematic difference between households with and without access to WII except households with access to WII have more livestocks and higher participation in the local rotating saving and credit associations (eqqub). Table B.3 in the appendix also presents the balance test of sample households disaggregated by their purchase of WII. The results in Table B.3 show that while insured and uninsured households are similar in most of the variables tested, we still find significant differences in four variables across the two groups. Uninsured households are larger, have more livestock and farming land and are more likely to own houses with corrugated iron sheet roof than insured households. We control for these differences in our regression analysis below and provide further robustness checks to demonstrate that they are unlikely to drive our main outcomes.

\section{$3 \cdot 4$ ESTIMATION STRATEGY}

We analyze the effect of weather index insurance by estimating the following regression model:

$$
S c_{i}=\alpha_{1}+\beta_{1} I_{i}+X_{i} \gamma_{1}+\varepsilon_{i}
$$

where $S c_{i}$, the number of tokens shared in the public good game by household $i$, is our measure of social capital, $I_{i}$ is a dummy variable that takes value of $I$ if household $i$ has purchased WII, o otherwise, $X_{i}$ is a vector of controls, $\varepsilon_{i}$ is the random error term, and $\beta$ measures the effect of weather index insurance on social capital. We hypothesize that WII crowds out social capital and we expect $\beta$ to be negative $(\beta<0)$.

8 Tsimad is a local measurement of farm land. 1 hectare $\approx 4$ tsimad (Hagosa et al., 2010).

9 1 TLU is equivalent to o.8 camel, 1 cow, 8 goats or sheep (Storck et al., 1991).

10 In the literature subjects on average contribute $40 \%-60 \%$ of their endowment to the public good (Attanasio et al., 2015). 
In equation $3.2 S c_{i}$, is continuous. We also generate a dummy variable and categorize respondents as cooperative or not, based on their contribution in the public good game. To do so, we consider 10 as a threshold contribution amount for the following three reasons. First, respondents were given an endowment of 20 tokens and 10 is half of the total endowment. We consider respondents who contributed more than half of their endowment as high contributors and those who contributed exactly equal to or less than half of their endowment as low contributors. Second, the median value of the number of tokens shared in the public good game is also 10. Third, the average number of tokens shared in the public good game is about 9 tokens which is close to the threshold amount. Hence, we took 10 as a threshold contribution amount and categorize respondents accordingly into low and high contributors. We estimate the following Probit model:

$$
\operatorname{Pr}\left(S_{c} H_{i}=1 \mid I_{i}\right)=\alpha_{2}+\beta_{2} I_{i}+X_{i} \gamma_{2}+\varepsilon_{i}
$$

where $\mathrm{ScH}_{i}$ is a dummy variable that takes a value of 1 if household $i$ has contributed more than 10 tokens, o otherwise. Other notations have the same meaning as in equation 3.2 .

Weather index insurance uptake in our social capital equations 3.2 and 3.3, however, may be endogenous for the following reasons. First, as the decision to purchase WII is on a voluntary basis, there is a possibility of self-selection to purchase or not to purchase WII. Second, there might be omitted variables, such as innate ability, that simultaneously drive the decision to purchase WII and investment in social capital. Third, the endogeneity of WII purchase may also be due to a reverse causality from social capital to WII purchase. Hence, to attenuate the endogeneity concerns we employ an instrumental variable (IV) approach. However, the use of an IV approach requires the availability of a valid instrument, $\mathbf{z}$, which satisfies the following two conditions. First, the instrumental variable should be correlated with the endogenous regressor (in our case, WII uptake $(I)$ ). Second, the instrumental variable should be correlated with the dependent variable (social capital, $(S c)$ ) only through the endogenous variable $\left(I_{i}\right)$ (Angrist \& Pischke, 2008). To estimate the causal impact of an endogenous WII purchase on social capital we estimate the following equations:

$$
\begin{gathered}
S c_{i}=\kappa_{0}+\kappa_{1} I_{i}+X_{i} \lambda+\varepsilon_{i} \\
I_{i}^{*}=\pi_{0}+\pi_{1} z_{i}+Y_{i} \psi+v_{i} \\
I_{i}= \begin{cases}1, & \text { if } I_{i}^{*}>0 \\
0, & \text { if } I_{i}^{*} \leq 0\end{cases}
\end{gathered}
$$


In equations 3.4 and $3.5, \varepsilon_{i}$ and $v_{i}$ are correlated, i.e., $\operatorname{Cov}\left(\varepsilon_{i}, v_{i}\right) \neq$ o. Hence, OLS does not provide consistent estimates. In order to obtain consistent estimates of $\kappa_{1}$ while the $\operatorname{Cov}\left(\varepsilon_{i}, v_{i}\right) \neq 0$, we need to have an instrumental variable, $z_{i}$, which is correlated with $I$ and uncorrelated with $\varepsilon_{i}$.

The choice of our instrumental variable is guided by the literature. In the literature, geographical factors such as distance have been identified as key determinants of various socio-economic variables. As a consequence, several studies used distance an instrumental variable to attenuate endogeneity concerns. ${ }^{11}$ In this study, we use being geographically close to the insurance foreman (distance from farm-household's residence to the insurance foreman's residence) as an instrument for WII uptake.

WII is not an easy concept that farmers with low literacy levels understand instantly. Hence, for farmers to make an informed decision, they need to have adequate knowledge of the insurance product through substantial training sessions. However, the insurance companies and other partners mostly provide the trainings for the insurance foremen (Madajewicz et al., 2017). The insurance foreman, therefore, acts as a liaison between the farmers and insurance companies, and plays a vital role in providing trainings and in turn improving the understanding of farmers about index insurance, marketing and sales of the insurance product. As the foreman has a better knowledge of the insurance policy, he is the only person easily reachable to answer farmers' questions about the insurance policy. Accordingly, we expect that farmers living in a closer distance to the insurance foreman have the advantage of getting adequate information about the insurance policy and are possibly more easily inclined to purchase the insurance product.

We argue that living at a closer distance to the insurance foreman's home is purely exogenous. Due to the low mobility of rural farmers, they are less likely to self-select to be geographically closer to the insurance foreman. Nevertheless, one may speculate that if the insurance foremen are paid on a commission basis, that is, commensurate to the number of households decided to take-up insurance, distance to the insurance foreman's residence does not play a role because the foreman himself may cover a broader geographical area to convince farmers to purchase WII. Interestingly, the insurance foremen are paid a monthly fixed salary of 900 Ethiopian Birr (approximately \$40), which implies that insurance foremen do not have additional incentives such as commission payments to convince farmers to purchase WII. In support of this, Madajewicz et al. (2017) report the prevalence of limited knowledge dissemination due to lack of appropriate incentive mechanisms. This is consistent with the literature on the role of incentives in the sense that insurance foremen should be paid commensu-

11 Theil \& Finke (1983) used distance from the equator as an instrumental variable for per capita income. In a similar vein, Hall \& Jones (1999) also employed distance from the equator as an instrument for social infrastructure. More recently, Melesse \& Cecchi (2017) used distance from markets as instrument for farm-households market exposure. 
rate to their effort ("pay enough or do not pay at all" - Gneezy \& Rustichini (2000)). Another potential concern is that if the insurance foreman holds other positions in the village, fore example, if the foreman is a village leader or an agricultural extension agent, he may directly affect the outcome variable (social capital). In the study area, the insurance foremen do not assume other positions - they are neither village leaders nor agricultural extension workers. Any farmer who can read and write is eligible to be an insurance foreman. The tabia insurance team is in charge of selecting the insurance foreman. The insurance team advertises the vacancy and then selects the insurance foreman based on his/her literacy level. ${ }^{12}$ As the insurance foreman is appointed by the insurance team, we argue that the appointment process is an administrative level decision which is unlikely to affect individual household's decision such as investment in social capital. The last concern is that the insurance foreman may be spatially central, and distance from the foreman may be a proxy for marginalization, which is commonly considered as an important determinant of the density of social networks. During our data collection, we did not observe a systematic pattern in the spatial location of the foremen. In any case, if this argument is valid, we expect higher investment in social capital by insured households residing closer to the foreman. By contrast, our results show the reverse. Therefore, we argue that being geographically closer to the insurance foreman is a plausible instrument that affects social capital only through the decision to purchase WII.

We establish the admissibility of our instrument using a series of tests. First, we estimate a probit model explaining variation in WII uptake and check whether the distance to the insurance foreman's residence significantly affects farm-households WII uptake. Second, we probe the validity of our instrument by performing the falsification test in Di Falco et al. (2011). According to the falsification test, a variable is a valid instrument if it affects the endogenous variable but not the outcome variable of households that did not receive the treatment. In our case, the distance to the insurance foreman's residence is a valid instrument if it significantly affects the insurance uptake variable but not the investment in social capital by the uninsured households. Third, as the falsification test proposed by Di Falco et al. (2011) put some conditions in the sense that the instrument should not be correlated with the outcome variable only for the control group, we further prob the validity of the instrument by relaxing this condition. We check whether the instrument has no unconditional correlation with the outcome variable for both treatment and control groups. Finally, we estimate an OLS model to check if the instrumental variable has only an indirect effect on the outcome variable through the WII uptake.

12 In our study area, the highest level of education of an insurance foreman is secondary level of education. 


\subsection{RESULtS}

\subsubsection{Does WII Crowds Out Social Capital?}

We begin our results section by presenting the naïve OLS and Probit estimates. Columns (1) and (2) of Table 3.2 reports the result of OLS regression model. It shows the presence of a negative and statistically significant correlation between WII purchase and social capital. The correlation is economically meaningful: on average, uninsured households contribute about 2.2 tokens more than insured households. In the public good experiment, we ask respondents to make any contribution to the public good from their initial endowment of 20 tokens. However, their contribution to the public good might be bounded by their initial endowment. Hence, the dependent variable, number of tokens contributed to the public good might be right censored. To address the censoring issue, we also employ a Tobit regression model with right censoring. Columns (3) of Table 3.2 reports the result of the Tobit regression model and shows that WII purchase affects social capital negatively and significantly. To be precise, insured households, on average, contribute about 2.2 fewer tokens than uninsured households. As discussed in section 3.4, to check the robustness of our results in columns (1-3), we generate a dummy dependent variable based on the existing continuous dependent variable. Hence, columns (4) and (5) present the probit estimation results and show a negative and significant correlation between WII purchase and making a higher contribution to the public good. This implies that uninsured households are more likely to be high contributors to the public good than insured households. More specifically, WII purchase decreases the probability of contributing more than 10 tokens to the public good by 18 percentage points.

Our regression results in Table 3.2 show that contribution to the public good is correlated with a few household covariates. Consistent with the literature, females invest more than males in social capital. On average, males contribute about 2 fewer tokens than females. Moreover, the age of the household head positively affects contribution to the public good. However, the relationship between age and contribution to the public good is non-linear. The age square variable enters negatively in all regression models. This implies that contribution to the public good initially increases with age then decreases after a certain threshold age level. After respondents made their decision on how much to contribute to the public good and how much to keep for themselves, we asked them to reveal their expectations about the average contribution of other players in their group. This specific question captures the belief of respondents about others' contributions to the public good. Consistent with Kocher et al. (2015), beliefs of respondents about others' contribution positively and significantly affects their own contribution to the public good. One token increase in the expectation of 
others' contribution to the public good, on average, increases own contribution by about 0.432 tokens.

Table 3.2: OLS, Probit and Tobit Estimates on the Effect of WII on Social Capital

\begin{tabular}{|c|c|c|c|c|c|}
\hline & $\begin{array}{c}(1) \\
\text { OLS }\end{array}$ & $\begin{array}{c}(2) \\
\text { OLS }\end{array}$ & $\begin{array}{l}\text { (3) } \\
\text { Tobit }\end{array}$ & $\begin{array}{c}(4) \\
\text { Probit }\end{array}$ & $\begin{array}{c}(5) \\
\text { Probit }\end{array}$ \\
\hline WII uptake & $\begin{array}{c}-3.002^{* * *} \\
(0.811)\end{array}$ & $\begin{array}{c}-2.233^{* * *} \\
(0.813)\end{array}$ & $\begin{array}{l}-2.172^{* *} \\
(0.875)\end{array}$ & $\begin{array}{c}-0.222^{* * *} \\
(0.064)\end{array}$ & $\begin{array}{c}-0.178^{* * *} \\
(0.068)\end{array}$ \\
\hline Age & $\begin{array}{l}0.376^{* *} \\
(0.175)\end{array}$ & $\begin{array}{c}0.267 \\
(0.166)\end{array}$ & $\begin{array}{l}0.299^{*} \\
(0.175)\end{array}$ & $\begin{array}{c}0.058^{* * *} \\
(0.021)\end{array}$ & $\begin{array}{c}0.063^{* * *} \\
(0.021)\end{array}$ \\
\hline Age square & $\begin{array}{l}-0.004^{*} \\
(0.002)\end{array}$ & $\begin{array}{c}-0.003 \\
(0.002)\end{array}$ & $\begin{array}{l}-0.003 \\
(0.002)\end{array}$ & $\begin{array}{c}-0.001^{* * *} \\
(0.000)\end{array}$ & $\begin{array}{c}-0.001^{* * *} \\
(0.000)\end{array}$ \\
\hline Male & $\begin{array}{l}-1.552 \\
(1.059)\end{array}$ & $\begin{array}{l}-1.953^{*} \\
(1.016)\end{array}$ & $\begin{array}{l}-2.572^{* *} \\
(1.191)\end{array}$ & $\begin{array}{l}-0.067 \\
(0.106)\end{array}$ & $\begin{array}{l}-0.101 \\
(0.113)\end{array}$ \\
\hline Household size & $\begin{array}{l}-0.030 \\
(0.181)\end{array}$ & $\begin{array}{l}-0.055 \\
(0.174)\end{array}$ & $\begin{array}{l}-0.073 \\
(0.187)\end{array}$ & $\begin{array}{l}-0.008 \\
(0.022)\end{array}$ & $\begin{array}{l}-0.016 \\
(0.022)\end{array}$ \\
\hline Education & $\begin{array}{c}0.671 \\
(0.716)\end{array}$ & $\begin{array}{c}0.444 \\
(0.701)\end{array}$ & $\begin{array}{c}0.343 \\
(0.730)\end{array}$ & $\begin{array}{l}-0.001 \\
(0.083)\end{array}$ & $\begin{array}{l}-0.011 \\
(0.084)\end{array}$ \\
\hline Livestock & $\begin{array}{c}0.024 \\
(0.085)\end{array}$ & $\begin{array}{l}-0.010 \\
(0.086)\end{array}$ & $\begin{array}{c}0.000 \\
(0.090)\end{array}$ & $\begin{array}{l}-0.005 \\
(0.011)\end{array}$ & $\begin{array}{l}-0.004 \\
(0.011)\end{array}$ \\
\hline Land owned & $\begin{array}{c}-0.280^{* *} \\
(0.123)\end{array}$ & $\begin{array}{l}-0.155 \\
(0.119)\end{array}$ & $\begin{array}{l}-0.162 \\
(0.121)\end{array}$ & $\begin{array}{c}-0.034^{* *} \\
(0.014)\end{array}$ & $\begin{array}{l}-0.021 \\
(0.016)\end{array}$ \\
\hline Corrugated iron sheet & $\begin{array}{l}-1.190 \\
(0.736)\end{array}$ & $\begin{array}{l}-0.330 \\
(0.717)\end{array}$ & $\begin{array}{l}-0.265 \\
(0.760)\end{array}$ & $\begin{array}{c}0.002 \\
(0.084)\end{array}$ & $\begin{array}{c}0.047 \\
(0.093)\end{array}$ \\
\hline Belief & $\begin{array}{c}0.576^{* * *} \\
(0.072)\end{array}$ & $\begin{array}{c}0.436^{* * *} \\
(0.088)\end{array}$ & $\begin{array}{c}0.466^{* * *} \\
(0.091)\end{array}$ & $\begin{array}{c}0.063^{* * *} \\
(0.010)\end{array}$ & $\begin{array}{c}0.051^{* * *} \\
(0.010)\end{array}$ \\
\hline Religion & $\begin{array}{l}-1.034 \\
(0.941)\end{array}$ & $\begin{array}{l}-0.462 \\
(0.989)\end{array}$ & $\begin{array}{l}-0.515 \\
(1.137)\end{array}$ & $\begin{array}{l}-0.016 \\
(0.099)\end{array}$ & $\begin{array}{c}0.003 \\
(0.104)\end{array}$ \\
\hline Constant & $\begin{array}{l}-1.240 \\
(3.799)\end{array}$ & $\begin{array}{c}3.792 \\
(3.908)\end{array}$ & $\begin{array}{c}3.369 \\
(4.075)\end{array}$ & & \\
\hline Village FE & No & Yes & Yes & No & Yes \\
\hline Observations & 240 & 240 & 240 & 240 & 240 \\
\hline R-squared & 0.378 & 0.434 & & & \\
\hline Pseudo $\mathrm{R}^{2}$ & & & 0.088 & 0.353 & 0.40 \\
\hline
\end{tabular}

Notes. The dependent variable in columns (1), (2), and (3) is the number of tokens shared in the public good game. The dependent variable in columns (4) and (5) is a dummy variable taking a value of $I$ if household $i$ contributed more than 10 tokens to the public good, o otherwise. Marginal effects are reported in columns (4) and (5). Robust standard errors in parentheses, ${ }^{* * *}$ $\mathrm{p}<0.01,{ }^{* *} \mathrm{p}<0.05,{ }^{*} \mathrm{p}<0.1$. 
Table 3.3: Tests on the Validity of the Selected Instrument

\begin{tabular}{|c|c|c|c|c|c|c|}
\hline & $\begin{array}{c}(1) \\
\text { First } \\
\text { stage IV }\end{array}$ & $\begin{array}{c}\text { (2) } \\
\text { First } \\
\text { stage IV }\end{array}$ & $\begin{array}{c}\quad(3) \\
\text { Falsification } \\
\text { (conditional) } \\
\text { test }\end{array}$ & $\begin{array}{c}\quad(4) \\
\text { Falsification } \\
\text { (conditional) } \\
\text { test }\end{array}$ & $\begin{array}{c}(5) \\
\text { Falsification } \\
\text { (unconditional) } \\
\text { test }\end{array}$ & $\begin{array}{c}(6) \\
\text { Falsification } \\
\text { (unconditional) } \\
\text { test }\end{array}$ \\
\hline WII uptake & & & & & & $\begin{array}{l}-1.849^{* *} \\
(0.921)\end{array}$ \\
\hline Distance to foreman & $\begin{array}{c}-0.013^{* * *} \\
(0.002)\end{array}$ & $\begin{array}{c}-0.012^{* * *} \\
(0.002)\end{array}$ & $\begin{array}{l}-0.022 \\
(0.038)\end{array}$ & $\begin{array}{c}0.024 \\
(0.029)\end{array}$ & $\begin{array}{c}0.009 \\
(0.030)\end{array}$ & $\begin{array}{c}0.024 \\
(0.025)\end{array}$ \\
\hline Age & & $\begin{array}{c}0.010 \\
(0.013)\end{array}$ & & $\begin{array}{l}0.450^{* *} \\
(0.187)\end{array}$ & & $\begin{array}{l}0.291^{*} \\
(0.167)\end{array}$ \\
\hline Age square & & $\begin{array}{l}-0.000 \\
(0.000)\end{array}$ & & $\begin{array}{l}-0.005^{* *} \\
(0.002)\end{array}$ & & $\begin{array}{l}-0.003^{*} \\
(0.002)\end{array}$ \\
\hline Male & & $\begin{array}{c}-0.168^{* *} \\
(0.083)\end{array}$ & & $\begin{array}{l}-1.771 \\
(1.226)\end{array}$ & & $\begin{array}{l}-1.802^{*} \\
(1.042)\end{array}$ \\
\hline Household size & & $\begin{array}{l}-0.020^{*} \\
(0.011)\end{array}$ & & $\begin{array}{l}-0.220 \\
(0.196)\end{array}$ & & $\begin{array}{l}-0.049 \\
(0.173)\end{array}$ \\
\hline Education & & $\begin{array}{c}0.016 \\
(0.043)\end{array}$ & & $\begin{array}{c}0.156 \\
(0.803)\end{array}$ & & $\begin{array}{l}0.511 \\
(0.693)\end{array}$ \\
\hline Livestock & & $\begin{array}{c}0.004 \\
(0.005)\end{array}$ & & $\begin{array}{c}0.035 \\
(0.095)\end{array}$ & & $\begin{array}{l}-0.015 \\
(0.087)\end{array}$ \\
\hline Land owned & & $\begin{array}{l}-0.014^{*} \\
(0.008)\end{array}$ & & $\begin{array}{l}-0.151 \\
(0.140)\end{array}$ & & $\begin{array}{l}-0.150 \\
(0.121)\end{array}$ \\
\hline Corrugated iron sheet & & $\begin{array}{l}-0.061 \\
(0.042)\end{array}$ & & $\begin{array}{l}-0.438 \\
(0.858)\end{array}$ & & $\begin{array}{l}-0.409 \\
(0.730)\end{array}$ \\
\hline Belief & & $\begin{array}{c}0.002 \\
(0.004)\end{array}$ & & $\begin{array}{l}0.452^{* * *} \\
(0.125)\end{array}$ & & $\begin{array}{c}0.445^{* * *} \\
(0.088)\end{array}$ \\
\hline Religion & & $\begin{array}{c}0.094^{* * *} \\
(0.036)\end{array}$ & & $\begin{array}{l}-0.077 \\
(1.072)\end{array}$ & & $\begin{array}{l}-0.531 \\
(0.986)\end{array}$ \\
\hline Constant & & & $\begin{array}{c}10.589^{* * *} \\
(1.450)\end{array}$ & $\begin{array}{l}-0.156 \\
(4.997)\end{array}$ & $\begin{array}{l}9.138^{* * *} \\
(1.007)\end{array}$ & $\begin{array}{c}2.222 \\
(4.138)\end{array}$ \\
\hline Village FE & Yes & Yes & Yes & Yes & Yes & Yes \\
\hline Observations & 240 & 240 & 120 & 120 & 240 & 240 \\
\hline Pseudo R2 & 0.234 & 0.315 & & & & \\
\hline R-squared & & & 0.003 & 0.573 & 0.001 & 0.437 \\
\hline
\end{tabular}

Notes. The dependent variable in columns (1) and (2) is WII uptake. Whereas, the dependent variable in columns (3) and (4) is the number of tokens shared in the public good game by uninsured households. The dependent variable in columns (5) and (6) is the number of tokens shared in the public good game by insured and uninsured households. Robust standard errors in parentheses, ${ }^{* * *} \mathrm{p}<0.01$, ${ }^{* *} \mathrm{p}<0.05,{ }^{*} \mathrm{p}<0.1$. 
As mentioned before, WII uptake is non-random, and there is a possibility of selfselection to purchase or not to purchase WII. To attenuate the potential endogeneity concern, we use an instrumental variable (IV) approach. We use the distance from farm-household's residence to the insurance foreman's residence as an instrument for WII uptake. Before running the IV regression model, we check the validity of our instrument in several ways. First, to probe whether the instrumental variable is robustly correlated with the endogenous explanatory variable, we run a series of regression analysis starting from the most parsimonious specification of column (1) with the instrumental variable as the only explanatory variable to the most elaborative regression specification of column (2) of Table 3.3 where household covariates and village fixed effects are included in the model. Our regression results show a negative and statistically significant correlation between the distance to insurance foreman's residence and purchase of WII. The coefficient for the insurance foreman variable is stable across all regression specifications. Column (2) of Table 3.3 shows that households living in a closer distance to the insurance foreman have 12 percentage points higher probability of being insured. This indicates that the first criterion for a valid instrument - the instrument should be significantly correlated with the endogenous explanatory variable (WII uptake) - is effectively met.

To probe the admissibility of our instrumental variable, we perform the falsification test in Di Falco et al. (2011). According to the falsification test, an instrument is a valid instrument if it affects the endogenous variable but not the outcome variable of households that did not receive the treatment. Columns (3) and (4) of Table 3.3 show that the instrumental variable has no significant effect on the number of tokens contributed to the public good by the uninsured households, indicating the instrument satisfies the falsification test.

However, in the falsification test of columns (3) and (4), we imposed a certain restriction or condition in the sense that we test whether or not the instrument is correlated with the number of tokens contributed to the public good only by the uninsured households. To further probe the validity of our instrument, we relax the conditional assumption and test whether or not the instrument has no unconditional correlation with the number of tokens contributed to the public good by both insured and uninsured households. Columns (5) of Table 3.3 shows no significant correlation between the instrumental variable and the contribution to the public good, indicating that the instrumental variable has no unconditional effect on the outcome variable. As we have only one instrument for one endogenous variable, we could not run an overidentification test. Although imperfect, we check whether the instrumental variable directly affects the outcome variable or only indirectly through the purchase of WII. Column (6) of Table 3.3 reports that while WII uptake has a significant effect on social capital, the instrumental variable has no significant effect. Based on columns (5) and (6), we conclude that the instrumental variable has no direct effect on the outcome variable. 
We next turn into running our instrumental regression model. We report the relevance test for the instrumental variable in Table 3.4. The Cragg-Donald Wald F statistic is reported and used to test the relevance of the instrument. The relevance test for the instrumental variable in Table 3.4 indicates that being geographically closer to the insurance foreman is a relevant instrument for WII purchase. Referring to the Stock et al. (2002) critical values for the relevance test, the associated partial F statistic exceeds the minimum to threshold value, and we reject the null hypothesis of having a weak instrument. As mentioned before, since we have only one instrument, we could not run an overidentification test. We, however, showed that the instrumental variable affects the outcome variable only indirectly through the endogenous explanatory variable, purchase of WII. This indicates that our instrument is relevant in capturing an exogenous change in the decision to purchase WII.

Columns (1) and (2) in Table 3.4 reports the 2SLS estimates corresponding to the OLS estimates in columns (1) and (2) of Table 3.2. Columns (3) and (4) also report IV-LPM (linear probability model) estimates corresponding to the Probit estimates in columns (4) and (5) of Table 3.2. Columns (1) to (4) of Table 3.4 show that WII purchase affects social capital negatively and significantly. The coefficient for the WII uptake in column (2) is -3.9, meaning that insured households contributed about 3.9 fewer tokens than uninsured households. Likewise, the coefficient for the purchase of WII in column (4) is -0.31 , meaning that being insured decreases the probability of contributing more than 10 tokens to the public good by 31 percentage points. Thus, our 2 SLS regression results reinforce the hypothesis that the introduction of formal insurance mechanisms such as WII may crowd out social capital and suggest that the relationship between WII uptake and social capital is causal - WII uptake lowers investment in social capital. However, the coefficients of 2SLS estimates are larger than its corresponding OLS estimates. This may be because either 2SLS attenuates measurement error or mitigates the problem of 'reverse causality' - the effect of social capital on WII uptake. If social capital increases WII uptake, OLS estimates may underestimate the true causal effect of WII uptake on social capital. 
Table 3.4: IV Estimates on the Effect of WII on Social Capital

\begin{tabular}{|c|c|c|c|c|}
\hline & $\begin{array}{c}(1) \\
\text { 2SLS }\end{array}$ & $\begin{array}{c}(2) \\
2 S L S\end{array}$ & $\begin{array}{c}\text { (3) } \\
\text { IV-LPM }\end{array}$ & $\begin{array}{c}(4) \\
\text { IV-LPM }\end{array}$ \\
\hline WII uptake & $\begin{array}{c}-4.878^{* * *} \\
(1.861)\end{array}$ & $\begin{array}{l}-3.870^{* *} \\
(1.824)\end{array}$ & $\begin{array}{l}-0.335^{* *} \\
(0.144)\end{array}$ & $\begin{array}{l}-0.313^{* *} \\
(0.151)\end{array}$ \\
\hline Age & $\begin{array}{l}0.416^{* *} \\
(0.173)\end{array}$ & $\begin{array}{l}0.310^{*} \\
(0.166)\end{array}$ & $\begin{array}{c}0.045^{* * *} \\
(0.016)\end{array}$ & $\begin{array}{c}0.047^{* * *} \\
(0.015)\end{array}$ \\
\hline Age square & $\begin{array}{l}-0.004^{* *} \\
(0.002)\end{array}$ & $\begin{array}{l}-0.003^{*} \\
(0.002)\end{array}$ & $\begin{array}{l}-0.001^{* * *} \\
(0.000)\end{array}$ & $\begin{array}{c}-0.001^{* * *} \\
(0.000)\end{array}$ \\
\hline Male & $\begin{array}{l}-1.725^{*} \\
(1.034)\end{array}$ & $\begin{array}{c}-2.048^{* *} \\
(0.987)\end{array}$ & $\begin{array}{l}-0.049 \\
(0.077)\end{array}$ & $\begin{array}{l}-0.062 \\
(0.075)\end{array}$ \\
\hline Household size & $\begin{array}{l}-0.072 \\
(0.172)\end{array}$ & $\begin{array}{l}-0.087 \\
(0.168)\end{array}$ & $\begin{array}{l}-0.013 \\
(0.016)\end{array}$ & $\begin{array}{l}-0.015 \\
(0.016)\end{array}$ \\
\hline Education & $\begin{array}{c}0.748 \\
(0.701)\end{array}$ & $\begin{array}{c}0.523 \\
(0.669)\end{array}$ & $\begin{array}{c}0.010 \\
(0.060)\end{array}$ & $\begin{array}{c}0.007 \\
(0.060)\end{array}$ \\
\hline Livestock & $\begin{array}{c}0.016 \\
(0.083)\end{array}$ & $\begin{array}{l}-0.014 \\
(0.083)\end{array}$ & $\begin{array}{l}-0.005 \\
(0.007)\end{array}$ & $\begin{array}{l}-0.002 \\
(0.007)\end{array}$ \\
\hline Land owned & $\begin{array}{l}-0.304^{* *} \\
(0.118)\end{array}$ & $\begin{array}{l}-0.181 \\
(0.112)\end{array}$ & $\begin{array}{c}-0.019^{* *} \\
(0.009)\end{array}$ & $\begin{array}{l}-0.013 \\
(0.009)\end{array}$ \\
\hline Corrugated iron sheet & $\begin{array}{l}-1.333^{*} \\
(0.748)\end{array}$ & $\begin{array}{l}-0.526 \\
(0.757)\end{array}$ & $\begin{array}{l}-0.016 \\
(0.063)\end{array}$ & $\begin{array}{l}0.005 \\
(0.068)\end{array}$ \\
\hline Belief & $\begin{array}{l}0.585^{* * *} \\
(0.070)\end{array}$ & $\begin{array}{c}0.455^{* * *} \\
(0.087)\end{array}$ & $\begin{array}{c}0.052^{* * *} \\
(0.006)\end{array}$ & $\begin{array}{c}0.042^{* * * *} \\
(0.007)\end{array}$ \\
\hline Religion & $\begin{array}{l}-0.795 \\
(0.918)\end{array}$ & $\begin{array}{l}-0.280 \\
(0.990)\end{array}$ & $\begin{array}{c}0.000 \\
(0.078)\end{array}$ & $\begin{array}{l}0.010 \\
(0.083)\end{array}$ \\
\hline Constant & $\begin{array}{l}-1.547 \\
(3.770)\end{array}$ & $\begin{array}{l}3.003 \\
(3.887)\end{array}$ & $\begin{array}{c}-0.810^{* *} \\
(0.341)\end{array}$ & $\begin{array}{c}-0.748^{* *} \\
(0.333)\end{array}$ \\
\hline Observations & 240 & 240 & 240 & 240 \\
\hline R-squared & 0.365 & 0.424 & 0.363 & 0.405 \\
\hline $\begin{array}{l}\text { Village FE } \\
\text { First stage F-test }\end{array}$ & No & Yes & No & Yes \\
\hline Distance to foreman & 59.168 & 59.168 & 59.168 & 59.168 \\
\hline R-squared & 0.364 & 0.424 & 0.364 & 0.404 \\
\hline
\end{tabular}

Notes. The dependent variable in columns (1) and (2) is the number of tokens shared in the public good game. The dependent variable in columns (3) and (4) is dummy taking a value of 1 if household $i$ contributed more than 10 tokens to the public good, o otherwise. Robust standard errors in parentheses, ${ }^{* * *} \mathrm{p}<0.01,{ }^{* *} \mathrm{p}<0.05,{ }^{*} \mathrm{p}<0.1$.

\subsubsection{Does WII Premium Payment Modality Matter?}

The WII market in Tigray region has a unique feature in the sense that farmers can purchase insurance either in cash or in labor by working extra days in the Ethiopian productive safety net program (PSNP), which is one of the largest social protection programs in Sub-Saharan Africa (Tadesse et al., 2017). PSNP was introduced in 2005 to 
support food-insecure households via its two main components - food/cash-for-work and direct support of free food access programs. The food/cash-for-work program targets households who can provide labor in public environmental rehabilitation activities. The food/cash-for-work program helps to mitigate chronic food insecurity problems in the country by creating labor market opportunities for unskilled but ablebodied households. On the other hand, the direct support of free food aid component targets households who are unable to provide labor in the public works. PSNP participation helps poor farmers to smooth their consumption during good seasons and to smooth their consumption and protect their productive assets during lean seasons. To circumvent the liquidity constraint of poor and cash-constrained households, the insurance companies introduced the insurance-for-work (IFW) model. This model enables poor households who are beneficiaries of the safety net program to pay the insurance premium in labor by working extra days in the PSNP. However, non-PSNP households have to pay the insurance premium fully in cash.

In this section, we explore whether purchasing WII either in labor or cash has a systematically different impact on social capital. To investigate the effect of paying the insurance premium either in cash or labor on social capital, we group our sample households into three; (i) households who paid the insurance premium in labor, (ii) households who paid the insurance premium in cash and (iii) uninsured households but residing in villages with access to WII. As stated above, of the 240 households, 120 of them are insured households while the remaining 120 are uninsured households but having the access to WII. Moreover, of the 120 insured households, while $75 \%$ of them paid the insurance premium in labor by working extra days in the PSNP, $25 \%$ of the insured households paid the insurance premium fully in cash.

Hence, to investigate the effect of the payment methods on social capital, we compare households who paid the insurance premium in labor with the uninsured households and households who paid the insurance premium fully in cash with the uninsured households. As shown in Table 3.5 below, purchasing insurance both in labor and in cash has a significant effect on social capital, which implies that both types of insured households are responsible for the crowding-out effect. Column (1) of Table 3.5 show that insured households who paid their insurance premium in labor contributed about 2.3 fewer tokens than uninsured households respectively. Likewise, columns (2) and (5) of Table 3.5 report that purchasing insurance either in labor or in cash decreases the probability of contributing more than 1o tokens to the public good by about 18 percentage points. 
Table 3.5: Does WII Premium Payment Modality Matter?

\begin{tabular}{|c|c|c|c|c|c|c|}
\hline & \multicolumn{3}{|c|}{ WII premium paid in labor vs Uninsured } & \multicolumn{3}{|c|}{ WII premium paid in cash vs Uninsured } \\
\hline & $\begin{array}{l}(1) \\
\text { OLS }\end{array}$ & $\begin{array}{c}(2) \\
\text { Probit }\end{array}$ & $\begin{array}{c}(3) \\
\text { 2SLS }\end{array}$ & $\begin{array}{l}\text { (4) } \\
\text { OLS }\end{array}$ & $\begin{array}{l}(5) \\
\text { Probit }\end{array}$ & $\begin{array}{c}(6) \\
2 S L S\end{array}$ \\
\hline Labor & $\begin{array}{c}-2.291^{* *} \\
(0.937)\end{array}$ & $\begin{array}{c}-0.176^{* *} \\
(0.072)\end{array}$ & $\begin{array}{l}-4.110^{*} \\
(2.242)\end{array}$ & & & \\
\hline Cash & & & & $\begin{array}{c}-2.214 \\
(1.352)\end{array}$ & $\begin{array}{c}-0.184^{* *} \\
(0.079)\end{array}$ & $\begin{array}{l}-4.023^{*} \\
(2.190)\end{array}$ \\
\hline Age & $\begin{array}{c}0.277 \\
(0.176)\end{array}$ & $\begin{array}{c}0.067^{* * *} \\
(0.022)\end{array}$ & $\begin{array}{l}0.323^{*} \\
(0.178)\end{array}$ & $\begin{array}{l}0.403^{* *} \\
(0.169)\end{array}$ & $\begin{array}{c}0.077^{* * *} \\
(0.026)\end{array}$ & $\begin{array}{l}0.393^{* *} \\
\text { (o.190) }\end{array}$ \\
\hline Age square & $\begin{array}{l}-0.003 \\
\text { (0.002) }\end{array}$ & $\begin{array}{c}-0.001^{* * *} \\
(0.000)\end{array}$ & $\begin{array}{l}-0.003^{*} \\
(0.002)\end{array}$ & $\begin{array}{c}-0.005^{* *} \\
(0.002)\end{array}$ & $\begin{array}{c}-0.001^{* * *} \\
(0.000)\end{array}$ & $\begin{array}{c}-0.004^{* *} \\
(0.002)\end{array}$ \\
\hline Male & $\begin{array}{l}-1.88 \mathrm{o}^{*} \\
(1.086)\end{array}$ & $\begin{array}{l}-0.107 \\
(0.119)\end{array}$ & $\begin{array}{l}-1.956^{*} \\
(1.047)\end{array}$ & $\begin{array}{l}-2.023^{*} \\
(1.096)\end{array}$ & $\begin{array}{c}-0.126 \\
(0.145)\end{array}$ & $\begin{array}{c}-2.259^{* * *} \\
(1.056)\end{array}$ \\
\hline Household size & $\begin{array}{c}-0.030 \\
(0.183)\end{array}$ & $\begin{array}{c}-0.016 \\
(0.023)\end{array}$ & $\begin{array}{l}-0.052 \\
(0.174)\end{array}$ & $\begin{array}{l}-0.252 \\
(0.182)\end{array}$ & $\begin{array}{l}-0.028 \\
(0.026)\end{array}$ & $\begin{array}{l}-0.356^{*} \\
(0.211)\end{array}$ \\
\hline Education & $\begin{array}{c}0.446 \\
(0.728)\end{array}$ & $\begin{array}{l}-0.017 \\
\text { (0.088) }\end{array}$ & $\begin{array}{c}0.516 \\
(0.692)\end{array}$ & $\begin{array}{c}0.097 \\
(0.779)\end{array}$ & $\begin{array}{l}-0.027 \\
(0.099)\end{array}$ & $\begin{array}{c}0.174 \\
(0.767)\end{array}$ \\
\hline Livestock & $\begin{array}{l}-0.013 \\
\text { (0.088) }\end{array}$ & $\begin{array}{l}-0.003 \\
(0.012)\end{array}$ & $\begin{array}{l}-0.013 \\
(0.085)\end{array}$ & $\begin{array}{c}0.044 \\
(0.091)\end{array}$ & $\begin{array}{l}-0.003 \\
(0.014)\end{array}$ & $\begin{array}{c}0.019 \\
(0.096)\end{array}$ \\
\hline Land owned & $\begin{array}{l}-0.167 \\
(0.123)\end{array}$ & $\begin{array}{l}-0.022 \\
(0.017)\end{array}$ & $\begin{array}{l}-0.196^{*} \\
\text { (o.115) }\end{array}$ & $\begin{array}{l}-0.144 \\
(0.130)\end{array}$ & $\begin{array}{l}-0.023 \\
(0.019)\end{array}$ & $\begin{array}{l}-0.114 \\
(0.120)\end{array}$ \\
\hline Corrugated iron sheet & $\begin{array}{c}-0.502 \\
(0.748)\end{array}$ & $\begin{array}{c}0.039 \\
(0.097)\end{array}$ & $\begin{array}{c}-0.729 \\
(0.806)\end{array}$ & $\begin{array}{l}-0.170 \\
(0.782)\end{array}$ & $\begin{array}{c}0.071 \\
(0.120)\end{array}$ & $\begin{array}{c}0.113 \\
(0.772)\end{array}$ \\
\hline Belief & $\begin{array}{c}0.412^{* * *} \\
(0.092)\end{array}$ & $\begin{array}{c}0.051^{* * *} \\
(0.011)\end{array}$ & $\begin{array}{c}0.431^{* * *} \\
(0.090)\end{array}$ & $\begin{array}{c}0.475^{* * *} \\
(0.117)\end{array}$ & $\begin{array}{c}0.059^{* * *} \\
(0.015)\end{array}$ & $\begin{array}{c}0.517^{* * *} \\
(0.115)\end{array}$ \\
\hline Religion & $\begin{array}{c}-0.342 \\
(1.035)\end{array}$ & $\begin{array}{c}0.010 \\
(0.108)\end{array}$ & $\begin{array}{c}-0.189 \\
(1.029)\end{array}$ & $\begin{array}{l}-0.124 \\
(1.026)\end{array}$ & $\begin{array}{c}0.031 \\
(0.121)\end{array}$ & $\begin{array}{c}-0.089 \\
(1.037)\end{array}$ \\
\hline Constant & $\begin{array}{c}3.660 \\
(4.152)\end{array}$ & & $\begin{array}{c}2.717 \\
(4.174)\end{array}$ & $\begin{array}{c}1.759 \\
(4.249)\end{array}$ & & $\begin{array}{c}2.318 \\
(4.526)\end{array}$ \\
\hline Village FE & Yes & Yes & Yes & Yes & Yes & Yes \\
\hline $\begin{array}{l}\text { Observations } \\
\text { Distance to foreman }\end{array}$ & 210 & 210 & $\begin{array}{c}210 \\
-0.010^{* * *} \\
(0.002)\end{array}$ & 150 & 150 & $\begin{array}{c}150 \\
-0.011^{* * *} \\
0.002\end{array}$ \\
\hline First stage F-test & & & 43.014 & & & 36.974 \\
\hline R-squared & 0.435 & & 0.424 & 0.557 & & 0.527 \\
\hline Pseudo $R^{2}$ & & 0.391 & & & 0.464 & \\
\hline
\end{tabular}

Notes. The dependent variable in columns (1), (3), (4), and (6) is the number of tokens shared in the public good game. The dependent variable in columns (2) and (5) is a dummy variable taking a value of 1 if household $i$ contributed more than 10 tokens to the public good, o otherwise. Robust standard errors in parentheses, ${ }^{* * *} \mathrm{p}<0.01,{ }^{* *} \mathrm{p}<0.05,{ }^{*} \mathrm{p}<0.1$. 
Columns (3) and (6) of Table 3.5 report the IV estimation results. The results show that both types of insured households contributed about 4 fewer tokens than uninsured households which reinforce the results in Tables 3.2 and 3.4. The coefficients are similar for both payment methods across different estimation methods, which indicates that both types of insured households are almost equally responsible for the crowding out effect. To further check the robustness of the results in Table 3.5, we also compare the contribution to the public good between both types of insured households. We find no significant difference in contribution to the public good between them, which also indicates that both types of insured households are equally responsible for the crowding out effect.

\subsubsection{Robustness Checks}

\subsubsection{A The Impact of Access to WII on Social Capital}

In this section, following Cecchi et al. (2016), we seek to estimate the effect of having access to WII on social capital, irrespective of whether individual households took up the treatment. To gauge the effect of access to WII on social capital, we collected data from three groups of households - (i) insured households, (ii) uninsured households residing in villages with access to WII and (iii) uninsured households residing in villages without access to WII. To this end, we compare contributions to the public good between households residing in villages with access to WII, thereby pooling groups (i) and (ii) with households living in villages without access to WII (group iii).

One may argue that villages with and without access to WII may be systematically different from each other. We, however, believe that access and no access villages are comparable to each other for the following three reasons. First, as stated before, so as to have comparable access and no access villages, we exclude all villages that are not eligible to receive the WII scheme (villages with less vulnerability to frequent droughts) from our sampling frame. Put differently, the no access villages in our sampling frame are eligible to receive the WII scheme but were not selected to receive the access because of the mismatch between satellite climate data and farmers' selfreported data. This criterion is more important for the insurance companies to sell their insurance policy in a certain village as the mismatch between satellite climate data and farmers' self-reported data is an indication of the presence of basis risk. The mismatch may occur due to several reasons, some of them plausibly related to the difficulty of accurately measuring rainfall data through satellite images in some areas. We, however, believe that none of these reasons are systematically correlated with our outcome variable (social capital).

Second, we compare access and no access villages using pre-intervention data. As already noted, the WII scheme was introduced between 2010 - 2012. Thus, to explore 
whether access and no access villages were comparable before the introduction of the insurance scheme, we use the 2007 Ethiopian Population and Housing Census data. While there is no information on social capital in these data, we can still compare intervention and non-intervention villages on the basis of other relevant characteristics, some of which are plausibly related to social capital. Table 3.6 presents the balance test of farm households in access and no access villages. Table 3.6 shows that households in access and no access villages are not systematically different in most of the variables tested except that no access villages are dominated by male headed households more than access villages and that no access villages are more religiously diversified than access villages. Thus, we argue that access and no access villages are comparable to each other and the assignment of villages into access and no access can arguably be considered as exogenous.

As shown in Tables 3.2 and 3.4 males invest less in social capital than females. Accordingly, as no access villages are dominated by male headed households, other things remain constant, we expect lower contribution to the public good in no access villages than access villages. Moreover, as religious diversity is associated with lower provision of public goods (Miguel \& Gugerty, 2005), ceteris paribus, we expect households in no access villages to contribute less to the public good than households in access villages. We, however, find the opposite effect, suggesting that the observed imbalance in these pre-intervention variables cannot be driving our results. Third, to create a better counterfactual, we employ a propensity score matching (PSM). We estimate the propensity score of WII uptake by using the sample with and without access to WII. Afterwards, we estimate the effect of access to WII on social capital using only the matched sample.

Table 3.6: Balance Test by Access to WII Using the 2007 Census Data

\begin{tabular}{lcccc}
\hline & $(1)$ & $(2)$ & $(3)$ & $(4)$ \\
& No access & Access & Diff. & P-value \\
\hline Age of the household head & 43.720 & 43.769 & -0.049 & 0.949 \\
Age square & 2167.236 & 2174.412 & -7.176 & 0.925 \\
Male headed & 0.732 & 0.670 & 0.062 & 0.005 \\
Marital status of the household head & 2.523 & 2.567 & -0.044 & 0.722 \\
Literacy level of the household head & 43.720 & 43.769 & -0.049 & 0.949 \\
Currently attending school & 0.038 & 0.041 & -0.003 & 0.782 \\
Employment status of the household head & 0.166 & 0.155 & 0.011 & 0.532 \\
Religion of the household head & 0.627 & 0.815 & -0.188 & 0.000 \\
\hline Observations & & & & 1935 \\
\hline
\end{tabular}

Source: Central Statistical Authority, Ethiopia 
Columns (1) and (2) of Table 3.7 presents the effect of having access to WII on social capital. The estimation result in column (1) of Table 3.7 shows that the introduction of WII has a negative and statistically significant effect on social capital. Households in villages with access to WII on average contribute 0.6 fewer tokens than households in no access villages. The estimation result in column (2) of Table 3.7 also shows that households residing in villages with access to WII are less likely to contribute more than half of their endowment to the public good than households residing in no access villages. More specifically, having access to WII decreases the probability of contributing more than 1o tokens to the public good by 15 percentage points.

Next, we investigate which group is driving the crowding out effect, the insured or uninsured households. For this purpose, first, we compare contributions to the public good between insured households (group i), and uninsured households residing in villages without access to WII (group iii). Second, we compare contributions to the public good between uninsured households with access to WII (group ii) and uninsured households without access to WII (group iii). If our results are driven by the purchase of WII, we expect insured households to contribute fewer number of tokens to the public good than uninsured households without access to WII. We also expect no significant difference in contributions to the public good between uninsured households with access to WII and uninsured households without access to WII unless there are spillover effects in access villages.

We run a series of specifications starting from the parsimonious specification with the access to WII as only regressor to the full specification where household covariates and village fixed effects are included in the model. Results in columns (3) and (4) of Table 3.7 compare the contribution to the public good between insured households and uninsured households with no access to WII. We find that insured households invest less in social capital than uninsured households without access to WII. The regression result in column (3) of Table 3.7 shows that, on average, WII purchasers contribute about 1.3 fewer tokens than uninsured households without access to WII. Likewise, column (4) of Table 3.7 reports that purchasing WII decreases the probability of contributing more than 10 tokens by 31 percentage points as compared to uninsured households without access to WII. On the other hand, columns (5) and (6) of Table 3.7 show that there is no significant difference in contribution to the public good between uninsured households with and without access to WII. This reinforces our main findings that the introduction of formal insurance crowds out social capital. 
Table 3.7: The Effect Access to WII on Social Capital

\begin{tabular}{|c|c|c|c|c|c|c|}
\hline & \multicolumn{2}{|c|}{$\begin{array}{c}\text { Full-sample } \\
\text { Access (Insured+Uninsured) vs No-access (NA) }\end{array}$} & \multicolumn{2}{|c|}{$\begin{array}{l}\text { Sub-sample } \\
\text { Insured vs NA }\end{array}$} & \multicolumn{2}{|c|}{$\begin{array}{c}\text { Sub-sample } \\
\text { Uninsured (A) vs NA }\end{array}$} \\
\hline & $\begin{array}{l}(1) \\
\text { OLS }\end{array}$ & $\begin{array}{c}(2) \\
\text { Probit }\end{array}$ & $\begin{array}{l}\text { (3) } \\
\text { OLS }\end{array}$ & $\begin{array}{c}(4) \\
\text { Probit }\end{array}$ & OLS & $\begin{array}{c}(6) \\
\text { Probit }\end{array}$ \\
\hline Access to WII & $\begin{array}{l}-0.606^{* *} \\
(0.210)\end{array}$ & $\begin{array}{l}-0.147^{* *} \\
(0.062)\end{array}$ & & & & \\
\hline Insured & & & $\begin{array}{l}-1.259^{* * *} \\
(0.244)\end{array}$ & $\begin{array}{l}-0.310^{* * *} \\
(0.056)\end{array}$ & & \\
\hline Uninsured with access (A) & & & & & $\begin{array}{c}0.334 \\
(0.346)\end{array}$ & $\begin{array}{l}-0.069 \\
(0.066)\end{array}$ \\
\hline Age & $\begin{array}{c}0.118 \\
(0.206)\end{array}$ & $\begin{array}{c}0.024 \\
(0.018)\end{array}$ & $\begin{array}{l}0.053 \\
(0.300)\end{array}$ & $\begin{array}{c}0.015 \\
(0.020)\end{array}$ & $\begin{array}{c}0.336 \\
(0.272)\end{array}$ & $\begin{array}{c}0.037 \\
(0.027)\end{array}$ \\
\hline Age square & $\begin{array}{l}-0.001 \\
(0.002)\end{array}$ & $\begin{array}{l}-0.000 \\
(0.000)\end{array}$ & $\begin{array}{l}0.000 \\
(0.003)\end{array}$ & $\begin{array}{l}-0.000 \\
(0.000)\end{array}$ & $\begin{array}{l}-0.003 \\
(0.003)\end{array}$ & $\begin{array}{l}-0.000 \\
(0.000)\end{array}$ \\
\hline Male & $\begin{array}{l}-0.694 \\
(1.047)\end{array}$ & $\begin{array}{c}0.004 \\
(0.089)\end{array}$ & $\begin{array}{l}-0.355 \\
(0.981)\end{array}$ & $\begin{array}{c}0.025 \\
(0.097)\end{array}$ & $\begin{array}{c}0.001 \\
(0.886)\end{array}$ & $\begin{array}{c}0.057 \\
(0.080)\end{array}$ \\
\hline Household size & $\begin{array}{l}-0.120 \\
(0.253)\end{array}$ & $\begin{array}{l}-0.025 \\
(0.021)\end{array}$ & $\begin{array}{l}-0.085 \\
(0.331)\end{array}$ & $\begin{array}{l}-0.028 \\
\text { (0.018) }\end{array}$ & $\begin{array}{l}-0.441 \\
(0.282)\end{array}$ & $\begin{array}{c}-0.047^{* *} \\
(0.020)\end{array}$ \\
\hline Education & $\begin{array}{c}1.033 \\
(0.750)\end{array}$ & $\begin{array}{c}0.031 \\
(0.070)\end{array}$ & $\begin{array}{c}1.558 \\
(1.145)\end{array}$ & $\begin{array}{c}0.087 \\
(0.088)\end{array}$ & $\begin{array}{c}0.966 \\
(1.075)\end{array}$ & $\begin{array}{c}0.031 \\
(0.105)\end{array}$ \\
\hline Livestock & $\begin{array}{l}-0.039 \\
(0.064)\end{array}$ & $\begin{array}{c}0.001 \\
(0.008)\end{array}$ & $\begin{array}{c}-0.094 \\
(0.105)\end{array}$ & $\begin{array}{c}0.006 \\
\text { (0.009) }\end{array}$ & $\begin{array}{c}0.015 \\
(0.056)\end{array}$ & $\begin{array}{c}0.001 \\
(0.007)\end{array}$ \\
\hline Land owned & $\begin{array}{l}-0.051 \\
(0.096)\end{array}$ & $\begin{array}{l}-0.009 \\
(0.006)\end{array}$ & $\begin{array}{l}-0.030 \\
(0.129)\end{array}$ & $\begin{array}{l}-0.011^{*} \\
(0.006)\end{array}$ & $\begin{array}{c}-0.082^{* *} \\
(0.033)\end{array}$ & $\begin{array}{c}-0.013^{* * *} \\
(0.005)\end{array}$ \\
\hline Corrugated iron sheet & $\begin{array}{c}1.060 \\
(0.792)\end{array}$ & $\begin{array}{l}0.076^{* *} \\
(0.032)\end{array}$ & $\begin{array}{c}1.518 \\
(0.968)\end{array}$ & $\begin{array}{l}0.070^{*} \\
(0.040)\end{array}$ & $\begin{array}{c}1.285 \\
(0.852)\end{array}$ & $\begin{array}{l}0.106^{* *} \\
(0.050)\end{array}$ \\
\hline Belief & $\begin{array}{c}0.470^{* * *} \\
(0.044)\end{array}$ & $\begin{array}{c}0.042^{* * *} \\
(0.005)\end{array}$ & $\begin{array}{c}0.493^{* * *} \\
(0.077)\end{array}$ & $\begin{array}{c}0.041^{* * *} \\
(0.006)\end{array}$ & $\begin{array}{c}0.516^{* * *} \\
(0.070)\end{array}$ & $\begin{array}{c}0.046^{* * *} \\
(0.007)\end{array}$ \\
\hline Religion & $\begin{array}{l}-0.085 \\
(0.914)\end{array}$ & $\begin{array}{c}0.017 \\
(0.075)\end{array}$ & $\begin{array}{c}0.106 \\
(1.401)\end{array}$ & $\begin{array}{c}0.021 \\
(0.080)\end{array}$ & $\begin{array}{c}0.826 \\
(0.478)\end{array}$ & $\begin{array}{c}0.069 \\
(0.059)\end{array}$ \\
\hline Constant & $\begin{array}{c}2.432 \\
(5.279)\end{array}$ & & $\begin{array}{c}1.333 \\
(7.571)\end{array}$ & & $\begin{array}{l}-2.504 \\
(6.179)\end{array}$ & \\
\hline Village FE & Yes & Yes & Yes & Yes & Yes & Yes \\
\hline $\begin{array}{l}\text { Observations } \\
\text { R-squared }\end{array}$ & $\begin{array}{l}383 \\
0.296\end{array}$ & 383 & $\begin{array}{c}263 \\
0.268\end{array}$ & 263 & 263 & 263 \\
\hline Pseudo $R^{2}$ & & 0.288 & & 0.262 & & 0.306 \\
\hline
\end{tabular}

Notes. The dependent variable in columns (1), (3) and (5) is the number of tokens shared to the public good. The dependent variable in columns (2), (4) and (6) is a dummy variable taking a value of 1 if household $i$ contributed more than 10 tokens to the public good, o otherwise. Robust standard errors in parentheses, ${ }^{* *} \mathrm{p}<0.01,{ }^{* *} \mathrm{p}<0.05,{ }^{*} \mathrm{p}<0.1$. 


\subsubsection{B Alternative Measures of Social Capital}

As a further robustness check we use two alternative survey-based measures of social capital: (i) making private transfers to fellow villagers and (ii) financial contributions to community projects in the past 12 months. We examine if there is any systematic difference in investments in social capital between insured and uninsured households living in the same village. We find that the proportion of households who made private transfers to fellow villagers or finance community projects among insured households is about $34 \%$ and $74 \%$ respectively (standard deviation, 0.044 and 0.040 ) while that of those uninsured households is about $45 \%$ and $90 \%$ respectively (standard deviation, 0.046 and 0.030). This indicates that insured households are less likely to make private transfers to fellow villagers and finance community projects than uninsured households.

More formally, our regression result in column (I) of Table 3.8 shows that insured households are less likely to make private transfers to fellow villagers than uninsured households. The result shows that insured households have 11.5 percentage points lower probability of making private transfers to fellow villagers. In a similar vein, column (3) of Table 3.8 also shows that insured households are less likely to finance community projects than uninsured households. To be precise, insured households have 17.7 percentage points percentage points lower probability of contributing to community projects. However, private transfer to fellow villagers and financial contribution to community projects may be endogenous. To attenuate the endogeneity concern, we employ an IV approach. We use distance from the farm households' residence to the insurance foreman's residence as an instrument to WII uptake. We find somewhat weaker results in our IV model in columns (2) and (4) compared to the results in columns (1) and (3). Columns (2) and (4) of Table 3.8, show that although both making private transfers to fellow villagers and financing community projects have the expected negative sign, the coefficients enter insignificantly in the IV-LPM model.

As shown in Table B.3, insured households are relatively poor compared to uninsured households. On average, uninsured households own more livestock and farming land, and are more likely to own houses with improved roof than insured households. Hence, this may raise an important concern that insured households provided less transfer (contribution) to fellow villagers (community projects) not because of WII purchase per se rather because they are relatively poor. To address this concern, we confine our analysis to those who purchased WII only in cash (non-PSNP participants) and exclude those who purchased WII in labour (PSNP participants) from the analysis.

We first demonstrate that uninsured households and insured households (nonPSNP participants) are balanced and comparable in most of the wealth indicators. We find that insured households are no more poorer than uninsured households in 
terms of farming land and type of roof. However, insured households still own less livestock than uninsured households and we control for this difference in our regression analysis. We next examine whether insured households are still investing less in social capital after we restrict our insured households to the non-PSNP participants only. Interestingly, the results remain qualitatively the same. We find that insured households are less likely to provide transfers to fellow villagers and contribute to community projects. Furthermore, we explore the investment in social capital between insured households who purchase WII in labour and insured households who purchase WII in cash. If the argument that insured households provide less transfer (contribution) because they are disproportionately poor, we expect insured households who purchase WII in labour (PSNP participants) to transfer (contribute) less compared to those insured but non-PSNP households. However, our results show the reverse. Whilst we find that PSNP participants provided significantly more transfers to fellow villagers than non-PSNP participants, no significant difference is found in terms of contribution to community projects. To sum up, consistent with our hypothesis and findings from our experimental game, we still find that WII purchase appears to reduce investment in social capital. To economize on space, we do not provide the results but make them available upon request.

To further probe the robustness of our results, we examine the effect of WII purchase on other measures of social capital such as membership in informal institutions iddir and eqqub. The coefficients of both variables have the expected negative sign but not significantly different from zero. ${ }^{13}$ The lack of significant effect of WII on iddir membership may be driven by the fact that almost all insured and uninsured households are members of the funeral insurance group. As shown in Tables B.1 and B.2 in the appendix, about $95 \%$ of both insured and uninsured households are members of iddir, and this is consistent with what is reported in previous studies that more than $90 \%$ of rural households in Ethiopia are members of iddirs (Dercon et al., 2012). On the other hand, the insignificant effect of WII uptake on eqqub membership may be because, as farmers are cash-constrained, insured farmers still need to rely on these kinds of informal financial institutions to pay their insurance premium.

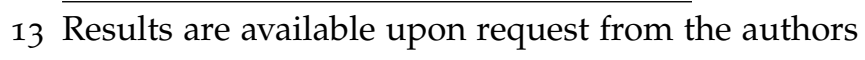


Table 3.8: Impact of WII on Real-life Measures of Social Capital

\begin{tabular}{|c|c|c|c|c|}
\hline & \multicolumn{2}{|c|}{ Private Transfers } & \multicolumn{2}{|c|}{ Financial Contribution } \\
\hline & $\begin{array}{c}(1) \\
\text { Probit } \\
\end{array}$ & $\begin{array}{c}(2) \\
\text { IV-LPM }\end{array}$ & $\begin{array}{c}(3) \\
\text { Probit }\end{array}$ & $\begin{array}{c}(4) \\
\text { IV-LPM } \\
\end{array}$ \\
\hline WII uptake & $\begin{array}{l}-0.115^{*} \\
(0.068)\end{array}$ & $\begin{array}{l}-0.065 \\
(0.194)\end{array}$ & $\begin{array}{c}-0.177^{* * *} \\
(0.053)\end{array}$ & $\begin{array}{l}-0.161 \\
(0.132)\end{array}$ \\
\hline Age & $\begin{array}{c}0.006 \\
(0.023)\end{array}$ & $\begin{array}{c}0.004 \\
(0.022)\end{array}$ & $\begin{array}{l}-0.015 \\
(0.013)\end{array}$ & $\begin{array}{l}-0.017 \\
(0.013)\end{array}$ \\
\hline Age square & $\begin{array}{l}-0.000 \\
(0.000)\end{array}$ & $\begin{array}{l}-0.000 \\
(0.000)\end{array}$ & $\begin{array}{c}0.000 \\
(0.000)\end{array}$ & $\begin{array}{c}0.000 \\
(0.000)\end{array}$ \\
\hline Male & $\begin{array}{l}-0.084 \\
(0.105)\end{array}$ & $\begin{array}{l}-0.078 \\
(0.099)\end{array}$ & $\begin{array}{c}0.082 \\
(0.071)\end{array}$ & $\begin{array}{c}0.070 \\
(0.069)\end{array}$ \\
\hline Household size & $\begin{array}{l}-0.021 \\
(0.022)\end{array}$ & $\begin{array}{l}-0.018 \\
(0.020)\end{array}$ & $\begin{array}{l}0.020^{*} \\
(0.011)\end{array}$ & $\begin{array}{l}0.026^{*} \\
(0.014)\end{array}$ \\
\hline Education & $\begin{array}{c}0.041 \\
(0.087)\end{array}$ & $\begin{array}{c}0.032 \\
(0.080)\end{array}$ & $\begin{array}{c}0.001 \\
(0.041)\end{array}$ & $\begin{array}{c}0.012 \\
(0.053)\end{array}$ \\
\hline Livestock & $\begin{array}{l}-0.022^{*} \\
(0.012)\end{array}$ & $\begin{array}{l}-0.020^{* *} \\
(0.010)\end{array}$ & $\begin{array}{c}0.005 \\
(0.006)\end{array}$ & $\begin{array}{c}0.004 \\
(0.005)\end{array}$ \\
\hline Land owned & $\begin{array}{l}0.043^{* *} \\
(0.017)\end{array}$ & $\begin{array}{l}0.041^{* * *} \\
(0.014)\end{array}$ & $\begin{array}{l}-0.010 \\
(0.008)\end{array}$ & $\begin{array}{l}-0.010 \\
(0.010)\end{array}$ \\
\hline Corrugated iron sheet & $\begin{array}{c}0.115 \\
(0.086)\end{array}$ & $\begin{array}{c}0.105 \\
(0.083)\end{array}$ & $\begin{array}{l}-0.109^{* *} \\
(0.047)\end{array}$ & $\begin{array}{c}-0.126^{* *} \\
(0.054)\end{array}$ \\
\hline Religion & $\begin{array}{l}-0.029 \\
(0.115)\end{array}$ & $\begin{array}{l}-0.028 \\
(0.107)\end{array}$ & $\begin{array}{l}-0.030 \\
(0.039)\end{array}$ & $\begin{array}{l}-0.048 \\
(0.048)\end{array}$ \\
\hline Constant & & $\begin{array}{c}0.191 \\
(0.488)\end{array}$ & & $\begin{array}{c}1.011^{* * *} \\
(0.257)\end{array}$ \\
\hline Village FE & Yes & Yes & Yes & Yes \\
\hline Observations & 240 & 240 & 240 & 240 \\
\hline R-squared & & 0.107 & & 0.138 \\
\hline Pseudo $R^{2}$ & 0.083 & & 0.181 & \\
\hline Distance to foreman & & $\begin{array}{c}-0.012^{* * *} \\
(0.002)\end{array}$ & & $\begin{array}{c}-0.012^{* * *} \\
(0.002)\end{array}$ \\
\hline First stage F-test & & 59.168 & & 59.168 \\
\hline
\end{tabular}

Notes. The dependent variable in columns (1) and (2) is a dummy variable taking a value of 1 if a household provided private transfers to fellow villagers, o otherwise. The dependent variable in columns (3) and (4) is a dummy variable taking a value of 1 if a household made financial contributions to community projects, o otherwise. The table reports marginal effects probit in (1) and (3). Robust standard errors in parentheses, ${ }^{* * *} \mathrm{p}<0.01,{ }^{* *} \mathrm{p}<0.05,{ }^{*} \mathrm{p}<0.1$. 


\subsubsection{Propensity Score Matching}

To further probe the robustness of our results, that is, the introduction of formal insurance crowds out pre-existing informal insurance mechanisms, estimates from the OLS and 2SLS models are compared with estimates obtained using kernel based matching methods. We are well aware that PSM does not account for selection bias due to unobservable factors.

The credibility of our matching results depend on whether the two underlying assumptions - conditional independence assumption (CIA) and common support condition - are satisfied. To check whether the CIA is met, we conduct a two-sample t-test to test for the difference in observable means for insured and uninsured households before and after matching. We also conduct a chi-square test for the joint significance of variables used in the propensity score estimation before and after matching. Table B. 5 in the appendix shows that although there were significant differences in some of the covariates before matching, these differences disappear after matching and matching has substantially reduced the difference in mean bias between insured and uninsured households. Table 3.9 presents the chi-square test, pseudo $R^{2}$ and mean standardized bias. The chi-square $\left(\mathrm{P}>\mathrm{Chi}^{2}=1.000\right)$ test indicates that the covariates are not jointly significant after matching. Also the low pseudo $R^{2}$ (Pseudo $\left.R^{2}=0.005\right)$, indicates no systematic difference in the distribution of covariates between insured and uninsured households after matching. Moreover, Table 3.9 presents the mean difference before and after matching. It shows that the mean standardized bias has reduced from $15.3 \%$ before matching to $3.6 \%$ after matching. This implies that matching has reduced total mean bias by about $77 \%$.

Table 3.9: Matching Quality Test

\begin{tabular}{cccc}
\hline & $\begin{array}{c}(1) \\
\text { Pseudo } \mathrm{R}^{2}\end{array}$ & $\begin{array}{c}(2) \\
\mathrm{P}>\mathrm{chi}^{2}\end{array}$ & $\begin{array}{c}\text { (3) } \\
\text { Mean bias }\end{array}$ \\
\hline Before matching & 0.078 & 0.017 & 15.3 \\
After matching & 0.005 & 1.000 & 3.6 \\
\hline
\end{tabular}

We then proceed by checking the common support condition after estimating the propensity scores for insured and uninsured households. The predicted propensity scores for insured and uninsured households ranges from 0.188 to 0.848 , and 0.147 to 0.785 respectively. Thus, the common support condition is satisfied in the region of 0.188 to 0.785 , which indicates a substantial overlap between insured and uninsured groups, as also shown in the propensity scores distributions and density distribution graphs presented in Figures B.1 and B.2 in the appendix. In sum, this suggests we have been able to generate comparable groups through matching. 
Table 3.10: Impact of WII on Social Capital - Matching Results

\begin{tabular}{lccc}
\hline & Insured & Uninsured & Difference \\
\hline Unmatched & 7.975 & 9.433 & $-1.458^{*}$ \\
& & & $(0.831)$ \\
Matched (ATT) & 8 & 10.336 & $-2.336^{* *}$ \\
& & & $(0.935)$ \\
\hline
\end{tabular}

Notes. Standard errors in parentheses, ${ }^{* * *} \mathrm{p}<0.01,{ }^{* *} \mathrm{p}<0.05,{ }^{*} \mathrm{p}<0.1$.

Table 3.10 presents the treatment effect of WII on social capital. We used Kernel matching with the default kernel type and bandwidth. Table 3.10 presents a negative and statistically significant effect of WII on social capital. However, the coefficient of matching estimates are larger than the coefficients in OLS estimates but smaller than the coefficients in the 2SLS estimates, indicating the presence of selection-bias due to observable and unobservable factors. Our matching estimates remain robust for other matching algorithms such as nearest neighbour matching.

\subsubsection{Impact Pathways}

In this section, we attempt to uncover the channels through which WII crowds out social capital. First, we scrutinize the argument put forward by (Boucher \& Delpierre, 2014) that the introduction of WII may crowd out informal risk sharing arrangements if the informal risk sharing groups suffer from a moral hazard problem. That is, WII may encourage insured households to adopt or experiment very risky technologies and impose external costs on the informal risk sharing groups, specifically, on the uninsured ones, who in turn respond by lowering their investment in social capital. For moral hazard to be a causal mechanism in this context, we should observe insured households to significantly adopt more risky technologies such as chemical fertilizer and improved seed than uninsured households. Also, we should observe lower contribution among uninsured households, driving the crowding out effect. However, we do not find a significant difference in technology adoption between insured and uninsured households. ${ }^{14}$ Moreover, insured rather than uninsured households made lower contributions to the public good, suggesting that moral hazard is unlikely to be the underlying mechanism.

14 To check whether insured households adopt more risky technologies than uninsured households, we collected data on households adoption of chemical fertilizer, improved seeds and pesticides. We ran Probit and IV-LPM models and find no significant difference in the adoption of these technologies between insured and uninsured households. Details are available upon request. 
Table 3.11: Free-riding and Self-sufficiency Behaviours as the Causal Mechanisms?

\begin{tabular}{|c|c|c|c|c|}
\hline & \multicolumn{2}{|c|}{ No Free-riding } & \multicolumn{2}{|c|}{ Self-sufficiency } \\
\hline & $\begin{array}{c}(1) \\
\text { Probit }\end{array}$ & $\begin{array}{c}(2) \\
\text { IV-LPM }\end{array}$ & $\begin{array}{c}(3) \\
\text { Probit }\end{array}$ & $\begin{array}{c}(4) \\
\text { IV-LPM }\end{array}$ \\
\hline WII uptake & $\begin{array}{l}-0.105^{*} \\
(0.062)\end{array}$ & $\begin{array}{c}-0.428^{* *} \\
(0.183)\end{array}$ & $\begin{array}{l}0.191^{* *} \\
(0.075)\end{array}$ & $\begin{array}{l}0.361^{* *} \\
(0.167)\end{array}$ \\
\hline Age & $\begin{array}{l}-0.018 \\
(0.018)\end{array}$ & $\begin{array}{l}-0.006 \\
(0.020)\end{array}$ & $\begin{array}{c}0.021 \\
(0.022)\end{array}$ & $\begin{array}{c}0.014 \\
(0.020)\end{array}$ \\
\hline Age square & $\begin{array}{c}0.000 \\
(0.000)\end{array}$ & $\begin{array}{c}0.000 \\
(0.000)\end{array}$ & $\begin{array}{l}-0.000 \\
(0.000)\end{array}$ & $\begin{array}{l}-0.000 \\
(0.000)\end{array}$ \\
\hline Male & $\begin{array}{l}-0.047 \\
(0.077)\end{array}$ & $\begin{array}{l}-0.078 \\
(0.093)\end{array}$ & $\begin{array}{c}0.088 \\
(0.088)\end{array}$ & $\begin{array}{c}0.092 \\
(0.085)\end{array}$ \\
\hline Household size & $\begin{array}{c}0.030 \\
(0.021)\end{array}$ & $\begin{array}{c}0.017 \\
(0.020)\end{array}$ & $\begin{array}{l}-0.005 \\
(0.023)\end{array}$ & $\begin{array}{c}0.005 \\
(0.019)\end{array}$ \\
\hline Education & $\begin{array}{l}-0.133^{*} \\
(0.072)\end{array}$ & $\begin{array}{l}-0.092 \\
(0.072)\end{array}$ & $\begin{array}{c}0.229^{* * *} \\
(0.083)\end{array}$ & $\begin{array}{l}0.185^{* *} \\
(0.075)\end{array}$ \\
\hline Livestock & $\begin{array}{l}0.019^{* *} \\
(0.009)\end{array}$ & $\begin{array}{l}0.014^{*} \\
(0.008)\end{array}$ & $\begin{array}{c}-0.030^{* * *} \\
(0.011)\end{array}$ & $\begin{array}{c}-0.024^{* * *} \\
(0.008)\end{array}$ \\
\hline Land owned & $\begin{array}{l}-0.023^{*} \\
(0.013)\end{array}$ & $\begin{array}{l}-0.023^{*} \\
(0.012)\end{array}$ & $\begin{array}{c}0.011 \\
(0.014)\end{array}$ & $\begin{array}{c}0.011 \\
(0.014)\end{array}$ \\
\hline Corrugated iron sheet & $\begin{array}{l}-0.135^{*} \\
(0.071)\end{array}$ & $\begin{array}{c}-0.155^{* *} \\
(0.066)\end{array}$ & $\begin{array}{l}0.181^{* *} \\
(0.080)\end{array}$ & $\begin{array}{l}0.183^{* *} \\
(0.072)\end{array}$ \\
\hline Religion & $\begin{array}{c}0.076 \\
(0.100)\end{array}$ & $\begin{array}{c}0.104 \\
(0.106)\end{array}$ & $\begin{array}{l}-0.204^{*} \\
(0.118)\end{array}$ & $\begin{array}{l}-0.169^{*} \\
(0.087)\end{array}$ \\
\hline Constant & & $\begin{array}{l}0.957^{* *} \\
(0.441)\end{array}$ & & $\begin{array}{c}0.223 \\
(0.463)\end{array}$ \\
\hline Village FE & Yes & Yes & Yes & Yes \\
\hline Observations & 240 & 240 & 240 & 240 \\
\hline R-squared & & 0.024 & & 0.188 \\
\hline Pseudo $R^{2}$ & 0.122 & & 0.193 & \\
\hline Distance to foreman & & $\begin{array}{c}-0.012^{* * *} \\
(0.001)\end{array}$ & & $\begin{array}{c}-0.012^{* * *} \\
(0.001)\end{array}$ \\
\hline First stage F-test & & 59.168 & & 59.168 \\
\hline
\end{tabular}

Notes. The dependent variable in columns (1) and (2) is a dummy variable taking a value of $I$ if the respondent believes that most people in the village would try to be fair, o otherwise. The dependent variable in columns (3) and (4) is also is a dummy variable taking a value of 1 if the respondent believes that he can be successful on his own, o otherwise. The table reports marginal effects probit in (1) and (3). Robust standard errors in parentheses, ${ }^{* * *} p<0.01$, ${ }^{* *} \mathrm{p}<0.05,{ }^{*} \mathrm{p}<0.1$. 
Second, one may think that WII creates a positive externality thereby inducing freeriding behavior among the uninsured that insured households anticipate, thereby lowering their contribution (De Janvry et al., 2014). Third, the effect may be due to what we call self-sufficiency behavior. Yet, as both effects would go in the same direction (i.e. reduced contributions among the insured), it is hard to empirically disentangle between the two. Although far from perfect, our data goes some way in examining the two explanations. In our survey we included questions about households' self-sufficiency behavior and their perception about the free-riding problem in their villages. More precisely, to measure households' self-sufficiency behavior following Di Tella et al. (2007) we ask households: "Do you believe that it is possible to be successful on your own, or a large group that supports each other is necessary?" In a similar vein, to measure problems of free-riding in each village, we ask households the question in the World Value Survey (WVS) questionnaire: "Do you think most people in this village would try to take advantage of you if they got a chance, or would they try to be fair?"

The proportion of households answering "it is possible to be successful on your own" and "village people would take advantage of you if they got a chance" among those who have purchased WII is 0.483 and 0.342 respectively (standard deviation, 0.0458 and 0.044 ) while that of those who have not purchased WII is respectively 0.325 and 0.25 (standard deviation, 0.0429 and 0.040). Similarly, our regression results in Table 3.11 show a statistically significant correlation between purchase of WII and perception about villagers free-riding and self-sufficiency behavior, both in the probit and IV (we use the distance from farm household's residence to the insurance foreman's residence as an instrument) models. Thus, insured households are more likely to perceive that fellow villagers would free-ride on them if they got a chance and are more likely to believe that they can be successful without the support of a large group, suggesting both mechanisms may be at work.

\subsection{CONCLUSION}

This study provides the first empirical evidence on the impact of weather index insurance (WII) on social capital. While index insurance is a promising innovation that helps small-holder farmers to buffer against weather shocks, the introduction of index insurance may crowd out pre-existing informal insurance mechanisms and related social capital. We use a unique data set from a lab-in-the-field experiment from northern Ethiopia where WII has been commercially traded to small-holder farmers since 2010. We use contributions in the public good game, and self-reported survey responses on private transfers to fellow villagers and financial contributions to community projects as measures of social capital. As the WII uptake was on a voluntary basis, we use an instrumental variables (IV) approach to attenuate the potential endogeneity concern. 
We utilize the low-mobility of farm households in the rural areas of Tigray region, northern Ethiopia to instrument WII uptake with the distance from farm household's residence to the insurance foreman's residence. The insurance foreman acts as a liaison between farmers and the insurance companies, and plays a paramount role in the promotion and marketing of the insurance policy.

Our empirical results support the crowding out hypothesis. We find that insured households contribute fewer tokens to the public good than uninsured households. Ceteris paribus, insured households contribute about 3.9 fewer tokens to the public good than uninsured households. In a similar vein, WII uptake decreases the probability of being high cooperative, that is, contributing more than half of his/her endowment to the public good by 31 percentage points. The WII market in the study area has a unique feature as farmers have the option to pay their insurance premium either in cash or in labor. In our sample, we included farm households who paid their insurance premium either in cash or in labor. We find that both types of insured households are equally responsible for the crowding out effect, meaning that the payment method has no systematic impact on the crowding out effect. To probe the robustness of our findings, we conduct a series of robustness checks. First, we examine the effect of access to WII, irrespective of whether or not individual households received the treatment, on social capital. Before estimating the effect of access to WII, we show that households in access and no access villages are similar in their socio-economic and demographic characteristics using pre-intervention data - the 2007 Ethiopian Population and Housing Census data. Moreover, using the propensity score matching, we created better counterfactual. We find that households in access villages invest less in social capital than households in no access villages and this result is mainly driven by the insured households. Second, we gauge the impact of WII uptake on alternative measures of social capital such as transfers to fellow villagers and financial contribution to community projects. We find that insured households are less likely to make private transfers to fellow villagers or finance community projects than uninsured households. Furthermore, we also conduct other robustness checks that all point in the same direction as our main findings and support the notion that issues of selfselection are not driving our results.

We next investigate the potential channels through which WII crowds out social capital. Theoretically, WII may crowd out social capital through; (i) a moral hazard problem in the informal risk sharing arrangements, (ii) issues of free-riding created by the positive externality of WII and (iii) self-sufficiency behavior. We find that anticipated free-riding by uninsured households and self-sufficiency behavior are plausible channels through which WII crowds out social capital. We find no support for the idea that moral hazard is a possible mechanism explaining our results.

Finally, some directions for future research are relevant. First, further studies on the effect of index insurance on social capital are relevant to probe the robustness of our 
findings in other contexts such as in different population and study area. Second, as WII and social capital indemnify aggregate and idiosyncratic risks respectively, the net effect of WII on welfare depends on whether the intended positive effects of WII outweigh its unintended (crowding out effect) negative effects. On the one hand, WII may improve welfare through increased technology adoption and productivity. On the other hand, it may deteriorate welfare as idiosyncratic risks may remain uncovered as a result of crowding out effect of social capital. Thus far, empirical evidence on the effect of WII on welfare accounting for such crowding effects is scarce. Third, overcoming such potential unintended (crowding out) effects require novel insurance product designs and marketing strategies, including for example offering WII to groups instead of to individuals as suggested by Boucher \& Delpierre (2014) and De Janvry et al. (2014). Evaluating and comparing such alternatives is left for future work. 


\section{REFERENCES}

Amha, W., Peck, D., Berhane, G., Assefa, Y. \& Kidanu, B. (2013), 'Diagnostic study of providing micro-insurance services to low-income households in Ethiopia: An input to a national micro-insurance strategy.'. Ethiopia Strategy Support Program II - International Food Policy Research Institute.

Angrist, J. D. \& Pischke, J. S. (2008), Mostly harmless econometrics: An empiricist's companion, Princeton University Press.

Attanasio, O., Polanía-Reyes, S. \& Pellerano, L. (2015), 'Building social capital: Conditional cash transfer programmes and cooperation', Journal of Economic Behavior $\mathcal{E}$ Organization 118, 22-39.

Attanasio, O. \& Rios-Rull, J.-V. (2000), ‘Consumption smoothing in island economies: Can public insurance reduce welfare?', European Economic Review 44(7), 1225-1258.

Awel, Y. \& Azomahou, T. T. (2015), Risk preference or financial literacy? behavioural experiment on index insurance demand. UNU-MERIT Working Paper No. 005.

Baland, J.-M., Guirkinger, C. \& Mali, C. (2011), 'Pretending to be poor: Borrowing to escape forced solidarity in cameroon', Economic Development and Cultural Change 60(1), $1-16$.

Beekman, G., Gatto, M. \& Nillesen, E. (2015), 'Family networks and income hiding: evidence from lab-in-the-field experiments in rural liberia', Journal of African Economies 24(3), 453-469.

Belissa, T., Bulte, E., Cecchi, F., Gangopadhyay, S. \& Lensink, R. (2019), 'Liquidity constraints, informal institutions, and the adoption of weather insurance: A randomized controlled trial in ethiopia', Journal of Development Economics .

Berg, E., Blake, M. \& Morsink, K. (2017), Risk sharing and the demand for insurance: Theory and experimental evidence from Ethiopia. CSAE Working Paper WPS/201701.

Bertram-Huemmer, V. \& Kraehnert, K. (2017), 'Does index insurance help households recover from disaster? evidence from ibli mongolia', American Journal of Agricultural Economics 100(1), 145-171.

Boltz, M., Marazyan, K. \& Villar, P. (2019), 'Income hiding and informal redistribution: A lab-in-the-field experiment in senegal', Journal of Development Economics 137, 7892.

Boucher, S. \& Delpierre, M. (2014), The impact of index-based insurance on informal risk-sharing arrangement. Luxembourg Institute of Socio-Economic Research (LISER) Working Paper Series. 
Bowles, S. (2008), 'Policies designed for self-interested citizens may undermine" the moral sentiments": Evidence from economic experiments', Science 320(5883), 16051609 .

Carpenter, J. P., Daniere, A. G. \& Takahashi, L. M. (2004), 'Cooperation, trust, and social capital in Southeast Asian urban slums', Journal of Economic Behavior E Organization 55(4), 533-551.

Cecchi, F., Duchoslav, J. \& Bulte, E. (2016), 'Formal insurance and the dynamics of social capital: Experimental evidence from Uganda', Journal of African Economies 25(3), 418-438.

Clarke, D. J. (2016), 'A theory of rational demand for index insurance', American Economic Journal: Microeconomics 8(1), 283-306.

Cochard, F., Van, P. N. \& Willinger, M. (2004), 'Trusting behavior in a repeated investment game', Journal of Economic Behavior E Organization 55(1), 31-44.

Cole, S., Giné, X., Tobacman, J., Topalova, P., Townsend, R. \& Vickery, J. (2013), ‘Barriers to household risk management: Evidence from India', American Economic Journal: Applied Economics 5(1), 104-135.

Cole, S., Giné, X. \& Vickery, J. (2017), 'How does risk management influence production decisions? Evidence from a field experiment', The Review of Financial Studies 30(6), 1935-1970.

Coleman, J. S. (1988), 'Social capital in the creation of human capital', American Journal of Sociology 94, S95-S120.

Collier, B. L. (2018), 'Strengthening local credit markets through lender-level index insurance', Journal of Risk and Insurance.

Collier, P. \& Garg, A. (1999), 'On kin groups and wages in the ghanaian labour market', Oxford Bulletin of Economics and Statistics 61(2), 133-151.

De Janvry, A., Dequiedt, V. \& Sadoulet, E. (2014), 'The demand for insurance against common shocks', Journal of Development Economics 106, 227-238.

de Nicola, F. (2015), 'The impact of weather insurance on consumption, investment, and welfare', Quantitative Economics 6(3), 637-661.

Dercon, S., Hill, R. V., Clarke, D., Outes-Leon, I. \& Taffesse, A. S. (2014), 'Offering rainfall insurance to informal insurance groups: Evidence from a field experiment in Ethiopia', Journal of Development Economics 106, 132-143.

Dercon, S., Hoddinott, J., Krishnan, P. \& Woldehanna, T. (2012), Burial societies in rural Ethiopia, in E. Mwangi, H. Markelova \& R. Meinzen-Dick, eds, 'Collective Action and Property Rights for Poverty Reduction: Insights from Africa and Asia', Johns Hopkins University Press, Baltimore, pp. 51-78.

Dercon, S. \& Krishnan, P. (2003), 'Risk sharing and public transfers', The Economic Journal 113(486), C86-C94. 
Dercon, S. \& Porter, C. (2014), 'Live aid revisited: Long-term impacts of the 1984 Ethiopian famine on children', Journal of the European Economic Association 12(4), 927948.

Di Falco, S. \& Bulte, E. (2011), 'A dark side of social capital? Kinship, consumption, and savings', Journal of Development Studies 47(8), 1128-1151.

Di Falco, S., Chavas, J.-P. \& Smale, M. (2007), 'Farmer management of production risk on degraded lands: the role of wheat variety diversity in the Tigray region, Ethiopia', Agricultural Economics 36(2), 147-156.

Di Falco, S., Feri, F., Pin, P. \& Vollenweider, X. (2018), 'Ties that bind: Network redistributive pressure and economic decisions in village economies', Journal of Development Economics 131, 123-131.

Di Falco, S., Veronesi, M. \& Yesuf, M. (2011), 'Does adaptation to climate change provide food security? A micro-perspective from Ethiopia', American Journal of Agricultural Economics 93(3), 829-846.

Di Tella, R., Galiant, S. \& Schargrodsky, E. (2007), 'The formation of beliefs: Evidence from the allocation of land titles to squatters', The Quarterly Journal of Economics 122(1), 209-241.

Duru, M. J. (2016), 'Too Certain to Invest? Public Safety Nets and Insurance Markets in Ethiopia', World Development 78, 37-51.

Engle-Warnick, J. \& Slonim, R. L. (2004), 'The evolution of strategies in a repeated trust game', Journal of Economic Behavior E Organization 55(4), 553-573.

Engle-Warnick, J. \& Slonim, R. L. (2006), 'Learning to trust in indefinitely repeated games', Games and Economic Behavior 54(1), 95-114.

Falk, A. \& Fischbacher, U. (2006), 'A theory of reciprocity', Games and economic behavior 54(2), 293-315.

Fehr, E. \& Gächter, S. (2000), 'Fairness and retaliation: The economics of reciprocity', Journal of Economic Perspectives 14(3), 159-181.

Fudenberg, D. \& Maskin, E. (2009), The folk theorem in repeated games with discounting or with incomplete information, in 'A Long-Run Collaboration On Long-Run Games', World Scientific, pp. 209-230.

Gilligan, M. J., Pasquale, B. J. \& Samii, C. (2015), 'Civil war and social cohesion: Labin-the-field evidence from Nepal', American Journal of Political Science 58(3), 604-619.

Giné, X., Townsend, R. \& Vickery, J. (2008), 'Patterns of rainfall insurance participation in rural India', The World Bank Economic Review 22(3), 539-566.

Giné, X. \& Yang, D. (2009), 'Insurance, credit, and technology adoption: Field experimental evidence from Malawi', Journal of Development Economics 89(1), 1-11.

Gneezy, U. \& Rustichini, A. (2000), 'Pay enough or don't pay at all', The Quarterly Journal of Economics 115(3), 791-810. 
Grimm, M., Hartwig, R. \& Lay, J. (2017), 'Does forced solidarity hamper investment in small and micro enterprises?', Journal of Comparative Economics 45(4), 827-846.

Hagos, F., Pender, J. \& Gebreselassie, N. (1999), Land degradation in the highlands of Tigray and strategies for sustainable land management. Socioeconomic and Policy Research Working Paper 25.

Hagosa, F., Makombe, G., Namara, R. \& Awulachew, S. (2010), 'Importance of irrigated agriculture to the Ethiopian economy: Capturing the direct net benefits of irrigation', Ethiopian Journal of Development Research 32(1).

Hall, R. E. \& Jones, C. I. (1999), 'Why do some countries produce so much more output per worker than others?', The Quarterly Journal of Economics 114(1), 83-116.

Hill, R. V., Hoddinott, J. \& Kumar, N. (2013), 'Adoption of weather-index insurance: learning from willingness to pay among a panel of households in rural Ethiopia', Agricultural Economics 44(4-5), 385-398.

Jakiela, P. \& Ozier, O. (2015), 'Does africa need a rotten kin theorem? experimental evidence from village economies', The Review of Economic Studies 83(1), 231-268.

Janzen, S. A. \& Carter, M. R. (2018), 'After the drought: The impact of microinsurance on consumption smoothing and asset protection', American Journal of Agricultural Economics 101(3), 651-671.

Karlan, D., Osei, R., Osei-Akoto, I. \& Udry, C. (2014), 'Agricultural decisions after relaxing credit and risk constraints', The Quarterly Journal of Economics 129(2), 597652.

Karlan, D. S. (2005), 'Using experimental economics to measure social capital and predict financial decisions', American Economic Review 95(5), 1688-1699.

Kocher, M. G., Martinsson, P., Matzat, D. \& Wollbrant, C. (2015), 'The role of beliefs, trust, and risk in contributions to a public good', Journal of Economic Psychology 51, 236-244.

Landmann, A., Vollan, B. \& Frölich, M. (2012), Insurance versus savings for the poor: Why one should offer either both or none. IZA Discussion Paper No. 6298.

Leblois, A. \& Quirion, P. (2013), 'Agricultural insurances based on meteorological indices: Realizations, methods and research challenges', Meteorological Applications 20(1), 1-9.

Levitt, S. D. \& List, J. A. (2007), 'What do laboratory experiments measuring social preferences reveal about the real world?', Journal of Economic Perspectives 21(2), 153174 .

Lin, W., Liu, Y. \& Meng, J. (2014), 'The crowding-out effect of formal insurance on informal risk sharing: An experimental study', Games and Economic Behavior 86, 184211.

Madajewicz, M., Tsegay, A. H. \& Lee, R. (2017), Managing risks in smallholder agriculture: The impacts of $\mathrm{R}_{4}$ on livelihoods in Tigray, Ethiopia from 2012 to 2016, 
Technical report. Oxfam America Evaluation Report. Technical report, WFP/OA.

McIntosh, C., Sarris, A. \& Papadopoulos, F. (2013), 'Productivity, credit, risk, and the demand for weather index insurance in smallholder agriculture in Ethiopia', Agricultural Economics 44(4-5), 399-417.

Mehrotra, R., Vandewalle, L. \& Somville, V. (2019), 'Increasing trust in the bank to enhance savings: Experimental evidence from India', Economic Development and Cultural Change forthcoming.

Melesse, M. B. \& Cecchi, F. (2017), 'Does market experience attenuate risk aversion? evidence from landed farm households in ethiopia', World Development 98, 447-466.

Miguel, E. \& Gugerty, M. K. (2005), 'Ethnic diversity, social sanctions, and public goods in Kenya', Journal of Public Economics 89(11-12), 2325-2368.

Mobarak, A. M. \& Rosenzweig, M. R. (2012), Selling formal insurance to the informally insured. Yale Economics Department Working Paper No. 97.

Morduch, J. (1999), 'Between the state and the market: Can informal insurance patch the safety net?', The World Bank Research Observer 14(2), 187-207.

Munro, L. (2015), Risk Sharing, Networks and Investment Choices in Rural India, PhD thesis, London School of Economics and Political Science (LSE).

National Planning Commission (2017), 'Ethiopia's progress towards eradicating poverty: An interim report on 2015/16 poverty analysis study'. Addis Ababa, Ethiopia.

Oxfam America (2013), R4 rural resilience initiative annual report: January-December 2013, Technical report.

Oxfam America (2017), R4 rural resilience initiative quarterly report: April-June 2017, Technical report.

Pender, J. \& Gebremedhin, B. (2007), 'Determinants of agricultural and land management practices and impacts on crop production and household income in the highlands of Tigray, Ethiopia', Journal of African Economies 17(3), 395-450.

Rabin, M. (1993), 'Incorporating fairness into game theory and economics', The American Economic Rreview 85(3), 1281-1302.

Stock, J. H., Wright, J. H. \& Yogo, M. (2002), 'A survey of weak instruments and weak identification in generalized method of moments', Journal of Business $\mathcal{E}$ Economic Statistics 20(4), 518-529.

Storck, H., Doppler, W. et al. (1991), Farming systems and farm management practices of smallholders in the Hararghe Highlands, Wissenschaftsverlag Vauk Kiel.

Strupat, C. \& Klohn, F. (2018), 'Crowding out of solidarity? Public health insurance versus informal transfer networks in Ghana', World Development 104, 212-221.

Tadesse, M. A., Alfnes, F., Erenstein, O. \& Holden, S. T. (2017), ‘Demand for a laborbased drought insurance scheme in Ethiopia: A stated choice experiment approach', Agricultural Economics 48(4), 501-511. 
Tafere, K., Barrett, C. B. \& Lentz, E. (2018), 'Insuring well-being? Buyer's remorse and peace of mind effects from insurance', American Journal of Agricultural Economics $101(3), 627-650$.

Taffesse, A. S., Dorosh, P. \& Asrat, S. (2012), Crop production in Ethiopia: Regional patterns and trends, in P. Dorosh \& S. Asrat, eds, 'Food and agriculture in Ethiopia: Progress and policy challenges', Philadelphia: IFPRI/ Pennsylvania University Press, pp. 53-83.

Theil, H. \& Finke, R. (1983), 'The distance from the equator as an instrumental variable', Economics Letters 13(4), 357-360.

Townsend, R. M. (1994), 'Risk and insurance in village India', Econometrica 62(3), 295321.

Van Rijn, F., Bulte, E. \& Adekunle, A. (2012), 'Social capital and agricultural innovation in Sub-Saharan Africa', Agricultural Systems 108, 112-122.

Vohs, K. D., Mead, N. L. \& Goode, M. R. (2006), 'The psychological consequences of money', Science 314(5802), 1154-1156.

Vohs, K. D., Mead, N. L. \& Goode, M. R. (2008), 'Merely activating the concept of money changes personal and interpersonal behavior', Current Directions in Psychological Science 17(3), 208-212.

Zhou, X., Vohs, K. D. \& Baumeister, R. F. (2009), 'The symbolic power of money: Reminders of money alter social distress and physical pain', Psychological Science 20(6), 700-706. 
Table B.ı: Summary Statistics - Full Sample

\begin{tabular}{lccccc}
\hline \multicolumn{1}{c}{ Variable } & Mean & Std. Dev. & Min. & Max. & N \\
\hline Demographic Characteristics & & & & & \\
Age & 40.755 & 11.254 & 19 & 75 & 383 \\
Age square & 1787.261 & 1003.748 & 361 & 5625 & 383 \\
Male & 0.76 & 0.428 & 0 & 1 & 383 \\
Household size & 5.24 & 2.052 & 1 & 13 & 383 \\
Marital status & 0.820 & 0.385 & 0 & 1 & 383 \\
Illiterate & 0.598 & 0.491 & 0 & 1 & 383 \\
Can read and write & 0.133 & 0.34 & 0 & 1 & 383 \\
Primary school & 0.219 & 0.414 & 0 & 1 & 383 \\
Secondary school & 0.05 & 0.217 & 0 & 1 & 383 \\
Wealth & & & & & \\
Livestock (TLU) & 4.268 & 4.104 & 0 & 20 & 383 \\
Land size (Tsimad) & 4.745 & 3.471 & 0 & 18.5 & 383 \\
Corrugated iron sheet roof & 0.452 & 0.498 & 0 & 1 & 383 \\
Own radio & 0.198 & 0.399 & 0 & 1 & 383 \\
Own phone & 0.752 & 0.432 & 0 & 1 & 383 \\
Membership in associations & & & & & \\
Iddir participation & 0.950 & 0.217 & 0 & 1 & 383 \\
Eqqub participation & 0.418 & 0.494 & 0 & 1 & 383 \\
\hline & & & & &
\end{tabular}


Table B.2: Descriptive Statistics by Access to WII

\begin{tabular}{lcccc}
\hline & & & & \\
& No access & Access & Diff & P-Value \\
\hline Demographic Characteristics & & & & \\
Age & 41.091 & 40.554 & 0.537 & 0.652 \\
Age square & 1840.028 & 1755.821 & 84.207 & 0.428 \\
Male & 0.720 & 0.7833 & -0.063 & 0.163 \\
Household size & 5.056 & 5.350 & -0.294 & 0.175 \\
Illiterate & 0.580 & 0.608 & -0.028 & 0.591 \\
Can read and write & 0.168 & 0.113 & 0.055 & 0.124 \\
Primary school & 0.203 & 0.229 & -0.026 & 0.548 \\
Secondary school & 0.049 & 0.050 & -0.001 & 0.964 \\
Wealth & & & & \\
Livestock & 3.025 & 5.008 & -1.982 & 0.000 \\
Land size & 4.555 & 4.859 & -0.305 & 0.407 \\
Corrugated iron sheet roof & 0.504 & 0.421 & 0.083 & 0.117 \\
Membership in associations & & & & \\
Iddir participation & 0.930 & 0.963 & -0.032 & 0.158 \\
Eqqub participation & 0.357 & 0.454 & -0.097 & 0.062 \\
Own radio & 0.210 & 0.192 & 0.018 & 0.668 \\
Own phone & 0.748 & 0.754 & -0.006 & 0.897 \\
Observations & 240 & 143 & & \\
\hline
\end{tabular}


Table B.3: Descriptive Statistics by WII Uptake

\begin{tabular}{|c|c|c|c|c|}
\hline & Uninsured & Insured & Diff & P-value \\
\hline \multicolumn{5}{|l|}{ Demographic Characteristics } \\
\hline Age & $39 \cdot 575$ & 41.533 & -1.958 & 0.152 \\
\hline Age square & 1673.808 & 1837.833 & -164.025 & 0.176 \\
\hline Male & 0.825 & 0.742 & 0.083 & 0.118 \\
\hline Household size & $5 \cdot 575$ & 5.125 & 0.450 & 0.082 \\
\hline Marital status & 0.8667 & 0.8250 & 0.0417 & 0.3735 \\
\hline Illiterate & 0.625 & 0.592 & 0.033 & 0.599 \\
\hline Can read and write & 0.117 & 0.108 & 0.008 & 0.839 \\
\hline Primary school & 0.217 & 0.242 & -0.025 & 0.647 \\
\hline Secondary school & 0.042 & 0.058 & -0.017 & 0.556 \\
\hline \multicolumn{5}{|l|}{ Wealth } \\
\hline Livestock & $5 \cdot 75^{2}$ & 4.264 & 1.488 & 0.008 \\
\hline Land size & $5 \cdot 309$ & $4 \cdot 409$ & 0.900 & 0.034 \\
\hline Corrugated iron sheet roof & 0.500 & 0.342 & 0.158 & 0.013 \\
\hline Own radio & 0.192 & 0.192 & 0.000 & 1.000 \\
\hline Own phone & 0.775 & 0.733 & 0.042 & 0.456 \\
\hline \multicolumn{5}{|l|}{ Membership in associations } \\
\hline Iddir participation & 0.950 & 0.975 & -0.025 & 0.310 \\
\hline Eqqub participation & 0.467 & 0.442 & 0.025 & 0.699 \\
\hline Observations & 120 & 120 & & \\
\hline Religion of the head & 0.7750 & 0.8500 & -0.0750 & 0.1378 \\
\hline
\end{tabular}


Table B.4: Determinants of WII Uptake

\begin{tabular}{lc}
\hline & Probit \\
\hline Age & $0.036^{*}$ \\
Age square & $(0.021)$ \\
Male & -0.000 \\
& $(0.000)$ \\
Household size & -0.079 \\
& $(0.093)$ \\
Education & -0.024 \\
& $(0.020)$ \\
Livestock & 0.085 \\
& $(0.074)$ \\
Land owned & -0.006 \\
Corrugated iron sheet & $(0.010)$ \\
Religion & $-0.028^{* *}$ \\
Village FE & $(0.014)$ \\
PseudoR & $-0.155^{* *}$ \\
Observations & $(0.075)$ \\
\hline Standard & 0.160 \\
& $(0.099)$ \\
Yes & 0.078 \\
& 240 \\
\hline
\end{tabular}

Standard errors in parentheses

${ }^{*} p<0.1,{ }^{* *} p<0.05,{ }^{* * *} p<0.01$ 
Table B.5: Covariate Balance Test - Matching Quality Test

\begin{tabular}{|c|c|c|c|c|c|c|}
\hline Variable & Match & $\begin{array}{c}\text { Mean } \\
\text { Insured }\end{array}$ & $\begin{array}{c}\text { Mean } \\
\text { Uninsured }\end{array}$ & $\%$ Bias & $\begin{array}{c}\% \text { Reduction } \\
\text { Bias }\end{array}$ & $\begin{array}{l}\text { t-test } \\
p>|t|\end{array}$ \\
\hline \multirow[t]{2}{*}{ Age } & $\mathrm{U}$ & 41,533 & 39,575 & 18.6 & & 0.152 \\
\hline & M & 41,487 & 41,422 & 0.6 & 96.7 & 0.963 \\
\hline \multirow[t]{2}{*}{ Age square } & $\mathrm{U}$ & 1837.8 & 1673.8 & 17.5 & & 0.176 \\
\hline & $\mathrm{M}$ & 1834.7 & 1836.9 & -0.2 & 98.7 & 0.986 \\
\hline \multirow[t]{2}{*}{ Male } & $\mathrm{U}$ & 0.74167 & 0.825 & -20.2 & & 0.118 \\
\hline & M & 0.7479 & 0.76837 & -5.0 & $75 \cdot 4$ & 0.714 \\
\hline \multirow[t]{2}{*}{ Household size } & $\mathrm{U}$ & 5.125 & $5 \cdot 575$ & -22.5 & & 0.082 \\
\hline & M & 5.1597 & 5.0634 & 4.8 & 78.6 & 0.716 \\
\hline \multirow[t]{2}{*}{ Education } & $\mathrm{U}$ & .40833 & 0.375 & 6.8 & & 0.599 \\
\hline & M & .41176 & .43198 & -4.1 & $39 \cdot 3$ & 0.753 \\
\hline \multirow[t]{2}{*}{ Livestock } & $\mathrm{U}$ & 42,638 & 57,519 & $-34 \cdot 5$ & & 0.008 \\
\hline & $\mathrm{M}$ & 42,996 & 43,952 & -2.2 & 93.6 & 0.852 \\
\hline \multirow[t]{2}{*}{ Land owned } & $\mathrm{U}$ & 44,092 & 53,092 & $-27 \cdot 5$ & & 0.034 \\
\hline & M & 4,421 & 44,411 & -0.6 & 97.8 & 0.959 \\
\hline \multirow[t]{2}{*}{ Corrugated iron sheet } & $\mathrm{U}$ & 0.34167 & 0.5 & -32.4 & & 0.013 \\
\hline & M & 0.34454 & 0.3331 & 2.3 & 92.8 & 0.853 \\
\hline \multirow[t]{2}{*}{ Religion } & $\mathrm{U}$ & 0.85 & 0.775 & 19.2 & & 0.138 \\
\hline & M & 0.84874 & 0.83285 & 4.1 & 78.8 & 0.739 \\
\hline
\end{tabular}




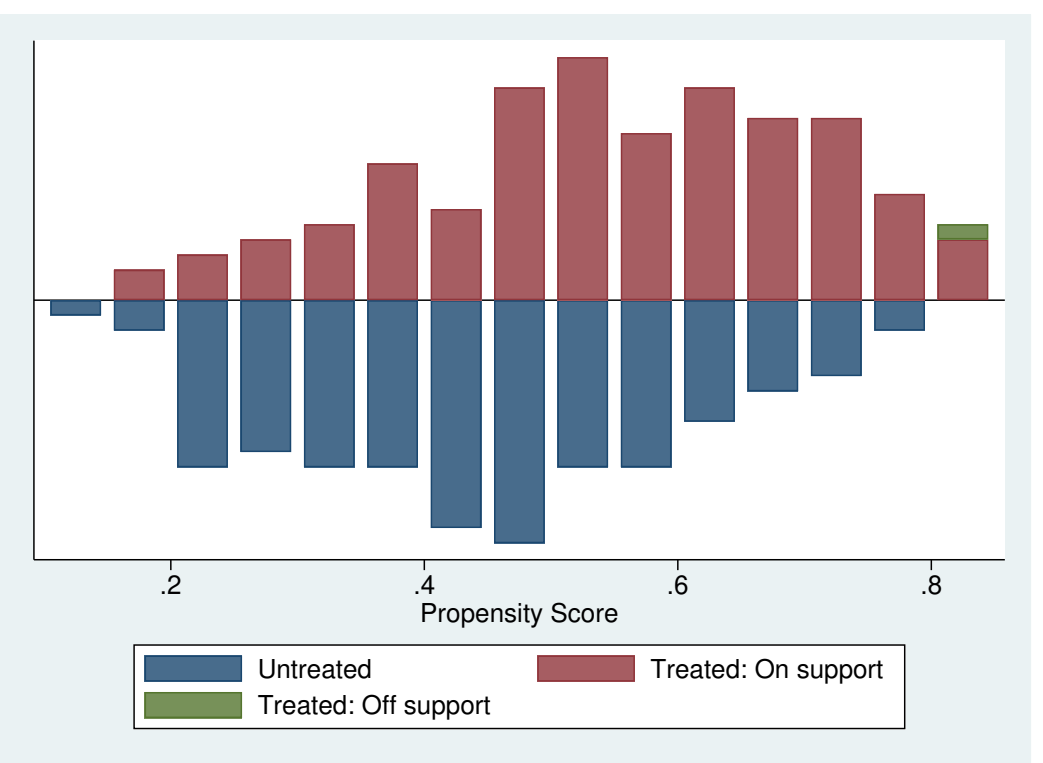

Figure B.1: Propensity score distribution and common support for propensity score estimation

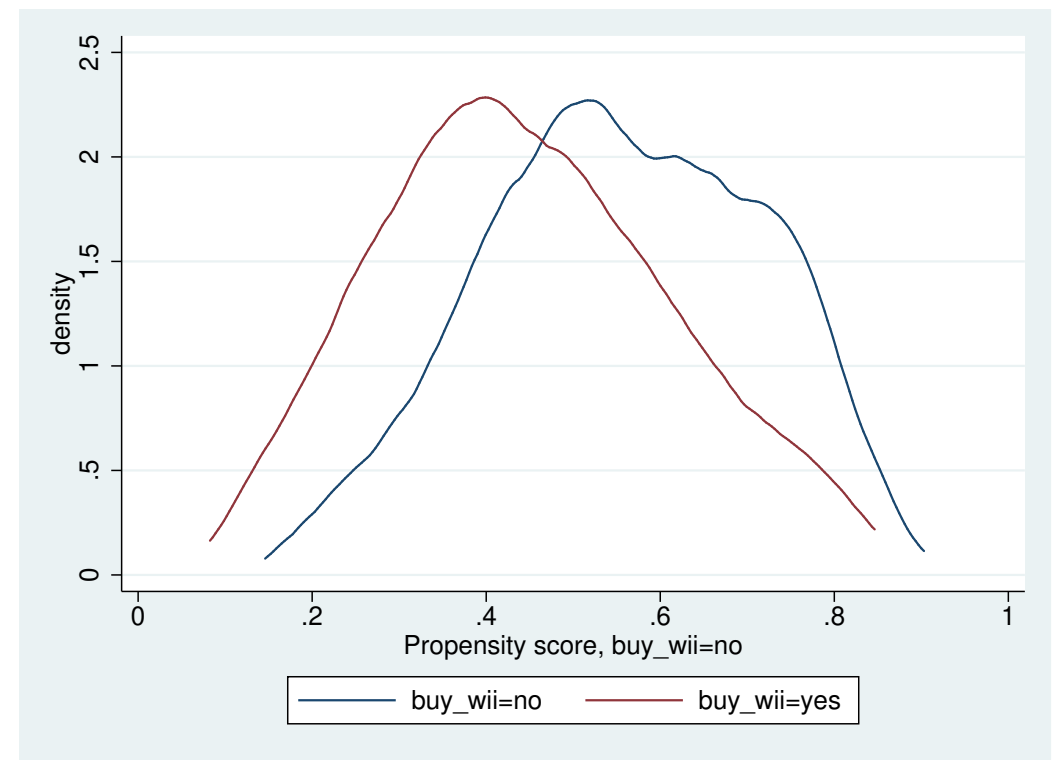

Figure B.2: Kernel density distribution of propensity scores for treated and control groups 
Good morning! Thank you very much for coming today to participate in this activity. Today's activity may take up to one hour. Thus, if you think you will not be able to stay that long let us know now, before the activity begins. Please listen to the instructions carefully. During the entire activity, it is very important that you do not ask questions or talk about the activity to any of the other participants. If you have any question, please raise your hand and the enumerator will come to you and answer your question privately. It is very important that you obey this rule because violation of this rule will lead to the exclusion from this activity. Your participation in this activity is entirely voluntary and you can withdraw at any time without giving reasons.

This activity aims to study individual and group economic decision makings. In this activity, you will earn money. The amount you will earn depends on the decision you make and the decision of other participants with whom you will be grouped. This money will be paid to you in cash at the end of the activity. Any decision you make in this activity will be strictly confidential. Since your decision is private, we ask that you do not reveal your decision to any other participants either during or after the activity.

In this activity, you will be assigned to a group of four people, that is, there will be three other people in the group with you. But, you will not know who your group members are either during or after the activity. At the beginning of the activity, each of you will be given an envelope with 20 tokens inside. All transactions throughout this activity will be calculated in tokens. At the end of the activity, the total number of tokens you have earned will be converted to Birr. In this activity, each token is equivalent with 1 Ethiopian Birr. After receiving an endowment of 20 tokens, you will be asked to decide privately how many of these 20 tokens to contribute to a group project and how many tokens to keep for yourself. You are free to decide how many tokens (ranging from o to 20 tokens) to contribute to the group project and to keep for yourself. In each group, everyone will benefit equally from the group project but only you benefit from the amount that you kept for yourself. After all four members of the group have decided how many tokens to contribute to the group project, the enumerator will then collect and add up all the contributions. The total number of tokens contributed to the group project will then be doubled by the enumerator and shared equally by all four members of the group.

Your earning is computed as the initial endowment 20 tokens minus the number of tokens contributed to the group project plus half of the sum of number of tokens contributed to the group project.

To have better understanding about the activity, let us do the following examples. This is how the activity is played. 
Example 1: Suppose that each participant in the group contributes all their 20 tokens to the group project.

Total number of tokens in the group project will be: $20+20+20+20=80$ tokens. The enumerator will then double this amount: $2 \times 80=160$ tokens. Each member of the group will receive an equal share of 40 tokens. Since no one keeps for his/herself, total earning of each group member will be 40 tokens from the group project.

Example 2: Let's say that one person contributes nothing to the group project but the other three participants in the group contribute all their 20 tokens to the group project.

Total number of tokens contributed to the group project will be: $0+20+20+20=60$ tokens. The enumerator will then double this amount: $2 \times 60=120$ tokens. Each member of the group will receive an equal share of 30 tokens. Since one person keeps his/her 20 tokens and receives 30 tokens from the group project, his/her total earning will be 50 tokens. While the total earning of the other three members of the group will be 30 tokens.

Example 3: Let's say that everyone in the group contributes o tokens to the group project.

Total number of tokens in the group project will be: $\mathrm{O}+\mathrm{O}+\mathrm{O}+\mathrm{O}=\mathrm{O}$ tokens. The enumerator will then double this amount: $2 \mathrm{xO}=\mathrm{O}$ tokens. Since everyone contributes nothing to the group project, everybody in the group will receive nothing from the group project. Since everyone in the group keeps all his/her 20 tokens, each group member's total earning will be 20 tokens.

Example 4: Suppose that one person contributes all the 20 tokens to the group project while the other three members of the group contribute nothing to the group project.

Total number of tokens in the group project will be: $20+0+0+0=20$ tokens. The enumerator will then double this amount: $2 \times 20=40$ tokens. Each member of the group will receive an equal share of 10 tokens from the group project. Since one person keeps o tokens for his/herself, his/her total earning will be only 1o tokens from the group project. However, the other three members of the group keep all their 20 tokens for themselves and they receive 1o tokens each from the group project, thus, their earning will be 30 tokens each.

To have better understanding about the enumerator let's do the following exercises. If you have any question, please raise your hand and the enumerator will come to you and answer your question privately.

Exercise 1: Suppose that each group member contributes 10 tokens to the group project.

Total number of tokens in the group project will be: [ ] tokens. The enumerator will then double this amount:[ ] tokens. Each member of the group will receive an equal share of [ ] tokens from the group project. Total earning of each group member will be [ ] tokens. 
Exercise 2: Let's say that two persons contribute nothing to the group project but the other two persons in the group contribute all their 20 tokens to the group project.

Total number of tokens contributed to the group project will be: [ ] tokens. The enumerator will then double this amount:[ ] tokens. Each member of the group will receive an equal share of [ ] tokens from the group project. Thus, the total earning of two persons who contribute all their 20 tokens will be [ ] tokens and the total earning of the other two persons who contribute nothing will be [ ] tokens.

Exercise 3: Let's say that two persons contribute 20 tokens to the group project while the other two persons contribute 5 tokens to the group project.

Total number of tokens in the group project will be: [ ] tokens. The enumerator will then double this amount: [ ] tokens. Each member of the group will receive an equal share of [ ] tokens from the group project. Thus, the total earning of two persons who contribute all their 20 tokens will be [ ] tokens and the total earning of the other two persons who contribute 5 tokens will be [ ] tokens.

Exercise 4: Suppose that one person contributes 1o tokens to the group project while the other three members of the group contribute nothing to the group project.

Total number of tokens in the group project will be: [ ] tokens. The enumerator will then double this amount: [ ] tokens. Each member of the group will receive an equal share of [ ] tokens from the group project. Thus, the total earning of one person who contribute 10 tokens will be [ ] tokens and the total earning of the other three persons who contribute nothing will be [ ] tokens.

Now, we will start the activity. "Enumerator: please ask participants the following two questions and record their response on the record sheet."

"1. Indicate how much of your endowment of 20 tokens you want to keep for yourself and contribute to the group project?"

"2. On average, how much tokens do you think other participants in your group will contribute to the group project?"

All information regarding your contributions and earnings will be kept confidential and will not be revealed to anyone. 


\section{Record Sheet}

\begin{tabular}{|c|c|c|c|c|c|c|}
\hline & ID. No & $\begin{array}{c}\text { Tokens } \\
\text { kept for } \\
\text { oneself } \\
{[1]}\end{array}$ & $\begin{array}{c}\text { Tokens } \\
\text { shared to } \\
\text { the group } \\
\text { project }\end{array}$ & $\begin{array}{c}\text { Returns } \\
\text { from the } \\
\text { group } \\
\text { project } \\
{[2]}\end{array}$ & $\begin{array}{c}\text { Total } \\
\text { earning } \\
{[1+2]}\end{array}$ & $\begin{array}{c}\text { Guessed } \\
\text { average } \\
\text { contribution of } \\
\text { others }\end{array}$ \\
\hline & & & & & & \\
\hline & & & & & & \\
\hline & & & & & & \\
\hline $\begin{array}{l}\text { Total tokens } \\
\text { contributed }\end{array}$ & & & & & & \\
\hline
\end{tabular}




\section{Maastricht University inding Lamin!}

Faculty of Humanities and Sciences

Faculty Board

Postbus 616

6200 MD Maastricht

Ethical Review Committee Inner Gity

Our reference

ERCIC_028_28_02_2017

direct dial

0031.43.388.4834

Moostricht

28 March 2017

Dear Board,

After examination of the research study protocol regarding 'Does formal insurance crowd out social capital in developing countries?', submitted by Pierre Mohnen, the Ethical Review Committee Inner City faculties (ERCIC) came to the conclusion that there are no objections to the execution of the research project.

Any changes in the research design require a renewed review by the ERCIC.

Yours sincerely,

Prof. W. Bijker

Chair

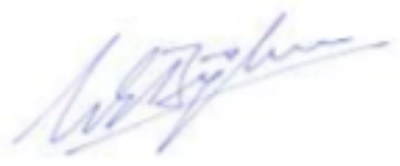

Dr. N. Reslow

Secretary

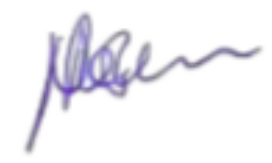

CC Pierre Mohnen; Halefom Nigus; Eleonora Nillesen 


\section{4}

DOES EXPOSURE TO MARKETS PROMOTE FARMERS' INVESTMENT BEHAVIOR? EMPIRICAL EVIDENCE FROM RURAL ETHIOPIA

\section{ABSTRACT}

This study investigates the effect of exposure to markets on farm households' agricultural investment decisions. Specifically, we explore whether and how access to markets affects farmers' adoption of risky but profitable technologies in a setting where farmers can not directly purchase these technologies from the market. This study provides new evidence by focusing on the demand-side, instead of the supply-side impact of market exposure on investment decisions. We utilize survey and incentivized experimental data collected from the Tigray regional state of Ethiopia. We use an Endogenous Switching Probit and IV-Probit models to attenuate the potential selfselection bias. We find that market exposure induces farmers to adopt agricultural technologies, such as chemical fertilizer, improved seeds, manure, and row planting. We test for two potential causal mechanisms through which market exposure may affect farmers' agricultural investment behavior: risk-aversion and locus of control. We find evidence that market exposure promotes investment behavior by attenuating farmers' risk-aversion and enhancing their internal locus of control. The findings in this study suggest that markets promote investment behavior not only through the direct provision of modern technologies but also by shaping farmers' personality traits that are essential for investment behavior.

JEL Classification: $\mathrm{C}_{93}, \mathrm{G} 22, \mathrm{H}_{41}, \mathrm{O}_{17}$

Keywords: Agricultural investment, locus of control, markets, risk preference, Ethiopia

The chapter is based on:

Nigus, H. Y., Mohnen, P., and Nillesen, E. (2018). Does exposure to markets promote farmers' investment behavior? Empirical evidence from rural Ethiopia 


\subsection{INTRODUCTION}

Agriculture remains the cornerstone of several developing countries' economies and continues to serve as the principal source of income, employment, and foreign exchange. However, most existing studies unequivocally point out that the performance of agriculture did not live up to the expectations. In Sub-Saharan Africa and elsewhere in developing countries, the sector is still characterized by stagnant and volatile productivity (Evenson \& Gollin, 2003; Pretty et al., 2011; Suri, 2011; Block, 2014; Barrett et al., 2017). The use of modern agricultural technologies has been considered as a pathway to boost productivity and curb the existing high food insecurity and poverty in the region. However, despite concerted policy efforts to increase the use of modern agricultural technologies, the adoption rate has been far from complete (Zerfu \& Larson, 2010; Sheahan \& Barrett, 2017), and the low adoption of improved technologies remains an empirical puzzle in the literature (Foster \& Rosenzweig, 2010).

There is a plethora of explanations for the low take up of productivity enhancing agricultural technologies, including heterogeneous return to these technologies (Suri, 2011), weather risks (Alem et al., 2010; Dercon \& Christiaensen, 2011; Holden \& Quiggin, 2017), credit and insurance market imperfections (Duflo et al., 2011; Karlan et al., 2014), social network and learning (Oster \& Thornton, 2012; Maertens \& Barrett, 2012; Conley \& Udry, 2010; Krishnan \& Patnam, 2013), access to agricultural cooperatives and extension services (Abebaw \& Haile, 2013; Krishnan \& Patnam, 2013; Minten et al., 2013), quality of inputs (Bold et al., 2017), access to input and output markets (Zeller et al., 1998; Minten et al., 2013; Aggarwal, 2018; Aggarwal et al., 2018), knowledge and education (Asfaw \& Admassie, 2004). ${ }^{1}$ Following Abay et al. (2017), we labelled these factors as external constraints.

More recently, behavioral economists provide behavioral and psychological explanations pertaining to the low investment in remunerative agricultural technologies (Duflo et al., 2011; Liu, 2013; Brick \& Visser, 2015; Holden \& Quiggin, 2017; Bernard et al., 2014; Abay et al., 2017; Taffesse \& Tadesse, 2017). In this regard, Duflo et al. (2011) find that farmers with time-inconsistent preferences are less likely to invest in inorganic fertilizer in Western Kenya. Relatedly, an emerging body of literature suggests that as farmers in the developing world operate in inherently risky environments, the existing low uptake of agricultural technologies is related to risk-aversion of farm households. For instance, Liu (2013) finds that risk and loss averse Chinese farmers' exhibited substantial delays in the adoption of new technologies (Bt cotton). Similarly, using laboratory framed field experiments in South Africa, Brick \& Visser (2015) demonstrates that risk-aversion deters the use of modern farming inputs, although index insurance for crop loss is available. The findings of a recent field experimental study from Central and Southern Malawi by Holden \& Quiggin (2017)

1 see Foster \& Rosenzweig (2010) for a review. 
also lend support to these empirical findings. The authors show that while risk-averse farmers are more likely to adopt and dis-adopt drought tolerant and traditional maize varieties, respectively, they are less likely to use improved maize varieties. Another recent strand of literature argues that farmers' personality traits, such as locus of control, are key drivers of technology adoption. Bernard et al. (2014) conducted a randomized behavioral intervention aiming to improve the aspiration and forward-looking, and in turn, investment behavior of farm households in Ethiopia. They show that households who received the behavioral intervention ${ }^{2}$ have higher aspirations and locus of control, which in turn translated into a higher propensity of adopting modern farming inputs. Using multiple longitudinal data from rural Ethiopia, Abay et al. (2017) and Taffesse \& Tadesse (2017) also show that farmers with higher internal and lower external locus of control are more likely to opt into high-risk-high-return agricultural technologies. Following Abay et al. (2017), we labelled these factors as internal constraints.

This paper contributes to this bulk literature by linking the internal and external constraints to agricultural technology adoption. Particularly, this paper aims to examine the effect of farmers' market exposure on their investment behavior - the propensity of adopting agricultural technologies. We argue that the internal and external factors may be intertwined, and exposure to markets (an external constraint) may affect farmers' investment behavior through its effect on the internal constraints, such as risk-preference and locus of control. This paper is motivated by the economics and psychological literature that suggests economic preferences and personality traits may be endogenous and malleable. Economic preferences (Stigler \& Becker, 1977) and personality traits (Andrisani, 1977; Cebi, 2007; Semykina \& Linz, 2007; Heineck \& Anger, 2010) has long been considered as exogenous and stable. However, recent theoretical and empirical studies challenged this argument and suggest that preferences (Becker \& Mulligan, 1997; Bowles, 1998; Netzer, 2009) and personality traits (Cobb-Clark \& Schurer, 2013; Elkins et al., 2017) may endogenously change due to individual experience and change in economic institutions, including markets. Market experience may alter risk preferences and locus of control in several ways. First, market experience attenuates behavioral anomalies, such as the endowment effect (List, 2003), eliminate individual biases (Smith, 1982), and promote rational behavior (Cecchi \& Bulte, 2013; List \& Millimet, 2008). Second, exposure to markets may provide a new experience to induce significant changes in risk preferences (Becker \& Mulligan, 1997; Bowles, 1998). Most notably, market experience may provide individuals with real-world risky environments such as tradings which involve risky but profitable situations. Market experience may attenuate risk aversion by either increasing their appetite for risk, reducing loss-aversion, or both (Melesse \& Cecchi, 2017). Likewise, markets may also affect the internal locus of control by making individuals more self-reliant, self-sufficient, and

2 Farm households who watched stories of fellow farmers who achieved economic success without support from any governmental and non-governmental organizations. 
less dependent on others (Vohs et al., 2008, 2015), which are important components of a strong internal locus of control. For instance, a growing body of literature shows that market societies have a more internal locus of control than non-market societies (Ross, 2018).

A small but rapidly emerging literature documented that markets significantly affect risk preferences (Melesse \& Cecchi, 2017; Haile et al., 2020). ${ }^{34}$ Although we are not aware of previous studies on the effect of market experience on the locus of control, some empirical studies provided indirect pieces of evidence that may lend support to our premise. Using longitudinal data, Cobb-Clark \& Schurer (2013) suggests that while locus of control is fairly stable in the short and medium-run, it may not be truly time-invariant. Further, Bernard et al. (2014) shows that the locus of control can be changed through simple behavioral interventions. In a recent study, Elkins et al. (2017) also reported that locus of control systematically varies with small but frequent life events rather than with large and less frequent events. We think that market experience can be categorized into the former type of events - small but frequent life events - and may have significant implications on the locus of control.

In this paper, we hypothesize that farmers with high market exposure will exhibit less risk-aversion and high internal locus of control, and in turn, are more likely to use productivity-enhancing agricultural technologies. To test the tenability of this hypothesis, we take advantage of a unique, albeit cross-sectional survey and field experimental data collected from landed farm households in the Tigray regional state of Ethiopia. Ethiopia, especially, Tigray regional state, is an interesting testing ground to study the indirect effect of market exposure on farmers' investment behavior. This is because in rural Tigray and elsewhere in the country, modern agricultural inputs are primarily supplied through a parastatal agricultural cooperatives (Dercon \& Christiaensen, 2011; Abebaw \& Haile, 2013; Minten et al., 2013). Interestingly, these cooperatives are established in nearly all villages in the country, and farmers hardly have a significant difference in access to these inputs. Markets may thus promote the adoption of modern farming inputs through attenuating risk-aversion and enhancing internal locus of control. 5

Identifying the causal effect of market exposure on farmers' investment behavior is, however, empirically challenging and poses a serious concern for at least two rea-

3 Markets also significantly affect social (Henrich et al., 2001, 2010; Siziba \& Bulte, 2012; Dietrich et al., 2018) and moral (Falk \& Szech, 2013; Bartling et al., 2015; Nigus et al., 2021) preferences.

4 The concept of endogeneity of preferences and the role of social, economic, and environmental factors in the formation of preferences has garnered the attention of researchers over the course of the last two decades. Existing empirical evidence show that environmental shocks and natural disasters (Page et al., 2014; Cameron \& Shah, 2015; Hanaoka et al., 2018; Kahsay \& Osberghaus, 2018; Di Falco et al., 2019; Sakha, 2019), macroeconomic and financial shocks (Malmendier \& Nagel, 2011; Cohn et al., 2015; Guiso et al., 2018; Sakha, 2019), exposure to violence and crime (Voors et al., 2012; Callen et al., 2014; Jakiela \& Ozier, 2019; Brown et al., 2019) shape preferences.

5 Market exposure may affect investment behavior through a multitude of channels, e.g., via increasing income, social network, and access to information. Nevertheless, this is beyond the scope of this paper. 
sons. First, market experience and investment decisions may co-evolve - the causal effect may go from investment behavior to experience in trading. Second, there might be omitted variables, such as entrepreneurial ability, which drive both market experience and investment behavior simultaneously. To attenuate these concerns, we employ an endogenous switching probit (ESP) and instrumental variable (IV) approaches. Following previous studies, we instrument farmers' market exposure using householdlevel distance to the market (Melesse \& Cecchi, 2017). ${ }^{6}$ We find that market exposure significantly increases the adoption of risky but profitable agricultural technologies. We show that market exposure alters farmers' investment behavior by attenuating risk-aversion and improving internal locus of control.

Our findings contribute to two strands of literature. First, the findings extend the large literature on the drivers of farm households' investment behavior. To date, the existing literature treat internal and external constraints as independent. However, we argue that both constraints may not be independent, and external factors, such as markets, may predict the changes in the internal constraints, including preferences and personality traits. Second, it contributes to the thin literature on the effect of change in economic institutions on economic preferences and personality traits. ${ }^{7}$ Our findings have important policy implications, especially in Sub-Saharan Africa, where concerted policy efforts are undertaking to spur the use of modern inputs and boost agricultural productivity. The results suggest that market exposure is an important mechanism to attenuate risk-aversion and improve locus of control, thereby increasing the adoption of productivity-enhancing agricultural technologies.

The remainder of the paper proceeds as follows. Section 4.2 provides details on the field setting, data type, and source. Section 4.3 presents the identification and estimation strategies. In section 4.3 , we present the results of the study. Section 4.4 concludes.

\subsection{CONTEXT AND DATA}

\subsubsection{Sample and setting}

The present study is part of a larger experiment that focuses on whether or not markets erode socially responsible behavior and the role of regulations and culture on social responsibility in competitive markets (Nigus et al., 2021). We collected both survey and monetary incentivized experimental data from a randomly selected 544 farm households belong to 32 tabias $^{8}$ located in five woredas (districts) in the Tigray

6 Geographical distance has also been employed as an instrument to address the endogeneity concerns in previous studies (e.g., see Theil \& Finke (1983); Hall \& Jones (1999); Nigus et al. (2018))

7 To our knowledge, the study by Melesse \& Cecchi (2017) is a notable exception to establish a causal and rigorous effect of market exposure on risk preference.

8 Tabia, synonymous to a village, is the smallest administrative unit in Ethiopia. 
regional state of Ethiopia. Farm households were invited to participate in some lab-inthe-field experiments, namely, risk, competition, market and joy of destruction, and a follow-up survey. Farmers first take part in the experimental games and then be involved in a household survey. The household survey extracts detailed information on farm households' demographic characteristics, wealth and assets, social capital, selfreported information on idiosyncratic and covariate shocks. The survey also contains information on farmers' locus of control, market exposure, adoption of agricultural technologies (chemical fertilizer, improved seed, organic fertilizer, and row planting), etc. Although we collected the data from 544 households, the analysis in this study is confined to 502 farm households who own agricultural land. This is mainly because farm households who do not own any agricultural land by default do not adopt any of the agricultural technologies. The description and descriptive statistics of the variables used in this study are presented in Table C.I in the appendix.

\subsubsection{Outcome variables}

The key variable of interest is farmers' investment behavior, which is proxied by the adoption of agricultural technologies. This study focuses on four agricultural technologies, namely, chemical fertilizer, improved seed, organic fertilizer, and row planting. Following the standard practice in the literature, we measure technology adoption using survey data (Dercon \& Christiaensen, 2011; Kebede \& Zizzo, 2015; Abay et al., 2017). Agricultural technology adoption is a binary variable taking the value of 1 if the farmer adopted an agricultural technology, and o otherwise.

\subsubsection{Mechanisms}

\subsubsection{A Risk preference}

To elicit farmers' risk preference, we use an incentivized risk game with positive expected payoffs that follow Gneezy \& Potters (1997) and Gneezy et al. (2009). This is one of the simplest risk elicitation methods one can use, especially in rural areas of developing countries where the majority of households cannot read and write. At the beginning of the experiment, subjects received an initial endowment of 30 Birr and subsequently asked to decide on how much of their initial endowment to keep on a risk-free account with a zero-interest rate and how much to invest in a risky investment with a $50 \%$ probability of tripling and 50\% probability of losing their entire investment. The precise form of the risk experiment is provided in appendix $C$.

The main interest in this study is to test whether market exposure affects investment behavior through attenuating risk-aversion. Hence, we measure households' risk-aversion as the proportion of the initial endowment, which is not invested in 
a risky investment relative to the total endowment of 30 Birr. Figure 4.1 displays the distribution of farmers' risk-aversion index. The figure shows the presence of considerable heterogeneity in the risk preference of the farmers in our sample. While a relatively large number of farmers (13\%) decided not to invest in the risky investment at all, a non-trivial number of farmers ( $9 \%$ ) chose to spend their entire endowment in the risky investment. Figure 4.1 also reveals that most of the farm households are risk-averse and decided to invest only about one-third of their entire endowment.

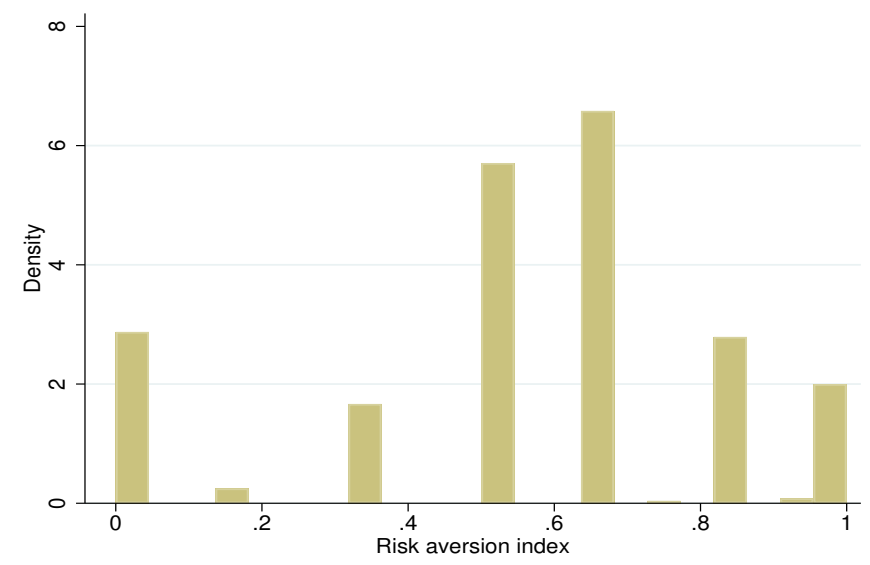

Figure 4.1: Distribution of Farmers' Risk-aversion

\subsubsection{B Locus of control}

We elicit farmers' locus of control using farmers' response to Rotter (1966) scale. Specifically, respondents were asked to indicate how much they agree with the statements presented in Table 4.1 using a five-point Likert scale ranging from "strongly disagree" to "strongly agree." We use factor analysis to construct a single index of the five items measuring locus of control. The use of factor analysis to create a single index of locus of control is not new. Such an approach has been commonly used in previous studies exploring the effect of locus of control on various economic outcomes (e.g., see Heckman et al. (2006); Caliendo et al. (2015); Cobb-Clark et al. (2016); Abay et al. (2017); Schurer (2017)). The factor analysis shows that all five items load unambiguously onto one factor, and we used the first predicted factor in our analysis. Larger values of the locus of control index correspond to an increasing internal locus of control. For ease of interpretation, we standardize this index to have zero mean and standard deviation of 1. Figure 4.2 offers the distribution of the locus of control index. The figure reveals substantial heterogeneity in farmers' internal locus of control, with most farmers' locus of control concentrated around the mean. 
Table 4.1: Components of Internal Locus of Control

\begin{tabular}{lcc}
\hline Item & Mean & Std. Dev \\
\hline My life is determined by my own actions. & 4.221 & 0.623 \\
When I get what I want, it is usually because I worked hard for it. & 4.070 & 0.68 \\
I am usually able to protect my personal interests. & 4.024 & 0.736 \\
I can mostly determine what will happen in my life. & 3.962 & 0.800 \\
When I make plans, I am almost certain/guaranteed/sure to make them work. & 4.046 & 0.718 \\
\hline
\end{tabular}

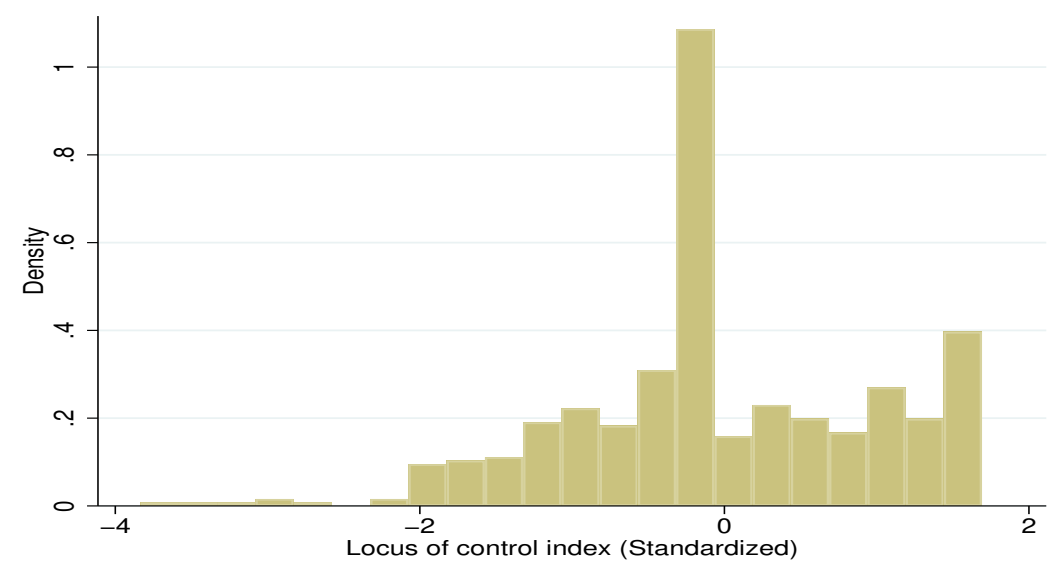

Figure 4.2: Distribution of Farmers' Internal Locus of Control (Standardized)

\subsubsection{Market Exposure}

In the economics literature, exposure to market ${ }^{9}$ has been defined and measured in several ways. For instance, Henrich et al. (2001, 2010) and Dietrich et al. (2018) define exposure to market as the share of calories purchased from the market relative to the total calorie consumption. Market exposure has also been measured as income earned from different sources (wage labor, trades, and rent) other than home production. Furthermore, market exposure was also proxied by the frequency of wage labor and the frequency of purchasing goods for a future resale (Henrich et al., 2001, 2010). On the other hand, market exposure has been measured as the average number of actual transactions (both buying and selling) made in a typical month (Melesse \& Cecchi, 2017). Further, market exposure is defined as the number of trips to markets regardless of whether or not farmers made transactions and the volumes of transactions (Melesse \& Cecchi, 2017; Henrich et al., 2001, 2010).

We measure farmers' exposure to the market in terms of the average number of market transactions, instead of the share of consumption goods purchased from the

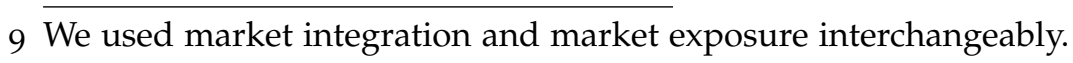


market. This is because measuring market exposure using the former approach offers several advantages. First, the latter approach captures the buying, not the selling-side of the market. Second, in developing countries where Ethiopia is not an exception, the majority of farm households are male-headed households, which constitute more than $70 \%$ of our sample households. However, females are primarily responsible for the purchase of consumption goods. Hence, the latter approach may impede us from properly measuring male-headed households' market exposure. Further, the caloriebased approach is very susceptible to measurement errors and extreme values compared to the transaction-based measure of exposure to the market. We constructed two measures of exposure to the market. First is a continuous measure of exposure to market - market experience - the average number of market transactions made in a typical month. Second is a binary measure of market exposure - market exposure - taking a value of 1 if a farm household made greater than the median number of market transactions, o otherwise.

\subsection{ESTIMATION STRATEgy}

This study aims to examine whether and how exposure to large output markets affects farmers' agricultural investment decisions. However, exposure to markets may be endogenous as farmers may self-select into making trades (buying and selling) or not. Perhaps, the endogeneity problem may also eventuate from the opposite direction due to reverse causality, that is, from farmers' investment behavior to market participation. Additionally, there might be omitted variables, such as innate ability and entrepreneurship, that affect the decision to make trades and farmers' investment decisions. Hence, in the absence of randomization, failure to address the endogeneity concern may impair the causal impact of exposure to markets on investment decisions. We attempted to address the endogeneity concern by using two econometric models, which have received considerable attention in the recent econometrics literature - endogenous switching probit (ESP) and instrumental variable (IV) models.

As has already been mentioned, we constructed two proxies of exposure to the market: (i) "market experience" - a continuous variable capturing the number of actual market transactions made in a typical month, (ii) "market exposure" - a binary variable taking a value of $I$ if a household made greater than the median number of market transactions. To estimate the impact of a continuous endogenous regressor market experience - on binary outcomes (adoption of agricultural technologies), we use the IV-probit model. Similarly, we utilize the ESP model to estimate the impact of a binary endogenous regressor - market exposure - on binary outcomes.

We use both econometric models as each model has its own advantage over the other. Both estimation methods rely on the normality assumption. The IV-probit performs well when applied to the estimation of binary choice models with continuous 
endogenous regressors such as the market experience variable. On the other hand, the ESP method fits well when applied to a binary choice model with a binary endogenous regressor. Moreover, as the ESP model relaxes the assumption of the equality of coefficients of the outcome variable in two regimes, it is more efficient than the IV strategy. Further, while the ESP model enables to estimate the average treatment effect on the treated (ATT) and marginal treatment effect (MTE) (Lokshin \& Glinskaya, 2009), the IV strategy measures only local average treatment effect (LATE) (Angrist, 1991). Next, we discuss the details of ESP and the IV-probit models.

\subsubsection{Endogenous switching probit model}

Following Lokshin \& Sajaia (2011), consider a farm household with two binary outcome equations (adoption of modern agricultural technologies) and the criterion function $M_{i}$ (market exposure) that determines which regime the farm household faces.

$$
\begin{gathered}
M_{i}=1 \text { if } \Gamma Z_{i}+\mu_{i}>0 \\
M_{i}=0 \text { if } \Gamma Z_{i}+\mu_{i} \leq 0 \\
y_{1 i}^{*}=\eta_{1} X_{1 i}+\epsilon_{i} \quad y_{1 i}=I\left(y_{1 i}^{*}>0\right) \\
y_{0 i}^{*}=\eta_{0} X_{0 i}+\epsilon_{i} \quad y_{0 i}=I\left(y_{0 i}^{*}>0\right)
\end{gathered}
$$

where $y_{1 i}^{*}$ and $y_{0 i}^{*}$ are the latent variables (use of modern agricultural technologies) that define the observed binary outcomes $y_{1}$ and $y_{0}$ (whether the farm household adopted improved agricultural technologies) for a household with high or less market exposure, respectively; $X_{i}$ is a vector of exogenous variables determining adoption of agricultural technologies; $Z_{i}$ is a vector of variables that determines market exposure; $\eta 1, \eta 0$, and $\Gamma$ are vectors of unknown parameters to be estimated; and $\mu_{i}, \epsilon_{1 i}$, and $\epsilon_{0 i}$ are the error terms of the selection and outcome equations, respectively, which are assumed to be jointly normally distributed with a mean-zero vector and correlation matrix:

$$
\Omega=\left(\begin{array}{ccc}
1 & \rho_{0} & \rho_{1} \\
& 1 & \rho_{10} \\
& & 1
\end{array}\right)
$$

while $\rho_{0}$ and $\rho_{1}$ are the correlations between $\mu_{i}, \epsilon_{0 i}$, and $\mu_{i}, \epsilon_{1 i}$, respectively, $\rho_{10}$ is the correlation between $\epsilon_{0 i}$ and $\epsilon_{1 i}$. The statistical significance of either $\rho_{0}$ or $\rho_{1}$ is an indication of the presence of self-selection bias in markets exposure. In addition, the 
likelihood ratio test, $\rho_{0}=\rho_{1}$, is used to test the joint independence of equations [(4.1) - (4.3)]. Equations [(4.1) - (4.3)] can be estimated using the full information maximum likelihood (FIML) following the procedure of ESP model in previous studies (Lokshin \& Glinskaya, 2009; Lokshin \& Sajaia, 2011). However, since we do not observe $y_{1 i}$ and $y_{0 i}$ simultaneously, the joint distribution of $\left(\epsilon_{0}, \epsilon_{1}\right)$ is not identified, and thus, $\rho_{10}$ cannot be estimated. The model is identified by nonlinearities of its functional form of the bivariate normal distribution. Nevertheless, to improve identification, we employ a variable (household distance to a market) which is believed to affect household's market exposure but not to directly influence investment decisions (we will discuss this in detail later in this section).

The advantage of the ESP model is that it enables us to estimate a range of treatment effect measures. Following Aakvik et al. (2005) and Lokshin \& Sajaia (2011), after estimating the ESP's parameters, we can calculate a variant of treatment effects - the effect of the treatment on the treated (TT), the effect of the treatment on the untreated (TU), the treatment effect (TE), and the marginal treatment effect (MTE) - using equations $4.5,4.6,4.7$, and 4.8 , respectively:

$$
\begin{array}{r}
T T(x)=\operatorname{Pr}\left(y_{1}=1 \mid M=1, X=x\right)-\operatorname{Pr}\left(y_{0}=1 \mid M=1, X=x\right)= \\
\frac{\Phi_{2}\left(X_{1} \eta_{1}, Z \gamma, \rho_{1}\right)-\Phi_{2}\left(X_{0} \eta_{0}, Z \gamma, \rho_{0}\right)}{F(Z \gamma)} \\
T u(x)=\operatorname{Pr}\left(y_{1}=1 \mid M=0, X=x\right)-\operatorname{Pr}\left(y_{0}=1 \mid M=0, X=x\right)= \\
\frac{\Phi_{2}\left(X_{1} \eta_{1},-Z \gamma,-\rho_{1}\right)-\Phi_{2}\left(X_{0} \eta_{0},-Z \gamma,-\rho_{0}\right)}{F(-Z \gamma)} \\
T E(x)=\operatorname{Pr}(M=1, X=x)-\operatorname{Pr}(M=0, X=x)= \\
F\left(X_{1} \eta_{1}\right)-F\left(X_{0} \eta_{0}\right) \\
\operatorname{MTE}(x, \bar{v})=\operatorname{Pr}(M=1 \mid X=x, \mu=\bar{\mu})-\operatorname{Pr}(M=0 \mid X=x, \mu=\bar{\mu})= \\
\left.F\left(\frac{X_{1} \eta_{1}+\rho_{1} \bar{\mu}}{\sqrt{1-\rho_{1}^{2}}}\right)-\frac{X_{0} \eta_{0}+\rho_{0} \bar{\mu}}{\sqrt{1-\rho_{0}^{2}}}\right) \\
\sqrt{1}
\end{array}
$$

where $F$ is the cumulative function of the univariate normal distribution, and $\Phi 2$ is the cumulative function of a bivariate normal distribution. TT is the difference between the predicted probability of adopting agricultural technologies for households with high market exposure and the probability of adopting agricultural technologies 
for households if they had no exposure to the market. TU is the expected effect on the adoption of agricultural technologies if households with less market exposure have had high exposure to the market. TE is the effect of market exposure for a farmer randomly drawn from the population, and MTE is the effect of the treatment for farmers with observed characteristics $x$ and unobserved characteristics, $\bar{\mu}$. The average treatment effects (ATT, ATU, and ATE) for the corresponding subgroups of the population can be calculated by averaging 4.6 through 4.8 over the observations in the subgroups.

\subsubsection{Instrumental Variable (IV) Approach}

To account for the continuous nature of our key variable of interest (market experience), we employ the IV-probit model. The IV-probit fits models with a dichotomous dependent variable and a continuous endogenous regressor. Given the binary nature of the outcome variable (whether a farm household adopts modern agricultural technologies or not) and the continuous nature of the endogenous regressor (market experience), we utilize the IV-probit model.

The IV-probit model can be defined as:

$$
\begin{gathered}
A_{i}^{*}=M_{i} \beta+x_{1 i} \gamma+v_{i} \\
M_{i}=x_{1 i} \pi_{1}+x_{2 i} \pi_{2}+\epsilon_{i}
\end{gathered}
$$

where $i=1, \ldots, N, M_{i}$ stands for a $1 \times \rho$ vector of endogenous variables such as market experience, $x_{1 i}$ is a $\kappa_{1} \times 1$ vector of exogenous variables, $x_{2 i}$ is a $\kappa_{2} \times 1$ vector of additional instruments, and the equation for $M_{i}$ is written in reduced form. By assumption, $\left(\epsilon_{i} ; v_{i}\right) \sim \mathrm{N}(0 ; \Sigma)$, where $\sigma_{11}$ is normalized to one to identify the model. $\beta$ and $\gamma$ are vectors of structural parameters, and $\pi_{1}$ and $\pi_{2}$ are matrices of reducedform parameters. This is a recursive model: $M_{i}$ appears in the equation for $A_{i}^{*}$, but $A_{i}^{*}$ does not appear in the equation for $M_{i}$. While we do not observe the latent variable $A_{i}^{*}$, we observe

$$
A_{i}= \begin{cases}1, & \text { if } A_{i}^{*} \geq 0 \\ 0, & \text { if } A_{i}^{*}<0\end{cases}
$$

The necessary condition for identification of the structural parameters requires at least one instrumental variable for one endogenous variable. We use household-level distance to market as an instrument for farmers' market exposure. 


\subsection{RESULTS AND DisCUSSIONS}

In this section, we first present the estimation results of the endogenous switching probit followed by the results of the IV-probit model. Next, we discuss the causal mechanisms through which market exposure affects farmers' investment behavior.

\subsubsection{Results of Endogenous Switching Probit Model}

Tables 4.2, C.3 and C.4 present the estimation results of the full information maximum likelihood (FIML) of the ESP model. At the bottom of Tables C.3 and C.4, we report the correlation between the error terms in the selection $\left(\mu_{i}\right)$ and outcome equations for adopter's $\left(\epsilon_{1}\right)$ and non-adopters of $\left(\epsilon_{0}\right)$ of agricultural technologies which is used to test for the presence of self-selection in market exposure. The tables also report the wald $\chi 2$ test statistic to test the joint independence of the equations. The tables show that the correlation between the error terms in the selection (market exposure) and the technology adoption equations of farmers with high market exposure $\left(\rho_{1}\right)$ are negative and statistically significant, ${ }^{10}$ suggesting that self-selection exists for farmers with high market exposure. This implies that using the ESP model to account for the self-selection bias is necessary. The wald $\chi 2$ test is also significantly different from zero, indicating that the regimes of technology adoption for households with high and less market exposure are distinct, and the ESP model is preferred to probit and bivariate probit models.

Table 4.2: Impact of Market Exposure on Agricultural Investment Decisions

\begin{tabular}{lcccc}
\hline & $(1)$ & $(2)$ & $(3)$ & $(4)$ \\
& ATT & ATU & ATE & MTE \\
\hline Chemical fertilizer adoption & $0.160^{* * *}$ & $0.126^{* * *}$ & $0.147^{* * *}$ & $0.168^{* * *}$ \\
& $(0.014)$ & $(0.014)$ & $(0.008)$ & $(0.005)$ \\
Improved seed adoption & $0.493^{* * *}$ & $0.44^{* * *}$ & $0.477^{* * *}$ & $0.644^{* * *}$ \\
& $(0.013)$ & $(0.015)$ & $(0.007)$ & $(0.010)$ \\
Organic fertilizer adoption & $-0.071^{* * *}$ & $0.491^{* * *}$ & $0.154^{* * *}$ & $0.470^{* * *}$ \\
& $(0.015)$ & $(0.014)$ & $(0.005)$ & $(0.005)$ \\
Row planting adoption & $0.333^{* * *}$ & $0.623^{* * *}$ & $0.456^{* * *}$ & $0.936^{* * *}$ \\
& $(0.017)$ & $(0.023)$ & $(0.010)$ & $(0.013)$ \\
\hline
\end{tabular}

Notes. ATT, ATU, ATE, and MTE stand for Average Treatment Effect on the Treated, Average Treatment Effect on the Untreated, Average Treatment Effect, and Marginal Treatment Effect, respectively; Bootstrapped standard errors; ${ }^{* * *} \mathrm{p}<0.01,{ }^{* *} \mathrm{p}<0.05,{ }^{*} \mathrm{p}<0.1$.

10 Except for the adoption of chemical fertilizer. 
Although the ESP model is identified by the non-linearities in the functional form of the bivariate normal distribution and does not require exclusion restrictions, for better identification, we used household-level distance to a weekly market as an exclusion restriction. We run several diagnostic tests to verify the validity of our exclusion restriction, and these tests are reported in Tables C.3, C.4, and C.5. First, following Di Falco et al. (2011), we conducted the falsification test - whether the selected instrument (distance to market) affects farmers' market exposure but not the technology adoption decisions of farmers with less market exposure. The falsification test for the admissibility of the exclusion restriction shows that the selected instrument is valid as the distance to market is negatively and significantly correlated with market exposure $(p<0.01)$, but not correlated with the investment decisions of farm households who are less exposed to the market (Table C.5). Second, in parsimonious and full specifications, we show that distance to the market negatively and significantly affects market exposure (not shown, but available upon request). Finally, we executed a series of tests to validate the admissibility of our results, including the test for the weak and underidentification of the selected instrument. The results reveal that our instruments are not weak and correctly identified.

The effects of market exposure on farmers' agricultural investment decisions, which are estimated using equations 4.5 through 4.8 , are presented in Table 4.2 . The results of the average treatment effect on the treated (ATT) reveals that, on average, market exposure increases the probability of chemical fertilizer adoption by 16 percentage points for farmers with high market exposure than in the counterfactual scenario of less market exposure. In a similar vein, farmers with less than median exposure to the market would also have increased the adoption of chemical fertilizer by 13 percentage points if they have had high exposure to the market. Further, the results of the average treatment effect (ATE) indicate that if all farm households have had high access to the market, they would have increased the adoption of mineral fertilizer by about 15 percentage points. Since the treatment effects can be influenced not only by observed factors per se but also by unobserved factors, we compute the marginal treatment effect (MTE) to address this concern. Table 4.2 report that the MTE results are qualitatively the same with the average treatment effects, which vary only by observed characteristics.

Table 4.2 also shows that exposure to the market increases the use of improved seeds by 49 percentage points compared to the counterfactual case. Likewise, exposure to markets would have led to about 44 percentage points increase in the use of improved seed among farmers with less than median market exposure. The estimation results from the ATE and MTE also report qualitatively similar results. As shown in Table 4.2, we also estimated the impact of market exposure on organic fertilizer use. Market exposure has a differential impact on organic fertilizer use among farmers with high and less market exposure. While the ATT shows that exposure to market 
decreases the use of organic fertilizer by 7 percentage points for households with high market exposure, market exposure would have increased organic fertilizer adoption by 49 percentage points if farmers with less market exposure have had high market exposure. Finally, we also find that market exposure has a large and significant effect on the probability of using row planting. It increases the use of row planting by 33 percentage points for farm households with high market exposure compared to the counterfactual scenario of less market exposure. Likewise, the adoption rate of row planting of farmers with less market exposure would have increased by 62 percentage points if they have had higher than median exposure to the market. Overall, the estimation results suggest that market exposure significantly affects farmers' agricultural investment decisions. Interestingly, the estimated coefficients are economically meaningful and indicate that markets are important institutions in influencing preferences and behavior besides their indispensable role in the efficient allocation of scarce resources.

\subsubsection{Results of the IV Probit Model}

To probe the robustness of our results in section 4.4.1 and to account for the continuous nature of our key variable of interest (market experience), we use the IV-probit model. Table 4.3 presents IV-probit estimates, using a household-level distance to a weekly market as an instrument for the market experience. At the bottom of Table 4.3, the Wald test of exogeneity rejects the null hypothesis that market exposure is exogenous. This suggests that using a naïve probit model may not be appropriate, instead, the IV-probit model should be used to attenuate the endogeneity concern. Next, we verify the validity of our instrument - household distance to market. For an instrument to be valid, it should satisfy two conditions: (i) the instrument should be correlated with the endogenous variable, and (ii) it should not be correlated with the outcome variable. Based on previous studies (e.g., see Melesse \& Cecchi (2017)), we believe that household distance to market meets these criteria.

First stage estimates of the IV-probit model are provided in Table C.6 in the appendix and shows that distance to market is negatively and significantly associated with market exposure. On average, one hour increase in the distance to the nearest market leads to a 0.6 decrease in the number of market transactions. The result is robust across different specifications and with and without controls. Table 4.3 also reports the Kleibergen-Paap F statistic to test the relevance of the instrument. The F statistic exceeds the minimum 10 critical values, suggesting that the instrument is not weak (Stock et al., 2002). The Kleibergen-Paap rk LM statistic for the underidentification test is also significant, indicating that our model is correctly identified. ${ }^{11}$

11 Since we have one instrument for one endogenous variable, we are unable to conduct the overidentification test. 
Table 4.3 shows that market experience positively and significantly affects farmers' agricultural investment decisions. Column (1) reports that farmers with a greater market experience are more likely to adopt chemical fertilizer. Results are robust and stable even after controlling a battery of control variables (column 2). Columns (3) and (4) report that market experience has a positive and statistically significant effect on the adoption of improved seeds. However, although market experience has a positive effect on the adoption of organic fertilizer, the impact is not statistically significant. Interestingly, columns (7) and (8) show that market exposure positively and significantly affects the adoption of row planting. More precisely, the estimation result shows that a 1 percent increase in market experience leads to a 28,28 , and 34 percent increase in the adoption of chemical fertilizer, improved seed, and row planting, respectively. In a nutshell, the estimation results from the IV-probit model corroborates the results from the ESP model in section 4.4.1. We probe the robustness of the estimation results from the ESP and IV-probit models using the conditional mixed process estimator (CMP) (Roodman, 2011). We find qualitatively similar results that market exposure promotes farm households' investment behavior (results are not shown, but available upon request). 
Table 4.3: Effects of Market Experience on Agricultural Investment Decisions

\begin{tabular}{|c|c|c|c|c|c|c|c|c|}
\hline & $\begin{array}{c}\text { (1) } \\
\text { Chemical } \\
\text { fertilizer }\end{array}$ & $\begin{array}{l}\text { (2) } \\
\text { Chemical } \\
\text { fertilizer }\end{array}$ & $\begin{array}{c}(3) \\
\text { Improved } \\
\text { seed }\end{array}$ & $\begin{array}{c}(4) \\
\text { Improved } \\
\text { seed }\end{array}$ & $\begin{array}{c}(5) \\
\text { Organic } \\
\text { fertilizer }\end{array}$ & $\begin{array}{c}\text { (6) } \\
\text { Organic } \\
\text { fertilizer }\end{array}$ & $\begin{array}{c}(7) \\
\text { Row } \\
\text { planting }\end{array}$ & $\begin{array}{c}(8) \\
\text { Row } \\
\text { planting }\end{array}$ \\
\hline Market experience & $\begin{array}{c}0.309^{* * *} \\
(0.065)\end{array}$ & $\begin{array}{c}0.283^{* * *} \\
(0.088)\end{array}$ & $\begin{array}{c}0.297^{* * *} \\
(0.053)\end{array}$ & $\begin{array}{c}0.276^{* * *} \\
(0.068)\end{array}$ & $\begin{array}{c}0.135 \\
(0.084)\end{array}$ & $\begin{array}{c}0.064 \\
(0.110)\end{array}$ & $\begin{array}{l}0.315^{* * *} \\
(0.046)\end{array}$ & $\begin{array}{c}0.336^{* * *} \\
(0.048)\end{array}$ \\
\hline Age & & $\begin{array}{l}-0.011 \\
(0.032)\end{array}$ & & $\begin{array}{c}0.007 \\
(0.027)\end{array}$ & & $\begin{array}{c}0.040 \\
(0.032)\end{array}$ & & $\begin{array}{l}-0.043 \\
(0.027)\end{array}$ \\
\hline Age square & & $\begin{array}{l}-0.000 \\
(0.000)\end{array}$ & & $\begin{array}{l}-0.000 \\
(0.000)\end{array}$ & & $\begin{array}{l}-0.000 \\
(0.000)\end{array}$ & & $\begin{array}{l}0.000^{*} \\
(0.000)\end{array}$ \\
\hline Male & & $\begin{array}{l}0.312^{*} \\
(0.184)\end{array}$ & & $\begin{array}{c}0.079 \\
(0.157)\end{array}$ & & $\begin{array}{c}0.235 \\
(0.167)\end{array}$ & & $\begin{array}{c}0.240 \\
(0.157)\end{array}$ \\
\hline Household size & & $\begin{array}{c}0.125^{* * *} \\
(0.045)\end{array}$ & & $\begin{array}{c}0.044 \\
(0.033)\end{array}$ & & $\begin{array}{c}0.022 \\
(0.035)\end{array}$ & & $\begin{array}{c}0.020 \\
(0.033)\end{array}$ \\
\hline Education & & $\begin{array}{c}0.056 \\
(0.160)\end{array}$ & & $\begin{array}{c}0.119 \\
(0.134)\end{array}$ & & $\begin{array}{c}0.092 \\
(0.146)\end{array}$ & & $\begin{array}{l}-0.027 \\
(0.120)\end{array}$ \\
\hline Land size & & $\begin{array}{c}-0.096^{* *} \\
(0.046)\end{array}$ & & $\begin{array}{c}0.019 \\
(0.036)\end{array}$ & & $\begin{array}{l}-0.066 \\
(0.040)\end{array}$ & & $\begin{array}{l}-0.015 \\
(0.035)\end{array}$ \\
\hline Livestock & & $\begin{array}{c}0.024 \\
(0.020)\end{array}$ & & $\begin{array}{c}0.045^{* * *} \\
(0.016)\end{array}$ & & $\begin{array}{c}0.079^{* * *} \\
(0.019)\end{array}$ & & $\begin{array}{c}0.038^{* * *} \\
(0.014)\end{array}$ \\
\hline Housing condition & & $\begin{array}{c}0.049 \\
(0.253)\end{array}$ & & $\begin{array}{l}-0.138 \\
(0.205)\end{array}$ & & $\begin{array}{l}-0.489^{*} \\
(0.251)\end{array}$ & & $\begin{array}{c}0.054 \\
(0.218)\end{array}$ \\
\hline Own phone & & $\begin{array}{l}-0.406^{* *} \\
(0.177)\end{array}$ & & $\begin{array}{c}-0.337^{* *} \\
(0.136)\end{array}$ & & $\begin{array}{c}-0.445^{* * *} \\
(0.168)\end{array}$ & & $\begin{array}{l}-0.314^{* *} \\
(0.122)\end{array}$ \\
\hline Own radio & & $\begin{array}{c}0.206 \\
(0.162)\end{array}$ & & $\begin{array}{l}-0.167 \\
\text { (0.110) }\end{array}$ & & $\begin{array}{l}-0.116 \\
(0.137)\end{array}$ & & $\begin{array}{l}-0.150 \\
(0.112)\end{array}$ \\
\hline Iddir member & & $\begin{array}{l}-0.233 \\
(0.185)\end{array}$ & & $\begin{array}{l}0.276^{*} \\
(0.146)\end{array}$ & & $\begin{array}{c}0.024 \\
(0.147)\end{array}$ & & $\begin{array}{l}0.389^{* *} \\
(0.163)\end{array}$ \\
\hline Eqqub member & & $\begin{array}{l}-0.258^{*} \\
(0.142)\end{array}$ & & $\begin{array}{l}0.313^{* *} \\
(0.128)\end{array}$ & & $\begin{array}{c}0.357^{* * *} \\
(0.129)\end{array}$ & & $\begin{array}{l}0.262^{* *} \\
(0.127)\end{array}$ \\
\hline Cooperative member & & $\begin{array}{c}0.105 \\
(0.149)\end{array}$ & & $\begin{array}{c}0.122 \\
(0.119)\end{array}$ & & $\begin{array}{l}-0.013 \\
(0.121)\end{array}$ & & $\begin{array}{l}-0.096 \\
\text { (0.110) }\end{array}$ \\
\hline Distance to FTC & & $\begin{array}{c}-0.002 \\
(0.003)\end{array}$ & & $\begin{array}{l}-0.002 \\
(0.003)\end{array}$ & & $\begin{array}{c}0.002 \\
(0.003)\end{array}$ & & $\begin{array}{l}-0.000 \\
(0.003)\end{array}$ \\
\hline Drought exposure & & $\begin{array}{c}-0.063^{* * *} \\
(0.020)\end{array}$ & & $\begin{array}{l}-0.025^{*} \\
(0.015)\end{array}$ & & $\begin{array}{l}-0.027^{*} \\
(0.016)\end{array}$ & & $\begin{array}{c}0.023 \\
(0.015)\end{array}$ \\
\hline Constant & $\begin{array}{l}-0.242 \\
(0.325)\end{array}$ & $\begin{array}{c}0.681 \\
(0.816)\end{array}$ & $\begin{array}{c}-1.002^{* * *} \\
(0.172)\end{array}$ & $\begin{array}{c}-1.502^{* *} \\
(0.665)\end{array}$ & $\begin{array}{l}-0.430 \\
(0.295)\end{array}$ & $\begin{array}{l}-0.859 \\
(0.788)\end{array}$ & $\begin{array}{c}-1.388^{* * *} \\
(0.120)\end{array}$ & $\begin{array}{l}-1.283^{*} \\
(0.678)\end{array}$ \\
\hline Observations & 502 & 502 & 502 & 502 & 502 & 502 & 502 & 502 \\
\hline Wald test of exogeneity $\chi^{2}$ & $7 \cdot 48^{* * *}$ & $3.28^{*}$ & $19.07^{* * *}$ & $8.75^{* * *}$ & 1.66 & 0.06 & $24 \cdot 54^{* * *}$ & $22.55^{* * *}$ \\
\hline KP rk LM statistic & $22.935^{* * *}$ & $18.607^{* * *}$ & $22.935^{* * *}$ & $18.607^{* * *}$ & $22.935^{* * *}$ & $18.607^{* * *}$ & $22.935^{* * *}$ & $18.607^{* * *}$ \\
\hline Weak iden test (KP F-Stat) & 27.890 & 22.340 & 27.890 & 22.340 & 27.890 & 22.340 & 27.890 & 22.340 \\
\hline
\end{tabular}

Notes. KP stands for Kleibergen-Paap. Robust standard errors in parentheses, ${ }^{* * *} p<0.01,{ }^{* *} p<0.05,{ }^{*}$ $\mathrm{p}<$ o.1.

\subsubsection{Mechanisms}

In this section, we elucidate some of the causal mechanisms through which market exposure affects agricultural investment decisions. As has already been mentioned, access to the market may affect farmers' investment behavior in multiple ways. However, in this paper, we emphasize only on the personality traits - risk preference and 
locus of control - that are largely acknowledged by the recent theoretical and empirical studies as key determinants of the adoption of risky but profitable technologies.

Before discussing our main results, we first probe the findings of earlier studies on whether the adoption of agricultural technology is correlated with risk preference and locus of control. ${ }^{12}$ Table C.7 shows that risk-aversion is negatively and significantly associated with the adoption of agricultural technologies. Similarly, a greater internal locus of control is positively and significantly associated with modern agricultural technologies use. Particularly, the internal locus of control is positively and significantly correlated with the adoption of chemical fertilizer and improved seed. These results reaffirm the role of personality traits on investment decisions, specifically, the role of risk-aversion (Liu, 2013; Brick \& Visser, 2015; Holden \& Quiggin, 2017) and internal locus of control (Abay et al., 2017; Taffesse \& Tadesse, 2017; Bukchin \& Kerret, 2020) on agricultural households' investment decisions. Next, we present whether market exposure is associated with causal mechanisms. We first present the results of a descriptive analysis followed by the results of the endogenous switching regression model and 2SLS.

Figure 4.3 compares farmers' risk-aversion and locus of control across those with relatively high and less market exposure. The figure shows that farmers with high market exposure are less risk-averse compared to farmers with less market exposure $(P<0.10)$. Figure 4.3 also shows that farmers with high exposure to markets have a greater degree of internal locus of control $(P<0.001)$. In sum, we find that market exposure attenuates farmers' risk-aversion and boost their internal locus of control. ${ }^{13}$

Figures C.I and C.2 in the appendix provide the distribution of farmers' riskaversion and internal locus of control across farm households' with high and less market exposure. The figures support the results from Figure 4.3 in the sense that market exposure attenuates risk-aversion and enhances internal locus of control. However, the results of the unconditional mean difference test do not provide causal effects due to the fact that market exposure may be endogenous and the difference in risk-aversion and locus of control may not be the result of the difference in market exposure per se, rather it might also be due to differences in observable and unobservable factors. To address this concern, we present the estimation results of the endogenous switching and instrumental variable (IV) regression models in sections 4.4.3.a and 4.4.3.b, respectively.

12 Interestingly, we find no statistically significant correlation between risk-aversion and locus of control (-0.051, 0.252 (P-value)).

13 To probe the robustness of our findings in Figure 4.3, we also estimate a non-parametric regression (non-parametric series and kernel regressions) of the distance to market on risk aversion and locus of control. We find qualitatively similar results in that while an increase in distance to market increases farmers' risk-aversion and it decreases farmers internal locus of control. Results are available upon request from the authors. 

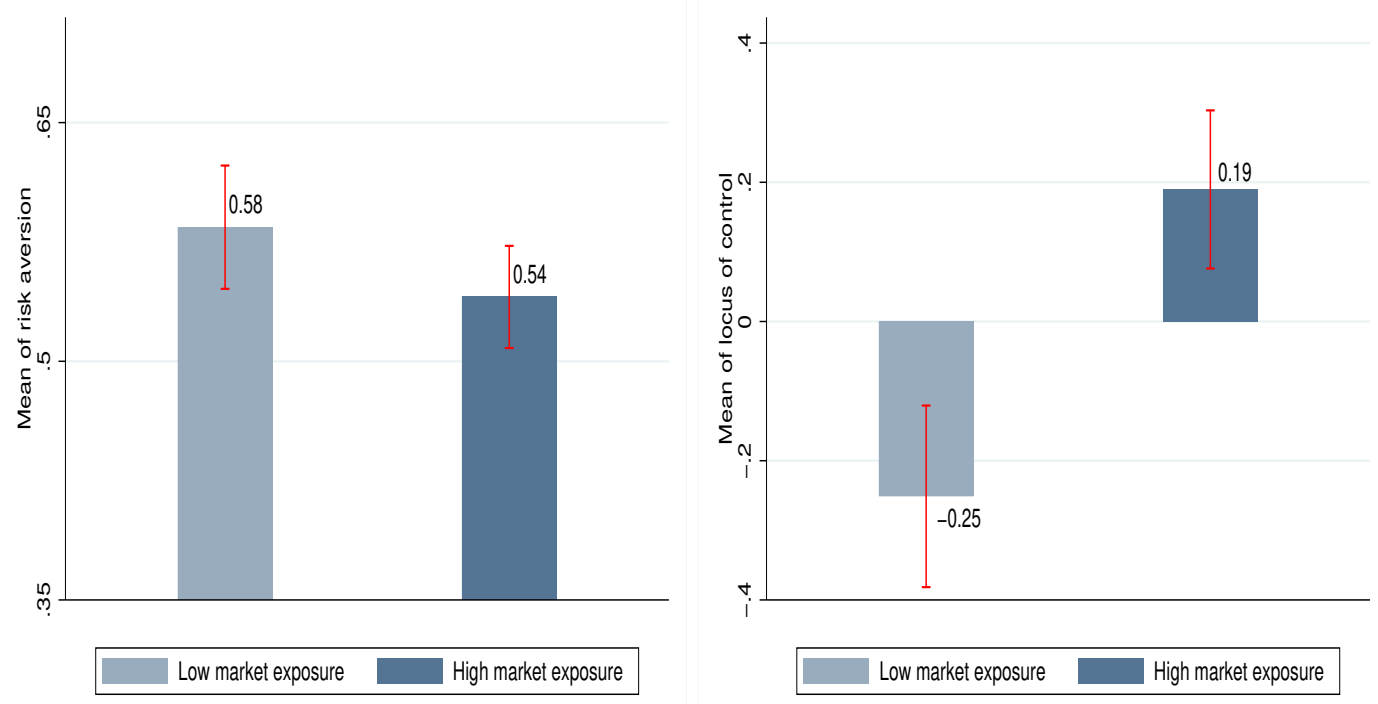

Figure 4.3: Market Exposure, Risk-aversion and Locus of Control, 95\% CI

\subsubsection{A Results of Endogenous Switching Regression model}

Table 4.4 and Table C.8 in the appendix present the FIML estimates of the endogenous switching regression (ESR) model. Before discussing the impact of market exposure on risk-aversion and locus of control, we first discuss the model diagnosis. The Wald $\chi 2$ test for joint independence of the outcome equations (risk-aversion and locus of control) and the selection equation (market exposure) presented in Table C.8 in the appendix shows that the outcome and selection equations are not independent (Abdulai \& Huffman, 2014). These suggest that OLS regression may yield biased estimates due to unobserved factors simultaneously affecting market exposure, and farmers' locus of control and risk-aversion.

Table 4.4 presents the estimates of the average treatment effect on the treated, on the untreated, and the transitional heterogeneous treatment effects under actual and counterfactual conditions. ${ }^{14}$ The results show that market exposure significantly decreases risk-aversion. The expected proportion of the amount of money not invested in the risky investment by households with high and less market exposure is 0.541 and 0.582 , respectively. In the counterfactual case, farmers with high market exposure would have invested 14 Birr less in the risky investment if they have had less exposure to the market. On the other hand, farmers with less market exposure would have invested 5 Birr more if they had high exposure to the market. The estimation results suggest that market exposure significantly attenuates risk-aversion. However,

14 This study aims to investigate whether market exposure promotes farmers' investment behavior by attenuating risk-aversion and enhancing locus of control. Thus, to economize on space, the detailed ESR model estimates such as the drivers of market exposure and the determinants of risk-aversion and locus of control other than market exposure are not discussed, but the full estimation results are available in Table C.8. 
the heterogeneous treatment effect is negative, indicating that the impact of market exposure is significantly smaller for farmers with less market exposure compared to those with high market exposure. The estimation results are consistent with the findings of a recent study by Melesse \& Cecchi (2017) who used similar risk preference elicitation experimental game in the Amhara regional state of Ethiopia and find that market exposure reduces risk-aversion.

Table 4.4: Impact of Market Exposure on Risk-Aversion and Locus of Control

\begin{tabular}{lcccc}
\hline & & \multicolumn{2}{c}{ Exposure stage } & \\
\cline { 3 - 4 } Outcomes & Household type & Exposed & Not exposed & \multirow{2}{*}{ Treatment effects } \\
\hline \multirow{2}{*}{ Risk-aversion } & High exposure (ATT) & 0.541 & 1.212 & $-0.672^{* * *}$ \\
& Low exposure (ATU) & 0.420 & 0.582 & $-0.162^{* * *}$ \\
& Heterogeneous effects & & & $-0.510^{* * *}$ \\
Locus of control & High exposure (ATT) & 0.198 & -0.138 & $0.336^{* * *}$ \\
& Low exposure (ATU) & 1.694 & -0.251 & $1.945^{* * *}$ \\
& Heterogeneous effects & & & $-1.609^{* * *}$ \\
\hline
\end{tabular}

Notes. ATT and ATU stand for Average Treatment Effect on the Treated and Average Treatment Effect on the Untreated, respectively; Robust standard errors; ${ }^{* * *} \mathrm{p}<0.01,{ }^{* *} \mathrm{p}<0.05,{ }^{*} \mathrm{p}<0.1$.

Table 4.4 also presents the impact of market exposure on internal locus of control. The results show that market exposure increases the internal locus of control by 0.2 standard deviations. On the other hand, farmers with less market exposure would have increased their internal locus of control by 1.70 standard deviations if they have had high exposure to the market. However, the transitional heterogeneity effects for internal locus control is negative, suggesting that the impact is smaller for farmers with high market exposure compared to those with less market exposure. The results from the ESR model reaffirms that locus of control may not be truly time-invariant (Cobb-Clark \& Schurer, 2013) and may systematically vary with small but frequent life events (Elkins et al., 2017). In a nutshell, the estimation results of the ESR model show that market exposure attenuates risk-aversion and enhances locus of control, and thus, promotes the adoption of high-risk-high-return technologies. 


\subsubsection{B Results of the Instrumental Variable Estimation}

To validate the results of the ESR model in section 4.4.3.a, we employ the instrumental variable (IV) method. The endogeneity test indicates that market exposure is indeed endogenous, and OLS may provide biased estimates. Household-level distance to a large weekly market is used as an instrument for both the continuous and binary measures of market exposure. We used the Kleibergen-Paap F statistic to test for weak instruments. Table 4.5 shows that the F statistic is greater than the minimum 10 threshold values of Stock et al. (2002), suggesting that our instrument is not weak. ${ }^{15}$ Table 4.5 also provides further support for the validity of our instruments in that the Kleibergen-Paap rk LM statistic which is used to test for the under-identification shows that the models are correctly identified. Table C.9 in the appendix also reports that household distance to the market negatively and significantly affects farmers' market exposure. The results are robust to different specifications and even after controlling a large battery of controls. ${ }^{16}$

Table 4.5 shows that market exposure significantly affects risk-aversion and internal locus of control. The most parsimonious specifications in columns (1) and (3) indicate the prevalence of negative and significant association between market exposure and risk-aversion. Column (1) suggests that risk-aversion decreases as farmers' market experience increases. Similarly, column (3) shows that the binary market exposure is also negatively associated with risk-aversion. In columns (2) and (4), we added a battery of controls. However, adding the control variables does not attenuate the significant effect of both the continuous (column 2) and the binary (column 4) measures of market exposure. Results for the internal locus of control are provided in columns (5) through (8). In columns (5) and (7), we again present the parsimonious specifications. The estimation results show that higher market exposure is positively associated with the internal locus of control. However, including relevant controls into the analysis attenuates the effect of market exposure (columns 6 and 8). Nevertheless, in sum, our estimation results suggest that market exposure stimulates agricultural investment behavior through attenuating risk-aversion and improving non-cognitive skills such as locus of control.

15 Since the threshold values for strong instruments do not exist for the Kleibergen-Paap statistic, following Baum et al. (2007), we apply the Stock and Yogo critical values in order to test for weak IV.

16 However, as we have only one instrument for one endogenous variable, we could not conduct the over-identification test. 
Table 4.5: Impact of Market Exposure on Risk-Aversion and Locus of Control

\begin{tabular}{|c|c|c|c|c|c|c|c|c|}
\hline & $\begin{array}{c}(1) \\
\text { Risk } \\
\text { aversion }\end{array}$ & $\begin{array}{c}(2) \\
\text { Risk } \\
\text { aversion }\end{array}$ & $\begin{array}{c}(3) \\
\text { Risk } \\
\text { aversion }\end{array}$ & $\begin{array}{c}\text { (4) } \\
\text { Risk } \\
\text { aversion }\end{array}$ & $\begin{array}{c}\text { (5) } \\
\text { Locus } \\
\text { of control }\end{array}$ & $\begin{array}{c}\text { (6) } \\
\text { Locus } \\
\text { of control }\end{array}$ & $\begin{array}{c}\text { (7) } \\
\text { Locus } \\
\text { of control }\end{array}$ & $\begin{array}{c}(8) \\
\text { Locus } \\
\text { of control }\end{array}$ \\
\hline Market experience & $\begin{array}{c}-0.093^{* * *} \\
(0.026)\end{array}$ & $\begin{array}{c}-0.078^{* * *} \\
(0.026)\end{array}$ & & & $\begin{array}{l}0.153^{* *} \\
(0.076)\end{array}$ & $\begin{array}{c}0.082 \\
(0.076)\end{array}$ & & \\
\hline Market exposure & & & $\begin{array}{c}-0.582^{* * *} \\
(0.174)\end{array}$ & $\begin{array}{c}-0.513^{* * *} \\
(0.190)\end{array}$ & & & $\begin{array}{l}0.957^{* *} \\
(0.485)\end{array}$ & $\begin{array}{c}0.541 \\
(0.509)\end{array}$ \\
\hline Age & & $\begin{array}{l}-0.001 \\
(0.007)\end{array}$ & & $\begin{array}{l}-0.002 \\
(0.007)\end{array}$ & & $\begin{array}{l}0.052^{* *} \\
(0.026)\end{array}$ & & $\begin{array}{l}0.053^{* *} \\
(0.026)\end{array}$ \\
\hline Age square & & $\begin{array}{c}0.000 \\
(0.000)\end{array}$ & & $\begin{array}{c}0.000 \\
(0.000)\end{array}$ & & $\begin{array}{c}-0.001^{* *} \\
(0.000)\end{array}$ & & $\begin{array}{c}-0.001^{* *} \\
(0.000)\end{array}$ \\
\hline Male & & $\begin{array}{c}-0.096^{* *} \\
(0.041)\end{array}$ & & $\begin{array}{c}-0.116^{* *} \\
(0.047)\end{array}$ & & $\begin{array}{c}0.146 \\
(0.112)\end{array}$ & & $\begin{array}{c}0.166 \\
(0.115)\end{array}$ \\
\hline Household size & & $\begin{array}{l}-0.012 \\
(0.009)\end{array}$ & & $\begin{array}{c}0.006 \\
(0.011)\end{array}$ & & $\begin{array}{c}0.041 \\
(0.025)\end{array}$ & & $\begin{array}{c}0.023 \\
(0.029)\end{array}$ \\
\hline Education & & $\begin{array}{c}0.027 \\
(0.032)\end{array}$ & & $\begin{array}{c}0.027 \\
(0.038)\end{array}$ & & $\begin{array}{l}0.215^{* *} \\
(0.096)\end{array}$ & & $\begin{array}{l}0.215^{* *} \\
(0.097)\end{array}$ \\
\hline Land size & & $\begin{array}{l}-0.001 \\
(0.010)\end{array}$ & & $\begin{array}{c}0.003 \\
(0.011)\end{array}$ & & $\begin{array}{c}0.001 \\
(0.027)\end{array}$ & & $\begin{array}{l}-0.003 \\
(0.027)\end{array}$ \\
\hline Livestock & & $\begin{array}{l}-0.005 \\
(0.004)\end{array}$ & & $\begin{array}{l}-0.002 \\
(0.005)\end{array}$ & & $\begin{array}{c}0.018 \\
(0.012)\end{array}$ & & $\begin{array}{c}0.015 \\
(0.011)\end{array}$ \\
\hline Housing condition & & $\begin{array}{l}-0.030 \\
(0.048)\end{array}$ & & $\begin{array}{l}-0.057 \\
(0.064)\end{array}$ & & $\begin{array}{l}0.430^{* *} \\
(0.201)\end{array}$ & & $\begin{array}{l}0.459^{* *} \\
(0.198)\end{array}$ \\
\hline Own phone & & $\begin{array}{l}-0.026 \\
(0.036)\end{array}$ & & $\begin{array}{l}-0.042 \\
(0.040)\end{array}$ & & $\begin{array}{l}-0.003 \\
(0.117)\end{array}$ & & $\begin{array}{c}0.013 \\
(0.114)\end{array}$ \\
\hline Own radio & & $\begin{array}{c}0.029 \\
(0.033)\end{array}$ & & $\begin{array}{c}0.006 \\
(0.036)\end{array}$ & & $\begin{array}{c}0.100 \\
(0.095)\end{array}$ & & $\begin{array}{c}0.124 \\
(0.089)\end{array}$ \\
\hline Iddir member & & $\begin{array}{l}-0.037 \\
(0.034)\end{array}$ & & $\begin{array}{l}-0.052 \\
(0.042)\end{array}$ & & $\begin{array}{c}0.162 \\
(0.100)\end{array}$ & & $\begin{array}{l}0.177^{*} \\
\text { (o.100) }\end{array}$ \\
\hline Eqqub member & & $\begin{array}{c}0.009 \\
(0.030)\end{array}$ & & $\begin{array}{c}0.015 \\
(0.036)\end{array}$ & & $\begin{array}{l}-0.101 \\
(0.089)\end{array}$ & & $\begin{array}{l}-0.108 \\
(0.091)\end{array}$ \\
\hline Cooperative member & & $\begin{array}{c}0.030 \\
(0.030)\end{array}$ & & $\begin{array}{c}0.042 \\
(0.034)\end{array}$ & & $\begin{array}{c}0.246^{* * *} \\
(0.082)\end{array}$ & & $\begin{array}{c}0.233^{* * *} \\
(0.083)\end{array}$ \\
\hline Distance to FTC & & $\begin{array}{c}0.000 \\
(0.001)\end{array}$ & & $\begin{array}{l}-0.000 \\
(0.001)\end{array}$ & & $\begin{array}{l}-0.000 \\
(0.002)\end{array}$ & & $\begin{array}{l}-0.000 \\
(0.002)\end{array}$ \\
\hline Drought exposure & & $\begin{array}{l}0.007^{*} \\
(0.004)\end{array}$ & & $\begin{array}{c}0.006 \\
(0.004)\end{array}$ & & $\begin{array}{c}0.016 \\
(0.011)\end{array}$ & & $\begin{array}{c}0.017 \\
(0.011)\end{array}$ \\
\hline Constant & $\begin{array}{c}0.879^{* * *} \\
(0.086)\end{array}$ & $\begin{array}{l}0.912^{* * *} \\
(0.170)\end{array}$ & $\begin{array}{c}0.891^{* * *} \\
(0.099)\end{array}$ & $\begin{array}{c}0.957^{* * *} \\
(0.181)\end{array}$ & $\begin{array}{l}-0.526^{* *} \\
(0.263)\end{array}$ & $\begin{array}{c}-2.570^{* * *} \\
(0.627)\end{array}$ & $\begin{array}{l}-0.545^{*} \\
\text { (0.280) }\end{array}$ & $\begin{array}{c}-2.618^{* * *} \\
(0.635)\end{array}$ \\
\hline KP F-Stat & 27.89 & 22.34 & 20.86 & $14 \cdot 34$ & 27.89 & 22.34 & 20.86 & $14 \cdot 34$ \\
\hline KP rk LM statistic & $22.935^{* * *}$ & $18.607^{* * *}$ & $22.935^{* * *}$ & $18.607^{* * *}$ & $22.935^{* * *}$ & $18.607^{* * *}$ & $22.935^{* * *}$ & $18.607^{* * *}$ \\
\hline Observations & 502 & 502 & 502 & 502 & 502 & 502 & 502 & 502 \\
\hline
\end{tabular}

Notes. KP stands for Kleibergen-Paap. Robust standard errors in parentheses, ${ }^{* * *} \mathrm{p}<0.01,{ }^{* *} \mathrm{p}<0.05$, ${ }^{*} \mathrm{p}<0.1$.

Table 4.5 also shows that a range of variables affects farmers' risk-aversion and internal locus of control. Male-headed households are less risk-averse compared to female-headed farm households. Farmers who reside in villages exposed to frequent droughts are also more risk-averse than those who live in villages with less exposure 
to drought. On the other hand, internal locus of control non-linearly decreases with the age of the household. Consistent with Abay et al. (2017) and Taffesse \& Tadesse (2017), locus of control initially increases with the age of the household head but declines after a certain age limit. Literate farmers have a relatively higher internal locus of control compared to the illiterate farmers that is in line with the findings of previous studies (Heckman et al., 2006). Relatively wealthy households (farmers who own houses with at least average condition) have a higher internal locus of control. Furthermore, internal locus of control is positively associated with membership in social networks such as membership in funeral insurance and agricultural cooperatives.

\subsection{CONCLUSION}

Understanding farmers' investment behavior is key to spur the adoption of modern farming inputs, thereby boost productivity and facilitate agricultural transformation in Sub-Saharan Africa. The existing literature, however, points out that the rate of investment in improved farming technologies in the region is rather slow, which resulted in low agricultural productivity. There is an extensive theoretical and empirical literature devoted to uncovering the constraining factors for the adoption of these technologies. A large body of literature demonstrates that external factors, including imperfect credit and insurance markets, transaction costs, quality of inputs, and heterogeneous returns to farming inputs (Duflo et al., 2011; Suri, 2011; Minten et al., 2013; Karlan et al., 2014; Bold et al., 2017) explain the low level of investments in profitable agricultural technologies. Recently, economists are increasingly pushing the frontiers of the economics of technology adoption literature to accommodate behavioral drivers (internal constraints) of risky but high return technologies (Duflo et al., 2011; Bernard et al., 2014; Abay et al., 2017; Taffesse \& Tadesse, 2017). However, to date, both strands of literature considered internal and external constraints as independent. This paper argue that internal and external constraints are interdependent, and external factors such as markets may predict the change in internal constraints, including risk preferences and locus of control, which in turn, influence the use of modern farming inputs.

In this paper, we investigate whether markets affect farmers' investment behavior by altering their preferences (risk aversion) and personality traits (locus of control). To this end, we utilize survey and lab-in-the-field experimental data collected from 544 farm households in Tigray regional state of Ethiopia. Ethiopia is an interesting context to test if this hypothesis indeed holds. This is due to the fact that in the country, agricultural inputs are supplied by the parastatal agricultural cooperatives, that are available in every village. However, in the absence of random or exogenous exposure to markets, identifying the causal effect of market exposure is challenging due to the potential endogeneity problem stemmed from simultaneity and omitted variable biases. To address these concerns, we employ the endogenous switching probit (ESP) 
and IV - probit models. The diagnosis tests in both models show that market experience is indeed endogenous and the use of ESP and IV - probit is preferred than the naïve probit or bivariate probit models.

We find that greater market integration promotes farmers' investment behavior use of productivity enhancing inputs such as chemical fertilizer, improved seeds, organic fertilizer and row planting. The findings show that farmers with higher market exposure tend to be less risk-averse and have high internal locus of control, and in turn, are more likely to adopt these farming inputs. Likewise, farm households with less market exposure would have substantially reduced their risk-aversion and increased their internal locus of control, and thereby would have used more improved agricultural technologies. The average treatment effects from the ESP model also shows that farmers would have increased use of chemical fertilizer, improved seeds, organic fertilizer and row planting by $15,48,15$, and 46 percentage points, respectively. Our results are robust to alternative measures of market exposure, and different specifications and estimation strategies.

Our study contributes to the extensive economics of technology adoption literature. We provide new evidence that internal and external factors which predict farmers' technology adoption decisions are interdependent, and external constraints such as markets may influence farm households investment behavior by modifying internal constraints (risk preference and locus of control). This paper, therefore, suggests alternative pathways through which adoption of improved technologies could be increased in developing countries, specially, in Sub-Saharan Africa. Further, our findings also contribute to the growing literature on whether preferences and personality traits are endogenous and malleable. Particularly, we add to the thin literature on the effect market exposure on risk preference. Consistent with the findings by Melesse \& Cecchi (2017), market exposure significantly and robustly attenuates risk-aversion. Additionally, in line with Cobb-Clark \& Schurer (2013) and Elkins et al. (2017), we show that locus of control may not be truly time-invariant and systematically respond to small but more frequent life events, such as market participation.

Finally, while our findings are informative and stimulate further research, we are constrained by lack of experimental and longitudinal data. Since this paper is based on cross-sectional data, it warrants further investigation through exogenously varying farmers exposure to markets. The Sub-Saharan African Challenge Program (SSA-CP) which involves penetration of markets in remote villages and linking farmers to regional and national markets is an interesting example (see Siziba \& Bulte (2012) for details). Additionally, further research is needed to probe the robustness of our findings using longitudinal data to better understand on the dynamics risk aversion and locus of control, and thus, investment behavior. 


\section{REFERENCES}

Aakvik, A., Heckman, J. J. \& Vytlacil, E. J. (2005), 'Estimating treatment effects for discrete outcomes when responses to treatment vary: an application to norwegian vocational rehabilitation programs', Journal of Econometrics 125(1-2), 15-51.

Abay, K. A., Blalock, G. \& Berhane, G. (2017), 'Locus of control and technology adoption in developing country agriculture: Evidence from ethiopia', Journal of Economic Behavior E Organization 143, 98-115.

Abdulai, A. \& Huffman, W. (2014), 'The adoption and impact of soil and water conservation technology: An endogenous switching regression application', Land economics 9o(1), 26-43.

Abebaw, D. \& Haile, M. G. (2013), 'The impact of cooperatives on agricultural technology adoption: Empirical evidence from ethiopia', Food policy 38, 82-91.

Aggarwal, S. (2018), 'Do rural roads create pathways out of poverty? Evidence from India', Journal of Development Economics 133, 375-395.

Aggarwal, S., Giera, B., Jeong, D., Robinson, J. \& Spearot, A. (2018), Market access, trade costs, and technology adoption: Evidence from northern tanzania, Technical report, National Bureau of Economic Research. NBER working paper No. w25253.

Alem, Y., Bezabih, M., Kassie, M. \& Zikhali, P. (2010), 'Does fertilizer use respond to rainfall variability? panel data evidence from ethiopia', Agricultural Economics 41(2), 165-175.

Andrisani, P. J. (1977), 'Internal-external attitudes, personal initiative, and the labor market experience of black and white men', Journal of Human Resources pp. 308-328.

Angrist, J. D. (1991), Instrumental variables estimation of average treatment effects in econometrics and epidemiology, Technical report, National Bureau of Economic Research. NBER Technical Working Paper No. 0115.

Asfaw, A. \& Admassie, A. (2004), 'The role of education on the adoption of chemical fertiliser under different socioeconomic environments in ethiopia', Agricultural economics 30(3), 215-228.

Barrett, C. B., Christiaensen, L., Sheahan, M. \& Shimeles, A. (2017), 'On the structural transformation of rural africa', Journal of African Economies 26(suppl_1), i11-i35.

Bartling, B., Weber, R. A. \& Yao, L. (2015), 'Do markets erode social responsibility?', Quarterly Journal of Economics 130(1), 219-266.

Baum, C. F., Schaffer, M. E. \& Stillman, S. (2007), 'Enhanced routines for instrumental variables/generalized method of moments estimation and testing', The Stata Journal $7(4), 465-506$. 
Becker, G. S. \& Mulligan, C. B. (1997), 'The endogenous determination of time preference', The Quarterly Journal of Economics 112(3), 729-758.

Bernard, T., Dercon, S., Orkin, K., Taffesse, A. et al. (2014), The future in mind: Aspirations and forward-looking behaviour in rural Ethiopia, Centre for Economic Policy Research London.

Block, S. A. (2014), 'The post-independence decline and rise of crop productivity in sub-saharan africa: measurement and explanations', Oxford Economic Papers 66(2), 373-396.

Bold, T., Kaizzi, K. C., Svensson, J. \& Yanagizawa-Drott, D. (2017), 'Lemon technologies and adoption: measurement, theory and evidence from agricultural markets in uganda', The Quarterly Journal of Economics 132(3), 1055-1100.

Bowles, S. (1998), 'Endogenous preferences: The cultural consequences of markets and other economic institutions', Journal of Economic Literature 36(1), 75-111.

Brick, K. \& Visser, M. (2015), 'Risk preferences, technology adoption and insurance uptake: A framed experiment', Journal of Economic Behavior E Organization 118, 383396.

Brown, R., Montalva, V., Thomas, D. \& Velásquez, A. (2019), 'Impact of violent crime on risk aversion: Evidence from the mexican drug war', Review of Economics and Statistics 101(5), 892-904.

Bukchin, S. \& Kerret, D. (2020), 'The role of self-control, hope and information in technology adoption by smallholder farmers-a moderation model', Journal of Rural Studies 74, 160-168.

Caliendo, M., Cobb-Clark, D. A. \& Uhlendorff, A. (2015), 'Locus of control and job search strategies', Review of Economics and Statistics 97(1), 88-103.

Callen, M., Isaqzadeh, M., Long, J. D. \& Sprenger, C. (2014), 'Violence and risk preference: Experimental evidence from Afghanistan', American Economic Review 104(1), 123-48.

Cameron, L. \& Shah, M. (2015), 'Risk-taking behavior in the wake of natural disasters', Journal of Human Resources 50(2), 484-515.

Cebi, M. (2007), 'Locus of control and human capital investment revisited', Journal of Human Resources 42(4), 919-932.

Cecchi, F. \& Bulte, E. (2013), 'Does market experience promote rational choice? Experimental evidence from rural Ethiopia', Economic Development and Cultural Change 61(2), 407-429.

Cobb-Clark, D. A., Kassenboehmer, S. C. \& Sinning, M. G. (2016), 'Locus of control and savings', Journal of Banking E Finance 73, 113-130.

Cobb-Clark, D. A. \& Schurer, S. (2013), 'Two economists' musings on the stability of locus of control', The Economic Journal 123(570), F358-F400. 
Cohn, A., Engelmann, J., Fehr, E. \& Maréchal, M. A. (2015), 'Evidence for countercyclical risk aversion: An experiment with financial professionals', American Economic Review 105(2), 860-85.

Conley, T. G. \& Udry, C. R. (2010), 'Learning about a new technology: Pineapple in ghana', American economic review 100(1), 35-69.

Dercon, S. \& Christiaensen, L. (2011), 'Consumption risk, technology adoption and poverty traps: Evidence from ethiopia', Journal of development economics 96(2), 159173.

Di Falco, S., Berck, P., Bezabih, M. \& Köhlin, G. (2019), ‘Rain and impatience: Evidence from rural ethiopia', Journal of Economic Behavior E Organization 160, 40-51.

Di Falco, S., Veronesi, M. \& Yesuf, M. (2011), 'Does adaptation to climate change provide food security? A micro-perspective from Ethiopia', American Journal of Agricultural Economics 93(3), 829-846.

Dietrich, S., Beekman, G. \& Nillesen, E. (2018), 'Market integration and pro-social behaviour in rural Liberia'. UNU-MERIT Working Paper No. о10.

Duflo, E., Kremer, M. \& Robinson, J. (2011), 'Nudging farmers to use fertilizer: Theory and experimental evidence from kenya', American economic review 101(6), 2350-90.

Elkins, R. K., Kassenboehmer, S. C. \& Schurer, S. (2017), 'The stability of personality traits in adolescence and young adulthood', Journal of Economic Psychology 60, 37-52.

Evenson, R. E. \& Gollin, D. (2003), 'Assessing the impact of the green revolution, 1960 to $2000^{\prime}$, science 300(5620), 758-762.

Falk, A. \& Szech, N. (2013), 'Morals and markets', Science 340(6133), 707-711.

Foster, A. D. \& Rosenzweig, M. R. (2010), 'Microeconomics of technology adoption', Annu. Rev. Econ. 2(1), 395-424.

Gneezy, U., Leonard, K. L. \& List, J. A. (2009), 'Gender differences in competition: Evidence from a matrilineal and a patriarchal society', Econometrica 77(5), 16371664.

Gneezy, U. \& Potters, J. (1997), 'An experiment on risk taking and evaluation periods', The Quarterly Journal of Economics 112(2), 631-645.

Guiso, L., Sapienza, P. \& Zingales, L. (2018), 'Time varying risk aversion', Journal of Financial Economics 128(3), 403-421.

Haile, K. K., Nillesen, E. \& Tirivayi, N. (2020), 'Impact of formal climate risk transfer mechanisms on risk-aversion: Empirical evidence from rural ethiopia', World Development 130, 104930.

Hall, R. E. \& Jones, C. I. (1999), ‘Why do some countries produce so much more output per worker than others?', The Quarterly Journal of Economics 114(1), 83-116.

Hanaoka, C., Shigeoka, H. \& Watanabe, Y. (2018), 'Do risk preferences change? evidence from the great east japan earthquake', American Economic Journal: Applied Economics 10(2), 298-330. 
Heckman, J. J., Stixrud, J. \& Urzua, S. (2006), 'The effects of cognitive and noncognitive abilities on labor market outcomes and social behavior', Journal of Labor Economics 24(3), 411-482.

Heineck, G. \& Anger, S. (2010), 'The returns to cognitive abilities and personality traits in germany', Labour economics 17(3), 535-546.

Henrich, J., Boyd, R., Bowles, S., Camerer, C., Fehr, E., Gintis, H. \& McElreath, R. (2001), 'In search of homo economicus: behavioral experiments in 15 small-scale societies', The American Economic Review 91(2), 73-78.

Henrich, J., Ensminger, J., McElreath, R., Barr, A., Barrett, C., Bolyanatz, A., Cardenas, J. C., Gurven, M., Gwako, E., Henrich, N. et al. (2010), 'Markets, religion, community size, and the evolution of fairness and punishment', Science 327(5972), 1480-1484.

Holden, S. T. \& Quiggin, J. (2017), 'Climate risk and state-contingent technology adoption: shocks, drought tolerance and preferences', European Review of Agricultural Economics 44(2), 285-308.

Jakiela, P. \& Ozier, O. (2019), 'The impact of violence on individual risk preferences: evidence from a natural experiment', Review of Economics and Statistics 101(3), 547559.

Kahsay, G. A. \& Osberghaus, D. (2018), 'Storm damage and risk preferences: panel evidence from germany', Environmental and resource economics 71(1), 301-318.

Karlan, D., Osei, R., Osei-Akoto, I. \& Udry, C. (2014), 'Agricultural decisions after relaxing credit and risk constraints', The Quarterly Journal of Economics 129(2), 597652.

Kebede, B. \& Zizzo, D. J. (2015), 'Social preferences and agricultural innovation: an experimental case study from ethiopia', World Development 67, 267-280.

Krishnan, P. \& Patnam, M. (2013), 'Neighbors and extension agents in ethiopia: Who matters more for technology adoption?', American Journal of Agricultural Economics 96(1), 308-327.

List, J. A. (2003), 'Does market experience eliminate market anomalies?', The Quarterly Journal of Economics 118(1), 41-71.

List, J. A. \& Millimet, D. L. (2008), 'The market: Catalyst for rationality and filter of irrationality', The BE Journal of Economic Analysis E Policy 8(1).

Liu, E. M. (2013), 'Time to change what to sow: Risk preferences and technology adoption decisions of cotton farmers in china', Review of Economics and Statistics 95(4), 1386-1403.

Lokshin, M. \& Glinskaya, E. (2009), 'The effect of male migration on employment patterns of women in nepal', The World Bank Economic Review 23(3), 481-507.

Lokshin, M. \& Sajaia, Z. (2011), 'Impact of interventions on discrete outcomes: Maximum likelihood estimation of the binary choice models with binary endogenous regressors', The Stata Journal 11(3), 368-385. 
Maertens, A. \& Barrett, C. B. (2012), 'Measuring social networks' effects on agricultural technology adoption', American Journal of Agricultural Economics 95(2), 353-359.

Malmendier, U. \& Nagel, S. (2011), 'Depression babies: do macroeconomic experiences affect risk taking?', The Quarterly Journal of Economics 126(1), 373-416.

Melesse, M. B. \& Cecchi, F. (2017), 'Does market experience attenuate risk aversion? evidence from landed farm households in ethiopia', World Development 98, 447-466.

Minten, B., Koru, B. \& Stifel, D. (2013), 'The last mile (s) in modern input distribution: Pricing, profitability, and adoption', Agricultural Economics 44(6), 629-646.

Netzer, N. (2009), 'Evolution of time preferences and attitudes toward risk', American Economic Review 99(3), 937-55.

Nigus, H. Y., Nillesen, E., Mohnen, P. \& Di Falco, S. (2021), 'Markets, social responsibility and welfare: Experimental evidence from Ethiopia'. Unpublished Working Paper.

Nigus, H. Y., Nillesen, E., Mohnen, P. et al. (2018), 'The effect of weather index insurance on social capital: Experimental evidence from ethiopia', UNU-MERIT Working Paper (2018-007).

Oster, E. \& Thornton, R. (2012), 'Determinants of technology adoption: Peer effects in menstrual cup take-up', Journal of the European Economic Association 1o(6), 1263-1293.

Page, L., Savage, D. A. \& Torgler, B. (2014), 'Variation in risk seeking behaviour following large losses: A natural experiment', European Economic Review 71, 121-131.

Pretty, J., Toulmin, C. \& Williams, S. (2011), 'Sustainable intensification in african agriculture', International journal of agricultural sustainability 9(1), 5-24.

Roodman, D. (2011), 'Fitting fully observed recursive mixed-process models with cmp', The Stata Journal 11(2), 159-206.

Ross, P. H. (2018), 'Ancestral roots of locus of control'. Job Market Paper.

Rotter, J. B. (1966), 'Generalized expectancies for internal versus external control of reinforcement.', Psychological monographs: General and applied 80(1), I.

Sakha, S. (2019), 'Determinants of risk aversion over time: Experimental evidence from rural thailand', Journal of Behavioral and Experimental Economics 80, 184-198.

Schurer, S. (2017), 'Bouncing back from health shocks: Locus of control and labor supply', Journal of Economic Behavior E Organization 133, 1-20.

Semykina, A. \& Linz, S. J. (2007), 'Gender differences in personality and earnings: Evidence from russia', Journal of Economic Psychology 28(3), 387-410.

Sheahan, M. \& Barrett, C. B. (2017), 'Ten striking facts about agricultural input use in sub-saharan africa', Food Policy 67, 12-25.

Siziba, S. \& Bulte, E. (2012), 'Does market participation promote generalized trust? Experimental evidence from Southern Africa', Economics Letters 117(1), 156-160.

Smith, V. L. (1982), 'Markets as economizers of information: experimental examination of the "hayek hypothesis"', Economic Inquiry 20(2), 165-179. 
Stigler, G. J. \& Becker, G. S. (1977), 'De gustibus non est disputandum', The american economic review 67(2), 76-90.

Stock, J. H., Wright, J. H. \& Yogo, M. (2002), 'A survey of weak instruments and weak identification in generalized method of moments', Journal of Business $\mathcal{E}$ Economic Statistics 20(4), 518-529.

Suri, T. (2011), 'Selection and comparative advantage in technology adoption', Econometrica 79(1), 159-209.

Taffesse, A. S. \& Tadesse, F. (2017), 'Pathways less explored-locus of control and technology adoption', Journal of African Economies 26(suppl_1), i36-i72.

Theil, H. \& Finke, R. (1983), 'The distance from the equator as an instrumental variable', Economics Letters 13(4), 357-360.

Vohs, K. D., Mead, N. L. \& Goode, M. R. (2008), 'Merely activating the concept of money changes personal and interpersonal behavior', Current Directions in Psychological Science 17(3), 208-212.

Vohs, K. D., Mead, N. L. \& Goode, M. R. (2015), 'Merely activating the concept of money changes personal and interpersonal behavior', Current Directions in Psychological Science 17(3), 208-212.

Voors, M. J., Nillesen, E. E., Verwimp, P., Bulte, E. H., Lensink, R. \& Van Soest, D. P. (2012), 'Violent conflict and behavior: a field experiment in burundi', American Economic Review 102(2), 941-64.

Zeller, M., Diagne, A. \& Mataya, C. (1998), 'Market access by smallholder farmers in malawi: Implications for technology adoption, agricultural productivity and crop income', Agricultural Economics 19(1-2), 219-229.

Zerfu, D. \& Larson, D. (2010), 'Incomplete markets and fertilizer use: evidence from ethiopia'. World Bank Policy Research Working Paper 5235. 


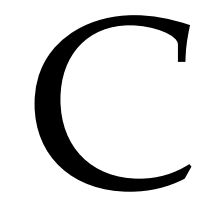

APPENDIX 
TABLES AND FIGURES

Table C.1: Variable Definitions and Summary Statistics

\begin{tabular}{|c|c|c|c|}
\hline Variables & Descriptions of variables & Mean & Standard Deviation \\
\hline \multicolumn{4}{|l|}{ Outcome Variables } \\
\hline Chemical fertilizer & Dummy: $=1$ if the respondent used chemical fertilizer, $=0$ otherwise & 0.843 & 0.365 \\
\hline Improved seed & Dummy: $=1$ if the respondent used improved seed, $=0$ otherwise & 0.51 & 0.5 \\
\hline Organic fertilizer & Dummy: $=1$ if the respondent used organic fertilizer, $=0$ otherwise & 0.514 & 0.5 \\
\hline Row planting & Dummy: $=1$ if the respondent used row planting,$=0$ otherwise & 0.323 & 0.468 \\
\hline \multicolumn{4}{|l|}{ Mechanisms } \\
\hline Risk aversion & Continuous: Risk aversion index & $0.55^{8}$ & 0.281 \\
\hline Locus of control & Continuous: Locus of control index (standardized) & o & 1 \\
\hline \multicolumn{4}{|l|}{ Treatments } \\
\hline Market transactions & Continuous: Average number of market transactions (buying \& selling) per month & 3.436 & 2.586 \\
\hline Market exposure & Dummy: $=1$ if the respondent has high market exposure, $=0$ otherwise & 0.591 & 0.492 \\
\hline \multicolumn{4}{|l|}{ Instrument } \\
\hline Distance to market & Continuous: Respondent's distance to the nearest weekly market & 1.806 & 0.886 \\
\hline \multicolumn{4}{|l|}{ Controls } \\
\hline Age & Continuous: Age of the household head & 43.972 & 11.84 \\
\hline Male & Dummy: $=1$ if the household head is Male,$=0$ Female & 0.737 & 0.441 \\
\hline Household size & Continuous: number of persons in the household & $5 \cdot 787$ & 2.073 \\
\hline Education & Dummy: $=1$ if the household head attend formal education, $=0$ otherwise & 0.582 & 0.494 \\
\hline Tsimad & Continuous: Agricultural land size & 3.044 & 1.942 \\
\hline Livestock & Continuous: total livestock holding (TLU) & 4.350 & 3.819 \\
\hline House condition & Dummy: $=1$ if the housing condition is average and above $=0$ otherwise & 0.932 & 0.252 \\
\hline Own phone & Dummy: $=1$ if the respondent own phone $=0$ otherwise & 0.723 & 0.448 \\
\hline Own radio & Dummy: $=1$ if the respondent own radio, $=0$ otherwise & 0.426 & 0.495 \\
\hline Iddir member & Dummy: $=1$ if the household head is member of funeral association, $=0$ otherwise & 0.787 & 0.410 \\
\hline Eqqub member & Dummy: $=1$ if the household head is member of eqqub, $=0$ otherwise & 0.476 & 0.500 \\
\hline Cooperative member & Dummy: $=1$ if the household head is member of agricultural cooperatives, $=0$ otherwise & 0.556 & 0.497 \\
\hline Distance to FTC & Continuous: Distance to the farmer training center & 25.863 & 24.75 \\
\hline Village exposure to drought & Continuous: Number of drought periods in 30 years & 6.985 & 4.109 \\
\hline
\end{tabular}


Table C.2: Mean Difference Test of Variables

\begin{tabular}{|c|c|c|c|c|}
\hline $\begin{array}{l}\text { Variables } \\
\text { Variables }\end{array}$ & $\begin{array}{l}\text { Low market } \\
\text { exposure }\end{array}$ & $\begin{array}{c}\text { High market } \\
\text { exposure }\end{array}$ & Diff. & P-value \\
\hline \multicolumn{5}{|l|}{ Outcome variables } \\
\hline Chemical fertilizer adoption & 0.806 & 0.871 & -0.065 & 0.048 \\
\hline Improved seed adoption & 0.435 & 0.566 & -0.131 & 0.004 \\
\hline Organic fertilizer adoption & 0.495 & 0.528 & -0.033 & 0.470 \\
\hline Row planting adoption & 0.282 & 0.353 & -0.071 & 0.094 \\
\hline \multicolumn{5}{|l|}{ Mechanisms } \\
\hline Risk aversion index & 0.584 & 0.540 & 0.044 & 0.086 \\
\hline Locus of control (Standardized) & -0.251 & 0.188 & -0.441 & 0.000 \\
\hline \multicolumn{5}{|l|}{ Instrument } \\
\hline Distance to market & 2.000 & 1.660 & 0.339 & 0.000 \\
\hline \multicolumn{5}{|l|}{ Control variables } \\
\hline Age & 45.819 & 42.577 & 3.243 & 0.002 \\
\hline Age square & 2265.912 & 1928.108 & 337.804 & 0.001 \\
\hline Male & 0.755 & 0.724 & 0.031 & 0.438 \\
\hline Household size & 5.607 & 5.923 & -0.317 & 0.090 \\
\hline Education & 0.514 & 0.633 & -0.119 & 0.007 \\
\hline Land size & 3.095 & 3.005 & 0.090 & 0.609 \\
\hline Livestock & 4.117 & 4.526 & -0.410 & 0.234 \\
\hline Housing condition & 0.917 & 0.944 & -0.027 & 0.227 \\
\hline Own phone & 0.662 & 0.769 & -0.107 & 0.008 \\
\hline Own radio & 0.389 & 0.455 & -0.066 & 0.141 \\
\hline Iddir member & 0.778 & 0.794 & -0.016 & 0.667 \\
\hline Eqqub member & 0.431 & 0.511 & -0.080 & 0.076 \\
\hline Cooperative member & 0.509 & 0.591 & -0.082 & 0.069 \\
\hline Distance to FTC & 25.037 & 26.486 & -1.449 & 0.517 \\
\hline Drought exposure & 6.995 & 7.039 & -0.043 & 0.907 \\
\hline Observations & & & & 502 \\
\hline
\end{tabular}


Table C.3: Endogenous Switching Probit Estimation

\begin{tabular}{|c|c|c|c|c|c|c|}
\hline & \multirow[b]{2}{*}{$\begin{array}{c}\text { Market } \\
\text { exposure }\end{array}$} & \multicolumn{2}{|c|}{ Chemical fertilizer } & \multirow[b]{2}{*}{$\begin{array}{c}\text { Market } \\
\text { exposure }\end{array}$} & \multicolumn{2}{|c|}{ Improved seed } \\
\hline & & Adopters & $\begin{array}{c}\text { Non - } \\
\text { adopters }\end{array}$ & & $\begin{array}{l}\text { Adopters } \\
\text { Adopters }\end{array}$ & $\begin{array}{c}\text { Non - } \\
\text { adopters }\end{array}$ \\
\hline Age & $\begin{array}{c}0.014 \\
(0.030)\end{array}$ & $\begin{array}{l}-0.008 \\
(0.062)\end{array}$ & $\begin{array}{c}0.011 \\
(0.044)\end{array}$ & $\begin{array}{c}0.012 \\
(0.032)\end{array}$ & $\begin{array}{l}-0.003 \\
(0.048)\end{array}$ & $\begin{array}{c}0.062 \\
(0.052)\end{array}$ \\
\hline Age square & $\begin{array}{l}-0.000 \\
(0.000)\end{array}$ & $\begin{array}{l}-0.000 \\
(0.001)\end{array}$ & $\begin{array}{l}-0.000 \\
(0.000)\end{array}$ & $\begin{array}{l}-0.000 \\
(0.000)\end{array}$ & $\begin{array}{c}0.000 \\
(0.001)\end{array}$ & $\begin{array}{l}-0.000 \\
(0.001)\end{array}$ \\
\hline Male & $\begin{array}{l}-0.209 \\
(0.162)\end{array}$ & $\begin{array}{c}0.300 \\
(0.243)\end{array}$ & $\begin{array}{l}0.446^{*} \\
(0.270)\end{array}$ & $\begin{array}{l}-0.187 \\
(0.162)\end{array}$ & $\begin{array}{l}-0.069 \\
(0.195)\end{array}$ & $\begin{array}{c}0.282 \\
(0.226)\end{array}$ \\
\hline Household size & $\begin{array}{l}0.060^{*} \\
(0.035)\end{array}$ & $\begin{array}{l}0.144^{* *} \\
(0.059)\end{array}$ & $\begin{array}{c}0.071 \\
(0.073)\end{array}$ & $\begin{array}{l}0.058^{*} \\
(0.035)\end{array}$ & $\begin{array}{c}0.067 \\
(0.051)\end{array}$ & $\begin{array}{l}-0.057 \\
(0.047)\end{array}$ \\
\hline Education & $\begin{array}{c}0.159 \\
(0.136)\end{array}$ & $\begin{array}{c}0.206 \\
(0.211)\end{array}$ & $\begin{array}{l}-0.160 \\
(0.234)\end{array}$ & $\begin{array}{c}0.144 \\
(0.141)\end{array}$ & $\begin{array}{c}0.168 \\
(0.171)\end{array}$ & $\begin{array}{c}0.156 \\
(0.270)\end{array}$ \\
\hline Land size & $\begin{array}{l}-0.003 \\
(0.035)\end{array}$ & $\begin{array}{l}-0.114^{* *} \\
(0.055)\end{array}$ & $\begin{array}{c}-0.200^{* * *} \\
(0.076)\end{array}$ & $\begin{array}{l}-0.007 \\
(0.040)\end{array}$ & $\begin{array}{l}-0.026 \\
(0.049)\end{array}$ & $\begin{array}{c}0.009 \\
(0.054)\end{array}$ \\
\hline Livestock & $\begin{array}{l}-0.001 \\
(0.018)\end{array}$ & $\begin{array}{c}0.004 \\
(0.031)\end{array}$ & $\begin{array}{c}0.029 \\
(0.032)\end{array}$ & $\begin{array}{c}0.001 \\
(0.018)\end{array}$ & $\begin{array}{l}0.050^{* *} \\
(0.025)\end{array}$ & $\begin{array}{c}0.029 \\
(0.024)\end{array}$ \\
\hline Housing condition & $\begin{array}{c}0.172 \\
(0.234)\end{array}$ & $\begin{array}{l}-0.173 \\
(0.403)\end{array}$ & $\begin{array}{c}0.477 \\
(0.379)\end{array}$ & $\begin{array}{c}0.157 \\
(0.249)\end{array}$ & $\begin{array}{l}-0.132 \\
(0.288)\end{array}$ & $\begin{array}{c}0.173 \\
(0.353)\end{array}$ \\
\hline Own phone & $\begin{array}{c}0.116 \\
(0.147)\end{array}$ & $\begin{array}{c}-0.527^{* *} \\
(0.268)\end{array}$ & $\begin{array}{l}-0.050 \\
(0.303)\end{array}$ & $\begin{array}{c}0.095 \\
(0.151)\end{array}$ & $\begin{array}{l}-0.077 \\
(0.188)\end{array}$ & $\begin{array}{l}-0.366 \\
(0.227)\end{array}$ \\
\hline Own radio & $\begin{array}{c}0.073 \\
(0.126)\end{array}$ & $\begin{array}{c}0.548^{* * *} \\
(0.199)\end{array}$ & $\begin{array}{c}0.080 \\
(0.242)\end{array}$ & $\begin{array}{c}0.073 \\
(0.126)\end{array}$ & $\begin{array}{c}0.005 \\
(0.147)\end{array}$ & $\begin{array}{l}-0.162 \\
(0.198)\end{array}$ \\
\hline Iddir member & $\begin{array}{l}-0.073 \\
(0.149)\end{array}$ & $\begin{array}{l}-0.240 \\
(0.288)\end{array}$ & $\begin{array}{l}-0.211 \\
(0.283)\end{array}$ & $\begin{array}{l}-0.077 \\
(0.150)\end{array}$ & $\begin{array}{l}0.321^{*} \\
(0.192)\end{array}$ & $\begin{array}{l}0.383^{*} \\
(0.217)\end{array}$ \\
\hline Eqqub member & $\begin{array}{c}0.108 \\
(0.125)\end{array}$ & $\begin{array}{l}-0.319 \\
(0.210)\end{array}$ & $\begin{array}{l}-0.069 \\
(0.215)\end{array}$ & $\begin{array}{c}0.107 \\
(0.124)\end{array}$ & $\begin{array}{l}0.407^{* * *} \\
(0.157)\end{array}$ & $\begin{array}{c}0.197 \\
(0.263)\end{array}$ \\
\hline Cooperative member & $\begin{array}{c}0.092 \\
(0.123)\end{array}$ & $\begin{array}{c}0.009 \\
(0.198)\end{array}$ & $\begin{array}{c}0.382 \\
(0.264)\end{array}$ & $\begin{array}{c}0.082 \\
(0.121)\end{array}$ & $\begin{array}{l}-0.054 \\
(0.145)\end{array}$ & $\begin{array}{c}0.325 \\
(0.283)\end{array}$ \\
\hline Distance to FTC & $\begin{array}{c}0.001 \\
(0.002)\end{array}$ & $\begin{array}{c}0.003 \\
(0.004)\end{array}$ & $\begin{array}{l}-0.006 \\
(0.004)\end{array}$ & $\begin{array}{c}0.001 \\
(0.002)\end{array}$ & $\begin{array}{l}-0.002 \\
(0.003)\end{array}$ & $\begin{array}{c}0.001 \\
(0.004)\end{array}$ \\
\hline Drought exposure & $\begin{array}{c}0.014 \\
(0.016)\end{array}$ & $\begin{array}{l}-0.054^{*} \\
(0.028)\end{array}$ & $\begin{array}{l}-0.075^{* *} \\
(0.029)\end{array}$ & $\begin{array}{c}0.016 \\
(0.016)\end{array}$ & $\begin{array}{l}-0.013 \\
(0.020)\end{array}$ & $\begin{array}{l}-0.029 \\
(0.025)\end{array}$ \\
\hline Distance to market & $\begin{array}{c}-0.261^{* * *} \\
(0.067)\end{array}$ & & & $\begin{array}{c}-0.278^{* * *} \\
(0.060)\end{array}$ & & \\
\hline Constant & $\begin{array}{l}-0.126 \\
(0.715)\end{array}$ & $\begin{array}{c}2.098 \\
(1.385)\end{array}$ & $\begin{array}{c}0.697 \\
(1.172)\end{array}$ & $\begin{array}{l}-0.020 \\
(0.793)\end{array}$ & $\begin{array}{l}-0.045 \\
(1.084)\end{array}$ & $\begin{array}{l}-2.844^{* *} \\
(1.304)\end{array}$ \\
\hline Wald $\chi^{2}$ & & & 3.13 & & & $6.26^{* *}$ \\
\hline$\rho_{i j}$ & & $\begin{array}{r}-0.658 \\
(0.269) \\
\end{array}$ & $\begin{array}{l}-0.367 \\
(0.484) \\
\end{array}$ & & $\begin{array}{c}-0.726^{* *} \\
(0.188)\end{array}$ & $\begin{array}{l}-0.721 \\
(0.598) \\
\end{array}$ \\
\hline Observations & 502 & $5 \mathrm{O} 2$ & 502 & 502 & 502 & 502 \\
\hline
\end{tabular}


Table C.4: Endogenous Switching Probit Estimation

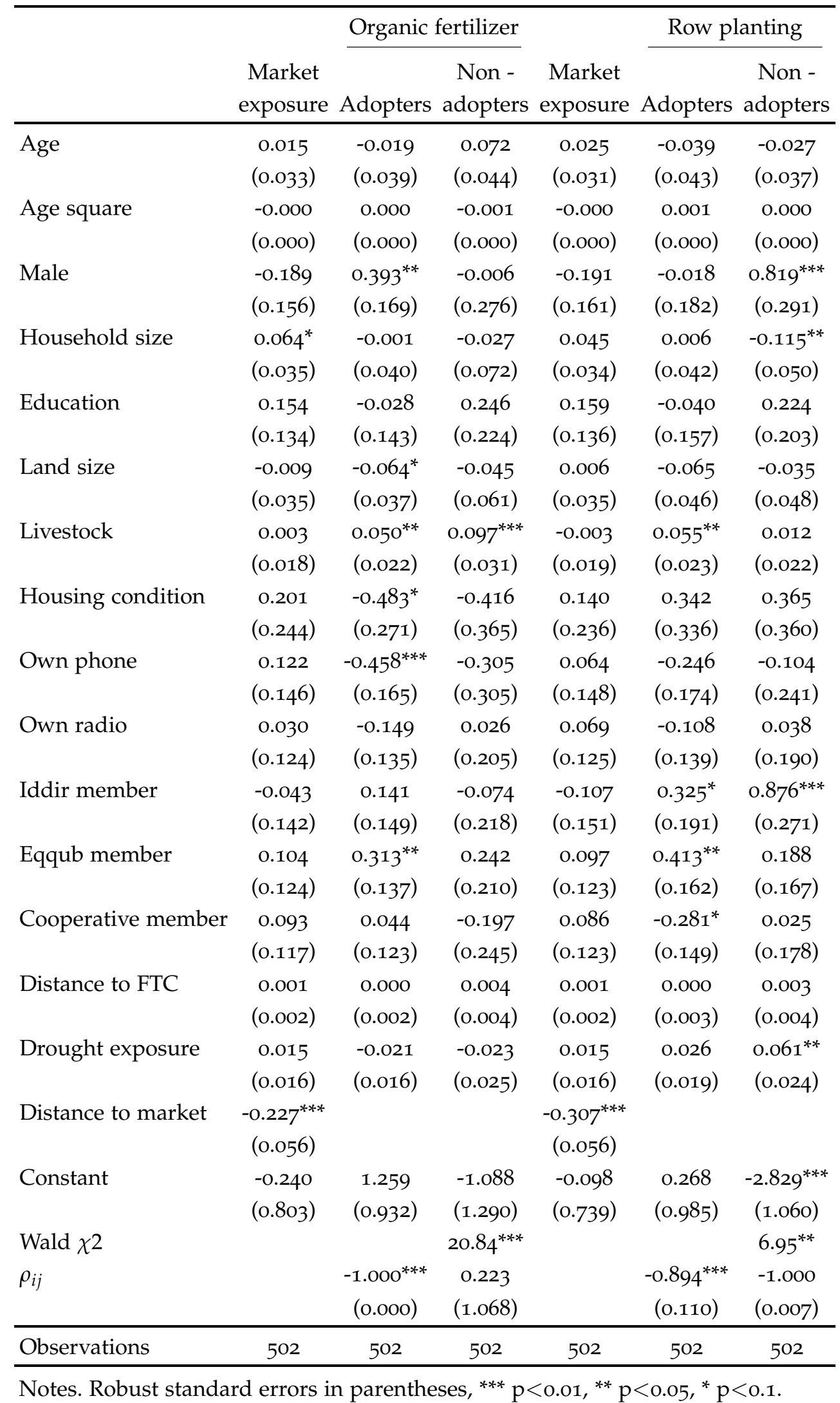


Table C.5: Test on the Validity of the Selection Instruments - Outcome Variables

\begin{tabular}{|c|c|c|c|c|}
\hline & $\begin{array}{l}\text { (1) } \\
\text { Chemical } \\
\text { fertilizer }\end{array}$ & $\begin{array}{c}(2) \\
\text { Improved } \\
\text { seed }\end{array}$ & $\begin{array}{c}(3) \\
\text { Organic } \\
\text { fertilizer }\end{array}$ & $\begin{array}{c}\text { (4) } \\
\text { Row } \\
\text { planting }\end{array}$ \\
\hline Age & $\begin{array}{c}0.002 \\
(0.009)\end{array}$ & $\begin{array}{l}0.033^{* *} \\
(0.014)\end{array}$ & $\begin{array}{c}0.029 \\
(0.019)\end{array}$ & $\begin{array}{l}-0.006 \\
(0.015)\end{array}$ \\
\hline Age square & $\begin{array}{l}-0.000 \\
(0.000)\end{array}$ & $\begin{array}{l}-0.000^{* *} \\
(0.000)\end{array}$ & $\begin{array}{l}-0.000 \\
(0.000)\end{array}$ & $\begin{array}{c}0.000 \\
(0.000)\end{array}$ \\
\hline Male & $\begin{array}{c}0.098 \\
(0.063)\end{array}$ & $\begin{array}{c}0.097 \\
(0.098)\end{array}$ & $\begin{array}{c}0.002 \\
(0.114)\end{array}$ & $\begin{array}{c}0.205^{* * *} \\
(0.058)\end{array}$ \\
\hline Household size & $\begin{array}{c}0.017 \\
(0.014)\end{array}$ & $\begin{array}{l}-0.017 \\
(0.021)\end{array}$ & $\begin{array}{l}-0.014 \\
(0.021)\end{array}$ & $\begin{array}{l}-0.031^{*} \\
(0.016)\end{array}$ \\
\hline Education & $\begin{array}{l}-0.010 \\
(0.048)\end{array}$ & $\begin{array}{c}0.118 \\
(0.111)\end{array}$ & $\begin{array}{c}0.098 \\
(0.087)\end{array}$ & $\begin{array}{c}0.110 \\
(0.067)\end{array}$ \\
\hline Land size & $\begin{array}{l}-0.044^{* *} \\
(0.022)\end{array}$ & $\begin{array}{c}0.003 \\
(0.022)\end{array}$ & $\begin{array}{l}-0.017 \\
(0.027)\end{array}$ & $\begin{array}{l}-0.017 \\
(0.017)\end{array}$ \\
\hline Livestock & $\begin{array}{c}0.005 \\
(0.008)\end{array}$ & $\begin{array}{c}0.015 \\
(0.011)\end{array}$ & $\begin{array}{c}0.040^{* * *} \\
(0.013)\end{array}$ & $\begin{array}{c}0.002 \\
(0.005)\end{array}$ \\
\hline Housing condition & $\begin{array}{c}0.147 \\
(0.120)\end{array}$ & $\begin{array}{c}0.099 \\
(0.118)\end{array}$ & $\begin{array}{l}-0.176 \\
(0.137)\end{array}$ & $\begin{array}{c}0.130^{* * *} \\
(0.046)\end{array}$ \\
\hline Own phone & $\begin{array}{l}-0.003 \\
(0.066)\end{array}$ & $\begin{array}{l}-0.166 \\
(0.105)\end{array}$ & $\begin{array}{l}-0.140 \\
(0.091)\end{array}$ & $\begin{array}{l}-0.018 \\
(0.104)\end{array}$ \\
\hline Own radio & $\begin{array}{c}0.028 \\
(0.052)\end{array}$ & $\begin{array}{l}-0.070 \\
(0.095)\end{array}$ & $\begin{array}{c}0.009 \\
(0.087)\end{array}$ & $\begin{array}{c}0.022 \\
(0.059)\end{array}$ \\
\hline Iddir member & $\begin{array}{l}-0.053 \\
(0.066)\end{array}$ & $\begin{array}{l}0.162^{*} \\
\text { (0.090) }\end{array}$ & $\begin{array}{l}-0.028 \\
(0.105)\end{array}$ & $\begin{array}{c}0.219^{* * *} \\
(0.052)\end{array}$ \\
\hline Eqqub member & $\begin{array}{l}-0.011 \\
(0.071)\end{array}$ & $\begin{array}{c}0.125 \\
(0.088)\end{array}$ & $\begin{array}{c}0.088 \\
(0.075)\end{array}$ & $\begin{array}{c}0.098 \\
(0.076)\end{array}$ \\
\hline Cooperative member & $\begin{array}{l}0.093^{*} \\
(0.048)\end{array}$ & $\begin{array}{l}0.173^{* *} \\
(0.073)\end{array}$ & $\begin{array}{l}-0.092 \\
(0.094)\end{array}$ & $\begin{array}{c}0.037 \\
(0.080)\end{array}$ \\
\hline Distance FTC & $\begin{array}{l}-0.001 \\
(0.001)\end{array}$ & $\begin{array}{c}0.001 \\
(0.002)\end{array}$ & $\begin{array}{c}0.002 \\
(0.002)\end{array}$ & $\begin{array}{c}0.002 \\
(0.001)\end{array}$ \\
\hline Drought exposure & $\begin{array}{l}-0.016^{*} \\
(0.008)\end{array}$ & $\begin{array}{l}-0.010 \\
(0.010)\end{array}$ & $\begin{array}{l}-0.009 \\
(0.012)\end{array}$ & $\begin{array}{c}0.028^{* * *} \\
(0.010)\end{array}$ \\
\hline Distance to market & $\begin{array}{l}-0.018 \\
(0.036)\end{array}$ & $\begin{array}{l}-0.073 \\
(0.049)\end{array}$ & $\begin{array}{l}-0.008 \\
(0.033)\end{array}$ & $\begin{array}{l}-0.083^{*} \\
(0.043)\end{array}$ \\
\hline Observations & 216 & 216 & 216 & 216 \\
\hline
\end{tabular}

Notes. Robust standard errors (clustered by village) in parentheses, ${ }^{* * *} \mathrm{p}<0.01$, ** $\mathrm{p}<0.05,{ }^{*} \mathrm{p}<0.1$. 
Table C.6: First Stage Estimation Results

\begin{tabular}{|c|c|c|c|c|c|c|c|c|}
\hline & \multicolumn{2}{|c|}{ Chemical fertilizer } & \multicolumn{2}{|c|}{ Improved seed } & \multicolumn{2}{|c|}{ Organic fertilizer } & \multicolumn{2}{|c|}{ Row planting } \\
\hline & $\begin{array}{l}\text { Market } \\
\text { exper. }\end{array}$ & $\begin{array}{l}\text { Market } \\
\text { exper. }\end{array}$ & $\begin{array}{l}\text { Market } \\
\text { exper. }\end{array}$ & $\begin{array}{c}\text { Market } \\
\text { exper. }\end{array}$ & $\begin{array}{c}\text { Market } \\
\text { exper. }\end{array}$ & $\begin{array}{c}\text { Market } \\
\text { exper. }\end{array}$ & $\begin{array}{c}\text { Market } \\
\text { exper. }\end{array}$ & $\begin{array}{c}\text { Market } \\
\text { exper. }\end{array}$ \\
\hline Distance to market & $\begin{array}{c}-0.663^{* * *} \\
(0.125)\end{array}$ & $\begin{array}{c}-0.614^{* * *} \\
(0.128)\end{array}$ & $\begin{array}{c}-0.663^{* * *} \\
(0.125)\end{array}$ & $\begin{array}{c}-0.614^{* * * *} \\
(0.128)\end{array}$ & $\begin{array}{c}-0.663^{* * *} \\
(0.125)\end{array}$ & $\begin{array}{c}-0.614^{* * *} \\
(0.128)\end{array}$ & $\begin{array}{c}-0.663^{* * *} \\
(0.125)\end{array}$ & $\begin{array}{c}-0.614^{* * *} \\
(0.128)\end{array}$ \\
\hline Age & & $\begin{array}{c}0.041 \\
(0.055)\end{array}$ & & $\begin{array}{c}0.041 \\
(0.055)\end{array}$ & & $\begin{array}{c}0.041 \\
(0.055)\end{array}$ & & $\begin{array}{c}0.041 \\
(0.055)\end{array}$ \\
\hline Age square & & $\begin{array}{l}-0.000 \\
(0.001)\end{array}$ & & $\begin{array}{l}-0.000 \\
(0.001)\end{array}$ & & $\begin{array}{l}-0.000 \\
(0.001)\end{array}$ & & $\begin{array}{l}-0.000 \\
(0.001)\end{array}$ \\
\hline Male & & $\begin{array}{l}-0.221 \\
(0.356)\end{array}$ & & $\begin{array}{l}-0.221 \\
(0.356)\end{array}$ & & $\begin{array}{l}-0.221 \\
(0.356)\end{array}$ & & $\begin{array}{l}-0.221 \\
(0.356)\end{array}$ \\
\hline Household size & & $\begin{array}{l}-0.077 \\
(0.078)\end{array}$ & & $\begin{array}{l}-0.077 \\
(0.078)\end{array}$ & & $\begin{array}{l}-0.077 \\
(0.078)\end{array}$ & & $\begin{array}{l}-0.077 \\
(0.078)\end{array}$ \\
\hline Education & & $\begin{array}{l}0.398^{*} \\
(0.234)\end{array}$ & & $\begin{array}{l}0.398^{*} \\
(0.234)\end{array}$ & & $\begin{array}{l}0.398^{*} \\
(0.234)\end{array}$ & & $\begin{array}{l}0.398^{*} \\
(0.234)\end{array}$ \\
\hline Land size & & $\begin{array}{l}-0.060 \\
(0.066)\end{array}$ & & $\begin{array}{l}-0.060 \\
(0.066)\end{array}$ & & $\begin{array}{l}-0.060 \\
(0.066)\end{array}$ & & $\begin{array}{l}-0.060 \\
(0.066)\end{array}$ \\
\hline Livestock & & $\begin{array}{l}-0.037 \\
(0.023)\end{array}$ & & $\begin{array}{l}-0.037 \\
(0.023)\end{array}$ & & $\begin{array}{l}-0.037 \\
(0.023)\end{array}$ & & $\begin{array}{l}-0.037 \\
(0.023)\end{array}$ \\
\hline Housing condition & & $\begin{array}{l}0.726^{* *} \\
(0.316)\end{array}$ & & $\begin{array}{l}0.726^{* *} \\
(0.316)\end{array}$ & & $\begin{array}{l}0.726^{* *} \\
(0.316)\end{array}$ & & $\begin{array}{l}0.726^{* *} \\
(0.316)\end{array}$ \\
\hline Own phone & & $\begin{array}{l}0.499^{* *} \\
(0.222)\end{array}$ & & $\begin{array}{l}0.499^{* *} \\
(0.222)\end{array}$ & & $\begin{array}{l}0.499^{* *} \\
(0.222)\end{array}$ & & $\begin{array}{l}0.499^{* *} \\
(0.222)\end{array}$ \\
\hline Own radio & & $\begin{array}{l}0.450^{*} \\
(0.231)\end{array}$ & & $\begin{array}{l}0.450^{*} \\
(0.231)\end{array}$ & & $\begin{array}{l}0.450^{*} \\
(0.231)\end{array}$ & & $\begin{array}{l}0.450^{*} \\
(0.231)\end{array}$ \\
\hline Iddir member & & $\begin{array}{c}0.004 \\
(0.241)\end{array}$ & & $\begin{array}{c}0.004 \\
(0.241)\end{array}$ & & $\begin{array}{c}0.004 \\
(0.241)\end{array}$ & & $\begin{array}{c}0.004 \\
(0.241)\end{array}$ \\
\hline Eqqub member & & $\begin{array}{c}0.182 \\
(0.206)\end{array}$ & & $\begin{array}{c}0.182 \\
(0.206)\end{array}$ & & $\begin{array}{c}0.182 \\
(0.206)\end{array}$ & & $\begin{array}{c}0.182 \\
(0.206)\end{array}$ \\
\hline Cooperative member & & $\begin{array}{c}0.043 \\
(0.242)\end{array}$ & & $\begin{array}{c}0.043 \\
(0.242)\end{array}$ & & $\begin{array}{c}0.043 \\
(0.242)\end{array}$ & & $\begin{array}{c}0.043 \\
(0.242)\end{array}$ \\
\hline Distance to FTC & & $\begin{array}{c}0.006 \\
(0.008)\end{array}$ & & $\begin{array}{c}0.006 \\
(0.008)\end{array}$ & & $\begin{array}{c}0.006 \\
(0.008)\end{array}$ & & $\begin{array}{c}0.006 \\
(0.008)\end{array}$ \\
\hline Drought exposure & & $\begin{array}{c}0.040 \\
(0.032)\end{array}$ & & $\begin{array}{c}0.040 \\
(0.032)\end{array}$ & & $\begin{array}{c}0.040 \\
(0.032)\end{array}$ & & $\begin{array}{c}0.040 \\
(0.032)\end{array}$ \\
\hline Constant & $\begin{array}{c}4.633^{* * *} \\
(0.301)\end{array}$ & $\begin{array}{l}2.547^{*} \\
(1.439)\end{array}$ & $\begin{array}{l}4.633^{* * *} \\
(0.301)\end{array}$ & $\begin{array}{l}2.547^{*} \\
(1.439)\end{array}$ & $\begin{array}{c}4.633^{* * *} \\
(0.301)\end{array}$ & $\begin{array}{l}2.547^{*} \\
(1.439)\end{array}$ & $\begin{array}{l}4.633^{* * *} \\
(0.301)\end{array}$ & $\begin{array}{l}2.547^{*} \\
(1.439)\end{array}$ \\
\hline Observations & 502 & 502 & 502 & 502 & 502 & 502 & 502 & 502 \\
\hline
\end{tabular}

Notes. Robust standard errors in parentheses, ${ }^{* * *} \mathrm{p}<0.01,{ }^{* *} \mathrm{p}<0.05,{ }^{*} \mathrm{p}<0.1$. 
Table C.7: Correlation Between Risk Aversion, Locus of Control and Investment Behavior

\begin{tabular}{lcccc}
\hline & Chemical fertilizer & Improved seed & Organic fertilizer & Row planting \\
\hline Risk aversion & $-0.097^{* *}$ & $-0.121^{* * *}$ & $-0.082^{*}$ & $-0.150^{* * *}$ \\
& $(0.031)$ & $(0.007)$ & $(0.067)$ & $(0.001)$ \\
Locus of control & & & & \\
& $0.144^{* * *}$ & $0.083^{*}$ & 0.005 & 0.064 \\
& $($ o.001) & $(0.062)$ & $(0.904)$ & 0.152 \\
\hline
\end{tabular}

Notes. P-values in parentheses, ${ }^{* * *} \mathrm{p}<0.01,{ }^{* *} \mathrm{p}<0.05,{ }^{*} \mathrm{p}<0.1$.

(a) High market exposure

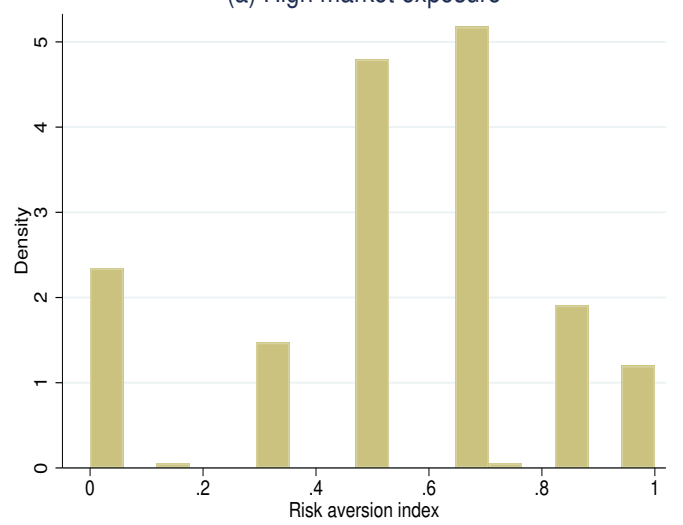

(b) Low market exposure

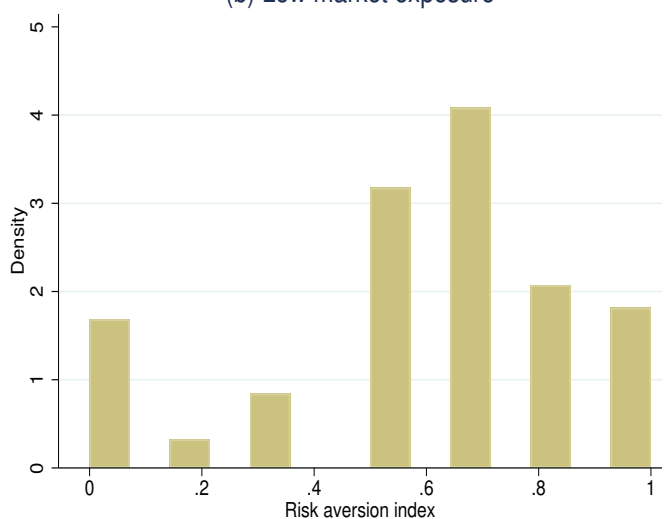

Figure C.1: Distribution of Farmers' Risk Aversion

(a) High market exposure

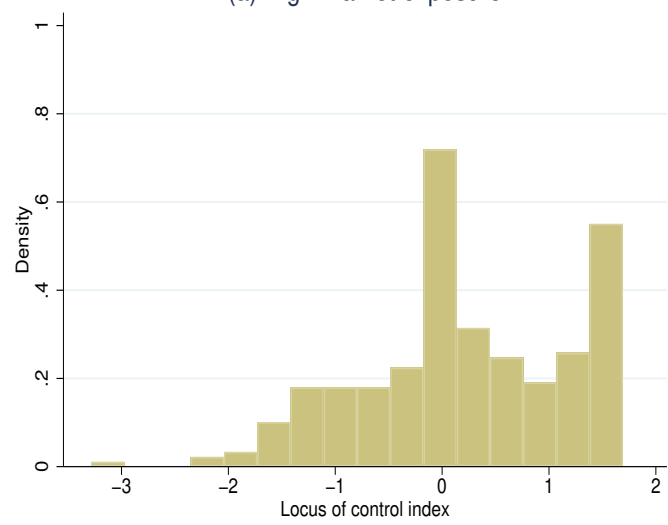

(b) Low market exposure

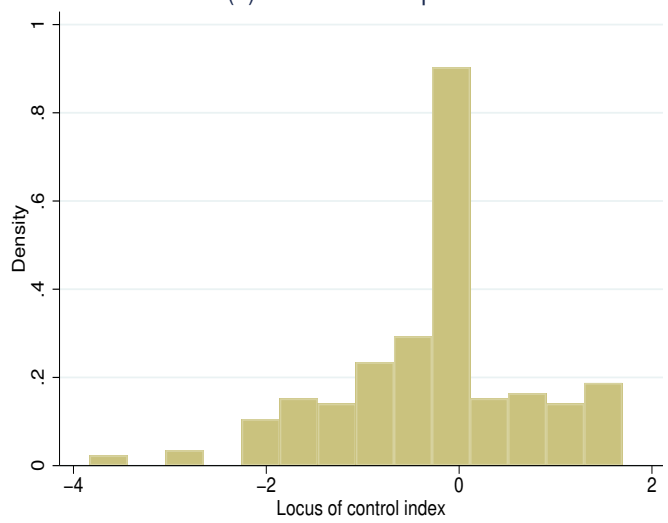

Figure C.2: Distribution of Farmers' Internal Locus of Control (Standardized) 
Table C.8: Endogenous Switching Regression

\begin{tabular}{|c|c|c|c|c|c|c|}
\hline & $\begin{array}{c}\text { (1) } \\
\text { Risk_1 }\end{array}$ & $\begin{array}{c}\text { (2) } \\
\text { Risk_o }\end{array}$ & $\begin{array}{c}(3) \\
\text { market } \\
\text { exposure }\end{array}$ & $\begin{array}{c}\text { (4) } \\
\text { Locus_of } \\
\text { control_1 }\end{array}$ & $\begin{array}{c}\text { (5) } \\
\text { Locus_of } \\
\text { control_o }\end{array}$ & $\begin{array}{c}(6) \\
\text { market } \\
\text { exposure }\end{array}$ \\
\hline Age & $\begin{array}{c}0.002 \\
(0.010)\end{array}$ & $\begin{array}{l}-0.008 \\
(0.015)\end{array}$ & $\begin{array}{c}0.003 \\
(0.078)\end{array}$ & $\begin{array}{c}0.010 \\
(0.049)\end{array}$ & $\begin{array}{l}0.065^{*} \\
(0.036)\end{array}$ & $\begin{array}{c}0.011 \\
(0.038)\end{array}$ \\
\hline Age square & $\begin{array}{c}0.000 \\
(0.000)\end{array}$ & $\begin{array}{c}0.000 \\
(0.000)\end{array}$ & $\begin{array}{l}-0.000 \\
(0.001)\end{array}$ & $\begin{array}{l}-0.000 \\
(0.001)\end{array}$ & $\begin{array}{l}-0.001^{*} \\
(0.000)\end{array}$ & $\begin{array}{l}-0.000 \\
(0.000)\end{array}$ \\
\hline Male & $\begin{array}{l}-0.074 \\
(0.064)\end{array}$ & $\begin{array}{l}-0.123 \\
(0.121)\end{array}$ & $\begin{array}{l}-0.197 \\
(0.189)\end{array}$ & $\begin{array}{c}0.282 \\
(0.319)\end{array}$ & $\begin{array}{c}0.225 \\
(0.188)\end{array}$ & $\begin{array}{l}-0.253 \\
(0.192)\end{array}$ \\
\hline Household size & $\begin{array}{l}-0.003 \\
(0.015)\end{array}$ & $\begin{array}{c}0.016 \\
(0.065)\end{array}$ & $\begin{array}{c}0.033 \\
(0.065)\end{array}$ & $\begin{array}{c}0.002 \\
(0.089)\end{array}$ & $\begin{array}{c}0.026 \\
(0.059)\end{array}$ & $\begin{array}{c}0.057 \\
(0.055)\end{array}$ \\
\hline Education & $\begin{array}{c}0.018 \\
(0.044)\end{array}$ & $\begin{array}{c}0.014 \\
(0.088)\end{array}$ & $\begin{array}{c}0.224 \\
(0.201)\end{array}$ & $\begin{array}{c}0.090 \\
(0.266)\end{array}$ & $\begin{array}{c}0.197 \\
\text { (o.169) }\end{array}$ & $\begin{array}{c}0.150 \\
(0.172)\end{array}$ \\
\hline Land size & $\begin{array}{c}0.007 \\
(0.011)\end{array}$ & $\begin{array}{l}-0.005 \\
(0.025)\end{array}$ & $\begin{array}{c}-0.006 \\
(0.053)\end{array}$ & $\begin{array}{l}-0.004 \\
(0.050)\end{array}$ & $\begin{array}{c}0.013 \\
(0.053)\end{array}$ & $\begin{array}{l}-0.011 \\
(0.043)\end{array}$ \\
\hline Livestock & $\begin{array}{l}-0.007 \\
(0.005)\end{array}$ & $\begin{array}{c}0.003 \\
(0.007)\end{array}$ & $\begin{array}{c}0.002 \\
(0.019)\end{array}$ & $\begin{array}{c}0.021 \\
(0.022)\end{array}$ & $\begin{array}{c}0.008 \\
(0.015)\end{array}$ & $\begin{array}{c}0.009 \\
(0.025)\end{array}$ \\
\hline Housing condition & $\begin{array}{l}-0.115^{*} \\
(0.062)\end{array}$ & $\begin{array}{c}0.008 \\
(0.223)\end{array}$ & $\begin{array}{c}0.064 \\
(0.372)\end{array}$ & $\begin{array}{c}0.277 \\
(0.548)\end{array}$ & $\begin{array}{l}0.507^{* *} \\
(0.227)\end{array}$ & $\begin{array}{c}0.108 \\
(0.322)\end{array}$ \\
\hline Own phone & $\begin{array}{l}-0.026 \\
(0.045)\end{array}$ & $\begin{array}{l}-0.050 \\
(0.128)\end{array}$ & $\begin{array}{c}0.032 \\
(0.139)\end{array}$ & $\begin{array}{c}0.143 \\
(0.265)\end{array}$ & $\begin{array}{c}-0.294 \\
(0.209)\end{array}$ & $\begin{array}{c}0.154 \\
(0.150)\end{array}$ \\
\hline Own radio & $\begin{array}{l}-0.003 \\
(0.030)\end{array}$ & $\begin{array}{l}-0.002 \\
(0.103)\end{array}$ & $\begin{array}{c}0.063 \\
(0.226)\end{array}$ & $\begin{array}{c}0.058 \\
(0.149)\end{array}$ & $\begin{array}{c}0.205 \\
(0.159)\end{array}$ & $\begin{array}{c}0.012 \\
(0.165)\end{array}$ \\
\hline Iddir member & $\begin{array}{l}-0.035 \\
(0.034)\end{array}$ & $\begin{array}{l}-0.065 \\
(0.052)\end{array}$ & $\begin{array}{l}-0.029 \\
(0.117)\end{array}$ & $\begin{array}{c}0.250 \\
(0.264)\end{array}$ & $\begin{array}{c}0.041 \\
(0.160)\end{array}$ & $\begin{array}{l}-0.002 \\
(0.126)\end{array}$ \\
\hline Cooperative member & $\begin{array}{c}0.027 \\
(0.035)\end{array}$ & $\begin{array}{c}0.048 \\
(0.092)\end{array}$ & $\begin{array}{c}0.133 \\
(0.126)\end{array}$ & $\begin{array}{c}0.215 \\
(0.136)\end{array}$ & $\begin{array}{c}0.240 \\
(0.208)\end{array}$ & $\begin{array}{c}0.150 \\
(0.129)\end{array}$ \\
\hline Drought exposure & $\begin{array}{c}0.004 \\
(0.006)\end{array}$ & $\begin{array}{c}0.008 \\
(0.007)\end{array}$ & $\begin{array}{c}0.013 \\
(0.032)\end{array}$ & $\begin{array}{c}0.030 \\
(0.020)\end{array}$ & $\begin{array}{l}-0.004 \\
\text { (0.019) }\end{array}$ & $\begin{array}{c}0.011 \\
(0.016)\end{array}$ \\
\hline Distance to market & & & $\begin{array}{l}-0.250 \\
(0.189)\end{array}$ & & & $\begin{array}{l}-0.187 \\
(0.122)\end{array}$ \\
\hline Constant & $\begin{array}{l}0.55^{* *} \\
(0.269)\end{array}$ & $\begin{array}{l}1.148^{* *} \\
(0.507)\end{array}$ & $\begin{array}{c}0.315 \\
(1.690)\end{array}$ & $\begin{array}{l}-0.742 \\
(2.162)\end{array}$ & $\begin{array}{c}-2.386^{* * *} \\
(0.915)\end{array}$ & $\begin{array}{l}-0.018 \\
(0.833)\end{array}$ \\
\hline \multicolumn{7}{|l|}{ Model diagnosis } \\
\hline$\sigma$ & $\begin{array}{c}0.274^{* * *} \\
(0.089)\end{array}$ & $\begin{array}{l}0.421^{* *} \\
(0.507)\end{array}$ & & $\begin{array}{l}1.180^{* *} \\
(0.674)\end{array}$ & $\begin{array}{c}0.875^{* * *} \\
(0.054)\end{array}$ & \\
\hline$\rho$ & $\begin{array}{c}0.328 \\
(0.779)\end{array}$ & $\begin{array}{c}0.969 \\
(0.406)\end{array}$ & & $\begin{array}{l}-0.867 \\
(0.584)\end{array}$ & $\begin{array}{c}0.008 \\
-1,240\end{array}$ & \\
\hline Wald $\chi 2$ & $30.49^{* * *}$ & & & $4 \cdot 39^{* *}$ & & \\
\hline $\operatorname{lns} 1$ & $\begin{array}{c}-1.293^{* * *} \\
(0.324)\end{array}$ & & & $\begin{array}{c}0.165 \\
(0.571)\end{array}$ & & \\
\hline $\operatorname{lns} 2$ & $\begin{array}{c}-0.864 \\
(1.203)\end{array}$ & & & $\begin{array}{l}-0.134^{* *} \\
(0.062)\end{array}$ & & \\
\hline ri & $\begin{array}{c}0.340 \\
(0.873)\end{array}$ & & & $\begin{array}{r}-1.322 \\
2.356\end{array}$ & & \\
\hline r2 & $\begin{array}{r}2.076 \\
(6.666)\end{array}$ & & & $\begin{array}{c}0.008 \\
(1.241)\end{array}$ & & \\
\hline Observations & 502 & 502 & $5 \mathrm{O} 2$ & 502 & 502 & $5 \mathrm{O} 2$ \\
\hline
\end{tabular}

Notes. Robust standard errors (clustered by village) in parentheses, ${ }^{* *} \mathrm{p}<0.01,{ }^{* *}$ $\mathrm{p}<0.05,{ }^{*} \mathrm{p}<0.1$. 
Table C.9: First Stage Estimation Results - Mechanisms

\begin{tabular}{|c|c|c|c|c|}
\hline & $\begin{array}{c}(1) \\
\text { Market } \\
\text { experience }\end{array}$ & $\begin{array}{c}(2) \\
\text { Market } \\
\text { experience }\end{array}$ & $\begin{array}{c}\text { (3) } \\
\text { Market } \\
\text { Market exposure }\end{array}$ & $\begin{array}{c}(4) \\
\text { Market } \\
\text { exposure }\end{array}$ \\
\hline Distance to market & $\begin{array}{c}-0.663^{* * *} \\
(0.125)\end{array}$ & $\begin{array}{c}-0.614^{* * *} \\
(0.130)\end{array}$ & $\begin{array}{c}-0.106^{* * *} \\
(0.023)\end{array}$ & $\begin{array}{c}-0.093^{* * *} \\
(0.025)\end{array}$ \\
\hline Age & & $\begin{array}{c}0.041 \\
(0.056)\end{array}$ & & $\begin{array}{l}0.005 \\
(0.010)\end{array}$ \\
\hline Age square & & $\begin{array}{l}-0.000 \\
(0.001)\end{array}$ & & $\begin{array}{l}-0.000 \\
(0.000)\end{array}$ \\
\hline Male & & $\begin{array}{l}-0.221 \\
(0.362)\end{array}$ & & $\begin{array}{l}-0.071 \\
(0.060)\end{array}$ \\
\hline Household size & & $\begin{array}{l}-0.077 \\
(0.079)\end{array}$ & & $\begin{array}{l}0.023^{*} \\
(0.013)\end{array}$ \\
\hline Education & & $\begin{array}{l}0.398^{*} \\
(0.238)\end{array}$ & & $\begin{array}{l}0.060 \\
(0.052)\end{array}$ \\
\hline Land size & & $\begin{array}{l}-0.060 \\
(0.067)\end{array}$ & & $\begin{array}{l}-0.001 \\
(0.013)\end{array}$ \\
\hline Livestock & & $\begin{array}{l}-0.037 \\
(0.023)\end{array}$ & & $\begin{array}{c}0.000 \\
(0.007)\end{array}$ \\
\hline Housing condition & & $\begin{array}{l}0.726^{* *} \\
(0.321)\end{array}$ & & $\begin{array}{c}0.057 \\
(0.090)\end{array}$ \\
\hline Own phone & & $\begin{array}{l}0.499^{* *} \\
(0.226)\end{array}$ & & $\begin{array}{l}0.045 \\
(0.056)\end{array}$ \\
\hline Own radio & & $\begin{array}{l}0.450^{*} \\
(0.235)\end{array}$ & & $\begin{array}{c}0.024 \\
(0.047)\end{array}$ \\
\hline Iddir member & & $\begin{array}{c}0.004 \\
(0.245)\end{array}$ & & $\begin{array}{l}-0.029 \\
(0.056)\end{array}$ \\
\hline Eqqub member & & $\begin{array}{c}0.182 \\
(0.209)\end{array}$ & & $\begin{array}{c}0.039 \\
(0.047)\end{array}$ \\
\hline Cooperative member & & $\begin{array}{c}0.043 \\
(0.246)\end{array}$ & & $\begin{array}{c}0.031 \\
(0.046)\end{array}$ \\
\hline Distance to FTC & & $\begin{array}{c}0.006 \\
(0.008)\end{array}$ & & $\begin{array}{l}0.000 \\
(0.001)\end{array}$ \\
\hline Drought exposure & & $\begin{array}{c}0.040 \\
(0.033)\end{array}$ & & $\begin{array}{c}0.005 \\
(0.006)\end{array}$ \\
\hline Constant & $\begin{array}{l}4.633^{* * *} \\
(0.302)\end{array}$ & $\begin{array}{l}2.547^{*} \\
(1.463)\end{array}$ & $\begin{array}{c}0.761^{* * * *} \\
(0.047)\end{array}$ & $\begin{array}{l}0.474^{*} \\
(0.247)\end{array}$ \\
\hline Observations & 502 & 502 & 502 & 502 \\
\hline R-squared & 0.052 & 0.105 & 0.036 & 0.079 \\
\hline
\end{tabular}

Notes. Robust standard errors in parentheses, ${ }^{* * *} \mathrm{p}<0.01,{ }^{* *} \mathrm{p}<0.05,{ }^{*} \mathrm{p}<0.1$. 
At the beginning of this activity you will receive 30 Birr. You are asked to choose the portion of this amount (between o and 30) that you wish to invest in a risky option. The rest of the money will be accumulated in your total balance.

The risky investment: there is an equal chance that the investment will fail or succeed. If the investment fails, you lose the amount you invested. If the investment succeeds, you receive 3 times the amount invested.

How do we determine if you win? After you have chosen how much you wish to invest, you toss a coin to determine whether you win or lose. If you choose heads and heads shows up, you win 3 times the amount you chose to invest. If you choose heads and tails shows up, you lose the amount invested.

\section{Examples}

1. If you choose to invest nothing, you will get the 30 Birr for sure. That is, the coin flip would not affect your profits.

2. If you choose to invest 15 Birr, then you choose heads or tails, and afterward you throw the coin. If you choose heads and heads shows up, you win 6o Birr $\left(15+3^{*} 15\right)$, and if the coin lands on tails, you win 15 Birr.

3. If you choose to invest all of the 30 Birr, then you choose heads or tails, and afterward you throw the coin. If you choose heads and heads shows up, you win 90 Birr, and if the coin comes up tails, you win nothing and end up with o.

Do you have any questions?

Now you may start.

Record Sheet - Activity Two

\begin{tabular}{|c|c|c|c|c|c|}
\hline \multicolumn{3}{|c|}{ Respondent Name: } & \multicolumn{3}{|c|}{ 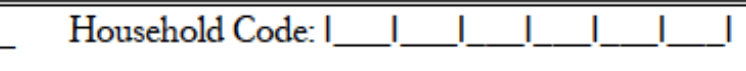 } \\
\hline & \multicolumn{3}{|c|}{ Village Code: I__________ I } \\
\hline \multicolumn{3}{|c|}{ District Name: } & \multirow{2}{*}{\multicolumn{3}{|c|}{ 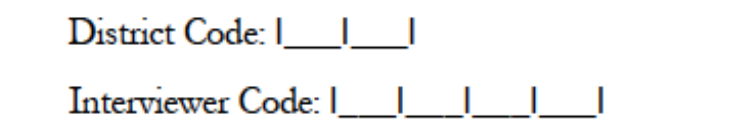 }} \\
\hline \multicolumn{3}{|c|}{ Interviewer Name: } & & & \\
\hline $\begin{array}{l}\text { Initial } \\
\text { endowment }\end{array}$ & $\begin{array}{l}\text { Amount kept } \\
\text { [1] }\end{array}$ & $\begin{array}{l}\text { Amount } \\
\text { invested } \\
{[2]}\end{array}$ & $\begin{array}{l}\text { Participant's choice } \\
0 . \text { Head } \\
\text { 1. Tail } \\
\text { [3] }\end{array}$ & $\begin{array}{l}\text { Result of } \\
\text { the draw } \\
0 . \text { Head } \\
\text { 1. Tail } \\
\text { [4] }\end{array}$ & $\begin{array}{l}\text { Amount earned } \\
{[1+3(2)] \text { if } 3=4} \\
{[1] \text { if } 3 \neq 4}\end{array}$ \\
\hline 30 & & & & & \\
\hline
\end{tabular}





\section{5}

\section{CONCLUSION}

\subsection{CONTRIBUTIONS AND MAIN FINDINGS}

Although markets have remained at the centerpiece of the economics discipline, the standard economic theory appears to be much concerned about the exchanges in markets but hardly about the people who engage in these exchanges. Markets indeed are the sites where market actors negotiate and exchange resources, goods, and information. However, markets do more than a mere allocation of resources and products. It is also a setting where buyers and sellers meet, interact and converse with each other. As humans are not automata, these market interactions commonly extend to economic and non-economic (social) relationships. In support of this, Bowles (1991) argued that markets are not only economic institutions, but they are equally cultural and political institutions too. Hence, studies focused on markets should concentrate not only on the resource allocation role markets but also on the agents who engage in markets and on the social and behavioral sequels of markets. This dissertation considers markets as both economic and social organizations that may, in one or another way, alter human behavior. It seeks to address a broader question of whether market activities shape human behavior or not. Specifically, it examines whether markets are likely to make people more cooperative and invest more in social capital. In addition, it explores whether market activities nurture or erode socially responsible behavior and invest more in high-risk high-return agricultural technologies by shaping their preferences (risk preference) and personality traits (locus of control) than would otherwise be the case. Further, it uncovers the pathways through which markets shape human behavior.

While markets are unequivocally efficiency-enhancing and Pareto-optimal, there has been a long-standing debate on whether market exchanges nurture or corrupt moral virtues, human's motivations to reveal concern for the social impact of their market actions and other-regarding motives (Smith, 1896/1763; Marx, 1957/ 1867; Veblen, 1899; Schumpeter, 1994/1942; Hirsch, 1976; Montesquieu, 1989/1748; Smith, 1896/1763; Storr \& Choi, 2019). Recently, a growing body of literature also provides theoretical and empirical evidence on this topic (Bowles, 1998; Falk \& Szech, 2013; 
Bartling et al., 2015; Pigors \& Rockenbach, 2016; Storr \& Choi, 2019). Chapter 2 contributes to this literature (particularly, this chapter is closest to the studies by Falk \& Szech (2013) and Bartling et al. (2015)) and examines whether or not market participants voluntarily internalize negative externalities and whether socially responsible behavior is less prevalent in market contexts compared to non-market contexts. As unregulated markets are often inculpated for creating negative externalities such as environmental pollution, this chapter investigates the effect of regulation mechanisms and culture on social responsibility in markets. Further, it examines the sequels of eroding socially responsible behavior and whether this effect is more pronounced in markets compared to non-market contexts. This chapter contributes to the emerging literature in several aspects. First, to our knowledge, it is the first study to use field instead of lab experiments to deal with the contended effect of markets on socially responsible behavior and moral values. Second, it fills the void on the effect of markets on socially responsible behavior in developing countries. Finally, it is the first study, to our knowledge, to examine the role regulation mechanisms and culture play in promoting social responsibility in markets and the sequels of eroding socially responsible behavior in markets.

To this end, we utilized two lab-in-the-field experiments in a typical Sub-Saharan African country, Ethiopia. In our first experiment, we used a laboratory product market where sellers and buyers, respectively, have the option to produce and buy a low-cost product with, or a high-cost product without, a negative externality. We randomly assigned participants either to a market or non-market context. Consistent with the findings of Bartling et al. (2015) but in contrast to the predictions of self-interest economic theory, the empirical results show that, irrespective of the framed context, a non-trivial share of participants exhibit concerns for the social impacts of their market activities and are willing to internalize negative externalities at a personal cost. We also find that market participants exhibit less socially responsible behavior relative to non-market participants, and this is in line with the findings of earlier studies (Falk \& Szech, 2013; Bartling et al., 2015). Furthermore, we find that regulation mechanisms (punishment) and culture (religion) are effective in the sense that they promote social responsibility in competitive markets. To understand the consequences of the erosion of socially responsible behavior, we used a second experiment - joy-of-destruction game. While eroding socially responsible behavior is socially harmful in that it triggers more anti-social behavior, this effect does not differ across the market and nonmarket contexts. Finally and most notably, the findings show that market participants engage in advantageous inequality, but not in a disadvantageous inequality.

Economists have increasingly recognized that institutions are fundamental drivers of economic growth and development. Institutions, as defined by North (1990), are humanly devised constraints that shape economic, social, and political interactions and consist of formal (constitutions, rules, laws, and property rights) and informal 
(social norms, values, and beliefs) institutions. Even though both formal and informal institutions are arguably interdependent, the interaction between both institutions is contested and not well understood. Besides, insofar, more emphasis has been given to the role formal institutions play in economic growth and development. This is mainly stems from the premise that informal institutions are mere appendages to formal institutions. However, in the microeconomic literature, informal institutions such as social capital are increasingly being identified as an important determinant of economic growth and development (Knack \& Keefer, 1997; Zak \& Knack, 2001), indicating that informal institutions may not be mere appendages and substitutes to the formal ones. Most development-related interventions assume that formal institutions occur in a vacuum and far less attention has been given to how informal institutions such as social capital respond to such exogenous institutions.

Chapter 3 contributes to this strand of literature and examines whether the introduction of a formal insurance market (weather index insurance (WII)) crowds in or crowds out social capital. We measured social capital by individuals' contribution to a public good in an experimental public good game, informal transfers to fellow villagers, and financial contributions to community projects. The chapter also explores the underlying mechanisms through which WII may crowd in or crowd out social capital. To account for unobserved heterogeneity and reverse causality, we employed an instrumental variables (IV) method in tandem with propensity score matching (PSM). The results show that WII appeared to crowd out social capital. In line with the theoretical predictions, the crowding out effect is mainly driven by insured households. Households with WII are less likely to contribute to the public good, make a transfer to fellow villagers, and contribute to community projects. The first mechanism lies in the premise that WII creates positive externalities on uninsured households, which in turn induces them to free-ride on insured households. Anticipating this, households with WII respond by lowering their investment in social capital. The second channel is that WII makes insured households feel self-sufficient and thereby need to rely less on others, particularly on uninsured households, in times of need.

Given the pervasiveness of food insecurity and poverty in developing countries, particularly in sub-Saharan African (SSA) countries, there have been concerted policy efforts to promote the use of green revolution agricultural technologies and thereby improving agricultural productivity. However, despite concerted efforts, the low uptake of profitable agricultural technologies has remained an empirical puzzle. A great deal of studies points that a range of factors such as access to input and output markets, imperfect credit and insurance markets, weather risks, heterogeneous return to agricultural technologies, social network and learning, quality of inputs as constraining factors to improved technology adoption in Sub-Saharan Africa. Recently, another emerging body of literature points to behavioral constraints as key determinants of the adoption of profitable agricultural technologies in developing countries. 
Chapter 4 builds on this literature and focuses on the demand instead of the supplyside effect of exposure to markets on farmers' agricultural investments. To do so, we choose a specific context in which farmers have hardly a significant difference in access to these technologies as these inputs are supplied via parastatal agricultural cooperatives. More specifically, it investigates whether farmers' market experience promotes their investment behavior (investment in farming technologies) by shaping their preferences (risk preference) and personality traits (locus of control). We used survey and lab-in-the-field experimental data from farm households with varying access to markets. We find that market exposure significantly reduces farm households' risk-aversion and increases their locus of control, and ultimately promotes farmers' adoption of profitable agricultural technologies.

\subsection{POLICY IMPLICATIONS}

Economists have long assumed that markets are economic institutions and primarily associated markets with the allocation of resources. However, markets are not only economic but also social institutions and do more than allocate goods and services. Markets also affect the evolution of tastes, values, and personalities. Hence, if markets shape human behavior, failing to account for the potential effect of markets on human preferences inhibits from coherently evaluating the consequences of institutional changes. The findings of this dissertation unambiguously show that markets shape human behavior and influence moral and socially responsible behavior, social capital, and investment behavior. The findings of the dissertation are imperative for policy interventions that aimed to promote market penetration in developing countries.

The findings in Chapter 2 show that in contrast to the predictions of self-interest economic theory, a non-trivial share of participants exhibit concerns for the social impacts of their market activities and are willing to internalize negative externalities at a personal cost. This suggests that such voluntary concerns may provide an alternative remedy to the problem of negative externalities stemmed from market exchanges and complement the standard economic policies, such as Pigouvian taxes. On the other hand, the findings also show that although socially responsible behavior is less prevalent in the market context relative to the non-market context, regulation mechanisms (punishment) and culture (religion) are effective in promoting social responsibility in markets. These findings have important policy implications in developing countries where market policies are either weak or nonexistent, and market and environmental regulations are not properly defined and enforced. In developing countries, there exists a widespread of markets with no inbuilt monitoring/sanctioning mechanisms. Thus, in these contexts, the results suggest that external regulation mechanisms and culture may play a significant role in promoting social responsibility in markets. 
The findings in this chapter have important policy implications for rural and urban inhabitants in the Tigray region and elsewhere in Ethiopia. Farmers in rural areas of Ethiopia rely on a range of livelihood strategies, such as crop, livestock and honey production, fishing, etc. However, farmers who produce crops may create negative externalities on honey producers and farmers engaged in fishing as crop producer farmers may use chemical inputs (e.g., pesticides) with adverse sequels such as surface and groundwater contamination and pollination problems. In the absence of properly defined property rights (which usually is the case in developing countries where Ethiopia is not an exception), it is somehow complicated to address such issues. Hence, the findings in this chapter suggest that, in these contexts, either voluntary internalization of negative externalities or external regulation mechanisms may help to tackle such negative externalities. ${ }^{1}$

The introduction of formal institutions is largely believed to be an important determinant of economic development in developing economies. However, formal institutions (e.g., formal insurance mechanisms) may not occur in a vacuum. That is, besides to their intended effects they may also have unintended effects as formal insurance mechanisms can change the incentives to engage in informal insurance mechanisms and the way in which these informal insurance mechanisms function. Chapter 3 provides policy-relevant information on whether the introduction of weather index insurance (WII) crowds in or crowds out social capital. The findings show that WII crowds out social capital and suggest important considerations that should be considered when designing and implementing formal insurance schemes in developing countries, particularly in Ethiopia. The findings in this chapter imply that formal institutions such as formal insurance mechanisms may have unintended effects - crowd out informal insurance mechanisms, and as a consequence, calls for a novel insurance product design and marketing strategies to ameliorate such unintended effects. One way to address this issue is, for example, offering WII to groups instead of to individuals. Offering WII to groups, on the one hand, it may increase the uptake of WII and on the other hand, it may help to eliminate the free-riding problem across insured and uninsured farmers and strengthen social capital among informal insurance groups. While in this chapter, we consider a relatively specific insurance mechanism (targeted to cover aggregate shocks), the mechanism that leads to crowding out of informal insurance mechanisms is operative in a variety of circumstances and may be relevant for many intervention programs.

The findings in chapter 4 have important implications for policies and programs that aim to promote the uptake of high-risk high-return agricultural technologies and thereby enhance agricultural productivity in developing countries. However, despite concerted policy and research efforts, the low uptake of profitable agricultural

1 This is also applicable in urban settings where water, air, and noise pollution by nearby factories is ubiquitous. 
technologies has remained an empirical puzzle. Chapter 4 attempts to enhance our understanding on the role that markets play in promoting adoption of improved agricultural technologies via attenuating risk-aversion and enhancing internal locus of control. Farmers' risk-aversion and internal locus of control are linked to improved income by influencing farmers' investment decisions on profitable agricultural technologies. Hence, this chapter sheds light on the importance of the penetration of rural markets in reducing risk aversion and enhancing locus of control, thereby improving agricultural productivity of rural households and ultimately enabling them to exit the poverty trap.

\subsection{LIMITATIONS AND AVENUE FOR FUTURE RESEARCH}

The main caveats in this dissertation are important, and future studies should address these caveats to probe the robustness of the findings in these studies. The primary limitations are related to the nature and type of data - two of the three chapters relied on non-randomized data, while all chapters are based on cross-sectional data.

Chapter 2 contributes to the emerging literature on markets and morals by utilizing lab-in-the-field experimental data to address the common criticisms of inferences drawn from conventional laboratory experiments. The inferences drawn from lab experiments often suffer from a perceived lack of generalizability and realism as they typically use standard student subjects. However, using lab-in-the-field experiments may not be a silver bullet to uncover the interplay between markets and morals (socially responsible behavior). This is mainly attributed to the fact that the relationship between markets and morals might be highly context-specific and is rooted in particular culture and norms (e.g., see the experiments by Bartling et al. (2015) - they find the level of socially responsible behavior is substantially higher in Switzerland than in China despite they employed the same experimental games in both countries and suggested that the effect of markets on social responsibility may be sensitive to differences in culture and institutions). Although this chapter uses context-free artefactual field experiments to overcome the drawbacks of lab experiments, yet it raises a pressing concern on the generalizability of inferences drawn from context-free experiments. Hence, future studies should employ framed and natural field experiments. The studies by Falk \& Szech (2013) (which investigates whether market participants are more likely to accept 10 Euros for the death of a mouse relative to non-market participants) and Sutter et al. (2020) (where participants are offered the option of concluding a trade and there will be no donation of measles vaccine to UNICEF and vice-versa) are interesting examples of using framed field experiments. Nevertheless, we are not aware of any study that employed natural field experiments to examine the effect of markets on social responsibility and moral behavior. This is an area for future research. 
Chapter 3 evaluates the impact of WII on social capital. While informative and stimulating further research, this study would have been more complete had it addressed the following caveats. First, this chapter uses a binary treatment variable, that is, whether farm households purchased WII or not at one point in time. Further research is needed to increase our understanding of the impact of the intensity of WII purchase (number of times purchased WII) and the dynamic effects of WII on social capital. Second, in this chapter social capital is measured using informal transfers, public good contributions, and engagement in community projects. Future studies should incorporate other dimensions of social capital, such as social trust (e.g., see Van Rijn et al. (2012) for more details) to examine the impact of WII on multiple dimensions of social capital. Finally, this chapter is based on non-randomized data. Even if we employed quasi-experimental and non-experimental methods such as the instrumental variables approach and propensity score matching as elixirs for the effects of unobserved heterogeneities and simultaneity bias, we cannot be completely certain that WII purchase is completely exogenous. Hence, the impact estimates that rely on quasi and non-experimental methods can be further improved using randomized interventions, that is, through random assignment of farm households into insured (treatment) and uninsured (control) groups (e.g., see Dercon et al. (2014)). Relatedly, this methodological concern can be attenuated via randomized incentive mechanisms, such as price discounts, to encourage the purchase of WII and use this as an exogenous instrument for WII purchase (e.g., see Takahashi et al. (2018)).

In Chapter 4, we present the impact of exposure to markets on farmers' risk-aversion, locus of control and thereby on their investment behavior (investment on profitable agricultural technologies). This chapter provides important contributions to the bulk literature on the low adoption rates of profitable agricultural technologies in developing countries, specifically in Sub-Saharan African countries. We used incentivized experiments, household survey and arguably exogenous instrument for farmers exposure to markets in order to move from mere associations to causal inference. Most notably, we used both binary (high and low) and continuous (number of market transactions) measures of exposure to markets. Despite these efforts, the findings in this study can be extended by attenuating any potential endogeneity bias via a randomized evaluation - randomly assigning farmers into treatment (high exposure to markets) and control groups (low exposure to markets). 


\section{REFERENCES}

Bartling, B., Weber, R. A. \& Yao, L. (2015), 'Do markets erode social responsibility?', Quarterly Journal of Economics 130(1), 219-266.

Bowles, S. (1991), 'What markets can-and cannot-do', Challenge 34(4), 11-16.

Bowles, S. (1998), 'Endogenous preferences: The cultural consequences of markets and other economic institutions', Journal of Economic Literature 36(1), 75-111.

Dercon, S., Hill, R. V., Clarke, D., Outes-Leon, I. \& Taffesse, A. S. (2014), 'Offering rainfall insurance to informal insurance groups: Evidence from a field experiment in Ethiopia', Journal of Development Economics 106, 132-143.

Falk, A. \& Szech, N. (2013), 'Morals and markets', Science 340(6133), 707-711.

Hirsch, F. (1976), 'Social limits to growth'.

Knack, S. \& Keefer, P. (1997), 'Does social capital have an economic payoff? A crosscountry investigation', The Quarterly Journal of Economics 112(4), 1251-1288.

Marx, K. (1957/1867), Capital: Vol. I. A critique of political economy, London: Penguin Books.

Montesquieu, C. (1989/1748), 'The spirit of the laws'.

North, D. C. (1990), Institutions, institutional change and economic performance, Cambridge university press.

Pigors, M. \& Rockenbach, B. (2016), 'Consumer social responsibility', Management Science 62(11), 3123-3137.

Schumpeter, J. A. (1994/1942), Socialism, capitalism and democracy, London: Routledge. Smith, A. (1896/1763), Lectures on jurisprudence, in R. Meek, D. Raphael \& P. Stein, eds, 'The Glasgow Edition of the Works and Correspondence of Adam Smith: VI: Correspondence', Cambridge: Cambridge University Press.

Storr, V. H. \& Choi, G. S. (2019), Do markets corrupt our morals?, Springer Nature.

Sutter, M., Huber, J., Kirchler, M., Stefan, M. \& Walzl, M. (2020), ‘Where to look for the morals in markets?', Experimental Economics 23(1), 30-52.

Takahashi, K., Barrett, C. B. \& Ikegami, M. (2018), 'Does index insurance crowd in or crowd out informal risk sharing? evidence from rural ethiopia', American Journal of Agricultural Economics 101(3), 672-691.

Van Rijn, F., Bulte, E. \& Adekunle, A. (2012), 'Social capital and agricultural innovation in Sub-Saharan Africa', Agricultural Systems 108, 112-122.

Veblen, T. (1899), 'The theory of the leisure class'.

Zak, P. J. \& Knack, S. (2001), 'Trust and growth', The Economic Journal 111(470), 295321. 


\section{IMPACT PARAGRAPH}

The impact paragraph of this doctoral dissertation is added in compliance with article 22.5 of the "Regulations for obtaining the doctoral degree at Maastricht University" decreed by resolution of the board of deans, dated 1 October 2020.

Markets are ubiquitous in the daily life of humankind, both in the developed and developing world. They are unequivocally sources of material wealth and overall wellbeing. As a consequence, market societies are materially better off than non-market societies. Market exchanges also lead to an efficient allocation of resources, and indeed, there exists a plethora of evidence showing that markets often realize this function. However, markets are not only economic but also social institutions where people meet and converse with each other, indicating that markets do more than a mere allocation of goods and resources. This dissertation aims to improve our understandings of whether and how markets affect human behavior. It consists of three self-contained yet interrelated empirical essays. The first essay examines the effect of markets on socially responsible behavior, and the role regulation mechanisms and culture play in promoting social responsibility in markets. The second essay evaluates whether and how weather index insurance affects social capital. Finally, the third essay evaluates the impact of exposure to markets on farm-households' investment behavior and whether this impact is mediated by preferences (risk preference) and personality traits (locus of control). To this end, the dissertation utilizes incentive-compatible lab-in-the-field experiments and household surveys. The results of this dissertation have relevant contributions to the emerging literature on whether and how markets shape human behavior. Further, the findings of the chapters in this dissertation provide important implications for policy in making informed decisions - particularly on the intended and unintended sequels of the introduction of formal institutions in developing countries.

The traditional economic welfare theory assumes that (moral) preferences are exogenously given and stable. However, there has been a long-standing debate that (moral) preferences may endogenously be related to markets, and markets are hypothesized to affect moral behavior in two opposing ways. While the first hypothesis extols the civilizing effects of markets, the second one criticizes markets for corroding social relations and eroding moral values. Therefore, if (moral) preferences can be endogenously changed via markets, then the welfare theory, which hinges on the exogenous moral preferences assumption, may be incomplete. Chapter 2 contributes to this debate and examines the effect of markets on socially responsible behavior. 
It also investigates the effect of regulation mechanisms and culture on social responsibility in markets. ${ }^{2}$ In contrast to the traditional self-interested economic theory, the results show that market participants reveal a considerable socially responsible behavior, indicating that market participants are willing to voluntarily internalize negative externalities at their own expense. This provides an alternative remedy to the problem of negative externalities stemmed from market failures and may complement the traditional economic policies, such as the Pigouvian taxes. The results also show that while social responsibility is less prevalent in markets compared to non-market contexts, both punishment and religion promote socially responsible behavior in markets. This has important policy implications in the sense that integrating market activities with regulation mechanisms and culture may help improving social responsibility in markets. Moreover, the findings in this chapter could have important implications for achieving sustainable development goal (SDG) 12 that targets responsible consumption and production.

Chapter 3 investigates how pre-existing informal institutions respond to the introduction of exogenous formal institutions. Specifically, it asks whether the introduction of weather index insurance (WII) alienates or reinforces social capital. The results reveal that WII does not complement instead alienate social capital, indicating that an introduction of new institutions may have unintended sequels. It is well documented that informal institutions such as social capital plays a significant role in economic growth and development, and they are not mere appendages of their formal counterparts. Hence, the results in this chapter suggest that great caution should be taken when introducing new institutions in developing countries and call for novel insurance product designs and marketing strategies, for example, offering WII to groups instead of to individuals.

Chapter 4 evaluates the impact of exposure to markets on farm-households' investment behavior. It also uncovers the potential channels through which market exposure affects investment behavior - investment in agricultural technologies. The low rate of adoption of profitable farm technologies has been at the centerpiece of agricultural economics literature and still it is a pressing issue in Sub-Saharan Africa, since the pervasive food insecurity in the region is primarily stemmed from the existing low agricultural productivity, which in-turn, emanated from the low use of productivity-enhancing agricultural technologies. The findings in this chapter show that exposure to markets attenuates farmers' risk-aversion, enhances their locus of control, and thereby induce them to adopt high-risk high-return agricultural technologies. The findings in this chapter highlights the importance of the penetration of rural markets in Sub-Saharan Africa and elsewhere in developing countries to enhance the adoption of modern farm technologies, improve agricultural productivity of rural households, and ultimately enabling farmers to exit the poverty trap. Further,

2 The terms moral and socially responsible behavior are used interchangeably. 
the empirical results have implications for achieving SDGs 1 and 2, end hunger and poverty by 2030, respectively.

In recapitulation, this dissertation provides empirical evidence on the intended and unintended consequences of the introduction formal institutions such as markets in a typical Sub-Saharan African country, Ethiopia. While markets affect real-life economic risk-taking behavior through reducing risk-aversion and enhancing locus of control and there exist substantial socially responsible behavior in markets, they are also responsible for the crowding out of social capital and socially responsible behavior. This implies that the introduction of formal institutions has both intended and unintended consequences, and suggests that for such institutions to be successful and bring about the desired behavioral changes, integrated or different approaches may be required. Overall, the findings in this dissertation may be of interest to researchers, policymakers, development practitioners, and the society at large.

Thus far, considerable efforts have been exerted to reach out the findings in this dissertation to the target groups - researchers, policymakers, and development practitioners - via various ways. Chapters 2 through 4 were presented in several seminars and conferences. Chapter 2 was presented in the 2019 Advances with Field Experiments Conference, University of Chicago, CSAE Conference, Economic Development in Africa, 2020, University of Oxford (Virtual), $35^{\text {th }}$ Annual Congress of the European Economic Association, 2020, ERASMUS University Rotterdam (Virtual), $3^{\text {rd }}$ UNU-MERIT Annual Internal Conference, UNU-MERIT, and Seminar in Experimental Economics, 2019, RWTH Aachen University. Chapter 3 was also presented in the 2018 Africa Meeting of the Econometric Society, African School of Economics, Symposium for Economic Experiments in Developing Countries (SEEDEC), 2018, Wageningen University and UNU-MERIT Seminar of Research Theme III (Economic Development, Innovation, Governance and Institutions). Chapter 4 was also recently presented in the Econometrics Seminar of School of Business and Economics, 26 November 2020, Maastricht University. Besides, while Chapter 3 has been published as UNU-MERIT Working Paper Series 2018-007 and is currently under a revise and resubmit status in the Journal of Risk and Insurance. Chapter 2 is also currently under a revise and resubmit status in the Journal of Economic Behavior and Organization and Chapter 4 is being prepared for submission to a journal. 


\section{ABOUT THE AUTHOR}

Halefom was born in Maichew, Tigray, Ethiopia. He holds a Bachelor of Arts degree in Economics with Very Great Distinction (2010) and a Master of Science degree in Economics (Development and Resource Economics) with Very Great Distinction (2014) - both from Mekelle University, Ethiopia. Before joining UNU - MERIT and the School of Business and Economics of Maastricht University in September 2015 as a Ph.D. fellow, Halefom has served Dilla University (DU) as a lecturer, researcher, and Chairman of the Department of Economics. During his stay in DU, he has taught several undergraduate courses and supervised undergraduate theses. He has also taught undergraduate courses at Mekelle University. Halefom has won a prestigious NWONUFFIC Netherlands Fellowship Programme (NFP) scholarship to pursue his Ph.D. at UNU - MERIT. After joining UNU-MERIT, he has worked as a tutor, MSc Thesis advisor, and a second reader alongside his Ph.D. dissertation. He has also worked as a consultant in the Refugee Economies Programme, University of Oxford. Recently, he has been working as an assistant researcher in the Ethiopian Policy Studies Institute (PSI). Currently, Halefom is working as a Consultant at the World Bank Group in Addis Ababa, Ethiopia.

Halefom's research interest lies in the fields of Development and Behavioral Economics. His specific research interest and expertise encompass, but not limited to, impact evaluation, institutional change, and rural development, culture and religion, technology adoption, markets and human behavior, moral values, socially responsible behavior, social networks, and social capital. He utilizes lab-in-the-field experiments, self-reported surveys, and microeconometrics.

Halefom is a member of professional associations, including the Econometric Society, American Risk and Insurance Association, Ethiopian Economics Association (EEA), and Urban Economics Association. 